\title{
Determinants of professional commitment to environmental sustainability
}

Citation for published version (APA):

Kientzel, J. (2015). Determinants of professional commitment to environmental sustainability. [Doctoral Thesis, Maastricht University]. Boekenplan. https://doi.org/10.26481/dis.20150909jk

Document status and date:

Published: 01/01/2015

DOI:

10.26481/dis.20150909jk

Document Version:

Publisher's PDF, also known as Version of record

\section{Please check the document version of this publication:}

- A submitted manuscript is the version of the article upon submission and before peer-review. There can be important differences between the submitted version and the official published version of record.

People interested in the research are advised to contact the author for the final version of the publication, or visit the DOI to the publisher's website.

- The final author version and the galley proof are versions of the publication after peer review.

- The final published version features the final layout of the paper including the volume, issue and page numbers.

Link to publication

\footnotetext{
General rights rights.

- You may freely distribute the URL identifying the publication in the public portal. please follow below link for the End User Agreement:

www.umlib.nl/taverne-license

Take down policy

If you believe that this document breaches copyright please contact us at:

repository@maastrichtuniversity.nl

providing details and we will investigate your claim.
}

Copyright and moral rights for the publications made accessible in the public portal are retained by the authors and/or other copyright owners and it is a condition of accessing publications that users recognise and abide by the legal requirements associated with these

- Users may download and print one copy of any publication from the public portal for the purpose of private study or research.

- You may not further distribute the material or use it for any profit-making activity or commercial gain

If the publication is distributed under the terms of Article $25 \mathrm{fa}$ of the Dutch Copyright Act, indicated by the "Taverne" license above, 


\title{
Determinants of Professional Commitment to Environmental Sustainability
}

\author{
Jasmin Kientzel
}

Boekenplan 
ISBN 9789086663774

Copyright (C) 2015 Jasmin Kientzel

Published by Boekenplan, Maastricht, the Netherlands 
Determinants of Professional Commitment to Environmental Sustainability

\section{Dissertation}

to obtain the degree of Doctor at Maastricht University, on the authority of the Rector Magnificus, Prof. dr. L.L.G. Soete, in accordance with the decision of the Board of Deans, to be defended in public on Wednesday 9 September 2015, at 16:00 hours

By

Jasmin Kientzel 


\section{Promotor}

Prof. Dr. Gerjo Kok

\section{Co-supervisor}

Dr. Mindel van de Laar

\section{Assessment Committee:}

Prof. Dr. Harm Hospers (Chair)

Prof. Dr. Piet Eichholtz

Prof. Dr. Rob Ruiter

Dr. Ruud Jonkers, Retired director of ResCon bv. 


\section{Acknowledgments}

"Even if we could turn back, we'd probably never end up where we started". (Haruki Murakami, 1Q84)

Drafting this dissertation has been a journey of discovery, and it would be almost impossible to list all the milestones, lessons learned and limits encountered on the way.

Just as everyone who embarks on a long journey into the wild, the experience itself has afforded me a wealth of knowledge about the world around me and my role in it and more than I had thought previously possible.

The biggest revelation was that no stage of this journey would have been possible without the many people whose support ensured my continuing even when I seemed to have hit a roadblock: Without their encouragements and understanding I would not be writing this acknowledgment.

I would like to express my special appreciations and thanks to my two supervisors, Professor Dr. Gerjo Kok and Dr. Mindel van de Laar. Both of them supported me tremendously in developing my interdisciplinary and often unconventional research interests while guiding me through the vast amounts of literature, methods and fields of application possible. The completion of this dissertation would not have been as enjoyable without their openmindedness towards unusual approaches and ideas, patience and encouragements during times of doubt and reticence. I am especially grateful for their support after my moving to Australia, which slowed the dissertation progress and made communication much more challenging due to geographical distance, time difference and work commitments.

This dissertation would not have been possible without the many capable staff members at the Maastricht Graduate School of Governance and UNU-MERIT, whose knowledge and commitment are essential parts of the process. Special thanks to Mieke Drossaert, Eveline in de Braek, Susan Roggen, Janneke Knaapen, Celine Duijsens, Herman Pijpers and so many more. Depending on their role, they have supported me enormously during my time in Maastricht and made the overall $\mathrm{PhD}$ experience so much more enjoyable. 
I gratefully acknowledge the funding sources that made my Ph.D. work possible. During my first 4 years I was funded by Maastricht University to work on my dissertation, which contributed to being able to focus completely on research, a luxury the extent of which I fully cam to realize after completing the remainder of my $\mathrm{PhD}$ while in fulltime work.

While moving to Australia during the dissertation writing process proved to be immensely challenging, I am grateful for the opportunities granted to me by a number of organisations and facilitating the transition to post-PhD life: First and foremost the Government of the Australian Capital Territory, including the Department of Environment and Planning (ESDD) and the Canberra Institute of Technology (CIT).

Support and encouragement of my colleagues and the development of additional workplace skills has contributed immensely to facilitate the transition period. Thank you!

I dedicate this book first and foremost to my family:

To my parents, Serge and Waltraud, and to my sister Daniela who always believed in my abilities and ambitions even if and when these seemed out of the ordinary. They have supported my living and working in many different countries, travelling even further afield for vacations and research or pitching to them professional and personal endeavours. I am deeply grateful for their support and sacrifices that enable me to be where I am now. When I mentioned starting a doctoral degree, it was met with enthusiastic support and encouragement. Their unwavering belief in my abilities made me find the courage to start this endeavour.

While in Maastricht, I was incredibly fortunate to meet my husband Jinjing, who has supported me unconditionally through all the highs and lows of the doctoral experience. His love, patience and kindness as well as experience with all things research and academic life made me continue even when doubts slowed my progress. His unwavering belief in my abilities has made the completion of this work possible. 


\section{Contents}

\section{Acknowledgments}

Contents vii

List of Tables $\quad$ xv

List of Figures $\quad$ xvii

1 General Introduction 1

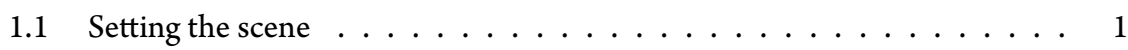

1.2 Individual differences and pro-environmental behavior . . . . . . . . 4

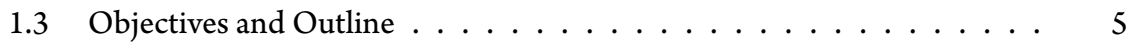

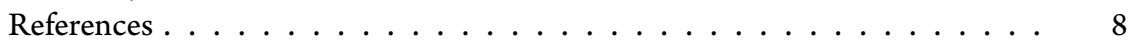

2 Explaining and Improving the Adoption of Voluntary Environmental Programs: A social cognition-based view on program design, implementation $\begin{array}{ll}\text { and evaluation } & 13\end{array}$

2.1 Introduction . . . . . . . . . . . . . . . 13

2.2 Voluntary Environmental Programs (VEP): an overview . . . . . . . . 14

2.3 Environmental Program Design and Evaluation: an application to VEPs 16

2.4 Frameworks for Program Planning and Analysis: PRECEDE/PROCEED and Intervention Mapping . . . . . . . . . . . . . . 18

2.5 Corporate environmentalism and decision-making: a management research perspective .................... 21

2.6 Pro-environmental decision-making and behavior: insights from social psychology .............................. 22

2.7 Pro-environmental decisions: Individual Decision Theories . . . . . . . 24

2.8 Pro-environmental Decision Making and Behavior: Organizations, Groups and Social Networks . . . . . . . . . . . . . . . . . 27 
2.9 Literature on Acceptance, Adoption and Diffusion of Technology and Innovations . . . . . . . . . . . . . . .

2.10 Acceptance, Adoption and Diffusion of Technology and Innovations: Individual Decision Theories . . . . . . . . . . . . . . . .

2.11 Acceptance, Adoption and Diffusion of Technology and Innovations: Organizations, Groups and Networks . . . . . . . . . . . . . . . . . . 30

2.12 Limitations . . . . . . . . . . . . . . . . . . . 31

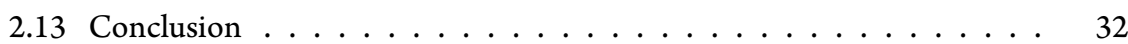

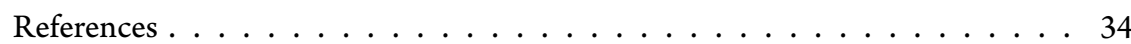

3 Environmental Assessment Methodologies for Commercial Buildings: A Study of Building Professionals' Beliefs and the Adoption of the LEED Scheme in the United States

3.1 Introduction . . . . . . . . . . . . . . . . 43

3.2 Green buildings: a historical development . . . . . . . . . . . . . 45

3.3 Energy efficiency for buildings in the United States: between building codes and voluntary assessment schemes . . . . . . . . . . . 46

3.4 Conceptual framework: Behavioral factors, beliefs and LEED . . . . . 50

3.5 Method ......................... 53

3.6 Reasoned Action Approach constructs and emerging topics . . . . . 55

3.7 Discussion . . . . . . . . . . . . . . . . 61

3.8 Limitations of the study $\ldots \ldots \ldots \ldots$. . . . . . . . . . 61

3.9 Conclusion ............................ 62

References ........................ 63

4 Adoption of Voluntary Environmental Building Rating Schemes: a Reasoned Action Approach (RAA) perspective on building professionals' LEED and Green Globes adoption in the US and Canada 69

4.1 Introduction . . . . . . . . . . . . . . . . 69

4.2 Environmental rating and assessment schemes for commercial buildings $\quad 70$

4.3 Professional behavior and behavior change in the building industry . . . 71

4.4 Theoretical Framework: Reasoned Action Approach (RAA) . . . . . 72

4.5 Intention-Behavior consistency . . . . . . . . . . . 75

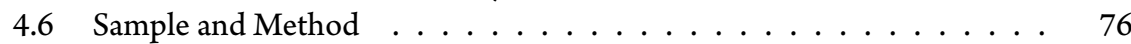

4.7 Questionnaire and Measurement . . . . . . . . . . . . . . 77

4.8 Results . . . . . . . . . . . . . . . . 79

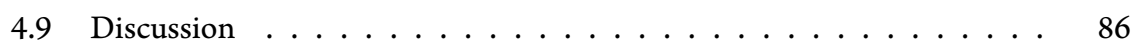

4.10 Behavior change strategies in fragmented project-based professional settings ..................... 87

4.11 Limitations . . . . . . . . . . . . . . . 88 


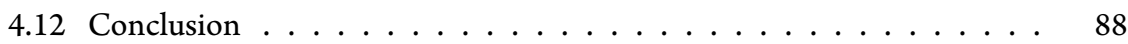

References . . . . . . . . . . . . . . . . . . 90

5 What do Clients want? Commercial Real Estate Developers' views on the LEED and Green Globes certification schemes in the United States 93

5.1 Introduction . . . . . . . . . . . . . . 93

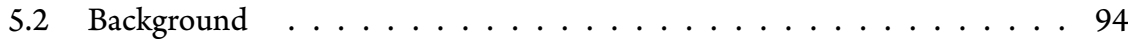

5.3 Literature . . . . . . . . . . . . . . . . . . 95

5.4 Method ............................ 96

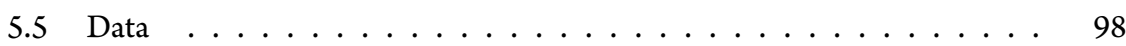

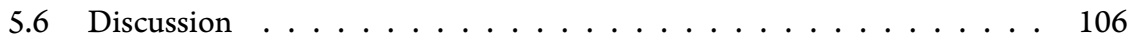

5.7 Limitations . . . . . . . . . . . . . . . . . . . . . . . . . . . . . . . . . . . . . . 108

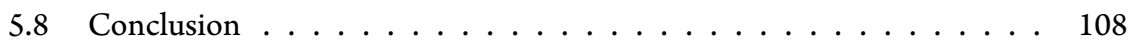

References . . . . . . . . . . . . . . . . . . 110

6 Environmental Building Rating and Assessment Schemes and Inter-firm Cooperation: an application of Social Interdependence Theory in the US, the UK and Canada

6.1 Introduction . . . . . . . . . . . . . . . . . 113

6.2 Green Building Councils . . . . . . . . . . . . . . . . . . . . 114

6.3 Pro-environmental behavior in building and construction literature . . 116

6.4 Theoretical framework: Social Interdependence Theory . . . . . . . . 117

6.5 Method and Data . . . . . . . . . . . . . . . . . . . 121

6.6 Results . . . . . . . . . . . . . . . . . . . . . 124

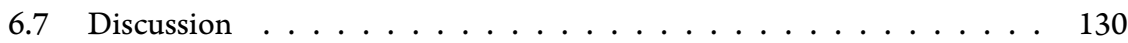

6.8 Limitations . . . . . . . . . . . . . . . . . . . . 131

6.9 Conclusion . . . . . . . . . . . . . . . . . 132

References . . . . . . . . . . . . . . . . . . . 133

7 Constructing Green: Social Identity, Professional and Organizational Group Affiliation in the US and Canadian Building and Construction Industry

7.1 Introduction . . . . . . . . . . . . . . . . . . 137

7.2 Environmental Building Rating Schemes uptake in the US and Canadian AEC industry . . . . . . . . . . . . . . . . . . 138

7.3 Theoretical Perspectives: Sociology of Professions, Social Identity and Self-Categorization Theories . . . . . . . . . . . . . . . 139

7.4 Method . . . . . . . . . . . . . . . . . . . . . . 144

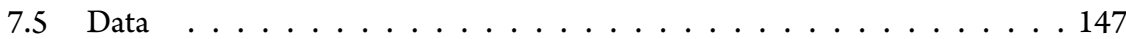

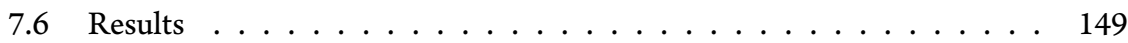


7.7 Discussion and Limitations $\ldots \ldots \ldots \ldots \ldots$

7.8 Conclusion . . . . . . . . . . . . . . . . . . . . 159

References . . . . . . . . . . . . . . . . . 160

8 Voluntary Professional Accreditation for Sustainability: An application of Self-Determination Theory to LEED AP professional accreditation in the United States and Canada.

8.1 Introduction . . . . . . . . . . . . . . . . . 163

8.2 Third-party professional accreditation schemes in the building sector: The LEED AP scheme . . . . . . . . . . . . . . . . . . . . . . . . . 164

8.3 Literature on professional accreditation schemes . . . . . . . . . . 165

8.4 Theoretical framework: Self-Determination Theory (SDT) . . . . . . . 167

8.5 Measures and method . . . . . . . . . . . . . . . . . 170

8.6 Data . . . . . . . . . . . . . . . . 172

8.7 Results and discussion . . . . . . . . . . . . . . . . . . . . 174

8.8 Discussion and limitations . . . . . . . . . . . . . . . . 178

8.9 Conclusion . . . . . . . . . . . . . . . . . . 181

References . . . . . . . . . . . . . . . . . 183

9 Voluntary Green Building Rating principles in Environmental Preferential Purchasing: Lessons from the Advocacy Coalition Framework and the $\begin{array}{ll}\text { Elaboration Likelihood Model } & 187\end{array}$

9.1 Introduction . . . . . . . . . . . . . . . . . . . . . 187

9.2 Green Building Councils and Voluntary Assessment Schemes _. . . . 188

9.3 EPP: Barriers and Opportunities . . . . . . . . . . . . . . . . . . . 191

9.4 Sustainable Procurement and Voluntary Rating and Assessment Schemes:

Social and Cognitive factors . . . . . . . . . . . . . . . . . . . 194

9.5 Policy Learning and Advocacy Coalition Frameworks . . . . . . . . . 195

9.6 Social and strategic cognition as a basis for persuasion . . . . . . . . . 197

9.7 The Elaboration Likelihood Model (ELM) . . . . . . . . . . . . . . . . 197

9.8 A strategy to influence policy-makers to integrate VEPs in their decision processes ........................ 200

9.9 Limitations and Conclusion . . . . . . . . . . . . . . . . . 201

References . . . . . . . . . . . . . . . . . 202

10 ISO 14001 Certification of Environmental Management Standards - Comparing the Netherlands and Germany 209

10.1 Introduction . . . . . . . . . . . . . . . . . . . . . . 209

10.2 Standards for Environmental Protection: the Development of Standards 210 
10.3 Environmental Management Systems and Governance: the case of the Netherlands and Germany . . . . . . . . . . . . . . . . 216

10.4 Theoretical perspectives: Diffusion of Innovation and Technology Acceptance literature . . . . . . . . . . . . . . 218

10.5 Methodology . . . . . . . . . . . . . . . . 221

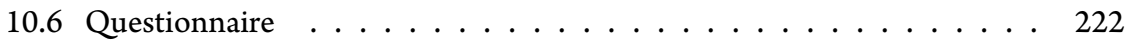

10.7 Data . . . . . . . . . . . . . . . . . . . . . . . . . . . . . . 223

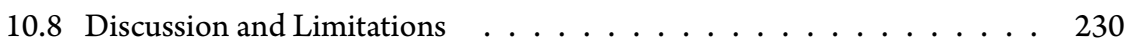

10.9 Conclusion . . . . . . . . . . . . . . . . 231

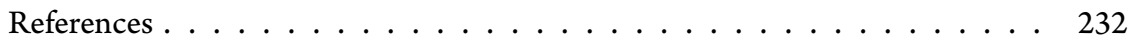

11 Information source choice and Environmental Management Systems (EMSs) $\begin{array}{ll}\text { certification in the Netherlands and Germany } & 237\end{array}$

11.1 Introduction . . . . . . . . . . . . . . . . 237

11.2 Background Literature . . . . . . . . . . . . . . . . . . . 238

11.3 Theoretical Framework: General Model of Information Behavior . . . . . 244

11.4 Methodology . . . . . . . . . . . . . . . . . . . . . . . . . . . . . . 246

11.5 Data . . . . . . . . . . . . . . . . . 248

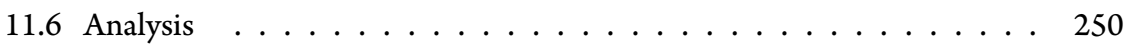

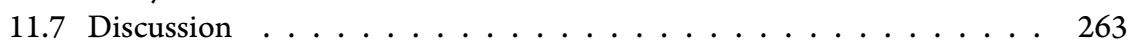

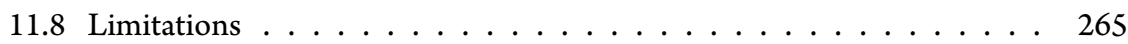

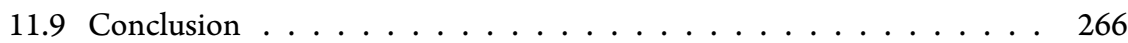

References . . . . . . . . . . . . . . . . . 268

12 Discussion and Conclusion $\quad 273$

12.1 Summary of Findings and Main Contributions . . . . . . . . . . . 273

12.2 Improving Environmental Compliance . . . . . . . . . . . . 278

12.3 Knowledge on Pro-environmental Behavior and Environmental Policy

Implications . . . . . . . . . . . . . . . . 281

12.4 Limitations and Lessons learned . . . . . . . . . . . . . . . . . . . . . . . . . . . . . . . . . . . . . . . . . . .

12.5 Further Research . . . . . . . . . . . . . . . . . . . . . . . . . . . . . . . . . . . . . . . . . . . . .

References . . . . . . . . . . . . . . . . . . . 284

$\begin{array}{lr}\text { Summary } & \mathbf{2 8 9}\end{array}$

$\begin{array}{lr}\text { Valorisation Addendum } & 293\end{array}$

Introduction . . . . . . . . . . . . . . . . . 293

Relevance . . . . . . . . . . . . . . . . . . . 293

Target Groups . . . . . . . . . . . . . . . . . . . . . . . . 294

Activities and Products . . . . . . . . . . . . . . . . . . . . 294 
Innovation . . . . . . . . . . . . . . . . . . . . 295

Implementation and Schedule . . . . . . . . . . . . . . . . . 295

Appendix A : Methodological considerations

Self-reported online survey data: limitations and opportunities . . . . . . . . . 297

Sampling . . . . . . . . . . . . . . . . . . . . 298

Questionnaire Design and Data collection . . . . . . . . . . . . . . . . . . . 298

Response rates . . . . . . . . . . . . . . . . . . . . . . . . 299

Supportive Technology and Data processing . . . . . . . . . . . . . . 300

Appendix B : Data collection instruments $\quad 301$

Interview guidelines . . . . . . . . . . . . . . . . 301

Questionnaire: Reasoned Action Approach (RAA) (Chapters 4, 5, 7, 8) . . . 301

Questionnaire: Social Identity Theory (Chapter 6) . . . . . . . . . . . . . 305

Questionnaire: Social Interdependence Theory (Chapter 7) . . . . . . . . . . 307

Questionnaire Self-Determination Theory (Chapter 8) . . . . . . . . . . 308

Questionnaire Diffusion of Innovation (Chapter 10) and Information Behavior

(Chapter 11)- The Netherlands . . . . . . . . . . . . . . . . 311

Questionnaire Diffusion of Innovation (Chapter 10) and Information Behavior

(Chapter 11)-Germany . . . . . . . . . . . . . . 326

Questionnaire use per chapter, theoretical framework and country . . . . . 342

Appendix C : Study respondent characteristics overview

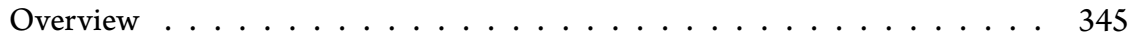

Chapter 3: Environmental Assessment Methodologies for Commercial Buildings: A study of building professionals' beliefs and the adoption of the

LEED scheme in the United States. . . . . . . . . . . . . . . . . 346

Chapter 4: Adoption of Voluntary Environmental Building Rating Schemes: a Reasoned Action Approach (RAA) perspective on building professionals' LEED and Green Globes adoption in the US and Canada . . . . . . . 346

Chapter 5: What do clients want? Commercial Real Estate Developers' views on the LEED and Green Globes certification schemes in the United States 352

Chapter 6: Environmental Building Rating and Assessment schemes and interfirm cooperation: an application of Social Interdependence Theory in the US, the UK and Canada . . . . . . . . . . . . . . . . . . . . 354

Chapter 7: Constructing Green: Social Identity, Professional and Organizational Group Affiliation in the US and Canadian Building and Construction Industry . . . . . . . . . . . . . . . . . . 358 
Chapter 8: Voluntary Professional Accreditation for Sustainability: an application of Self-Determination Theory to LEED AP professional accreditation in the United States and Canada . . . . . . . . . . . . . . . . 362

Chapter 10: ISO14001 certification of Environmental Management Standards:

Comparing the Netherlands and Germany . . . . . . . . . . . . . 364

Chapter 11: Information source choice and Environmental Management Sys-

tems (EMSs) certification in the Netherlands and Germany . . . . . . . . 367 



\section{List of Tables}

2.1 Overview of different VEP schemes adapted from Carmin et al. (2003). . . 15

2.2 Factors influencing pro-environmental decisions . . . . . . . . . 23

2.3 Selection of social-psychological models relevant to VEP adoption . . . . . 25

4.1 LEED and Green Globes Adopters per country (Source: Own survey data) 78

4.2 Pairwise correlations Reasoned Action Approach (RAA) constructs (LEED) 80

4.3 Pairwise correlation Reasoned Action Approach (RAA) constructs (Green Globes $\ldots \ldots \ldots \ldots$. . . . . . . . . . . . . . . . . .

4.4 LEED adoption intention. Regression Analysis with Intention as the Dependent Variable . . . . . . . . . . . . . . . . . . . . 81

4.5 Green Globes adoption intention. Regression Analysis with Intention as the Dependent Variable . . . . . . . . . . . . . . . . . . 83

4.6 LEED adoption. Probit Analysis with Behavior as the Dependent Variable . 85

5.1 Pairwise correlation Reasoned Action Approach (RAA) constructs (Green Globes . . . . . . . . . . . . . . . . . . 105

5.2 Pairwise correlation Reasoned Action Approach (RAA) constructs (LEED) 105

5.3 Regression results- LEED . . . . . . . . . . . . . . . . . . . . . . . . . . . . . . . . . . 105

5.4 Regression results- Green Globes . . . . . . . . . . . . . . . . . . . 106

6.1 Overview of variables influencing pro-environmental behavior (Source: $\mathrm{Au}-$

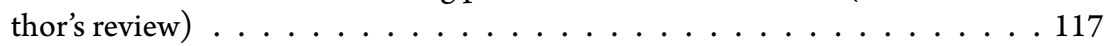

6.2 Determinants of Inter-firm and Inter-professional cooperation . . . . . . 120

6.3 Professional Groups in the UK, US and CAN . . . . . . . . . . . . . 123

6.4 Cronbach's alpha for cooperation constructs . . . . . . . . . . . . . . 124

6.5 Cooperation constructs: Means and Standard Deviation . . . . . . . . . . 125

6.6 Pairwise correlation for Social Interdependence Constructs (US) . . . . . . 125

6.7 Pairwise correlation for Social Interdependence Constructs (UK) . . . . . . 125

6.8 Pairwise correlation for Social Interdependence Constructs (CAN) . . . . 126 
6.9 Regression Analysis with Inter-firm cooperation as the Dependent Variable (UK) . . . . . . . . . . . . . . . . . . . . 127

6.10 Regression Analysis with Inter-firm cooperation as the Dependent Variable (CAN) . . . . . . . . . . . . . . . . . . 128

6.11 Regression Analysis with Inter-firm cooperation as the Dependent Variable (US) 129

7.1 Perceived influence of professional groups in the building and construction industry (as percentage of respondents) . . . . . . . . . . . . 149

7.2 Professional groups with perceived limited influence in the building and construction industry ( as percentage of respondents $) \ldots \ldots$. . . . . . . 150

7.3 Agreement with environmental sustainability practices in the building and construction industry (as percentage of respondents) . . . . . . . . . . 150

7.4 Perceived interest in sustainability practices by professional groups in the building and construction industry (as percentage of respondents) . . . . . 151

7.5 Likelihood of professional groups in the building and construction industry to engage in sustainable building practices (as percentage of respondents)* . . 151

7.6 Perception of respondens' own professional group and its sustainability practices in the building and construction industry (as percentage of respondents) 152

7.7 Pairwise correlation Reasoned Action and Social Identity constructs (LEED) 153

7.8 Pairwise correlation Reasoned Action and Social Identity constructs (Green Globes $\ldots$. . . . . . . . . . . . . . . . . . . . . . 154

7.9 LEED adoption intention. Regression Analysis with Intention as the Dependent Variable . . . . . . . . . . . . . . . . . . . . . . 156

7.10 Green Globes adoption intention. Regression Analysis with Intention as the Dependent Variable . . . . . . . . . . . . . . . . . . . . . 157

8.1 Pair-wise correlation Self-Determination Theory (SDT) constructs . . . . . 175

8.2 LEED AP accreditation. Logistic regression analysis with LEED AP accreditation as the dependent variable . . . . . . . . . . . . . . . . . . 177

8.3 LEED adoption intention. Regression Analysis with Intention as the Dependent Variable . . . . . . . . . . . . . . . . . . . . . . . . . 179

10.1 Overview of the main EMS certification schemes . . . . . . . . . . . 216

10.2 Regression ISO 14001 adoption (the Netherlands) . . . . . . . . . . . . . . 227

10.3 ISO 14001 adoption (Germany) . . . . . . . . . . . . . . . . . 229

11.1 Multivariate probabilistic regression Netherlands (ISO14001) . . . . . . . . 254

11.2 Multivariate probabilistic regression Germany (ISO14001) . . . . . . . . . 259

11.3 Multivariate probabilistic regression Germany (EMAS) . . . . . . . . . . . 261

11.4 Overview of factors significant for information source choice . . . . . . . . . 264 


\section{List of Figures}

2.1 "Black Box" issue (Astbury and Leeuw, 2010) . . . . . . . . . . . . . . . 17

2.2 PRECEDE/PROCEED model by Green and Kreuter (1999) applied to VEP evaluation processes ...................... 20

3.1 Reasoned Action Approach (Adapted from Fishbein, 2008) . . . . . . . . 53

4.1 Reasoned Action Approach (Fishbein and Ajzen, 2010) adapted to LEED adoption .......................... 74

5.1 Factors influencing Real Estate Developers' investment decisions . . . . . . 99

5.2 Real Estate Developers' evaluation of rating and assessment schemes . . . . 100

5.3 Real Estate Developers' experience with the LEED and Green Globes schemes 101

5.4 Real Estate Developers' intention and expectation to have their projects LEED and Green Globes certified . . . . . . . . . . . . . . . . . . . . 102

5.5 Real Estate Developers' evaluation of LEED and GG characteristics . . . . . 102

5.6 Real Estate Developers' assessment of government expectations with regards to LEED and Green Globes. . . . . . . . . . . . . . . . . . . . . . 103

5.7 Real Estate Developers' assessment of LEED and Green Globes necessity . . . 104

6.1 A brief overview of actors involved in the construction process (Source: Author) 116

7.1 Reasoned Action Approach (Adapted from Fishbein, 2008) . . . . . . . . . 144

8.1 The motivational continuum according to Self-Determination Theory (SDT) (Deci and Ryan, 2000) _ . . . . . . . . . . . . . . . . 168

8.2 Factors for LEED AP accreditation (Source: Own data) . . . . . . . . . . . 174

9.1 Actors involved in the construction process and voluntary rating scheme application (Source: Author's representation) . . . . . . . . . . . . . . 190

9.2 Factors influencing Environmentally Preferential Purchasing (EPP) processes. 192 
9.3 Advocacy Coalition Framework as represented by Weible et al. (2009) . . . 196

9.4 Elaboration Likelihood Model (ELM) by Petty and Cacioppo (1986) . . . 199

9.5 Elaboration Likelihood Model (ELM) in the Advocacy Coalition Framework (ACF) (Source: Author's representation) . . . . . . . . . . . . 200

10.1 Adoption Process of a Certified Management System (CMS) (Source: Author) 211

10.2 Diffusion of Innovation, Rogers (1995) . . . . . . . . . . . . . . 220

11.1 General model of information behavior by Wilson (1997) . . . . . . . . . . 243

11.2 Theoretical model of informational sources based on Wilson (1997) and Rulke et al. (2000) . . . . . . . . . . . . . . . . . . 245

11.3 Information source selection Netherlands by information source sub-groups (Source: Author's data) . . . . . . . . . . . . . . . . . 252

11.4 Information sources assigned to relational categories . . . . . . . . . . . 253

11.5 Information source selection Germany by information source sub-groups (Source: Author's data) . . . . . . . . . . . . . . . . . . 257

11.6 Information sources assigned to relational categories (Source: Author's data) 258 


\section{1}

\section{General Introduction}

"There are no safe paths in this part of the world. Remember, you are of the edge of the wild now, and in for all sorts of fun wherever you go" (J.R.R Tolkien, The Hobbit)

\subsection{Setting the scene}

nvironmental degradation, climate change and management of scarce natural re$\checkmark$ sources are among the most pressing social issues humanity faces today and will face 1 for generations to come. Climate change and environmental damage cannot be seen and treated as separate problems to be tackled only after other social issues higher on the political agenda have been solved. Diverse subjects such as water scarcity, land degradation, biodiversity reduction, rising sea levels and natural disasters need to be taken seriously to allow for successful climate change mitigation and adaptation. While some voices continue to maintain that climate change and environmental protection are "luxury issues" and less important than other pressing social matters such as job security and economic output, the reality is that we are likely to see changing environmental conditions influencing peace, political stability, access to natural resources, migration, poverty, food security and public health at a magnitude that would have been unimaginable only a generation ago.

Recent research and current affairs have demonstrated that environmental issues concern us all: Natural resource scarcity can lead to armed and latent conflicts; extreme weather in the form of droughts and floods decrease food production and increase poverty; warmer temperatures permit the spreading of diseases to areas they were not observed a few years 
ago. Environmental issues are linked to almost all social issues that occupy the minds and hearts of policy-makers, organizational, community and business leaders as well as concern the general public.

Due to the enormity of the environmental problems and the almost inevitable challenges that our and future generations will have to deal with, denial of climate change or general apathy is a common consequence. Similar to other areas in which people feel overwhelmed by an enormous task, procrastination and avoidance mechanisms are activated to defer actions and postpone important lifestyle and resource usage decisions. Energy efficiency, water usage reduction, travel choices, employment decisions and other behaviors with environmental influence are prime examples of this issue.

While policy-makers have the power to influence the way societies deal with the impeding environmental and climate change issues, laws and regulations are often either not feasible or desirable given the considerable efforts involved and limited enforcement capabilities. Hence, Voluntary Environmental Programs (VEPs) have gained considerable popularity in policy-makers' toolboxes. At first sight, the advantages of these programs are clear: Organizations and individuals engage in environmentally desirable behaviors not because they have to but because they see value in engaging in them.

Research on climate change, natural resource management and environmental degradation as well as the development of proposed solutions to behavioral issues associated with them is carried out across a large number of social sciences disciplines such as political science, economics, management, sociology anthropology and psychology.

While all of these research approaches have their definite merits and raison d' être, policies designed and promoted to reduce carbon footprints and resource usage do not fully integrate the knowledge created from these various disciplines. Most policy-makers resort purely to economic knowledge when it comes to developing and implementing large scale environmental and resource management policies.

Strategies to limit environmental change and or at least to successful adaptation and mitigation strategies have so far failed in the international policy arena (e.g., Andrew, 2008; Andrew et al, 2010). Global environmental governance and concerted efforts to increase the protection of biodiversity, water and natural resources have been hampered by national interests and disunity as to the limiting of carbon emissions and their effect of economic development (e.g. Wang and Chen, 2013).

For instance, the "poverty alleviation against environmental protection" card has been played repeatedly (e.g. Kaplowitz et al, 2013; Field, 2013). While the importance of economic development to facilitate poverty alleviation and the maintenance of existing life standards is well accepted, researchers and policy-makers alike have suggested that in many cases environmental protection and economic development have the potential to go hand 
in hand (e.g Adams et al, 2004; Pagiola and Patais, 2005; Stern, 2012). Examples of this are the successes of solar and wind power firms or green building materials developers. Some countries such as Germany or Japan have gained export success by specializing in green industries (Schreurs, 2012). Yet overall, environmental technologies and green business models still have the reputation of being too costly or burdensome, particularly in the light of the current financial and economic crisis, when job creation and economic growth has become the predominant concern for governments and businesses alike (e.g. Rondinella, 2012). However, it has been increasingly recognized that environmental protection and the reduction of climate change effects does not contradict economic development and poverty reduction. Due to the connection of natural disasters, climate change and economic activity, reducing the impact of environmentally damaging factors has become a significant factor for nations' economic, social and in some cases even physical survival. The latter case has been specifically predominant in the South Pacific where whole island chains such as the Solomon Islands are endangered by rising sea levels. While international and national environmental strategies need to be aligned for maximum effects, many governments seem to be too busy with other issues to focus their attention on environmental issues (e.g. Cole, 2010). As a result, the role of firms and households has been gradually moved in the center of attention with regards to environmental protection and the fight against climate change (e.g. Newell, 2010; Linnenluecke et al., 2013)

Sustainable business strategies have been hailed as an important part of the puzzle (Aggarwal and Dow, 2013) and individuals in households have simultaneously become a target for government policies to entice them to become more environmentally responsible and save natural resources (e.g. Bretschger and Smulders, 2011). Studies as to what factors contribute to make people more likely to save water, energy and to favor environmentally friendly modes of transport are rife. Economic, sociological, psychological, anthropological factors influencing environmental decisions by individuals and groups have become a matter of interest for policy makers and governments. Particularly Voluntary Environmental Programs (VEPs) as a means of cost-effective environmental governance and regulation has become a major focus of policy and regulatory interest (e.g. Borck and Coglianese, 2009; Darnall et al, 2010; Prakash and Potoski, 2012).

Social science knowledge has been increasingly integrated in government policy and private sector program development but is still mainly applied to community engagement programs or household behavior (e.g. Minsch et al, 2012). There seems to be reluctance in certain sectors when it comes to integrating knowledge from "soft"sciences such as sociology or psychology in VEP program design and evaluation. However, knowledge from the social science domain has merits when explaining why professionals comply with laws, policies and even "voluntary" programs (e.g. Riemer and Bickmann, 2011; Minsch et al, 2012).

Certain industries, such as engineering or the construction industry, are certainly guilty of favoring technical solutions without considering the determinants of professionals' behav- 
ior despite the long standing human factors research tradition and the rise of engineering psychology (e.g Viana et al, 2012). Hodgkinson and Healey (2008) suggest that research in cognition in organizations needs to receive more attention to better understand importance of individual differences to determine organizations' reaction to environmentally friendly solutions.. Further development of green technologies and associated reduced costs, however, may not be sufficient to make environmentally friendly solutions in the private sector more popular. Again, identifying social and psychological factors on the individual, organizational and institutional level is needed to influence social structures by providing rewards and incentives (monetary and non-monetary) (Hoffman and Henn, 2008).

Amir et al.(2005) suggest that the insights from research in psychology and behavioral research should be more prominent in informing policy decisions, beyond the field of economics. Fischoff (1990) suggests that the social sciences are needed when the results of policy decisions depend on and have an impact on human behavior.

To understand the determinants for voluntary environmental behavior and the effectiveness of VEPs is an intriguing topic. However, the decision processes of policy-makers themselves, business leaders and professionals in their work roles have not been studied extensively. The present dissertation aims to shed a light on environmental decision-making processes in the construction industry in the United Kingdom, the United States and Canada as well as service and manufacturing companies in the Netherlands and Germany. The main focus of these studies is to investigate the actions of business professionals to adopt voluntary environmental programs. The studies presented in this dissertation are based on various theoretical approaches ranging from social psychological models to information science, diffusion of innovation as well as governance and management literature.

\subsection{Individual differences and pro-environmental behavior}

A large number of studies have identified factors that influence individuals' propensity for pro-environmental behavior. In fact, the literature is so vast that many researchers have set out to provide extensive literature reviews and taxonomies of relevant factors (e.g. Heimlich and Ardoin, 2008; Vlek, 2000; Bamberg, 2003; Stern, 2000; Gatersleben et al., 2002; Kurz, 2002; Gifford, 2007, 2008; Steg and Vlek, 2009).

In this doctoral dissertation project the factors studied include attitudes, norms, perceived behavioral control, social identity, intrinsic and extrinsic motivations within the contexts of professional decisions and cooperation behavior.

While a detailed list of determinants of pro-environmental behavior is beyond the scope of this introduction section, Chapter 2 provides a more in-depth overview of the theoretical approaches studied. 


\subsection{Objectives and Outline}

This dissertation's main objective is to determine factors that drive voluntary and environmentally sustainable professional practices in the private sector. As voluntary professional behavior is extremely diverse, this thesis investigates "voluntarism" in the form of a adoption decision with regards of Voluntary Environmental Programs (VEPs). Several studies were conducted to explain professionals' environmentally relevant behavior within a professional decision-making context $^{1}$ :

Chapter 2 reviews social-psychological models that can be applied to VEP program evaluation. Commonly used theories and frameworks used to develop, analyze and evaluate programs and policies are outlined and discussed in the context of VEPs in the private sector.

In Chapter 3, the adoption of a voluntary environmental rating and assessment scheme, the Leadership in Environmental and Energy Design (LEED), is studied. Based on interviews conducted with building professionals in the North East of the United States, a qualitative elicitation study on determinants of voluntary building rating schemes adoption is carried out based on the Reasoned Action Approach (RAA) developed by Fishbein and Ajzen (2010). The underlying beliefs of building professionals with regards to voluntary environmental building assessment schemes are analyzed in detail. The study conducted in this chapter suggests that attitudes, norms, perceived behavioral control, social interdependence, social identity and motivations can influence intentions and behaviors to engage in sustainable building practices (or what is perceived as such). Hence, the knowledge generated in this chapter informs subsequent chapters in terms of theory selection and analysis.

Building on the results of this study, Chapter 4 applies the Reasoned Action Approach (RAA) with data collected in a survey study during this dissertation project among building and construction professionals in the United States and Canada. This research project is based on multivariate regression methods to estimate behavioral intentions and actual behavior of building professionals with regards to the Leadership in Environmental and Energy Design (LEED) and Green Globes (GG) building rating schemes.

Based on the results obtained, Chapter 5 analyzes the determinants of real estate developers' intentions based on the Reasoned Action Approach (RAA) in the US and Canada to further the understanding of building and construction professionals intentions and behaviors. As real estate developers act as other building professionals' clients and shape other groups' norms, their intentions are studied in more detail. Real estate developers are an understudied professional group in the context of environmental decisions. Hence,

\footnotetext{
${ }^{1}$ In this thesis "behavior" and "practices" are treated sometimes interchangeably, even though environmentally sustainable professional practices, in a proper sense, can be defined as a widespread pattern of pro-environmental behavior.
} 
data was collected within the framework of this dissertation project via a survey instrument from US real estate investors and subsequently examined with frequency and multivariate regression analysis.

Chapter 6, based on Social Interdependence Theory (Deutsch, 1949a; 1949b; Johnson and Johnson, 1989), analyzes the impact of previous experience with a voluntary green building schemes on inter-firm cooperation in the process of a commercial construction project. Some voluntary programs are implicitly (and explicitly in other cases) based on the assumption that participation in such a scheme will improve project partner cooperation, and thus better project and environmental outcomes. Hence, this chapter analysis several forms of cooperation beyond inter-firm cooperation such as inter-professional cooperation, intra-professional cooperation and intra-firm cooperation constructs. The study is based on survey data collected in the United States, Canada and the United Kingdom in the course of this dissertation project. The data analysis, as in previous chapters, is based on multivariate regression analyses.

In a similar fashion, Chapter 7 further sheds a light on group cohesion and the effect on green professional practices in the building and construction industry. The concept of social identity as a determinant of engagement in green construction and building practices is examined in more detail. This chapter focuses on building and construction professionals in the United States and Canada, adapting concepts from the Social Identity Approach (SIA) (Tajfel, 1978; Tajfel and Turner, 1979; Turner et al., 1987; Hogg and Abrams, 1988) and the Reasoned Action Approach (RAA) (Fishbein and Ajzen, 2010) to a survey study developed and implemented in the course of this dissertation.

Intrinsic and extrinsic motivation to obtain a professional accreditation associated with a voluntary green building rating and assessment standard is at the core of Chapter 8 . Concepts from Self-Determination Theory (SDT) (Deci and Ryan, 195; Ryan, 1995; Deci and Ryan, 2000) will be used to determine the likelihood of building professionals to obtain the Leadership for Environmental and Energy Design (LEED) Accredited Professional (AP) certification. As with previous chapters, data collected in the United States and Canada within the context of this dissertation project is subjected to multivariate regression analyses.

In Chapter 9, a theoretical exploration of the potential for principles from green building ratings and assessment schemes to be adapted to public procurement processes is outlined. To analyze policy-making processes that underlie green procurement decisions, elements from Advocacy Coalition Framework (ACF) (Sabatier and Jenkins-Smith, 1988) and the Elaboration Likelihood Model (ELM) (Petty and Cacioppo, 1986) are discussed.

Beyond green buildings and the construction industry, Chapter 10 explores certification of Environmental Management Standards with ISO14001 from an innovation diffusion 
and technology acceptance (Rogers, 2003) perspective. The chapter analyses survey data collected in Germany and the Netherlands within the context of this dissertation project.

Based on the same survey data set, Chapter 11 investigates the information source choice of Dutch and German managers in relation to Environmental Management Systems adoption. This study adopts elements from Wilson's (1997) “General Model of Information Behavior” to determine the type of information sources business professionals commonly resort to in EMS adoption processes.

Finally, in Chapter 12, the findings from the previous chapters are summarized and the main contributions of this dissertation are synthesized. Additionally, policy implications and the limits of social science research's influence on environmental policy and private sector transformation are discussed in detail. Potential future research strategies will be outlined. 


\section{References}

Adams, W. M., Aveling, R., Brockington, D., Dickson, B., Elliott, J., Hutton, J., \& Wolmer, W. (2004). Biodiversity conservation and the eradication of poverty. Science, 306(5699), 1146-1149.

Aggarwal, R., \& Dow, S. (2013). Corporate governance and business strategies for climate change and environmental mitigation. Entrepreneurship, Finance, Governance and Ethics, 315-340.

Amir, O., Ariely, D., Cooke, A., Dunning, D., Epley, N., Gneezy, U., ... Silva, J. (2005). Psychology behavioral economics and public policy. Marketing Letters, 16, 443-454.

Andrew, B. (2008). Market failure, government failure and externalities in climate change mitigation: the case for a carbon tax. Public Administration and Development, 28(5), 393-401.

Andrew, J., Kaidonis, M. A., \& Andrew, B. (2010). Carbon tax: Challenging neoliberal solutions to climate change. Critical perspectives on Accounting, 21(7), 611-618.

Bamberg, S. (2003). How does environmental concern influence specific environmentally related behaviors? a new answer to an old question. Journal of Environmental Psychology, 23, 21-32.

Borck, J. C., \& Coglianese, C. (2009). Voluntary environmental programs: assessing their effectiveness. Annual Review of Environment and Resources, 34, 305-324.

Bretschger, L., \& Smulders, S. (2011). Policies for a sustainable use of natural resources. Resource and Energy Economics, 33(4), 881-892.

Cole, J. (2010). Environmental protection versus economic development in the asia pacific: the impacts of copenhagen. In Proceedings of the 2 nd annual dialogue forum of the sino-australian joint research program: Collaboration and governance in the asia pacific (pp. 1-12).

Darnall, N., Potoski, M., \& Prakash, A. (2010). Sponsorship matters: Assessing business participation in government-and industry-sponsored voluntary environmental programs. Journal of Public Administration Research and Theory, 20(2), 283-307.

Deci, E. L., \& RM, R. (2000). The "what" and "why" of goal pursuits: human needs and the self-determination of behavior. Psychological Inquiry, 11, 227-268.

Deci, E. L., \& Ryan, R. M. (1985). Intrinsic motivation and self-determination in human behavior. Plenum, New York.

Deutsch, M. (1949a). An experimental study of the effects of cooperation and competition upon group processes. Human Relations, 2.

Deutsch, M. (1949b). A theory of cooperation and competition. Human Relations, 2, 129-151.

Field, N. (2013). Balancing economic development with environmental conservation: Challenges facing the north and south. future of food. Journal on Food, Agriculture and Society, 1(1), 49-54. 
Fischhoff, B. (1990). Psychology and public policy: Tool or tool maker. American Psychologist, 45, 657-663.

Fishbein, M., \& Ajzen, I. (2010). Predicting and changing behavior: The reasoned action approach. Taylor \& Francis.

Gatersleben, B., Steg, L., \& \&Vlek, C. (2002). The measurement and determinants of environmentally significant consumer behavior. Environment and Behaviour, 34(3), $335-362$.

Gifford, R. (2007). Environmental psychology and sustainable development: Expansion, maturation, and challenges. Journal of Social Issues, 63(1), 199-212.

Gifford, R. (2008). Psychology's essential role in alleviating the impacts of climate change. Canadian Psychology/Psychologie Canadienne, 49(4), 273-280.

Heimlich, J., \& Ardoin, N. (2008). Understanding behavior to understand behavior change: a literature review. Environmental Education Research, 14, 3-215.

Hodgkinson, G. P., \& Healey, M. P. (2008). Cognition in organizations. Annual Review of Psychology, 59, 387-417.

Hodgkinson, G. P., \& Healey, M. P. (2011). Psychological foundations of dynamic capabilities: Reflexion and reflection in strategic management.strategic. Management Journal, 32(13), 1500-1516.

Hodgkinson, P., G.P abd Herriot. (2002). Organizational effectiveness: The role of psychology. In M. C. T. Robertson \& D.Bartram (Eds.), (p. $45-60)$. Wiley New York.

Hoffman, A. J., \& Henn, R. (2008). Overcoming the social and psychological barriers to green building. Organization \& Environment, 21, 390-419.

Hogg, M. A., \& Abrams, D. (1990). Social motivation, self-esteem and social identity. Social identity theory: Constructive and critical advances, 28, 47.

Johnson, D. W., \& Johnson, R. T. (1989). Cooperation and competition: Theory and research. Edina, MN: Interaction.

Kaplowitz, M. D., Lupi, F., Yeboah, F. K., \& Thorp, L. G. (2013). Exploring the middle ground between environmental protection and economic growth. Public Understanding of Science, 22(4), 413-426.

Kurz, T. (2002). The psychology of environmentally sustainable behavior: Fitting together pieces of the puzzle. Analyses of Social Issues and Public Policy, 2, 257-278.

Linnenluecke, M. K., Griffiths, A., \& Winn, M. I. (2013). Firm and industry adaptation to climate change: a review of climate adaptation studies in the business and management field. Wiley Interdisciplinary Reviews: Climate Change, 4(5), 397-416.

Minsch, J., Goldblatt, D. L., Flueler, T., \& Spreng, D. (2012). The indispensable role of social science in energy research. In Tackling long-term global energy problems ( $\mathrm{pp}$. 23-43). Springer.

Newell, R. G. (2010). The role of markets and policies in delivering innovation for climate change mitigation. Oxford Review of Economic Policy, 26(2), 253-269. 
Pagiola, S., Arcenas, A., \& Platais, G. (2005). Can payments for environmental services help reduce poverty? an exploration of the issues and the evidence to date from latin america. World Development, 33(2), 237-253.

Petty, R. E., \& Cacioppo, J. T. (1986). The elaboration likelihood model of persuasion. In L. B. E. ) (Ed.), Advances in experimental social psychology (Vol. 19, pp. 123-203).

Prakash, A., \& Potoski, M. (2012). Voluntary environmental programs: A comparative perspective. Journal of Policy Analysis and Management, 31(1), 123-138.

Rogers, E. (2003a). Diffusion of innovations. Free Press.

Rogers, E. (2003b). Diffusion of innovations. Free Press.

Rondinella, T. (2012). Green industrial policies: economic recovery and emissions reduction in europe. In B. Galgocza (Ed.), Greening industries and creating jobs.

Ryan, R. M. (1995). Psychological needs and the facilitation of integrative processes. Journal of Personality, 63, 397-427.

Sabatier, P. A., \& Jenkins-Smith, H. (1988). An advocacy coalition model of policy change and the role of policy orientated learning therein. Policy Sciences, 21, 129-68.

Schreurs, M. A. (2012). Breaking the impasse in the international climate negotiations: The potential of green technologies. Energy Policy, 48, 5-12.

Sechrest, L.B., and Bootzin, R.R. (1996). Psychology and inferences about public policy. Psychology, Public Policy, and Law, 2, 377-392.

Steg, L., \& Vlek, C. (2009). Encouraging pro-environmental behavior: An integrative review and research agenda. Journal of Environmental Psychology, 29-309.

Stern, M. (2012). Assessing policies promoting poverty alleviation and marine resources. African Geographical Review, 31(2), 126-141.

Stern, P. (2000). New environmental theories: Toward a coherent theory of environmentally significant behavior. Journal of Social Issues, 56, 3-407.

Tajfel, H. (1978). Differentiation between social groups: Studies in the social psychology of intergroup relations. Academic Press.

Tajfel, H. (1981). Intergroup behavior. In J. C. Turner \& H. Giles (Eds.), (p. 144-167). Oxford, UK: Blackwell.

Tajfel, H., \& Billig, M. (1974). Familiarity and categorization in intergroup behavior. Journal of Experimental Social Psychology, 10, 159-170.

Tajfel, H., Billig, M., Bundy, R. P., \& Flament, C. (1971). Social categorization and intergroup behaviour. European Journal of Social Psychology, 1, 149-178.

Tajfel, H., \& Turner, J. (1979). The social psychology of intergroup relations. In W. A. . S. Worchel (Ed.), (p. 33-47). Monterey, CA: Brooks/Cole.

Tajfel, H., \& Wilkes, A. L. (1963). Classification and quantitative judgment. British Journal of Psychology, 54, 101-114.

Viana, D., Conte, T., Vilela, D., de Souza, C. R., Santos, G., \& Prikladnicki, R. (2012). The influence of human aspects on software process improvement: Qualitative research 
findings and comparison to previous studies. In Evaluation \& assessment in software engineering (ease 2012), 16th international conference on (pp. 121-125).

Vlek, C. (2000). psychology for environmental policy making. International Journal of Psychology, 35, 153-167.

Wang, Q. \& Chen, X. (2013). Rethinking and reshaping the climate policy: Literature review and proposed guidelines. Renewable and Sustainable Energy Reviews, 21, 469-477.

Wilson, T. D. (1997). Information behavior: an interdisciplinary perspective. Information Processing and Management, 33(4), 551-572. 



\title{
CHAPTER

\section{Explaining and Improving the Adoption of Voluntary Environmental Programs: A social cognition-based view on program design, implementation and evaluation ${ }^{1}$}

\author{
"A theory is a battlefield in your head" (Haruki Murakami, Kafka on the Shore)
}

\subsection{Introduction}

V

oluntary environmental programs (VEP) have become a prominent instrument to fight climate change and reduce the impact of business activities on the natural environment. In many sectors, mandatory regulations for environmental protection have been unfeasible or lack support due to political and economic reasons. The importance of VEPs in the national and international policy mix has been stressed in a large number of publications (e.g. Gunningham and Sinclair, 1999, Boerkey and Leveque, 2000). VEPs are designed and implemented by numerous sponsors such as international organizations, national governmental agencies, industry or trade associations, and non-governmental organizations (NGOs).

The predominant approach to developing environmental and energy programs in both regulatory and voluntary contexts has been grounded mainly in technical and economic considerations. Hence, technical and economic solutions have traditionally been high on

\footnotetext{
${ }^{1}$ A version of this chapter has been published as Kientzel, J. and Kok, G.(2011). Explaining and Improving the Adoption of Voluntary Environmental Programs: A social cognition-based view on program design, implementation and evaluation. Journal of Sustainable Development, 4(6): 85-102.
} 
the policy agenda dominating policy choice and program delivery (Lutzenhiser et al, 2009). The Physical-Technical-Economic Model (PTEM) has been the predominant paradigm for quite some time with choices and behavior considered to be influenced by information or economic incentives as suggested by rational actor theories. However, policy-making and resulting program design are hardly ever a neutral exercises and underlying behavioral assumptions shape program logics and Program Implementation Plans (PIP). Over recent years, social scientists from various disciplines have become critical of the PTEM paradigm focusing on costs and rationality with program processes being treated as a black box.

According to Lutzenhiser et al. (2009), the PTEM has been useful as a means of reaching the "low hanging fruits" in environmental and energy efficiency related issues but performs rather badly under more complex circumstances. While these issues are not specific to voluntary programs, the design and evaluation of these schemes suffer from the same limitations as other environmental initiatives. When designing and evaluating environmental programs, the analysis of social and psychological processes leading to adoption rates is still not perceived as being as useful as technical measurement or economic impact evaluation. Overall, the "human dimension" (Vine, 1994) of environmental program design and evaluation seems to be merely a secondary consideration in many environmental and energy-related schemes. The concept of "human dimension" relates to the way decisionmakers think about energy issues and decide on investing in measures that reduce the environmental impact of their business activities (Vine, 1994).

As a result, a systematic review of human factors research can provide additional insights to some important questions such as (1) why and under which circumstances some professionals choose to integrate a VEP in their projects while others do not (2) how behavior-centered models can improve the design and evaluation of environmental programs and (3) how to improve VEP adoption rates if a specific program has found to be useful for environmental purposes. The present chapter aims to fill this gap by reviewing relevant models from the social sciences that can contribute to an improved understanding of VEP adoption decisions and behavior. The systematic use of theories to assess and improve VEP adoption will be stressed and limitations will be explored. Hereby understanding of environmental initiatives will be advanced and for cognition and theory-based design and evaluation of VEPs argued for. Literature in the management studies, social psychology, and technology acceptance research fields which have dealt with the role of social cognition in behavior change situations, will be reviewed as a basis for VEP promotion.

\subsection{Voluntary Environmental Programs (VEP): an overview}

Business decisions have been traditionally analyzed in the economics, management and investment literature and mostly based on the assumption that managers will consider investments only if these are financially advantageous. Since the study of VEPs has become 


\begin{tabular}{|c|c|c|}
\hline $\begin{array}{l}\text { Sponsor } \\
\text { Organisation }\end{array}$ & Schemes (Examples) & Motivations for VEP design \\
\hline Governments & $\begin{array}{l}\text { Negotiated agreements (e.g. Long- } \\
\text { Term Agreement for Energy } \\
\text { Efficiency) } \\
\text { Environmental management } \\
\text { schemes } \\
\text { Standards } \\
\text { Building standards } \\
\text { Eco-labels }\end{array}$ & $\begin{array}{l}\text { Decrease costs for } \\
\text { administration and } \\
\text { enforcement } \\
\text { alternative and complement } \\
\text { to other environmental policy } \\
\text { instrument }\end{array}$ \\
\hline $\begin{array}{l}\text { Industry and Trade } \\
\text { Organizations }\end{array}$ & $\begin{array}{l}\text { Certifications for green buildings } \\
\text { Environmental management } \\
\text { scheme } \\
\text { Professional accreditation for } \\
\text { sustainability schemes } \\
\text { Eco-labels }\end{array}$ & $\begin{array}{l}\text { increase flexibility for } \\
\text { environmental management } \\
\text { affect, avoid or delay } \\
\text { regulations } \\
\text { create industry specific } \\
\text { solutions }\end{array}$ \\
\hline $\begin{array}{l}\text { Non-Profit } \\
\text { Organizations }\end{array}$ & $\begin{array}{l}\text { Certification for green buildings } \\
\text { Eco-labels } \\
\text { Professional accreditation for } \\
\text { sustainability schemes }\end{array}$ & $\begin{array}{l}\text { encourage environmentally } \\
\text { friendly- business practices } \\
\text { Non-governmental and } \\
\text { non-industry alternatives }\end{array}$ \\
\hline $\begin{array}{l}\text { International } \\
\text { Organizations }\end{array}$ & $\begin{array}{l}\text { Eco-labels } \\
\text { Environmental management } \\
\text { schemes } \\
\text { Certifications for green buildings }\end{array}$ & $\begin{array}{l}\text { provide international } \\
\text { guidelines } \\
\text { achieve more cooperation in } \\
\text { environmental issues }\end{array}$ \\
\hline
\end{tabular}

Table 2.1: Overview of different VEP schemes adapted from Carmin et al. (2003).

a thriving field of investigation different disciplines have contributed a variety of approaches, theories and methods of analysis. Steelman and Rivera (2006) as well as Carmin et al (2003) distinguish between several subcategories of Voluntary Environmental Programs:

As can be seen in Table 2.1, VEPs include schemes as diverse as environmental management system certification (Darnall and Edwards, 2006) to green labeling for products, eco-audit schemes, certifications for green buildings or Long-Term Agreements (LTAs) for energy efficiency etc. An increasing number of scientists have started to bring forward the importance of understanding and defining underlying behavioral assumptions in program design and evaluation. In this line of thinking, the effectiveness and success of voluntary schemes depends on their appeal to individuals and organizations and require acceptance from the decision-makers side (e.g. Nilsson and Biel, 2008; Lutzenhiser et al., 2009). However, only a few VEPs have been designed with an integrated or associated behavioral or educational 
component. Voluntary behavior as a function of intentions, perceptions and actual control (Harrison, 1995) is frequently neglected in VEP design and evaluation. Even for those programs that do take it into account there is neither theoretical nor empirical evidence that the behavioral components match and target the underlying problematic behaviors which VEPs should ideally aim to change.

The lack of consideration of psychological and social factors in program design and implementation is partly due to the fact that identifying factors to be changed and methods that work in specific contexts is a challenging task. As shown by Syme et al. (2000) in an extensive review on behavior change campaigns for household water conservation, altering decisions and behavior is a complex and frequently misunderstood task. Many failed programs, voluntary or not, are based on over simplistic models of decision-making, behavior and behavior change. A better understanding of social cognition can improve this situation.

Social cognition aims "to understand and explain how the thoughts, feelings, and behavior of individuals are influenced by the actual, imagined, or implied presence of others" (Allport, 1985). Research conducted in this field analyzes individual decision-making and behavior as a function of social or cultural context determining in which ways people interpret information they receive from others or generate themselves (Sternberg, 1994). While cognitive processes' influences on decision-making and mental shortcuts (i.e. heuristics) determine behavioral outcomes, the social cognition tradition focuses on the interaction between an individual and their respective context (Smith and Semin, 2004). Hence, cognition is embedded in a social context and internal cognitive schema are not sufficient to analyze and predict behavior. From this perspective, decisions and behavior will depend on an individual's goal, communication processes and social influence. These insights are valuable for the development, implementation and evaluation of voluntary environmental programs.

\subsection{Environmental Program Design and Evaluation: an application to VEPs}

The vast majority of VEPs are designed to achieve quantifiable outcomes and indicators, such as greenhouse gas (GHG) emission reduction. Even though VEPs in their diversity are ideal to experiment with innovation in program design and evaluation, most organizations tasked with developing them have not yet seized this opportunity.

Even though environmental policy analysis and program evaluation research has established methods such as needs analysis or program theory analysis, behavior and social cognitioncentered theories have been frequently left out of the picture. Even though PTEM can be seen as theory-based since it is building on rational actor theories, the designers of mainstream environmental programs have been few to explicitly state the use and limitations of 


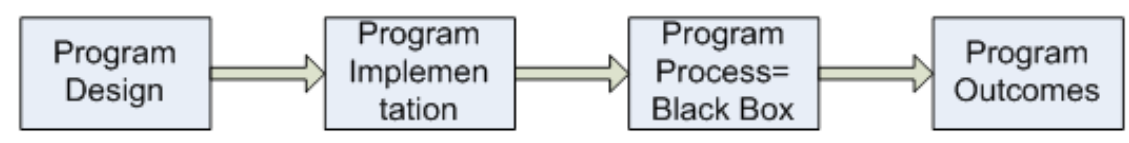

Figure 2.1: "Black Box" issue (Astbury and Leeuw, 2010)

the underlying assumptions in their schemes. In addition, the methods to induce behavior change are frequently limited within the PTEM paradigm focusing merely on providing incentives and information. Furthermore, there seems to be a lack of awareness that VEPs are essentially behavior change programs with environmental outcomes as results of human action (Vine, 1994). This issue links with a larger discussion in the design and evaluation literature: the debate on method-based and theory-oriented approaches (Weiss, 1997). Method-based approaches have been criticized heavily for creating a situation in which information on outcomes does not allow for informing analyses of impacts at higher levels or improve the understanding of programs (Stame, 2004). This "evaluation deficit" resulting from methods-based approaches neglecting the theory side has led in many cases to misconception of environmental programs and their meeting intended objectives (Stame, 2004). Such a "black box" problem (Astbury and Leeuw, 2010) can be represented as follows:

Theory-based programs have been advocated bringing forward an agent-centered perspective (Pawson and Tilley, 1997) and select variables explicitly assumed to achieve the program goals. Advantages of this approach are exposure of assumptions, comparability and hence the advancement of knowledge (Fitz-Gibbon and Morris, 1996). According to Daamen et al (2001), intervention and evaluation programs will be more successful if they take into account the specific characteristics of a receiver and can influence attitudes, beliefs and subsequently behavior. This principle should also apply to VEPs which have been less commonly designed as behavioral change programs even though they aim essentially to alter stakeholders' decisions and behaviors.

While theories from health planning have found their way in research and policies on pro-environmental behavior in private or household settings, programs targeted at environmental decisions in a professional setting are less common. Since the policy level does and should, however, take interest in promoting environmentally significant behavior from managers and firms, these frameworks can and have been applied to environmental program design and evaluation. There are two potential fields of application to program design: Either a program is (1) conceived by their sponsoring organization to fill a gap in the existing framework or a (2) program is designed to improve the adoption rate of a previous program. Both situations require a good understanding of both contextual and behavioral factors. Even if the behavioral antecedents and the reason for non-adoption are 
known, changing behavior can prove to be extremely challenging (Lippke and Ziegelmann, 2008; Michie et al., 2008; Bartoholomew et al. 2011). While value and attitude change is desirable, infrastructures, incentives, institutions, abilities, knowledge and the difficulty of behavior will determine outcomes. Attitudinal factors, habits, routines, attitudinal factors but also contextual forces (interpersonal influences, community expectations, regulations, laws, advertising, costs and technological possibilities) need to be studied in context (Stern, 2004). Hence, broader frames of analysis are needed to study "voluntary" environmental decisions and behavior.

\subsection{Frameworks for Program Planning and Analysis: PRECEDE/PROCEED and Intervention Mapping}

In order to make VEPs more effective, their design, implementation and evaluation need to have a clear perspective on which behaviors need to be targeted and changed to make the program successful. Behavior change approaches assume that each person, be it a citizen or even a CEO has some level of choice and control over sustainability-related behaviors and actions. Policies, programs and regulations themselves cannot induce change if they are refused by the individuals or organizations they target. The PRECEDE/PROCEED framework (Green and Kreuter, 2005) and the Intervention Mapping approach (Bartholomew et al., 2006) are comprehensive frameworks which can be used to design an environmental program and constitute a solid basis for VEP evaluation. The models mentioned in previous sections can serve as a foundation for program design and induce behavioral change. Behavior change is required when a VEP is not adopted by firms it was targeted at or when an existing program has not yielded the expected results. In addition, theories that target change in organizations are listed below.

A model that has been specifically developed to explain and promote environmentally significant behavior is the model proposed by Hines et al. (1987). They suggest that environmental education will contribute to improved pro-environmental behavior though (a) improved knowledge of environmental problems (2) the knowledge of potential strategies for action (3) the ability to apply these strategies (4) and the ownership of personality attributes. However, education by providing information alone has frequently led to poorly performing programs (Lutzenhiser et al., 2009). In addition, environmental education research has frequently been criticized as having an impact on improved environmental behavior in private settings but has been less applied to professional contexts. One of the few behavior change programs for environmental professional practice is the Professional Practice for Sustainable Development initiative (PP4SD) in the United Kingdom. ${ }^{2}$ Most programs targeted at firms do not explicitly include behavioral components in their program

\footnotetext{
${ }^{2}$ http://www.pp4sd.org.uk (Link accessed 29 October 2014)
} 
implementation plans (PIPs). For a detailed review of behavior change models from the environmental education field see Heimlich and Hardoin (2008).

A well-known theory to analyze pro-environmental behavior change is Banduras' (1985) Social Cognitive Theory. According to this framework, individual decisions and behavior are a function of personal factors and their environment. Within Social Cognitive Theory, the main focus is on self-reflective, cognitive and self-regulatory processes (Bandura, 1985) as driving factors for change. Individual needs to perceive that they will be able to perform a given behavior and perceive to have an incentive to do so (Bandura, 1985). Behavioral change may be induced on several distinct levels, such as the individual, organizational and governmental level and targets the individual embedded in the organization rather than the organization. Behavior change theories are not only targeted at the individuals in organizations but also at organizations as a whole. Lewin (1951) developed a change theory based on habits and resulting resistance to change. According to Lewin (1951), habits prevail also in the case when circumstances change within groups. The focus in this model is a three step change process "unfreezing" the status quo moving the current perceptions and "refreezing" after a change has taken place. This is mainly used in change management, when clear targets have been set by a firms' management and employee resistance prevails. While the techniques evoked can be very beneficial they have usually been applied within an organizational context when management has established an environmental goal. These change techniques are less common when it comes to explaining more formal schemes such as VEP adoption and implementation which are frequently "contingent authority decisions" (Zaltman et al., 1973).

Selecting theories for specific behaviors and target populations can be a complex task since target cognitions are frequently present in several theories, but under different names (Bartholomew et al., 2011). In addition, in complex situations, several theoretical frameworks may need to be combined in order to understand adoption and non-adoption phenomena (Langlois and Hallam, 2010). One framework which is useful as a guideline for both understanding program adoption and improving uptake is the PRECEDE/PROCEED model developed by Green and Kreuter (2005). While PRECEDE/PROCEED model has been developed for health promotion planning, it has been successfully applied to energy saving contexts (Egmond et al., 2005). In this framework, behavior is seen as a result of a large number of external and behavioral factors which need to be targeted in several stages. While the PRECEDE stage focuses on the analysis of the situation ex-ante or ex-post of a program including behavioral factors, context and policy instruments used, the PROCEED stage includes implementation as well as process, impact and outcome evaluations. Applied to VEP adoption, the process can be depicted in Figure 1.2.

While developers of VEPs need to take into account a large number of factors, they also should base their programs on models that can influence the target actors' behaviors realistically. Although contextual factors are crucial in program development, implementation and 


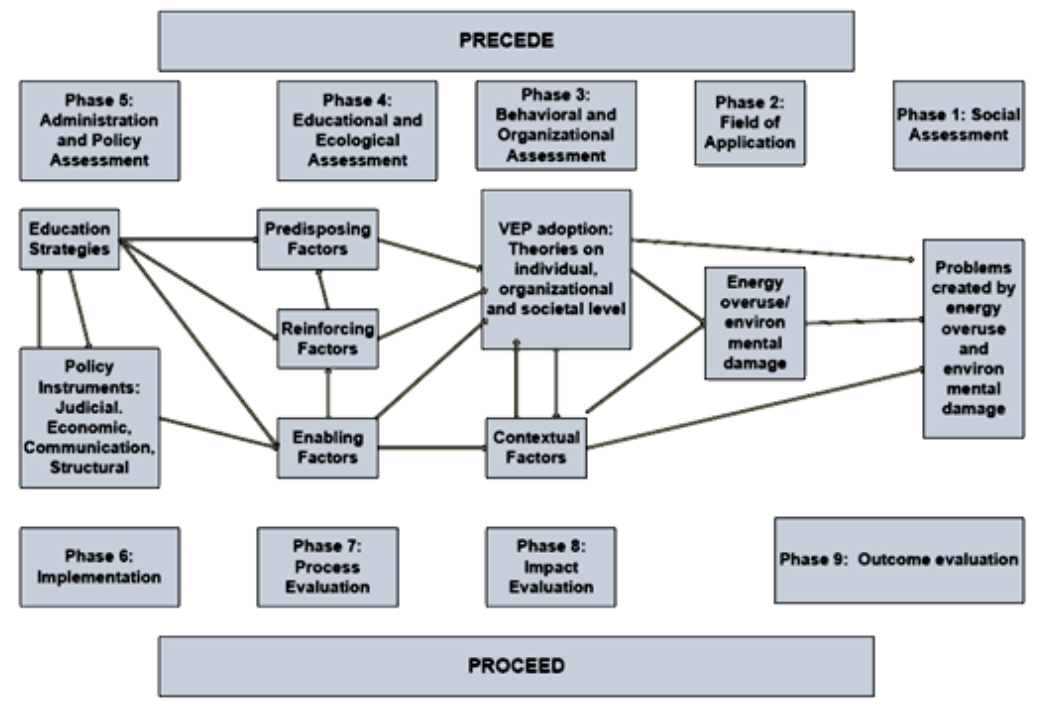

Figure 2.2: PRECEDE/PROCEED model by Green and Kreuter (1999) applied to VEP evaluation processes

evaluation, behavior-centered models analyzing the determinants of specific behaviors are crucial in Behavioral/Organizational Assessment (Phase 3) and Impact Evaluation (Phase $8)$.

The PRECEDE/PROCEED framework does not postulate which theories should be used for a specific VEP, but can be used as a guideline to select behavioral theories to explain the difference between adopters and non-adopters without neglecting contextual factors in which these behavioral factors are embedded in. Planning protocols and frameworks such as Intervention Mapping (Bartholomew et al., 2011) have emerged in order to discuss selection procedures for appropriate models and propose steps to create a structured theorybased program allowing for coherent evaluation based on known assumptions. Intervention Mapping (Bartholomew et al., 2011) is a protocol for theory and evidence-based program development which aims to provide guideline for selecting and applying theories to specific social problems in which behavior change is needed (Kok et. al., 2004). Intervention Mapping consists of six major steps in which (1) the needs assessment is performed (2) program objectives are defined based on previous scientific analyses of the problems caused by specific behaviors (3) theories and strategies to change determinants of these behaviors are to be selected (4) program components are determined (5) program adoption and 
implementation as well as (6) process and effect evaluations are anticipated (Bartholomew et al. 2011). Even though the domain of management studies has traditionally focused on the issue of VEP adoption, program design and the selection of behavior-based theories have been neglected to some extent as the following section will show.

\subsection{Corporate environmentalism and decision-making: a management research perspective}

The management literature on VEP adoption is vast and very diverse in nature. Most management-oriented studies are related in one way or the other to the concept of "corporate environmentalism". According to Banerjee (2002), corporate environmentalism can be defined as "the recognition and integration of environmental concerns into a firm's decision-making process". Previous research on the causes and consequences of corporate environmentalism has found significant variation in firm behavior (Darnall et al. 2010) and studies have identified market pressures, opportunities, government regulations and stakeholder pressure as potential causes for environmentally friendly firm practices (Banerjee, 2001).

According to Welch et al. (2000), "regulatory influence" is one of the major reasons why firm opt for VEP adoption. This theoretical perspective deems firm voluntarism to be a sign of commitment to environmental management with the intention of influencing the regulatory system. Moreover, the pressure of stakeholder such as customers, competitors, suppliers, investors and the community has frequently been cited as a prime influence on the decision to adopt a VEP (Khanna et al., 2007). Likewise, the reduction of risks has been identified as a major factor in the business decision since the voluntary adoption of environmental schemes is a response to consumers interested in buying environmentally friendly produced goods (Arora and Cason, 1996; Williams et al., 1993) and investors may favor environmentally proactive companies that can be successful in green markets (Khanna and Damon, 1999; Khanna et al., 1998). Studies on firm characteristics have focused on industry affiliation, firm size, networks, team performances, decision structures (Khanna et al., 2007) while organizational studies have looked at organizational structure, capabilities, barriers, firm networks, or power relations (Hoffman, 2001).

While the management literature is relatively silent on VEP design, implementation and evaluation, a number of studies on organizational and individual level decisions have heavily borrowed from models from sociology and social psychology. This provides evidence for some management scholars having recognized that "Corporate Environmentalism" as a concept treats the firm and the organization as a "black box" by emphasizing factors such as firm size, sector, financial performance or educational achievement on VEP adoption. 
There are now a few examples of scholars having adapted social cognition models to the management literature.

Cordano and Frieze (2000) evaluated the pollution reduction preferences of U.S. environmental managers and suggested that even though most had positive attitudes towards pollution prevention, barriers such as too few incentives or communication issues have prevented them from pushing for a more environmentally stringent agenda. In the same line of reasoning, Martin-Pena (2010) evaluated managers' behavioral intentions towards environmental problems and suggests that environmental actions on the firm level are at least partly correlated with management's behavioral intentions. Additionally, Aragon-Correa et al. (2004) found a distinct link between executive discretion and corporate environmental commitment while Branzei et al. (2004) suggested a match between corporate environmental responses and individual values and responses in Chinese firms. A common theme of these studies is that knowledge alone will not by itself bring about behavioral change and more complex psychological processes need to be taken into account.

Even though management research has focused on models of decision-making such as the sense making literature (Weick, 1996), sense making studies have mainly focused on social group interactions and organizational dynamics and have not focused on indepth mechanisms of cognitive processes and resulting behaviors (Weick, Sutcliffe and Obstfeld, 2005). In this respect, for a more thorough understanding of decision and behavior, sense making has been mentioned merely as a starting point for exploring more specified models from the cognitive and social psychology literature. Sensemaking research has been applied to issues of environmental management (e.g. Sharma, 2000; Schlange, 2009). For the basis of behavior change, however, in-depth insights are needed to target specific factors in decision-making and behavioral processes. This is an issue that VEP designers, implementers and evaluators should keep in mind.

\subsection{Pro-environmental decision-making and behavior: insights from social psychology}

Research grounded in social psychological theories has been crucial to opening the "black box" of the firm and analyze why and under which conditions certain barriers and drivers translate into pro-environmental behavior. The term "pro-environmental" is somewhat ambiguous, since it does not distinguish whether behavior is conscious, i.e. having environmental benefits as a goal or whether environmentally favorable outcomes are just a side effect of other considerations and decision processes. The literature generally encompasses both approaches to understanding behavior that reduces pollution, environmental damages and waste. Determinants affecting environmental decisions and behavior that have been identified in the social-psychology literature are presented in Table 2.2. 


\begin{tabular}{ll}
\hline External factors & Internal factors \\
\hline - Institutional factors (e.g. Clark & - Motivations (e.g. Tarbernero and \\
et al., 2003) & Herdandez, 2010) \\
- Economic factors (e.g. Clark et & - Intentions (e.g. Harland, 1999) \\
$\begin{array}{l}\text { al., 2003) } \\
\text { - Social and Cultural factors (e.g. }\end{array}$ & - Self-efficacy (e.g. Tarbernero and \\
Laroche, 1996) & Hernandez, 2010) \\
- Demographic factors (e.g. Kahn. & - Awareness (e.g. Gough, 2002) \\
2002) & - Attitudes (e.g. Stewart, 2001) \\
& - Emotions (e.g. Duran et al., 2007) \\
& - Values (e.g. Nordlund and Garvill, 2002) \\
& - Habit (e.g. Dahlstrand, 1997) \\
& - Norms (Stem et al., 1999) \\
& - Risk perception (Fischhoff et al., 1997) \\
\hline
\end{tabular}

Table 2.2: Factors influencing pro-environmental decisions

The factors in Table 2.2, however, will likely not be present in every environmental decision and affect all behavioral outcomes. As Stern (2004) suggested, conclusions about the causes of pro-environmental decisions and behaviors are unlikely to be generalizable across contexts and behavior types. Hence, the relative importance of determinants of behavior will depend on the type of behavior studied. Spatial and time dimension add to the complexity since responsibility for environmental action is perceived to be strongest at the local level where most people perceive environmental issues to be least concerning (Uzzell, 2007).

For that reason, VEP adoption must be evaluated on a case-to-case basis to understand which factors are relevant since programs tend to be diverse in nature and scope. According to Armitage and Conner (2000), social cognition models have been developed to account for differences in socio-demographic and social cognition variations in behavior. Two different categories are motivational and behavioral enactment models with the difference in the dependent variable: While motivational models frequently focus on behavioral intentions as the independent variable, behavioral enactment models aim to explain the difference between intention and action (Armitage and Conner, 2000). Social cognition has been important not only in the psychology field but has also found its way in the technology acceptance and adoption literature. Since a large number of behavior-centered models can explain individual differences in VEP adoption, the selection criteria in this chapter for including models as the basis of step 3 and 8 of the PRECEDE/ PROCEED model is (1) whether they account for both external and internal factors that explain the decisions and behavior of individuals in a professional context and (2) include both predictors of behavior 
and actual behavior variables. Additionally, this chapter focuses on theories targeted at two dimensions, the micro- (individual) and meso-(group/ organization) dimension. The selection presented here is bound to be limited since it will depend on the characteristics of a VEP which model(s) should be selected. Models for VEP program design, implementation and evaluation which include significant determinants of behavior and therefore crucial for behavior change (e.g. motivations, intentions, norms, knowledge, self-efficacy, awareness, attitudes, emotions, values and habits )will be subsequently presented. These theoretical frameworks can be used by VEP developers to establish which determinants need to be targeted and changed in the implementation and evaluation processes.

\subsection{Pro-environmental decisions: Individual Decision Theories}

Studies on individual-level determinants of pro-environmental behavior are abundant in social psychology and related fields. However, the focus in most of these studies has been environmental and energy-related behavior in households while behavior in a professional role has been researched to a lesser extent. In most of the frameworks, a set of capabilities and barriers will influence whether an individual will engage in a specific behavior (Stern, 2000).

Stern and Dietz's (1994) Value-Belief-Norm (VBN) theory of environmentalism links norm-activation theory (Schwartz, 1977) and value theories (Schwartz, 1992). Within the model, values, a general set of beliefs, awareness of consequences, ascription of responsibility and norms lead to pro-environmental action (Stern, 2000). In the context of VEP adoption, managerial values, beliefs on environmental issues, awareness of responsibilities and the consequences as well as norms, routines or habits and contextual factors are important factors. There have been numerous applications of the VBN theory to design programs targeted at household-level conservation behavior supporting the models predictions (Widegren, 1998; Steg et. al., 2005; Kaiser et al., 2005; Eriksson et al., 2008).

Similar to the VBN theory, the Attitude-Behavior- Context (ABC) Theory contributes to explaining environmentally significant behavior (Stern and Oskamp 1987, Guagnano, Stern and Dietz, 1995, Stern 2000). In this framework, Behavior (B) is the product of attitudes $(A)$ and contextual factors $(C)$ with a behavior being performed depending on personal and contextual factors that influence individuals in their decision to take action at a given point in time (Stern, 2000). The A-B-C model developed by Guagnano, Stern and Dietz (1995) postulates that behavior is determined jointly by an individual's structural environment and their general attitudes towards a given behavior (Guagnano, Stern and Dietz, 1995). This theoretical framework assumes that individuals with positive attitudes towards a proenvironmental behavior will perform this behavior even when they face high external constraints. However, if external conditions are very facilitating, even those individuals with negative attitudes towards certain behavior will engage in this behavior (Jackson, 


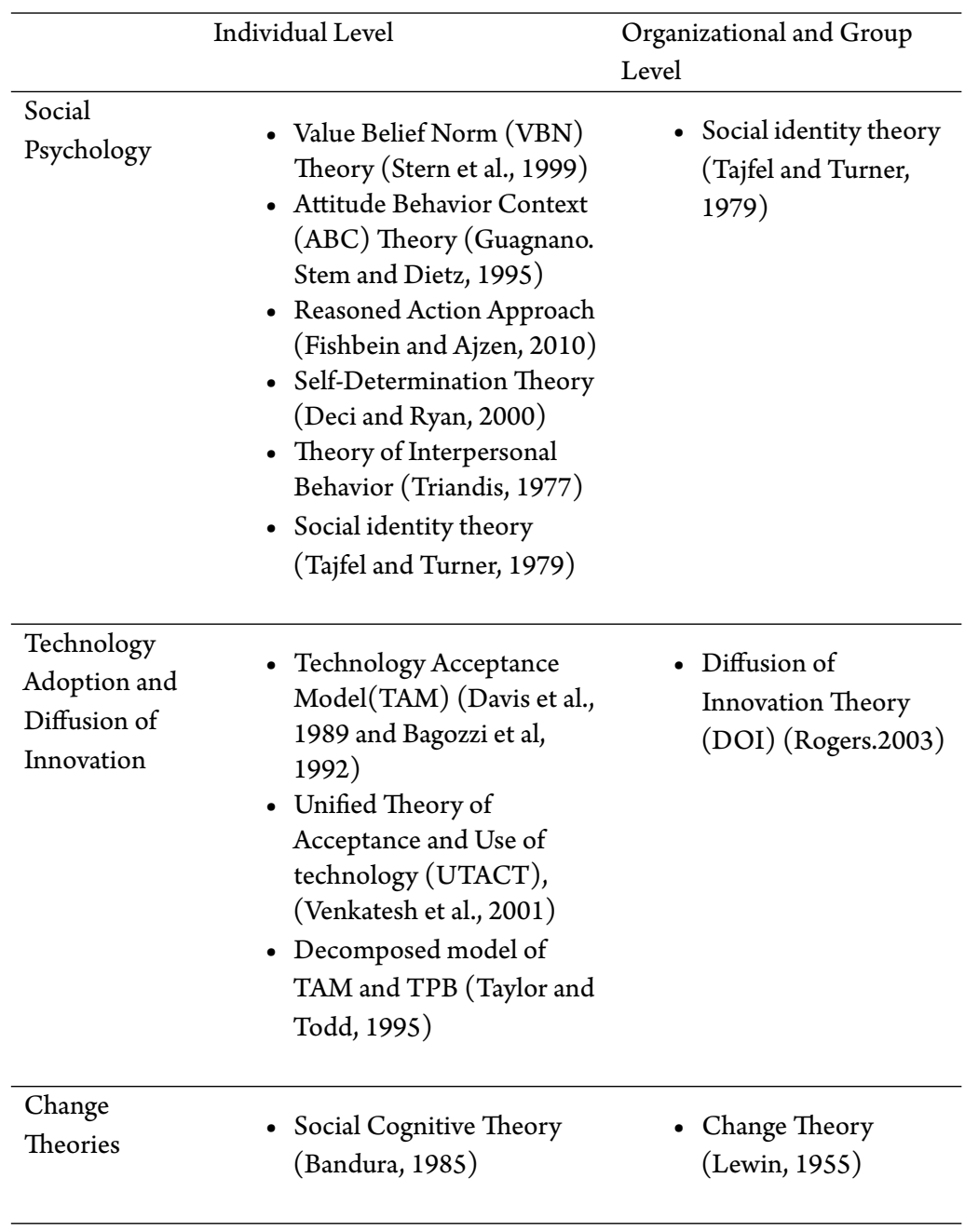

Table 2.3: Selection of social-psychological models relevant to VEP adoption 
2005). According to Jackson (2005), the A-B-C model can be useful for policy-makers to improve facilitating conditions in environmental areas with low compliance. Since a number of VEPs have been found to yield rather unsatisfactory results, this model can be used as the basis to analyze behavioral determinants of VEPs adoption by professionals. Even though managers might have a pro-environmental attitude, contextual factors such as economic or policy related issues may prevent them from adopting more environmentally friendly business practices.

This aspect of professional VEP adoption is closely linked to the concept of self-efficacy or Perceived Behavioral Control (PBC). Developed by Bandura (1985), this concept has been subsequently used within the series of models developed by Fishbein and Ajzen (1980). Fishbein and Ajzen developed their Theory of Reasoned Action (TRA) model (1980) in order to evaluate the differences they found between attitude and behavior. The Theory of Reasoned Action postulates that an individual is determined by their intentions to carry out a certain action and that this intention will be a function of their attitudes towards a certain behavior and social norms surrounding the action (Ajzen and Fishbein, 1980). In consequence, intention can be considered to be the best predictor of a given behavior and its antecedent. In an extension of the TRA, the Theory of Planned Behavior (TPB) (Ajzen, 1991) states that behavior is in many cases not fully under control of an individual alone. Thus, the TPB builds on the TRA model and extends it with the concept of perceived behavioral control (Ajzen, 1985); intention is not only determined by subjective norms and attitudes but also by the control that individuals believe to have over their actions.

In order to predict intentions, the knowledge of underlying beliefs is crucial and necessary. Generally, the more favorable a certain attitude and subjective norm and the greater the perception of control individuals have regarding a given behavior, the more likely it is that a person's intention to perform a behavior will be stronger. In various settings, the TPB has turned out to have a good explanatory power for analyzing decision-making (Armitage and Conner, 2000; Godin and Kok, 1996; Hagger et al., 2002). To date, the TPB has been used successfully to understand a range of environmentally responsible behaviors such as recycling (e.g., Boldero, 1995; Cheung et al., 1999; Taylor and Todd, 1995), composting (Taylor and Todd, 1995), energy use (Harland et al., 1999), water conservation(Kantola et al., 1982), as well as sustainable agriculture practices(e.g. Beedell and Rehman, 2000). Fishbein and Ajzen (2010) have kept with the Reasoned Action Approach (RAA) most of the TBP elements but added additional variables: environmental constraints, actual control and skills. By doing this, they recognized that the lack of skills or certain abilities for performing the behavior can prevent action just as external factors or perception of control. The Reasoned Action Approach is significant because it assumes that design of VEPs needs to induce positive attitudes, improve either the expectations of the target populations peers or reduce their perceived influence while improving the control perceptions of the individual. However, factors such as actual control or skills have also to be integrated in the 
program design and evaluation to allow for realistic design, implementation and evaluation processes.

There are significant debates how much an individual "plans" to act, with motivation and routines as significant determinants of behavior. Routines and habits have been identified in the literature to be a source of barrier to behavior change. The Theory of Interpersonal Behavior (Triandis, 1977, 1980), while being in many aspects similar to the Reasoned Action Approach (RAA), includes habit as a predictor variable of intention and behavior. Triandis (1980) suggests that situation and behavior become automatic and are partially non-conscious. On the other hand, motivation has been found to be a major determinant of behavior and motivational theories can offer some explanations regarding the origins of social cognitive beliefs (Deci and Ryan, 1985). In the context of pro-environmental behavior, positive and negative emotions have also been found to determine action through motivational processes (Vinning and Ebreo, 2002).

According to Self-Determination Theory (SDT), individuals' motivation can be categorized in self-determined vs. controlled types of motivation (Deci and Ryan, 2000). In this sense, individuals who perceive their actions to be self-determined and as a personal choice will have intrinsic motivation to act pro-environmentally (i.e. to higher VEP uptake rates). On the opposite, those individuals whose motivations are not self-determined will act only because of control and pressure. In the context of VEP adoption this aspect is crucial, since self-determination is positively correlated with behavioral engagement (Chatzisarantis et al., 2003) and can be either promoted or hindered by environmental factors (Hagger et al., 2002). Hence, VEPs which are targeted at behavioral change will have to take the question into account how to promote self-determined behavior change. Since VEP adoption decisions are either made by managers or management teams or project managers in project-based markets such as construction, interpersonal and inter-professional aspects also need to be taken into account. This transition from individual decisions and behavior to interpersonal relations leads to next higher level of analysis: the organization, groups and social networks.

\subsection{Pro-environmental Decision Making and Behavior: Organizations, Groups and Social Networks}

Perrow (1997) describes organizations as "the most intensive and effective environmental destroyer.” In addition to individual factors, research has suggested that organizational factors (i.e. organizational culture, capability to influence the strategy, long-term orientation, organizational structure, formation of environmental teams) have a substantial impact on decision-making and subsequent behavior (Nilsson et al., 2004). Certain elements are important to understanding the influence of organizations environmental behavior 
and decisions. One of the key issues to be solved is whether personal priorities among decision-makers or organizational mechanisms are the most influential determinants of decisions and behavior related to pro-environmental behavior. This is also the case for the VEP design and implementation process in which the right level of intervention is of high importance. While there are an abundant number of theories on organizational behavior models specifically related to environmental issues are rare. VEP adoption is different in many ways from the adaptation of new practices in organizations, since the decisions to work with these schemes are usually made at the managerial level. While some of these decisions bear consequences for individuals within organizations, "regular" employee's decisions are generally less important for VEP adoption (Lutzenhiser et al., 2003). However, some theories that have their origin on the individual level of analysis can be applied to higher order units such as organizational or group behavior. Social Identity Theory(SIT) (Tajfel and Turner, 1979), for instance, postulates that individual behavior is a reflection of larger societal phenomena. Groups and organizations as well as the individuals' identification with them will guide internal processes and subsequently shape behavior. Social identity theory postulates that social cognitions are formed partially on group affiliation and can contribute to explain intergroup relations. Hence, a positive self-concept is derived largely from group identification and comparison between in-group and out-group (Operario and Fiske, 1999). In the context of VEP adoption, this theoretical framework suggests that the success of adoption of a scheme is dependent not only by individual motivation but also on conflicts between groups or organizations. In that sense, decision-makers in firms will be influenced in their adoption decision and who they perceive to be their peers. Conflicts between groups can contribute to a delay in uptake or make the scheme unsuccessful altogether.

The social context of environmental behaviors has been repeatedly stressed in the literature. Olli et al. (2001) suggest that network participation is an additional factor influencing pro-environmental decisions. In a professional context managers are likely to learn from their peers and the experiences of other decision-makers. Individual behaviors accumulate to social systems that will affect the social perceptions under study (Robins and Kashima, 2008). In this line of reasoning, the individual-centered social cognition research tradition can and should be complemented with social network approaches taking into account the more structural dimensions of behavior and decisions. Social network theories and analysis predicts that the more connected a decision-maker is to social network in which VEP adoption is the rule, the more likely a CEO or manager will be to adopt a VEP (Jaeger et al., 1993). Social cognition has been acknowledged to be influenced by social networks (Robins and Kashima, 2008) and the influence of peers is likely to depend on an individual's resistance and the self-efficacy to "build, maintain and mobilize social networks" (Conner and Norman, 2005; Jessor, 1998). Individual psychological differences have been found to influence networks structures; hence, even if adopting a network perspective on VEP programs, knowledge on individual differences in cognition will facilitate targeting and 
changing behaviors of network actors. These issues have been also addressed in theoretical models from the technology and innovation acceptance literature.

\subsection{Literature on Acceptance, Adoption and Diffusion of Technology and Innovations}

The role of technology in environmental and climate change research has been strongly emphasized. Indeed, technology has often been praised in a process that Gifford (2008) has called "techno-salvation". Despite these praises, technology is not in all cases a favorable solution. The development of new environmental technology does hardly guarantee that it will be accepted or used and might in some circumstances reinforce the problems it has been thought to solve (Midden et al., 2007). The adoption of new practices and behavior change has been widely discussed in another stream of literature based on models from social psychology: studies on the adoption, acceptance and diffusion of innovations and technology. VEPs can be seen as innovations, since they are frequently related to the promotion of technological novelties such as building materials, industrial environmental management practices, or energy control mechanisms. According to Zaltman and Lin (1971), Innovation is "any idea, practice, or material artifact perceived to be new to the relevant adopting unit "with Adoption being "the acceptance and continued use of a product, service, or idea. The adoption process refers to a series of mental and behavioral states that a person passes through leading to the adoption or rejection of an innovation" while Diffusion "is the spread of an innovation throughout a social system" (Howard and Moore, 1982). For a detailed discussion on research streams within the literature on innovation and technology diffusion, acceptance and adoption, Wejnert (2002) has proposed a conceptual framework that contributes to understanding the diffusion of innovations such as the characteristics of innovations, the characteristics of innovators and the environmental context of the decision. In addition, Gopalakrishnan and Damanpour (1997), Gallivan (2001) and MacVaugh and Schiavone (2010) provide an overview on the vast diffusion of innovation and technology acceptance literature.

\subsection{Acceptance, Adoption and Diffusion of Technology and Innovations: Individual Decision Theories}

Within the study of innovation diffusion, several cognition models are well suited for the development and evaluation of VEPs. Surprisingly, models on technology and innovation acceptance models have been rarely applied to environmental decision and behavior problems even though many VEPs are targeted at eco-innovations and environmental technology promotion. 
One of the predominant frameworks regarding the adoption of innovations is the Technology Acceptance Model (TAM) by Davis et al. (1989) and Bagozzi et.al (1992). Its extensions are the Technology Acceptance Model 2(TAM2) by Venkatesh and Davis (2000) and the TAM 3 (Venkatesh and Bala, 2008). Based on the Theory of Reasoned Action (TRA) by Ajzen and Fishbein (1985) these models also include Perceived Usefulness (PU) and Perceived Ease of Use (PEU) which determine the intention and actual system usage. Even though the TAM has become one of the most popular models in this field, Bagozzi (2007) has pointed out some problems with it such as a neglect of the use-to-goalattainment gap, i.e. the fact that the adoption is not the final step of the decision chain but only a medium stage to a later goal (i.e. adopting a VEP could only be the first step in a larger chain of decisions for a decision-maker). Since both the Theory of Planned Behavior (TPB) and the Technology Acceptance (TA) models include the attitude concept as a determinant of behavioral intention, several authors have focused on integrating both approaches in one model by refining the attitudinal approach into Perceived Usefulness (PU) and Perceived Ease of Use (PEU) constructs (Jacoby and Kaplan, 1972, Mathieson, 1991, Szajna, 1995 and Taylor and Todd , 1995).

Driven by criticism of the diversit and disconnectedness of models in this field, Venkatesh et al. (2001) developed a Unified Theory of Acceptance and Use of Technology (UTAUT). This comprehensive model includes the Theory of Reasoned Action (TRA), the Technology Acceptance Model, the Motivational Model, the Theory of Planned Behavior (TPB), a Combined Theory of Planned Behavior/Technology Acceptance Model, the Model of PC Utilization, the Innovation Diffusion Theory, and Social Cognitive Theory. According to the UTAUT, performance expectancy, effort expectancy, facilitating conditions and influence determine adoption intention and behavior directly. Other relationships are mediated by gender, age, experience and voluntariness of use (Venkatesh et al., 2003). Bagozzi (2007) has pointed out the shortfalls of a model with " 41 independent variables for predicting intentions and at least eight independent variables for predicting behavior". The complexity of the model and that it is mostly interested in explaining IT adoption mechanisms limit its use significantly. Therefore, this is a case which shows that very complex behavioral models encounter limitations when used as the basis for VEP design and evaluation. Even though simplicity has led to program failures, over-complexity of models can also lead to confusion and inappropriate program development.

\subsection{Acceptance, Adoption and Diffusion of Technology and Innovations: Organizations, Groups and Networks}

In addition to the individual level, the literature on innovation adoption has a distinct organizational dimension. One of the theories linking the individual and the organizational level, and one of the most predominant to date is the Diffusion of Innovation Theory (DOI) 
by Rogers (2003). According to this framework, adoption of innovations in a society follows a distinct process, notably "the communication of an innovation over time through certain channels among a social system”. Rogers (2003), suggests five distinct adopter categories linked to the propensity of adopting innovations. According to the theory, network characteristics as well as the attributes of the innovation will determine on the adoption level (Rogers, 2003). An important framework less prominent in social cognition research applied to the adoption of an innovation or technology is the social network perspective. Similar to pro-environmental behavior, innovation and technology adoption has been found in some studies to accelerate the more individuals' peers adopt a specific innovation or technology. The "Innovation-Decision Process "describes the adoption as 'knowledge of the idea', 'persuasion', 'decision', 'information' and 'confirmation' (Rogers, 2003).

The underlying assumption of DOI is that adoption processes are deliberative and social interaction determines awareness. Even though Rogers (2003) describes the adoption process as a mechanistic process, he focuses on the role of individuals and networks as well as the interaction between these levels.

According to Gallivan (2001), evidence from the technology sector suggests that frameworks focusing on individual decisions and behavior frequently neglect the organizational dimension since decisions are frequently made at the organizational or team level. His criticism touches upon the question whether traditional frameworks are suitable to analyze adoption processes since individual autonomy might not be present in these contexts. However, some VEP adoption processes constitute "contingent authority innovation decisions" (Zaltman et al., 1973), i.e. situations in which an organizational authority makes the initial decision to adopt and organizational members have no choice than to follow along. Since VEPs are so diverse in nature, however, no general conclusion can be made in this regard; research on these schemes has to take these issues into account on a case-to-case basis. Most of the theoretical models reviewed in the sections above can be useful in order to design effective VEPs and similar programs.

\subsection{Limitations}

While behavior change should be considered as a major factor for policies and program design and implementation, the issue is whether this objective is possible and desirable. Fischhoff (1990) noted that behavior change methods are mainly appealed to when the public's behavior threatens policy-makers goals. Insights on decisions and behaviors can also be used to fortify power structures, overcoming resistance and legitimizing business and policy initiatives. While theory-based programs take the mechanisms into account by which behavior is changed, it needs to be acknowledged that there are limitations to using social cognition theories as a basis for VEP design and evaluation. Theories may not 
match a specific program since high degrees of abstraction found in some models may be difficult to be operationalized in practice. The behavioral assumptions underlying each model need to be properly understood to really advance program design and evaluation in a structured manner. In some cases, several theories may need to be included in the program design. However, the more theories need to be tracked, the more expensive the evaluation (Weiss, 2000). As stated in the PRECEDE/ PROCEED (Green and Kreuter, 1999) and the Intervention Mapping approach (Bartholomew et al., 2005), the choice of models and their combination to understand and improve VEP adoption can be difficult. Hence, a very structured approach and analysis of the problem at hand is required. Additionally, it is crucial to select a level of analysis and behavior change intervention likely to be most successful for VEP adoptions. In firms, analyzing employees' choice or preferences for a VEP are futile if the managers or CEO have decided not to adopt. Since certain factors such as technology, economy, demography, institutions and culture influence behavior and given the complexity of pro-environmental behavior and the numerous variables to be taken into account, many models are likely to be limited (Blake, 1999). Over-simplified models can be problematic when key variables missing in the model influence decision-making processes (Jackson, 2005). However, if models become too complex with a large number of variables and relationships, it gets more difficult to establish significant correlations or to detect influences on choice. Another limitation is of more theoretical than empirical concern. Since some VEPs might not be appropriate to tackle environmental issues in the first place, it needs to be thoroughly evaluated whether promoting a specific program does make sense. Based on some of the models suggested in this chapter, the foundations can be set to analyze environmental programs and subsequently design intervention programs in order to improve VEP adoption; this does not mean, however, to view every VEP as a beneficial scheme whose uptake needs to be improved.

In VEP design, the channels of communication are a decisive factor. To change behavior, values and beliefs have to be changed first. Attitudes per se are not good predictors of behavior, since both intrinsic and extrinsic motivations are decisive. Interpersonal communication contributes to persuasion but characteristics of audience, communicator, message and medium are decisive factors in the context of program design since individuals have existing attitudes and "latitudes of acceptance", a range of messages that can be accepted from their point of view (Thorngate, 2001).

\subsection{Conclusion}

In this chapter we have touched upon number of points in the design and analysis of Voluntary Environmental Programs that have not been mentioned in the existent literature so far. A major issue is the embeddedness of environmental and energy programs in the PTEM paradigm resulting in a reduced understanding of the adoption process, the so- 
called "black box" in the evaluation literature. It is argue that effective programs need to be grounded in theories that allow for coherent evaluation and reliable results. Hence, program designers and evaluators need to include behavior change components in all VEPs and not only those explicitly designed for behavior change. Other fields of inquiry such as health promotion and evaluation have a longstanding tradition of applying frameworks which not only include contextual factors and policy elements but also behavioral aspects of program adoption. Hence, the health promotion literature and its theory selection frameworks were considered, a field of research grounded in theory-based interventions and program planning to identify models influential in program analysis. Some of these models have already been applied to the pro-environmental behavior literature. For the behavioral analysis part behavioral assessment and evaluation stages were presented from the social psychology and technology acceptance literature which contribute to an improved theorybased understanding of the adoption process. The chapter suggests that embedding theories to understand and change behavioral factors in frameworks such as Intervention Mapping (Bartholomew et al., 2005) and PRECEDE/PROCEED (Green and Kreuter, 2005) are very useful for both design and analysis of VEPs. The aim was to propose directions for studying the underlying foundations of VEP adoption that can also serve as the basis for future intervention studies aimed at improving the uptake of specific Voluntary Environmental Programs. This review does not, however, suggest that the models proposed are the only ones that have the potential to contribute to the understanding of all VEPs neither does it suggest that all the models should be applied to a specific kind of VEP. Before applying a behavioral model to a decision problem, the background, the targets, the intended results and the usefulness of a Voluntary Environmental Program has to be well understood. 


\section{References}

Ajzen, I. (1991). The theory of planned behavior. Organizational behavior and human decision processes, 50(2), 179-211.

Ajzen, I. (2002). Perceived behavioral control, self-efficacy, locus of control and the theory of planned behavior. Journal of Applied Social Psychology, 32(4), 665-683.

Ajzen, I., Fishbein, M., \& RL, H. (1980). Understanding attitudes and predicting social behavior. Prentice-Hall Englewood Cliffs.

Ajzen, I., \& TJ, M. (1986). Prediction of goal-directed behavior: Attitudes, intentions, and perceived behavioral control. Journal of Experimental Social Psychology, 22, 5-453.

Allport, A. (1985). Handbook of social psychology. In G. Lindzey \& E. Aronson (Eds.), Handbook of social psychology (vol.1, 3rd ed (3rd ed., Vol. 1, pp. 1-46). Random House. (editor:In G. Lindzey \& E. Aronson (Eds)

Aragon-Correa, J. A., Matias-Reche, F., \& Senise-Barrio, M. E. (2004). Managerial discretion and corporate commitment to the natural environment. Journal of Business Research, 57(9), 964-975.

Armitage, C. J., \& Conner, M. (2000). Social cognition models and health behavior: A structured review. Psychology \& Health, 15(2), 173-189.

Arora, S., \& Cason, T. N. (1995). An experiment in voluntary environmental regulation: Participation in epa's 33/50 program. Journal of Environmental Economics and Management, 28(3), 271-286.

Astbury, B., \& Leeuw, F. (2010). Unpacking black boxes: Mechanisms and theory-building in evaluation. American Journal of Evaluation, 31(3), 363-381.

Bagozzi, R. (2007). The legacy of the technology acceptance model and a proposal for a paradigm shift. Journal of the Association for Information Systems, 8(4), 244-254.

Bagozzi, R. P., Davis, F. D., \& Warshaw, P. (1992). Development and test of a theory of technological learning and usage. Human Relations, 45(7), 659-686.

Bandura, A. (1985). Social foundations of thought and action: A social cognitive theory. englewood cliffs. Prentice Hall: Englewood Cliffs.

Banerjee, S. B. (2001). Managerial environmental attitudes and corporate environmentalism: A preliminary investigation. Journal of Environmental Education, 32(4), 49-50.

Banerjee, S. B. (2002). Corporate environmentalism: the construct and its measurement. Journal of Business Research, 55(3), 177-191.

Bartholomew, L. K., Kok, P. G. S., G, \& Gottlieb, N. H. (2011). Planning health promotion programs: An intervention mapping approach. San Francisco: Jossey-Bass.

Beedell, J., \& Rehman, T. (2000). Using social-psychology models to understand farmers' conservation behavior. Journal of Rural Studies, 16(1), 117-127.

Blake, J. (1999). Overcoming the 'value-action gap'in environmental policy: tensions between national policy and local experience. Local Environment, 4(3), 257-278. 
Boerkey, P., \& Leveque, F. (1998). Voluntary approaches for environmental protection in the european. Paris: OECD.

Boldero, J. (1995). The prediction of household recycling of newspapers: The role of attitudes, intentions, and situational factors. Journal of Applied Social Psychology, 25(5), 440-462.

Branzei, O., Ursacki-Bryant, T. J., Vertinsky, I., \& Weijiong, Z. (2004). The formation of green strategies in chinese firms: matching corporate environmental responses and individual principles. Strategic Management Journal, 25(11), 1075-1095.

Brug, J., Oenema, A., \& Ferreira, I. (2005). Theory, evidence and intervention mapping to improve behavior nutrition and physical activity interventions. International Journal of Behavioral Nutrition and Physical Activity, 2(1), 85-89.

Carmin, J., Darnall, N., \& Mil-Homens, J. (2003). Stakeholder involvement in the design of u.s. voluntary environmental programs: does sponsorship matter? Policy Studies Journal, 31(4), 527-543.

Chatzisarantis, N. L., Hagger, M. S., Biddle, S. J. H., \& Wang, B. S. . J. (2003). A metaanalysis of perceived locus of causality in exercise, sport, and physical education contexts. Journal of Sport and Exercise Psychology, 25, 284-306.

Cheung, S., Chan, D. K. S., \& Wong, M. (1999). Reexamining the theory of planned behavior in understanding wastepaper recycling. Environment and Behavior, 31(5), 587.

Clark, C., M. J., K., \& Moore, M. (2003). Internal and external influences on proenvironmental behavior: Participation in a green electricity program. Journal of Environmental Psychology, 23(3), 237-246.

Conner, M., \& Norman, P. (2005). Predicting health behavior. Buckingham: Open University Press.

Cordano, M., \& Frieze, I. (2000). Reduction preferences of u.s. environmental managers: Applying ajzen's theory of planned behavior. The Academy of Management Journal, 43(4), 627-641.

Daamen, D., Staats, H., Wilke, H. A. M., \& Engelen, M. (2001). Improving environmental behavior in companies. Environment and Behavior, 33(2), 229.

Dahlstrand, U., \& Biel, A. (1997). Pro-environmental habits: Propensity levels in behavioral change. Journal of Applied Social Psychology, 27(7), 588-601.

Darnall, N., \& Edwards, D. (2006). Predicting the cost of environmental management system adoption: the role of capabilities, resources and ownership structure. Strategic Management Journal, 27(4), 301-320.

Darnall, N., Potoski, M., \& Prakash, A. (2010). Sponsorship matters: Assessing business participation in government- and industry-sponsored voluntary environmental programs. Journal of Public Administration Research and Theory, 20(2), 283-307.

Davis, F. D. (1989). usefulness, perceived ease of use, and user acceptance of information technology. MIS Quarterly, 13(3), 319-340. 
Davis, F. D., Bagozzi, R. P., \& Warshaw, P. R. (1992). Extrinsic and intrinsic motivation to use computers in the work place. Journal of Applied Social Psychology, 22(14), 1111-1132.

Davis, F. D., \& Warshaw, R. P. B. . P. (1989). User acceptance of computer technology: a comparison of two theoretical models. Management Science, 35(8), 982-1003.

Deci, E. L., \& Ryan, R. (2000). The "what" and "why" of goal pursuits: human needs and the self-determination of behavior. Psychological Inquiry, 11, 227-68.

Deci, E. L., \& Ryan, R. M. (1985). Intrinsic motivation and self-determination in human behavior. New York: Plenum.

Duran, M., Alzate, M., Lopez, W., \& Sabucedo, J. M. (2007). Emotions and proenvironmental behavior. Revista Latinoamericana de Psicologia, 39, 287-296.

Eden, S. (1993). Individual environmental responsibility and its role in public environmentalism. Environment and Planning A, 25, 1743-1743.

Egmond, C., Jonkers, R., \& Kok, G. (2005). A strategy to encourage housing associations to invest in energy conservation. Energy Policy, 33, 2374-2384.

Eriksson, L., Garvill, J., \& Nordlund. (2008). Acceptability of single and combined transport policy measures: The importance of environmental and policy specific beliefs. Transportation Research Part A: Policy and Practice, 42(8), 1117-1128.

Fischhoff, B. (1990). Psychology and public policy: Tool or toolmaker. American Psychologist, 45, 647-653.

Fischhoff, B., Bostrom, A., \& Quadrel, M. (1997). Oxford textbook of public health. In R. Detels, W. Holland, J. McEwen, \& G. Omenn (Eds.), (pp. 987-1002). Oxford, Uk.: Oxford Univ. Press.

Fishbein, M., \& I, A. (1975). Belief, attitude, intention and behavior: An introduction to theory and research. Reading, MA.: Addison-Wesley.

Fishbein, M., \& I, A. (2010). Predicting and changing behavior: The reasoned action approach. New York: Psychology Press.

Fitz-Gibbon, C. T., \& Morris, L. L. (1996). Theory-based evaluation. Evaluation Practice, 17(2), 177-184.

Gallivan, M. (2001). Organizational adoption and assimilation of complex technological innovations: Development and application of a new framework. ACM Sigmis Database, 32(3), 51-85.

Gifford, R. (2008). Psychology's essential role in alleviating the impacts of climate change. Canadian Psychology, 49, 273-280.

Godin, G., \& Kok, G. (1996). The theory of planned behavior: a review of its applications to health-related behaviors. American Journal of Health Promotion: AJHP, 11(2), 87.

Gopalakrishnan, F. (1997). A review of innovation research in economics, sociology and technology management. Omega, 25(1), 1-15.

Gough, A. (2002). Mutualism: a different agenda for environmental and science education. International Journal of Science Education, 24(11), 1201-1215. 
Green, L. W., \& Kreuter, M. W. (1999). Health promotion planning: An educational and ecological approach. (3rd ed.). Mountain View (California): Mayfield Publishing Company.

Guagnano, G. A., Stern, P. C., \& Dietz, T. (1995). Influences on attitude-behavior relationships a natural experiment with curbside recycling. Environment and behavior, 27(5), 699-718.

Gunningham, N., \& Sinclair, D. (1999). Integrative regulation: A principle-based approach to environmental policy. Law \& Social Inquiry, 24(4), 853-896.

Hagger, M., \& Biddle, N. L. D. C. . S. H. (2002). A meta-analytic review of the theories of reasoned action and planned behavior in physical activity: Predictive validity and the contribution of additional variables. Journal of Sport \& Exercise Psychology, 24(1), 3-32.

Harland, P., H.Staats, \& Wilke, H. A. M. (1999). Explaining pro-environmental intention and behavior by personal norms and the theory of planned behavior. Journal of Applied Social Psychology, 29(12), 2505-2528.

Harrison, D. A. (1995). Volunteer motivation and attendance decisions: Competitive theory testing in multiple samples from a homeless shelter. Journal of Applied Psychology, 80, 371-385.

Heimlich, J., \& Ardoin, N. (2008). Understanding behavior to understand behavior change: a literature review. Environmental Education Research, 14(3), 215-237.

Hines, J. M., Hungerford, H. R., \& A.Tomera. (1987). Analysis and synthesis of research on responsible environmental behavior: A meta-analysis. Journal of Environmental Education, 18(1), 1-18.

Hoffman, A. J. (2001). Linking organizational and field-level analyses. Organization \& Environment, 14(2), 133-156.

Howard, J., \& WL, M. (1982). Readings in the management of innovation. In M. Tushman (Ed.), M.l. tushman. readings in the management of innovation (chap. Changes in consumer behavior over the product life cycle). Cambridge, MA.: Ballinger.

Jackson, T. (2005). Motivating sustainable consumption: a review of evidence on consumer behavior and behavioral change. Policy Studies Institute.

Jacoby, J., \& Kaplan, L. (1972). Components of perceived rsk. In Proceedings acr (pp. 382-393).

Jaeger, C., Durrenberger, G., Kastenholz, H., \& Truffer, B. (1993). Determinants of environmental action with regard to climatic change. Climatic Change, 23(3), 193211.

Jessor, R. (1998). New perspectives on adolescent risk behavior. Cambridge University Press.

Kahn, M. E. (2002). Demographic change and the demand for environmental regulation. Journal of Policy Analysis and Management, 21(1), 45-62.

Kaiser, F. G., Hubner, G., \& Bogner, F. X. (2005). Contrasting the theory of planned behavior with the value-belief-norm model in explaining conservation behavior1. 
Journal of Applied Social Psychology, 35(10), 2150-2170.

Kantola, S., Syme, G., \& Campbell, N. (1982). The role of individual differences and external variables in a test of the sufficiency of fishbein's model to explain behavioral intentions to conserve water. Journal of Applied Social Psychology, 12(1), 70-83.

Khanna, M., \& Damon, L. A. (1999). Epa's voluntary 33/50 program: impact on toxic releases and economic performance of firms. Journal of environmental economics and management, 37(1), 1-25.

Khanna, M., Koss, P., Jones, C., \& Ervin, D. (2007). Motivations for voluntary environmental management. Policy Studies Journal, 35(4), 751-772.

Langlois, M. A., \& Hallam, J. S. (2010). Integrating multiple health behavior theories into program planning: the per worksheet. Health promotion practice, 11(2), 282-288.

Lewin, K. (1951). Field theory in social science: selected theoretical papers. Haper and Row.

Lippke, S., \& Ziegelmann, J. P. (2008). Theory-based health behavior change: Developing, testing, and applying theories for evidence-based interventions. Applied Psychology, 57(4), 698-716.

Lutzenhiser, L. (2009). The evolution of electricity efficiency policy, the importance of behavior and implications for climate change intervention. In D. R. . M. Stabile (Ed.), Perspectives on energy policy. University of Toronto Press.

MacVaugh, J., \& Schiavone, F. (2010). Limits to the diffusion of innovation: A literature review and integrative model. European Journal of Innovation Management, 13(2), 197-221.

Martin-Pena, M. L., Diaz-Garrido, E., \& Sanchez-Lopez, J. M. (2010). Relation between management's behavioural intentions toward the environment and environmental actions. Journal of Environmental Planning and Management, 53(3), 297-315.

Mathieson, K. (1991). Predicting user intentions: comparing the technology acceptance model with the theory of planned behavior. Information systems research, 2(3), 173-191.

Michie, S., Johnston, M., Francis, J., Hardeman, W., \& Eccles, M. (2008). From theory to intervention: mapping theoretically derived behavioural determinants to behaviour change techniques. Applied psychology, 57(4), 660-680.

Nilsson, A., \& Biel, A. (2008). Acceptance of climate change policy measures: Role framing and value guidance. European Environment, 18(4), 203-215.

Nilsson, A., von Borgstede, C., \& Biel, A. (2004). Willingness to accept climate change strategies: The effect of values and norms. Journal of environmental psychology, 24(3), 267-277.

Nordlund, A. M., \& Garvill, J. (2002). Value structures behind proenvironmental behavior. Environment and Behavior, 34(6), 740-756.

Olli, E., Grendstad, G., \& Wollebaek, D. (2001). Correlates of environmental behaviors bringing back social context. Environment and Behavior, 33(2), 181-208. 
Operario, D., \& Fiske, S. T. (1999). Social cognition permeates social psychology: Motivated mental processes guide the study of human social behavior. Asian Journal of Social Psychology, 2(1), 63-78.

Pawson, R., \& Tilley, N. (1997). Realistic evaluation. Sage.

Perrow, C. (1997). Organizing for environmental destruction. Organization \& Environment, 10(1), 66-72.

Robins, G., \& Kashima, Y. (2008). Social psychology and social networks: Individuals and social systems. Asian Journal of Social Psychology, 11(1), 1-12.

Rogers, E. (2003). Diffusion of innovations. Free Press.

Schlange, L. E. (2008). Stakeholder identification in sustainability entrepreneurship: The role of managerial and organisational cognition. Greener Management International(55), 13.

Schwartz, S. H. (1977). Normative influences on altruism. Advances in experimental social psychology, 10, 221-279.

Schwartz, S. H. (1992). Universals in the content and structure of values: Theoretical advances and empirical tests in 20 countries. Advances in experimental social psychology, 25(1), 1-65.

Sharma, S. (2000). Managerial interpretations and organizational context as predictors of corporate choice of environmental strategy. Academy of Management journal, 43(4), 681-697.

Smith, E. R., \& Semin, G. R. (2007). Situated social cognition: cognition in its social context. Current Directions in Psychological Science, 16(3), 132-135.

Stame, N. (2004). Theory-based evaluation and types of complexity. Evaluation, 10(1), 58-76.

Steelman, T. A., \& Rivera, J. (2006). Voluntary environmental programs in the united states whose interests are served? Organization \& environment, 19(4), 505-526.

Steg, L., Dreijerink, L., \& Abrahamse, W. (2005). Factors influencing the acceptability of energy policies: A test of vbn theory. Journal of Environmental Psychology, 25(4), $415-425$.

Stern, P. C. (2000). New environmental theories: toward a coherent theory of environmentally significant behavior. Journal of social issues, 56(3), 407-424.

Stern, P. C., \& Dietz, T. (1994). The value basis of environmental concern. Journal of social issues, 50(3), 65-84.

Stern, P. C., \& Oskamp, S. (1987). Managing scarce environmental resources. Handbook of environmental psychology, 2, 1043-1088.

Tabernero, C., \& Hernández, B. (2011). Self-efficacy and intrinsic motivation guiding environmental behavior. Environment and Behavior, 43(5), 658-675.

Tajfel, H., \& Turner, J. C. (1979). An integrative theory of intergroup conflict. The social psychology of intergroup relations, 33, 47. 
Taylor, S., \& Todd, P. (1995a). An integrated model of waste management behavior a test of household recycling and composting intentions. Environment and Behavior, 27(5), 603-630.

Taylor, S., \& Todd, P. A. (1995b). Understanding information technology usage: A test of competing models. Information systems research, 6(2), 144-176.

Thorngate, W. (2001). The social psychology of policy analysis. Journal of Comparative Policy Analysis: Research and Practice, 3(1), 85-112.

Tilikidou, I. (2007). The effects of knowledge and attitudes upon greeks' pro-environmental purchasing behaviour. Corporate Social Responsibility and Environmental Management, 14(3), 121-134.

Triandis, H. C. (1977). Interpersonal behavior. Brooks/Cole Publishing Company Monterey, CA.

Triandis, H. C. (1979). Values, attitudes, and interpersonal behavior. In Nebraska symposium on motivation.

Uzzell, D. (2007). How the science of psychology can make a contribution to sustainable development. Working Paper.

Venkatesh, V. (2006). Where to go from here? thoughts on future directions for research on individual-level technology adoption with a focus on decision making*. Decision Sciences, 37(4), 497-518.

Venkatesh, V., \& Bala, H. (2008). Technology acceptance model 3 and a research agenda on interventions. Decision sciences, 39(2), 273-315.

Venkatesh, V., \& Davis, F. D. (2000). A theoretical extension of the technology acceptance model: four longitudinal field studies. Management science, 46(2), 186-204.

Venkatesh, V., Morris, M. G., Davis, G. B., \& Davis, F. D. (2003). User acceptance of information technology: Toward a unified view. MIS quarterly, 27(3), 425-478.

Vine, E. L. (1994). The human dimension of program evaluation. Energy, 19(2), 165-178.

Weick, K. E. (1996). Sensemaking in organizations (Vol. 3). Sage.

Weick, K. E., Sutcliffe, K. M., \& Obstfeld, D. (2005). Organizing and the process of sensemaking. Organization science, 16(4), 409-421.

Weiss, C. H. (1997). How can theory-based evaluation make greater headway? Evaluation review, 21(4), 501-524.

Weiss, C. H. (2000). Which links in which theories shall we evaluate? New directions for evaluation, $87,35-45$.

Wejnert, B. (2002). Integrating models of diffusion of innovations: a conceptual framework. Sociology, 28(1), 297-327.

Welch, E. W., Mazur, A., \& Bretschneider, S. (2000). Voluntary behavior by electric utilities: levels of adoption and contribution of the climate challenge program to the reduction of carbon dioxide. Journal of Policy Analysis and Management, 19(3), 407-425.

Wiidegren, Ö. (1998). The new environmental paradigm and personal norms. Environment and Behavior, 30(1), 75-100. 
Williams, H. E., Medhurst, J., \& Drew, K. (1993). Corporate strategies for a sustainable future. Environmental strategies for industry, 117-146.

Zaltman, G., Duncan, R., \& Holbeck, J. (1973). Innovativeness and organizations. New York, NY: John Wiley and Sons.

Zaltman, G., \& Lin, N. (1971). On the nature of innovations. American Behavioral Scientist, 14(5), 651-673. 



\title{
Environmental Assessment Methodologies for Commercial Buildings: A Study of Building Professionals' Beliefs and the Adoption of the LEED Scheme in the United States ${ }^{1}$
}

\begin{abstract}
"It's the job that's never started that takes longest to finish" (J.R.R Tolkien, Lord of the Rings)
\end{abstract}

\subsection{Introduction}

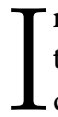
$\mathrm{n}$ both industrialized and developing countries buildings have been found to be one of the major sources of greenhouse gas emissions and been linked to other environmentally 1 damaging pollutants (Hart, 2009). In response to this pressing issue, energy efficiency schemes, both mandatory and voluntary, have been implemented as policy instruments and strategies to reduce natural resource use and to improve the sustainability of the building life cycle.

According to the United States Energy Information Administration (EIA) ${ }^{2}$, carbon emissions of the non-residential building sector in the United States grew about $25 \%$ faster than carbon emissions of the overall economy between 1971 and 2004 (Hart, 2009). To counter this trend some national governments, NGOs and international organizations have

\footnotetext{
${ }^{1}$ A version of this chapter has been published as an article as Kientzel, J., \& Kok, G. (2011). Environmental Assessment Methodologies for Commercial Buildings: An Elicitation Study of U.S. Building Professionals' Beliefs on Leadership in Energy and Environmental Design (LEED). Sustainability, 3(11):2392-2412

${ }^{2} \mathrm{http}: / /$ www.eia.gov (Accessed: 30 October 2014)
} 
established programs to raise awareness for these issues. In 2005, the European Union set up a "Green Building Programme" 3 while the United Nations Environment Programme followed by creating their "Sustainable Buildings and Climate Initiative". ${ }^{4}$ Both schemes are voluntary in nature and build on a partnership approach with actors in the building industry. These voluntary approaches are nothing new, since NGOs, industry associations and other third party actors have participated in the development of Voluntary Environmental Programs (VEPs).

In the commercial building sector, a large variety of voluntary assessment schemes have been developed to measure the energy impact of buildings. Some of the most prominent examples worldwide are the LEED, Green Globes and BREEAM schemes, launched by third party and mostly not-for-profit organizations. Since several voluntary environmental assessment certification schemes are operant simultaneously, building professionals have to determine which one to include in their building projects. Thus, the principles and workings of these systems have to be well understood, in particular the interaction between governmental (i.e. building codes) and third party interventions (LEED, Green Globes, BREEAM etc.).

To this point, existing studies have mainly focused on the technical or financial aspects of these programs, while research has been scarce on how they are used and perceived by professionals, even though psychological insights can contribute significantly to a better understanding of sustainability practices in the building sector. There is reason to assume that beliefs and perceptions influence sustainability practices in the building industry.

In 2009, a survey in the Architects' Magazine, a professional journal in the United States, revealed some astounding results: In this survey, $71 \%$ of respondents stated that they know of someone, colleagues or other design professionals, "that do not believe that climate change is a major problem and/or do not believe that it is caused by human activity". In addition to this, $33 \%$ of the respondents confirmed that "climate change skepticism in their professional network is common" (Architect Magazine, 2009). While that survey had been developed outside of an academic framework and likely includes significant selection bias, the results indicate that sustainability practices depend largely on AEC professionals being convinced of their necessity in their everyday work. In addition, governance schemes, including voluntary certification programs, can only be successful if the "end users", the building professionals, are convinced of their utility.

Thus, this chapter does not seek to evaluate the effectiveness of the schemes or to evaluate whether the use of these schemes is normatively wrong or right but investigate the behavioral foundations of the LEED adoption in the United States. The purpose of this study is to

\footnotetext{
${ }^{3} \mathrm{http}: / /$ iet.jrc.ec.europa.eu/energy efficiency/greenbuilding (Accessed: 30 October 2014)
}

${ }^{4} \mathrm{http}: / /$ www.unep.org/sbci/ (Accessed: 30 October 2014) 
identify the factors that influence how building professionals perceive third party-sponsored voluntary schemes in the building industry. The main focus will be on the beliefs and perceptions of the professionals working with the LEED scheme, the most widely known and used third party building assessment and certification program. In the following sections, the background on green building development and the legal framework for energy efficient buildings will be reviewed before moving to the conceptual framework for studying building professional's beliefs.

\subsection{Green buildings: a historical development}

In order to fully understand the importance of voluntary environmental building assessment schemes, it is necessary to trace back their development and place them into the context of the sustainable buildings debate. Environmental assessment schemes for buildings are not a new phenomenon and not specific to certain countries. Around the world, numerous schemes have appeared over the last twenty years (Jonsson, 2006; Todd et al., 2001; Liu et al., 2006) and are complementing existing building codes. As mentioned above, international organizations gradually endorse voluntary Green Building Programs (European Commission, 2005; UNEP, 2005).

Environmental design and construction principles have been traced back to the late 19th century (Cassidy, 2003). However, the first "green" design and construction movement started in the 1970s during the Global Energy Crisis. Papanek (1972) suggested in his study "Design for the real world" that building professionals needed to be socially responsible and criticized traditional approaches to architecture. The influence of this work suggests that beliefs of professionals play a large role in the present sustainability discussion, even though subsequent research focused mainly on technical aspects of the architectural field and the construction industry.

These ideas were mostly adopted in the industrialized world and the issues discussed were incorporated in the 1980s into the sustainable development discussion (Rees, 1989) as well as the sustainable design movement (St. John, 1992). As a result, both the number of publications in trade and professional journals on sustainable design techniques and college classes teaching sustainable design increased. During the 1990s, the efforts to provide instructions on green buildings to building professionals have manifested in more institutional structures such as the creation of BREEAM in the UK, the Leadership in Energy and Environmental Design (LEED) Rating System in the United States and the Green Globes in Canada. As mentioned before, much of the research on sustainable buildings has focused on technical aspects and economic benefits that come with their adoption. Yudelson (2004) explains green building development by growth in consumer demand. Even though ecological design has frequently been believed to lead to higher costs during the construction process and can be unattractive to investors and other building 
professionals, the studies conducted so far have yielded inconclusive results (Thompson, 2003). Yates (2001) has suggested that the total costs over a longer period are not higher than for conventional buildings and that green construction can act as a way to manage the risks of changing regulations and liability lawsuits. However, it has been suggested that cost savings, if applicable, depend on additional factors such as local building standards, timing or climate (Matthiessen and Morris, 2004). Despite some evidence on demand growth, green buildings are still considered to be a niche market (NBN, 2006).

In many countries voluntary green building assessment and certification schemes have become widely used in the building industry to signal sustainability and energy efficiency (Hart, 2009). This development has been attributed to government and procurement efforts: Even though most VEPs have been developed by third party organizations, the importance of government support has been emphasized in previous studies. According to Smith et al (2006), the demand has been driven largely by all kinds of government building project (municipal, state and federal). Additionally, government agencies as owners and buyers of commercial buildings have contributed to the increased use of third party certification schemes. Hart (2009) suggests that their role as land use and taxing authorities as well as regulators of construction have been influential in the uptake of these schemes. This is certainly the case for the United States, which this chapter focuses on. The following section will briefly lay out how different policy instruments regulate the energy efficiency in the US context. This step has been considered necessary in order to clarify in which way the situations that building professionals face might influence their perceptions and beliefs when it comes to actually working with voluntary schemes.

\subsection{Energy efficiency for buildings in the United States: between building codes and voluntary assessment schemes}

In order to understand the topic of voluntary green building schemes in the United States, it is helpful to take a closer look at the building industry. As in most countries, the construction and building industry is mainly separated in two segments, residential and commercial housing (including offices, factories, public buildings, colleges etc.). The building and construction industry in the United States is among the ten largest employment sectors and many different types of professional groups are involved in the construction process working on building development, building additions and extension projects, and alterations of existing structures or maintenance (Doleta, 2004). The building construction process normally involves many stakeholders and differs from case to case but involves in most instances local officials issuing permits, investors, commercial real estate developers, architects, building consultants, engineers (civil, mechanical, structural, water and plumbing), as well as real estate brokers and corporate clients. Hence, constructing a sustainable building is a very complex issue with many stakeholder interests involved. In the following sections, we wills 
shortly review the governance framework for buildings in the United States. For a more detailed review, including legislative acts issued by the U.S. federal government, Fischer (2010) has provided an extensive overview.

\section{Building codes and Energy Efficiency in the United States: governance issue and professional challenge}

One of the major strands of literature related to the analysis of energy efficiency in buildings has focused on the issue of innovation diffusion. The willingness to adopt innovations has been researched from different angles, such as Rogers' (1995) "Diffusion of Innovation" (DOI) theory. Some of the explanations of resistance to innovations in the US building and construction industry have been attributed to is its horizontal (disciplines and professional groups) and vertical (in terms of project life cycle) fragmentation. However, also issues of agency have been mentioned as reasons that prevens US building and construction professionals from adopting innovative approaches for sustainability (Sheffer and Levitt, 2010). These issues might be attributable to ad-hoc team composition which leads to barriers in the process of communication and passing on tacit knowledge (Augier and Vendelo, 1999).

Since voluntary schemes have often been described as complementary measures that go beyond existing building codes, it is especially important to understand the interaction between codes and voluntary programs. Building codes generally specify the level of health, safety and environmental concerns. In most cases, they are part of the legal framework in a certain jurisdiction on the international, national, regional or municipal level and can be legally enforced. As an example, a survey conducted by the American Institute of Architects, identified ninety-two municipal green building codes throughout the US on a municipal level (Rainwater, 2007).

It remains a special challenge that the building industry and its codes remain largely fragmented (Hart, 2009) and building codes are being established in the US by means of a complex network of agencies and other associations (Hart, 2009). Hart (2009) suggests that this system has been partly responsible for the slow improvements in building energy performance. The US Department of Energy (DOE) launched an attempt in the 1970s to establish binding building standards for energy efficiency but had to retract them after protests from the industry. Since the role of the federal government has been limited in this regard, a large number of state and local policies seek to influence decision making of building owners and developers (Hart, 2009). Sustainable buildings in the US have been governed by incentives and mandates at the local (Theaker and Cole, 2001), county (Sussman, 2008), state (Circo, 2008) and federal level (Park, 2007). On the state level, some states such as California have introduced stricter building codes during the energy crisis in the 1970s, but despite these efforts, nine states still had no such codes in 2008. Therefore, 
local governments in these areas have increasingly adopted energy codes to fill this gap, while in other states local administrations have chosen energy codes that go beyond the state mandates. The enforcement of these codes has also been subject to discussion and has frequently been described as being too lenient (Hart, 2009). As a result, other groups and schemes have appeared to fill this void. In the 1980s, acting on a mandate of the DOE, the American Society of Heating, Refrigeration, and Air-Conditioning Engineers (ASHRAE) ${ }^{5}$ has started develop standards for energy efficiency in relation to their member's products (Hart, 2009). The Congress adopted this form of third party governance and decided in the 1990s that all US states have to adopt the ASHRAE standard as well as future modifications of the code if the DOE deemed this to be suitable (Hart, 2009). In addition, the International Code Council (ICC), a non-profit and non-governmental organization, developed International Building Codes (IBC) that have been used throughout the United States. The ICC was founded in the 1990s with the goal to create a "single national system of model building codes" (Hart, 2009). This co-existence of many energy efficiency schemes has led to a situation in which building and construction professionals have to comply with local or state building codes that are compulsory but might also need to incorporate voluntary standards in order to meet client and regulators demands.

\section{Voluntary green building assessment and certification schemes in the US: historical development}

Voluntary environmental programs targeting industries have become increasingly popular in the United States since the 1990s. This trend has been triggered by increasingly complex regulations, innovations and public sector budget cutbacks (Maxwell and Lyon, 1999.As mentioned before, several voluntary schemes for non-residential buildings are currently being used in the United States with several programs operating on the national level such as LEED, Green Globes, BREEAM or Built it Green (Smith et al., 2006). These building assessment systems base the rating of the buildings on energy efficiency goals, comparable buildings or construction practices (Cole, 1999) and target the overall construction process.

For instance, a certification program at the state level is California's CalGREEN ${ }^{6}$ scheme, even though this program is a hybrid with compulsory elements and voluntary additions. Some of the points required in CalGREEN are compatible with the LEED scheme credits, some of them with the Built it Green Initiative. In addition, some cities across the US require newly built non-residential buildings to be certifiable with LEED but do not always demand actual certification (Ratzlaff, 2005). Given the large number of possibilities, requirements and standards, the building industry faces the issue how to react to this plethora 2014)

${ }^{5}$ https://www.ashrae.org/standards-research-technology/standards-guidelines (Accessed: 30 October

${ }^{6}$ http://www.hcd.ca.gov/CALGreen.html (Accessed: 30 October 2014) 
of government mandated and third party governance schemes. Voluntary certification schemes as LEED are not the only initiatives related to green buildings: Zero- Net Building initiatives, Building Life Cycle Assessment or the Passive house movement add to the complexity of green building construction processes.

\section{LEED and the US Green Building Council}

The LEED (Leadership in Energy and Environmental Design) Green Building Rating System is a voluntary rating system introduced in 2000 for developing high performance, sustainable buildings. Developed and maintained by the U.S. Green Building Council (US$\mathrm{GBC}$ ), the certification process assigns points along six assessment areas (Sustainable Sites, Water Efficiency, Energy \& Atmosphere, Materials \& Resources, Indoor Environmental Air, Quality and Innovation). The USGBC is a non-profit and non-governmental organization whose members come from all sectors of the building industry. LEED aims to be a voluntary and transparent scheme in which the technical criteria developed under the supervision of specialized LEED committees are reviewed in a public process and by the USGBC. Based on the outcome, LEED Silver, Gold and Platinum certifications are awarded (USGBC, 2010).

In addition to the building certification scheme, the LEED program also offers an educational dimension, the LEED accredited professional (AP) qualification. Professionals from all over the building industry as well as public officials can take the USGBC administered test and gain professional accreditation. While some professionals choose to become certified, this is not a pre-requisite for being able to work on a LEED building certification project.

\section{Literature on Green buildings and LEED}

While LEED has not been specifically studied widely in a social science or academic framework, the green building literature is much larger and diverse. For a detailed discussion please refer to Pitt et al. (2009). Most of the studies on the LEED scheme have been published in professionals or trade journals focusing on obtaining LEED credits and certification (see for example Vangeem and Marceau 2002, Hermann 2005, Yoon and Moeck 2005, Davis 2005, Miranda 2005).

Kats et al. (2003) have investigated and analyzed the costs related to LEED certification in California and suggested that there is evidence "that sustainable building is a cost-effective investment”. In addition, Matthiessen and Morris (2004) have analyzed which LEED credits are most commonly pursued by building officials and concluded that some credits are often chosen even though they are relatively insignificant in the big picture of the scheme. In addition, easier stages of credits are preferred, certain credits are obtained at a minimal cost, 
and credits that can be interpreted as being in conflict with other interests are not frequently chosen. Eichholtz et al. (2009) found in their study on LEED and Energy Star rated buildings in the US that buildings with a green rating lead to rental rates that are about three percent higher than in identical non-rated buildings. Apart from the more technical chapters on LEED, there have been some authors recently evaluating the governance dimension of the scheme. Hart (2009) describes in his work the position of LEED between government regulations and private business interests. Some studies have also focused on criticisms regarding the LEED scheme and have suggested that the certification process might be too costly and too easy at the same time and encourages "point chasing" (Rumsey and McLellan, 2005; Schendler and Udall, 2005). Some authors have also criticized that the credits selected for certification are frequently inconsistent with life-cycle analysis (Bowyer et al. , 2006; Scheuer and Keoleian, 2002).

Klotz (2010) in one of few studies on behavioral factors and their link to green commercial buildings has suggested that buildings energy performance is closely related to decisions made by architects, engineers and contractors during the planning and the construction phase of a project. The importance of this type of research is supported by Williams and Dair (2007) in their study on barriers to sustainable construction. The authors propose that the most common barriers to green buildings are sustainability measures disregarded by stakeholders. In addition, Hoffman and Henn (2008) proposed that social and psychological barriers at individual, organizational and institutional levels are responsible for slow developments in the design and construction field. In relations to this, Retzlaff (2009) has analyzed the use of LEED in Planning and Development Regulations, while Corbett and Muthulingam (2007) have focused on the signaling effect of LEED adoption. Chan et al. (2009) in turn has analyzed the market for green building in Asian cities from the perspectives of building designers. Nevertheless, none of these studies have investigated the underlying beliefs of building professionals that affect and contribute to the adoption of green building practices and in particular the LEED scheme.

\subsection{Conceptual framework: Behavioral factors, beliefs and LEED}

Since the LEED scheme is targeted at building professionals, it is important to understand which contextual and behavioral factors influence adoption behavior. Research on proenvironmental decisions is plentiful, notably in the management and social psychology literature. Most of the management literature focuses on strategic (Arragon-Correa, 1998; Stead and Stead, 1995), organizational (Lawrence and Morrell, 1995; Lober, 1996) or interorganizational perspectives (Clair, Milliman and Mitroff, 1995) while the current social psychology literature mainly focuses on the determinants of pro-environmental behavior in household settings(e.g. Kollmuss and Agyeman, 2002; Clark et al., 2003). To improve the understanding of the choices made by professionals, the present study aims to combine 
the two streams and analyze the behavioral foundations of LEED adoption by building professionals. An essential part of understanding decision-making and behavior is to focus on belief structures that guide the intentions to engage in a specific form of action. Beliefs elicitation is a field of study that has gained more importance over the last twenty years with both economists and psychologists working on understanding the importance of beliefs on decision outcomes. These have been studied from various angles via experiments, surveys and interview techniques. For a broader overview on issues relating to belief elicitation, refer to Grunert and Bech-Larsen (2004), Rutstroem and Wilcox (2009) and Hollard et al. (2010).

\section{The Reasoned Action Approach (RAA) and belief elicitation}

Since this chapter aims to identify beliefs that underlie the eventual process of adopting the LEED scheme, models based on cognitive theory will be included in this review. Cognitive theories suggest that an individuals' behavior is guided by cognitions about their direct environment. Part of personality psychology, this research stream includes a vast number of models which focus on beliefs as predictors of behavior. Examples of these social cognition models that have been applied to environmental issues are the Value-Belief-Norm Theory (VBN) by (Stern et al., 1999) and the Reasoned Action Approach (RAA) by Fishbein and Ajzen (2010).

The framework to be used as a guideline for belief elicitation in this context is the Reasoned Action Approach (RAA) by Fishbein and Ajzen (2010), a social-psychological framework that evaluates both internal and external factors that shape decisions and lead to a specific behavior. This model has frequently been used for studies on pro-environmental behavior and has proven to be a very useful tool for understanding beliefs, intentions and subsequent behavior in this respect. Even though its "pure form" has been mostly applied to decisions of individuals in a private decision context, such as household recycling behavior, it has also been used in the past to studies on decisions in a professional role and environmental management practices (e.g. Cordano and Frieze, 2000; Martin-Pena, 2010). In addition, it has formed the basis of more "applied models" such as the Technology Acceptance Model 1 (Bagozzi et al. 1992) and 2 (Venkatesh and Davis, 2000) or the Unified Theory of Acceptance and Use of Technology (UTAUT) model by Venkatesh et.al (2003).

The RAA builds on two predecessor models, the Theory of Reasoned Action (TRA) (Fishbein and Ajzen, 1975) and the Theory of Planned Behavior (TPB) (Ajzen, 1985). The TRA (Fishbein and Ajzen, 1975) suggests that under volitional control, the behavior of the individual is determined by behavioral intention which is jointly determined by the attitude towards the specific behavior and subjective norms. These intentions to perform a behavior are in many cases good predictors of behavior even though there are some cases in which this assumption does not apply (Perkins, 2007). Attitudes refer to an individual's 
perceptions of the inconveniences and advantages of performing a behavior while subjective norms are related to what an individual perceives to be important to other people around them. The strength of these perceptions is then complemented by the motivation to comply.

Since, however, not every behavior is under volitional control, Ajzen (1985) included the variable of Perceived Behavioral Control (PBC) to create the "Theory of Planned Behavior" (TBP). PBC refers to 'the person's belief as to how easy or difficult performance of the behavior is likely to be' (Ajzen \& Madden, 1986) and has an effect on behavioral intention and thereby on a specific behavior. The concept of Perceived Behavioral Control (PBC) builds on the concept of self-efficacy established by Bandura (1994). In addition to the elements above, Fishbein and Ajzen (2010) have added environmental factors and skills and abilities to the model to explain variance between intentions and subsequent behavior (see Fig 3.4).

As for the context of this study, there are three separate behaviors that would lend themselves to be the focus of investigation: (1) Working with LEED guidelines and principles, (2) working towards LEED certification and (3) personal accreditation as a LEED Accredited Professional (AP). To distinguish these three sets of behaviors is important define the TACT (Target, Action, Context, and Time) principle for each of them (Fishbein and Ajzen, 2010) to assure that the study measures exactly what it intends to. In this case, the "Target" is the building professionals; the "Action" is to work with the LEED scheme; the "Context" is sustainable building practices and assessment schemes while "Time" relates to current business practices.

In this study, the focus is on the beliefs underlying the first two categories of behaviors, since they are closely related. As for the third category, LEED AP accreditation, we consider this as a potential preparatory behavior (Yaryan and Festinger, 1961) intended to signal that a professional in question might be favorable to working with LEED.

In addition to belief elicitation, the proposed framework is very useful to determine whether intentions or perception of control is more useful for predicting the uptake of voluntary environmental programs. Also, building on belief elicitation, it will be interesting to see whether attitudes, subjective norms or perceived behavioral control are subsequently more decisive for decision-makers when it comes to the uptake of voluntary building rating schemes. Salient beliefs underlying the predictor variables such as behavioral, normative or control beliefs determine attitudes, subjective norms and the perception of behavioral control.

In this qualitative study, the focus is mainly on the first two levels of the model, i.e. background influences and salient beliefs. Fishbein and Ajzen (2010) have proposed detailed instructions for applying their model to a variety of situations and settings. Both researchers strongly recommend conducting a qualitative elicitation study to determine the underlying beliefs held by the target population(s) prior to large-scale research projects. Elicitation 


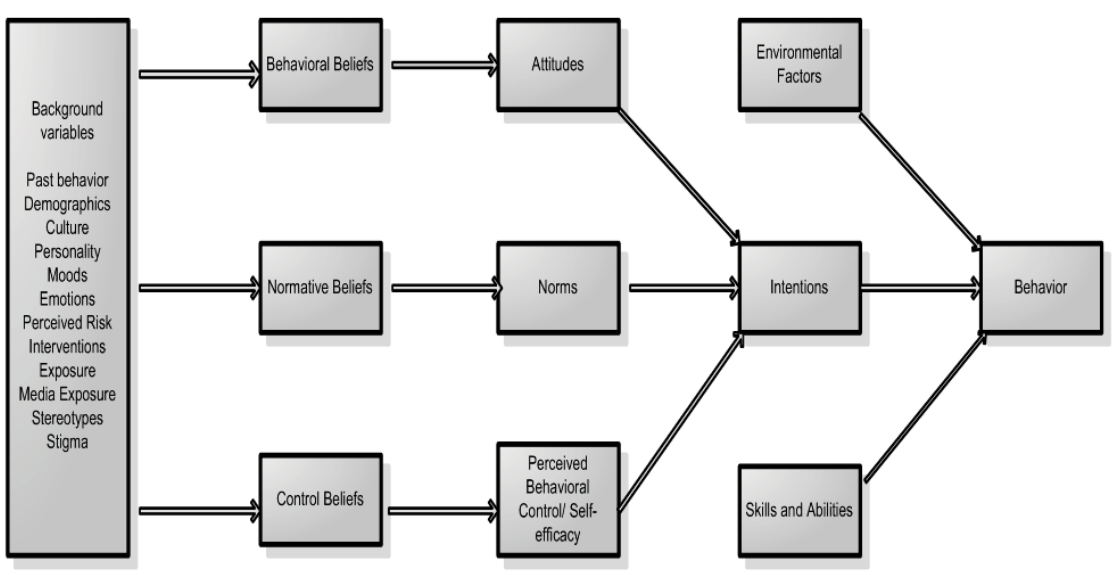

Figure 3.1: Reasoned Action Approach (Adapted from Fishbein, 2008)

studies establish the cognitive foundations of the beliefs the target population holds towards a specific behavior. The elicitation study tests the background influences and the beliefs underlying norms and attitudes towards and perceived control over access to VEPs in the US building industry context (Downs and Hausenblas, 2005).

\subsection{Method}

\section{Sample and Procedure}

Following the method proposed by Fishbein and Ajzen (2010), this study focuses on the first step in applying the Reasoned Action Approach (RAA), notably the elicitation procedure. The qualitative stage deals with obtaining background information on the perception of the LEED scheme and to construct variables and items appropriate to the target sample for further study. According to Ajzen (2006), an elicitation study, usually in the form of interviews, is necessary at this stage in order to identify beliefs that are readily accessible in memory.

The interviews included open-ended questions and collected information regarding the respondents' reason for LEED certification and personal accreditation, sustainable building, attitudes towards building codes, green voluntary standards, the usefulness and credibility of the LEED scheme and the educational aspects of LEED. The elicitation study was targeted at two professional groups in the building sector, architects and engineers. These professional 
groups have been chosen since they are the professions in which in which LEED is most widely used.

\section{Procedure and Data}

The elicitation study was conducted in April and May 2010 in two US states, Massachusetts and New York, with interview participants from two building professions: architects and engineers (civil, mechanical and structural). The participants were identified and randomly selected via the US Green Building Council Member Database and the yellow pages to avoid bias towards building professionals holding positive perceptions and beliefs towards LEED. They were first contacted by email in order to make an appointment for a subsequent face-toface interview. Fourteen interviews were conducted that lasted between 30 to 60 minutes. In total, ten architects ( 8 male and 2 female) and four engineers (4 male) participated in the study. Three of the interviewees were not LEED accredited while the remaining seven interviewees had taken the LEED AP test and passed it. For the elicitation study, thirty-four (34) architects and engineers in Massachussetts and NY State were contacted, with fourteen (14) respondents agreeing to face-to-face interviews. Reasons for non-participation were varied and ranged from disinterest to busy schedules. As the interviews did not yield additional insights after ten (10) interviews, the decision was taken not to contact any further potential participants.

\section{Analysis}

The analysis conducted followed closely the recommendations given by Ajzen and Fishbein (1980) to perform a content analysis to determine the salient beliefs a population holds. Using NVivo software for qualitative analysis, the participants' responses to the semistructured interview questions were selected and grouped electronically following the method suggested by Fonteyn and Bauer-Wu (2005). The questions were loosely based on the theoretical framework but emerging themes that were not related to the underlying conceptual RAA framework were also taken into consideration at this stage to allow for refining the model in the questionnaire study.

All the interviews were audio-taped, transcribed manually and then imported into NVivo. In order to gain the interviewees in-depth views and perception on working with the LEED scheme, the analysis started with a review of the transcripts in which the themes and key concepts were identified (Kumra, 2010). The use of NVivo facilitated the identification of emergent themes across individuals' responses and the thematic content analysis of the interview transcripts. The method suggested by Vinnicombe and Singh (2003) was adopted and the transcripts imported into the program after which coding structure was developed by using key concepts emerging from the data. The next step was then to code text at the nodes of interest (Miles and Huberman, 1994) after which the participants' responses were 
examined in sets in order to identify emerging patterns from the data. These nodes were then positioned as seen fit in the analytical framework. Sets of responses were categorized to a number of nodes and particular themes; proceeding this way and categorizing data to the different nodes allows for "an overall confidence in the coding and a clear audit trail through the findings" (Kumra, 2010).

After having analyzed the transcripts, beliefs were categorized building on the proposed framework as well as additional topics that came up repeatedly during the interview process. Beliefs have been regrouped in PART A building on the underlying framework, the Reasoned Action Approach (Fishbein and Ajzen, 2010) while other emerging issues were assigned to PART B.

\subsection{Reasoned Action Approach constructs and emerging topics}

\section{PART A: Reasoned Action Approach}

Based on the Reasoned Action Approach, behavioral beliefs, normative beliefs and control beliefs are crucial to understanding which impact attitudes, norms and self-efficacy have on the intentions of building professionals to adopt the LEED scheme.

\section{Normative Beliefs (Motivation to Comply with Expectations of Stakeholders)}

The main theme in the normative beliefs section is to identify the stakeholders that seem to have a large impact on professionals' decision to work with the scheme. Several groups of stakeholders have been identified by the interviewees to have a large influence on their LEED adoption process.

\section{Role of Government Expectations}

The role of government expectations, either as a client or legislator, has been stressed by a majority of interviewees.

"The US government was actually one of the first adopters of LEED" (Respondent 3, architect).

This is particularly insightful, since LEED is a third party sponsored scheme and some state governments have parallel programs. These findings are in line with Smith et al. (2006) and Hart (2009) suggesting the importance of government support of VEPs in the building sector.

"The government support is absolutely critical; many would not do it if there was no one helping them with it" (Respondent 7, architect). 


\section{Role of client demands}

In addition, the expectations of clients (in a larger sense, not only the building owners) about adopting the LEED scheme were repeatedly emphasized by respondents.

"It was required by a client" (Respondent 6, architect).

These results are hardly surprising given that the adoption of VEPs generally takes place in a business transaction environment. Therefore, these findings are in line with the business and management literature. However, there are different perceptions on the degree of influence the clients have.

"It is coming from owners, users. They are more pushing for the principles because they know LEED certification"(Respondent 7, architect).

Some building professionals emphasized the difficulty of adopting LEED when owners were not on board initially, but did not deem it impossible.

"We find that LEED is difficult with the type of clients we have, mostly commercial clients. It is a difficult thing for owners to swallow" (Respondent 7, architect).

\section{Behavioral Beliefs: Motivations for adopting LEED practices}

In this section, the findings were less intuitive than in the normative beliefs section. Behavioral beliefs, which relate to the motivations of AEC professionals, have been mostly related to educational aspects, sustainability practices in their profession, communication between professional groups.

\section{Educational Aspect and Sustainability Practices}

Most respondents cited the educational aspect as being important for their decision to work on a LEED program. Two main emerging themes were the roles of the LEED accreditation exam as well as the role LEED assumed in educating building professionals about sustainability.

"So LEED has helped to raise awareness and has helped to educate people but it is a very simplistic tool for a very complicated issue" (Respondent 5, architect)

The role of educational aspects beyond mere information provision within VEP programs has been neglected by the academic literature to a large extent. Even though education is one of the major strategies in intervention studies aimed at encouraging pro-environmental behavior at the household level (e.g. Abrahamse et al., 2005), the issue of educational aspects has not been discussed so far within the context of green building VEP adoption processes. Professional education levels in terms of highest qualification obtained have been 
considered as a determinant of VEP adoption, while the effect of including educational components within a program has not been subject to much attention.

"I think that it is very helpful to have gone through the educational portion, even though it is directed at a very specific scheme. The LEED scheme did introduce new concepts to me, but also made me realize that the LEED scheme is in some points not as sophisticated as I expected it to be." (Respondent 7, architect).

Even though the educational aspect of LEED was frequently emphasized, the importance of the different schemes was evaluated very differently by interviewees:

"The whole point of the LEED program was to change the way things were being done. So, there was a certain amount of reeducation but not complete reeducation" (Respondent 12, architect).

\section{Communication}

Additionally, LEED has been associated by the interviewees as a useful communication tool that has altered the way different groups of building professionals interact.

"It has provided a common language" (Respondent 5, architect)

This aspect relates to the work by Fitzsimmons and White (1997) emphasizing that "professional differences exist as a product of training and philosophical approaches underpinning the relevant professions". In this respect LEED is regarded by the respondents as a tool for bridging this gap in practices and as a "common language". These findings related to the literature on sociology of professions (e.g. Evetts, 2003) as well as inter-professional education (e.g. Martin, 2008).

"With LEED it is probably easier in terms of a common principle and language when it comes to buildings. Now there are more voices to orchestrate; this can be a challenge" (Respondent 8 , architect)

While some professionals mentioned the unifying function of the LEED principle, others emphasized that there were not so many differences between professions and their adoption and use of sustainable building practices.

"I do not sense a difference in how it is used and interpreted by disciplines. Where you see some differences is the -and maybe that is too far off-topic-but one of the good thing about LEED is that it is written by a consensus process where there are stakeholders all aspects of the building industry" (Respondent 3, engineer).

\section{Control Beliefs}

Perceived behavioral control in this context referred to the ease of interviewees to work with the LEED scheme or get LEED accreditation. Several barriers were mentioned that 
prevented the respondents from working with the LEED scheme. In some cases, the company was cited to have made the decision to work with LEED and tell their employees to get accredited. In other cases, the decision was up to the employees themselves. Other respondents cited willingness but faced resistance in their direct professional environment.

\section{Organizational culture}

Some of the persons interviewed regarded the choice to become LEED accredited as fully personal over which they had complete volitional control (Fishbein and Ajzen, 2010). While in traditional companies, managers and executives usually decide whether a firm engages in a scheme that in consequence applies to the whole organization is the situation not so clean cut in the building and construction industry in which building certifications are usually awarded on a project basis. For most of the respondents, the voluntary aspect is a major advantage of the scheme:

"It is perfectly voluntary, you do not need it to work on LEED projects, it is something I think that, you know, demonstrates a personal commitment because it is voluntary..." (Respondent 11, architect).

On the other side of the spectrum, participants felt that the choice to work with LEED did not depend on their own will, choice or attitudes, and hence perceived low volitional control over the process. Most of these decisions however refer to the diffusion of LEED practices within the office and not between firms.

"Oh, it was made for me. The president of my company told me to do it" (Respondent 12, engineer).

"I have been through a battle just to introduce LEED into our regime in the office" (Respondent 7, architect).

Hence, there are two very different levels of volitional control that have to be considered which depend very much on the situation an individual occupies in an organization. While the decision within a firm is frequently not perceived to under volitional control, company owners might perceive to have a higher volitional control over the choice to adopt a VEP. This, however, needs to be verified since they might also feel constraints to their adopting voluntary environmental assessment and rating schemes.

\section{Financial constraints}

Other barriers that blocked control over the LEED adoption behavior were related to financial constraints during the construction project.

"We designed a building the LEED way and when the price came, it could not be afforded" (Respondent 5, architect). 
Since the fulfillment of LEED credits and subsequent documentation increases the success chance of a building project, this factor is rather intuitive and supported by the mainstream economic and management literature.

\section{Organizational Capacities}

In addition, available capacities in the respondents' organizations were mentioned by the respondents as influencing the control that these individuals believe to exert over the adoption process. Organizational Capacities have been identified as a major factor influencing sustainable practices (Brulle, 2000).

"We had a client who wanted us to look at things that are related to LEED and we did not have the capacity to do them" (Respondent 11, architect).

\section{Inter-Professional Relations}

Another barrier that some respondents mentioned was related to the topic of inter- professional cooperation. This is a crucial point, since building projects involve a large number different professional groups that have to work together in order to make the construction process successful.

"You have to have everyone on board with the same mindset. This is why it is hard to get a sweeping effort together" (Respondent 11, architect)

As mentioned in the results on sustainability practices and communication, inter- professional relations and cooperation can not only be a reason for adopting a VEP but also represent a barrier to adoption.

\section{PART B: Emerging topics}

In addition to the Reasoned Action concepts discussed, other emerging themes were identified in the interview process. Most commonly the value of the LEED porfessional accreditation process as well as the position of the scheme in the overall building sustainability framework were mentioned by interviewees.

\section{The value of LEED professional accreditation}

The role of the professional accreditation has been emphasized by most professionals interviewed. However, most respondents agreed that LEED personal accreditation is not as important as having experience in sustainable building practices. Very different opinions have been voiced on the value of professional accreditation. Many respondents were quite skeptic regarding the LEED AP accreditation, for many different reasons: 
"If I was leading a team, I would much rather have a team of people that have gone through a LEED project previously than a room full of LEED APs that have never done it" (Respondent 2, engineer).

"I do not think that clients would notice if some of our collaborators were LEED accredited though" (Respondent 4, architect).

"Because everyone could become LEED AP it did not mean anything anymore. I am LEED AP, but what does that really mean?"(Respondent 9, architect).

"The more important thing probably is the history of the firm in terms of working on green projects and demonstrating knowledge in actual practice than having the personal accreditation (Respondent 3, engineer).

Research on voluntary professional accreditation within environmental programs is scarce outside of reports in trade journals (e.g. Toohey. 2002).

\section{The role of LEED in the governance framework}

As for the position of LEED as a voluntary scheme in the overall building governance framework, opinions differed significantly among the practitioners interviewed. Some respondents interpreted the LEED scheme as a de-facto legal authority:

"What was LEED yesterday might be a code tomorrow" (Respondent 4, architect)

In addition, respondents have been also emphasizing the power of the US Green Building Council within the market for voluntary sustainability standards:

"But it is interesting, the idea that USGBC is an independent body that gives you something similar to the law... LEED now has a certain power as an organization. The LEED scheme has gotten very influential among a certain kind of people who pay for buildings and design buildings, but that is a very small part of the population" (Respondent 6, architect)

Too many standards pushing onto the market has also been frequently cited as affecting their professional work:

"So, personally, the fact that there are competing standards, I do not see it as a problem but what does happen it that it gets a little crazy which standard to follow. I have actually heard of buildings that have both a LEED and Green Globes certification." (Respondent 10, engineer)

"What I sometimes find a little disturbing is the proliferation of standards " (Respondent 8, architect) 


\subsection{Discussion}

The present study shows that not only financial or marketing concerns, as often postulated in the management literature, influence adoption behavior of VEPs. In the case of LEED, normative, behavioral and control beliefs play a significant role in understanding VEP adoption practices.

As for the normative beliefs, the insights gained are very much in line with the existing management and psychology literature, i.e. that government and client demands play a significant role when it comes to LEED uptake. Behavioral beliefs are for some participants very much influenced by advantages linked to improved sustainability practices, the provision of an educational platform for sustainability practices and improved communication between building professionals.

When analyzing the control beliefs, there is evidence that several factors can constitute barriers to working with the LEED scheme. First, some of the respondents felt that they were very much in control of the process while others felt that the decision was made for them either explicitly or implicitly. Barriers to LEED uptake were closely linked to prohibitive organizational structures, financial constraints, and a lack of organizational capacities. In addition, inter-professional relations can also constitute a barrier to standards adoption if not all building professions have the same mindset (Martin, 2008). The value of LEED accreditation, the educational certificate that building professionals are able to achieve, was questioned by many interviewees. On the other hand some respondents regard LEED as a bridging factor that creates a platform and common language for communication between different building professions.

\subsection{Limitations of the study}

The findings discussed above leave many questions open since responses were quite diverse and a large variety in beliefs could be found. However, it must be noted that the findings presented in this section are limited to the fourteen respondents interviewed and their perceptions and beliefs of the LEED scheme and green building practices. Therefore, this study is only the first step in applying the Reasoned Action Framework to the research question. At this stage, the data cannot be regarded to be applicable to a wider section of building professionals- this will be the goal of a quantitative extension of this study currently planned to test the whole Reasoned Action Approach in this particular context. A particular issue when conducting a study with professional groups is to determine in which ways the salient beliefs are part of their individual domain or imposed by their adherence to a given professional group. It is understood, that for more validity other professional groups in the building industry aside architects and engineers must be included in future studies in order 
to gain a better understanding of the overall beliefs held by professionals in this industry and their adoption behavior.

In order to verify that the results of the present elicitation study apply to a wider set of participants in the North American context, the results will be tested in a more detailed survey study in the subsequent chapters.

\subsection{Conclusion}

Using the Reasoned Action Approach to understanding beliefs underlying LEED adoption practices yielded in depth results. The elicitation study has looked behavioral, normative or control beliefs of engineers and architects that might influence their decision to work with the LEED scheme and obtain LEED accreditation. The results revealed that the uptake of the LEED scheme is related to the importance of government support, the role of client demands, individual attitudes, group efforts, barriers to work with LEED, educational aspects of the LEED scheme, communication aspects as well as the position of LEED in the overall green building governance structure.

By examining the underlying beliefs of building professionals, a first step has been made to better understand the reasons for adopting a Voluntary Environmental Program such as LEED. The behavioral factors that lead professionals to engage in VEPs is an area which clearly warrants the potential for further investigation using quantitative techniques in order to achieve more generalizable results. This approach would also allow for distinguishing beliefs between LEED participating and non-participating individuals as well as between adopters of LEED and other comparable schemes.

This information is valuable for planning future studies that evaluate the uptake motivations, intentions and subsequent behavior of building professionals regarding Voluntary Environmental Programs. In addition, the knowledge gained has also the potential to improve the design of future VEPs. Without identifying the behavioral foundations of these schemes, these kinds of programs are bound to fail or misused within the policy mix for sustainability. 


\section{References}

Abrahamse, W., Steg, L., Vlek, C., \& Rothengatter, T. (2005). A review of intervention studies aimed at household energy conservation. Journal of environmental psychology, 25(3), 273-291.

Ajzen, I. (1991). The theory of planned behavior. Organizational behavior and human decision processes, $50(2), 179-211$.

Aragón-Correa, J. A. (1998). Strategic proactivity and firm approach to the natural environment. Academy of Management Journal, 41(5), 556-567.

Bagozzi, R. P., Davis, F. D., \& Warshaw, P. R. (1992). Development and test of a theory of technological learning and usage. Human relations, 45(7), 659-686.

Bandura, A. (1994). Self-efficacy. in. vs ramachaudran. Encyclopedia of human behavior, 4, $71-81$.

Bowyer, J. L., Howe, D. J., Fernholz, K., \& Lindburg, A. (2006). Designation of environmentally preferable building materials: Fundamental change needed within leed. Dovetail Partners, Incorporated.

Brulle, R. J. (2000). Agency, democracy, and nature: The us environmental movement from a critical theory perspective. MIT Press.

Cassidy, R. (2003). White paper on sustainability. Building Design and Construction, 10.

Circo, C. J. (2008). Using mandates and incentives to promote sustainable construction and green building projects in the private sector: a call for more state land use policy initiatives. Penn State Law Review, 112(3), 731-782.

Clair, J., Milliman, J., \& Mitroff, I. (1995). Clash or cooperation? understanding environmental organizations and their relationship to business. Research in Corporate Social Performance and Policy, Suppl, 1, 163-193.

Clark, C. F., Kotchen, M. J., \& Moore, M. R. (2003). Internal and external influences on pro-environmental behavior: Participation in a green electricity program. Journal of environmental psychology, 23(3), 237-246.

Cole, R. J. (1999). Building environmental assessment methods: clarifying intentions. Building Research \& Information, 27(4-5), 230-246.

Corbett, C. J., \& Muthulingam, S. (2007). Adoption of voluntary environmental standards: The role of signaling and intrinsic benefits in the diffusion of the leed green building standards. Los Angeles: UCLA Anderson School of Management..

Cordano, M., \& Frieze, I. H. (2000). Pollution reduction preferences of us environmental managers: Applying ajzen's theory of planned behavior. Academy of Management Journal, 43(4), 627-641.

Davis, E. D. (2005). Water conservation strategies for leed points. Landscape architecture, 95(6), 64-69.

Del Percio, S. T. (2004). Skyscraper, green design, \& the leed green building rating system: The creation of uniform sustainable standards for the 21 st century or the perpetuation 
of an architectural fiction, the. Environs: Envtl, L. \& Pol'y J., 28, 117.

Downs, D. S., \& Hausenblas, H. A. (2005). Elicitation studies and the theory of planned behavior: a systematic review of exercise beliefs. Psychology of Sport and Exercise, $6(1), 1-31$.

Education, \& Training Administration, E. (2004). America's construction industry: Identifying and addressing workforce challenges..

Eichholtz, P., Kok, N., \& Quigley, J. M. (2010). Doing well by doing good? green office buildings. The American Economic Review, 2492-2509.

Evetts, J. (2003). The sociological analysis of professionalism occupational change in the modern world. International sociology, 18(2), 395-415.

Fischer, E. A. (2010). Issues in green building and the federal response: An introduction. DIANE Publishing.

Fishbein, M. (2008). A reasoned action approach to health promotion. Medical Decision Making, 28(6), 834-844.

Fishbein, M., \& Ajzen, I. (1975). Belief, attitude, intention and behavior: An introduction to theory and research. Reading, Massachussetts: Addison-Wesley.

Fishbein, M., \& Ajzen, I. (2011). Predicting and changing behavior: The reasoned action approach. Taylor \& Francis.

Fonteyn, M., \& Bauer-Wu, S. (2005). Using qualitative evaluation in a feasibility study to improve and refine a complementary therapy intervention prior to subsequent research. Complementary therapies in clinical practice, 11(4), 247-252.

Goddard, A. (2004). Budgetary practices and accountability habitus: a grounded theory. Accounting, Auditing \& Accountability Journal, 17(4), 543-577.

Hart, D. M. (2009). Don't worry about the government? the leed-nc "green building" rating system and energy efficiency in us commercial buildings. MIT-IPC-Energy Innovation Working Paper Cambridge.

Herrmann, R. K. (2005). Building for the future-building automation and leed (r) credits. ASHRAE Journal-American Society Heating Refrigerating Airconditioning Engineering, 47(9), S10.

Janesick, V. J. (2000). Handbook of qualitative research. In (pp. 379-399). Sage.

K, H. A., \& Wood, D. H. (2009). The wide spectrum of green. Architect Magazine. (Washington DC: Hanley Wood)

Kats, G., Alevantis, L., Berman, A., Mills, E., \& Perlman, J. (2003). The costs and financial benefits of green buildings. A Report to California's sustainable building task force. (Sacramento: California Sustainable Building Task Force)

Klotz, L. (2011). Cognitive biases in energy decisions during the planning, design, and construction of commercial buildings in the united states: an analytical framework and research needs. Energy Efficiency, 4(2), 271-284.

Kollmuss, A., \& Agyeman, J. (2002). Mind the gap: why do people act environmentally and what are the barriers to pro-environmental behavior? Environmental education 
research, 8(3), 239-260.

Kumra, S. (2010). Exploring career "choices" of work-centred women in a professional service firm. Gender in Management: An International Journal, 25(3), 227-243.

Lawrence, A. T. (1995). Leading-edge environmental management: Motivation, opportunity, resources, and processes. Research in corporate social performance and policy.

Liu, Y., Prasad, D., Li, J., Fu, Y., \& Liu, J. (2005). A holistic approach to developing regionally specific framework for green building assessment tools in china. In Proceedings of the 2005 world sustainable building conference (sb05tokyo) (pp. 27-29).

Martin, S. (2008). Sustainable development, systems thinking and professional practice. Journal of education for sustainable development, 2(1), 31-40.

Martin-Pena, M. L., Diaz-Garrido, E., \& Sanchez-Lopez, J. M. (2010). Relation between management's behavioural intentions toward the environment and environmental actions. Journal of Environmental Planning and Management, 53(3), 297-315.

Matthiessen, L. F., Morris, P., \& Davis, L. (2004). Costing green: A comprehensive cost database and budgeting methodology. US Green Building Council.

Maxwell, J., \& Lyon, T. (1999). What caused us voluntary environmental agreements. In European research network on voluntary approaches, cava (1999) workshop (copenhagen).

McLennan, J. F., \& Rumsey, P. (2003). Is leed the holy grail of sustainable design? (Vol. 6; Tech. Rep. No. 5). Construction and Environment.

Miles, M. B., \& Huberman, A. M. (1994). Qualitative data analysis: An expanded sourcebook. Sage.

Miranda, H. (2005). Achieving low cost leed projects. HPAC Engineering, 4, 32-40.

News, N. (2006). Green buildings barrel into the mainstream market.nations building news: National association of homebuilders. In National association of homebuilders.

Papanek, V., \& Fuller, R. B. (1972). Design for the real world. Thames and Hudson London.

Park, E. (2007). The us federal green building policy. Sustainable Development Law \& Policy, 8(1), 26.

Pitt, M., Tucker, M., Riley, M., \& Longden, J. (2009). Towards sustainable construction: promotion and best practices. Construction Innovation: Information, Process, Management, 9(2), 201-224.

Rainwater, B., \& Martin, C. (2008). Local leaders in sustainability: a study of green building programs in our nation's communities. American Institute of Architects.

Rees, W. (1989). Planning for sustainable development. BC: UBC Center for Human Settlements.

Retzlaff, R. C. (2009). The use of leed in planning and development regulation an exploratory analysis. Journal of Planning education and research, 29(1), 67-77.

Roodman, D. M., Lenssen, N., \& Peterson, J. A. (1995). A building revolution: how ecology and health concerns are transforming construction. Worldwatch Institute Washington, 
DC.

Scheuer, C. W., \& Keoleian, G. (2002). Evaluation of leedtm using life cycle assessment methods (Tech. Rep.). National Institute of Standards and Technology. (Retrieved 15 December 2013 http://www.fire.nist.gov/bfrlpubs/build02/PDF/b02170.pdf)

Smith, T., Fischlein, M., Suh, S., \& Huelman, P. (2006). Green building rating systems: A comparison of the leed and green globes systems in the us (Tech. Rep.). Minneapolis: University of Minnesota Press.

Stead, W. E., \& Stead, J. G. (1995). An empirical investigation of sustainability strategy implementation in industrial organizations. Research in corporate social performance and policy, 1, 43-66.

Stern, P. C., Dietz, T., Abel, T., Guagnano, G. A., \& Kalof, L. (1999). A value-belief-norm theory of support for social movements: The case of environmentalism. Human ecology review, 6(2), 81-98.

St John, A. (1992). Sourcebook for sustainable design: A guide to environmentally responsible building materials and processes (Tech. Rep.). Boston Society of Architects.

Sussman, E. (2008). Reshaping municipal and county laws to foster green building, energy efficiency, and renewable energy. NYU Environmental Law Journal, 16(1), 1-43.

Theaker, I. G., \& Cole, R. J. (2001). The role of local governments in fostering 'green' buildings: a case study. Building Research \& Information, 29(5), 394-408.

Todd, J. A., Crawley, D., Geissler, S., \& Lindsey, G. (2001). Comparative assessment of environmental performance tools and the role of the green building challenge. Building Research \& Information, 29(5), 324-335.

Udall, R., \& A, S. (2005). Leed is broken ... let's fix it (Vol. 15; Tech. Rep.). GRIST magazine.

VanGeem, M. G., \& Marceau, M. L. (2002). Using concrete to maximize leed points. Concrete international, 24(11), 69-73.

Venkatesh, V., \& Davis, F. D. (2000). A theoretical extension of the technology acceptance model: four longitudinal field studies. Management science, 46(2), 186-204.

Venkatesh, V., Morris, M. G., Davis, G. B., \& Davis, F. D. (2003). User acceptance of information technology: Toward a unified view. MIS quarterly, 27(3), 425-478.

Vinnicombe, S., \& Singh, V. (2003). Locks and keys to the boardroom. Women in Management Review, 18(6), 325-333.

Williams, K., \& Dair, C. (2007). What is stopping sustainable building in england? barriers experienced by stakeholders in delivering sustainable developments. Sustainable development, 15(3), 135-147.

Yaryan, R. B., \& Festinger, L. (1961). Preparatory action and belief in the probable occurrence of future events. The Journal of Abnormal and Social Psychology, 63(3), 603.

Yates, A. (2001). Quantifying the business benefits of sustainable buildings - summary of existing research finds (Tech. Rep.). Center for Sustainable Construction. 
Yoon, Y. J., \& Moeck, M. (2005). Two studies that investigate the impact of ceiling and wall reflectance values on leed credits. Journal of architectural engineering, 11(3), 81-90.

Yudelson, J. (2004). The insider's guide to marketing green buildings. Green Building Marketing. 



\title{
CHAPTER

\section{Adoption of Voluntary Environmental Building Rating Schemes: a Reasoned Action Approach (RAA) perspective on building professionals' LEED and Green Globes adoption in the US and Canada}

\begin{abstract}
"There's nothing like looking if you want to find something.You certainly usually find something, if you look, but it's not always quite the something that you were after" ( J.R.R Tolkien, The Hobbit)
\end{abstract}

\subsection{Introduction}

1 uildings have been determined as a major source of $\mathrm{CO} 2$ emissions and pollution around the world. ${ }^{1}$ In the quest for a low-carbon society, construction processes leading towards more energy efficient and less consumption-based buildings will play a major role. Energy saving practices in household settings have been investigated more frequently than in commercial buildings and decisions and behavior during commercial building design and construction processes are not particularly high on the research agenda. In many cases, environmental and energy policies aim at the development of appropriate technological solutions to climate change issues without paying attention to human decisions and behaviors translating technology into common professional practices.

\footnotetext{
${ }^{1}$ See for instance information provided by the US Environmental Protection Agency (EPA) http://www.epa.gov/climatechange/ghgemissions/sources/commercialresidential.html (Accessed: 30 October 2014).
} 
This type of policy-making frequently applies to voluntary environmental rating schemes designed to create a more sustainable built environment. While it needs to be emphasised that best technological solutions will not have any effect if people are not convinced of their utility, this aspect has been left out of many policy and program design and implementation considerations. With the Physical-Technical- Economic Model (PTEM) paradigm still predominant in policy decision-making processes, programs and interventions often fail to take into account the variety of factors influencing human behavior. Economic, legal and political rules influence decision-making and behavior. However, research conducted in other disciplines including sociology, psychology or anthropology offer valuable insight (e.g. Oskamp, 2000; Rayner and Malone, 1998) to the adoption processes and ought to be included in program design, implementation and evaluation.

Building codes and rating schemes are frequently prime examples of PTEM-based programs focusing on technical aspects building design processes. While technical solutions and innovation in the building industry are crucial for transition towards a more environmentally sustainable society, the role of human behavior needs to be more strongly considered. This chapter fills the gap in the literature and adds to existing research by analyzing socialpsychological processes underlying building professionals' decision to include a voluntary building assessment and rating scheme in their work practices in the United States and Canada. For this purpose, this research study applies Fishbein and Ajzen's (2010) Reasoned Action Approach (RAA) to the integration of an environmental building assessment scheme via a survey study conducted among US and Canadian building professionals. The main aim of this project is to advance the understanding the determinants of building professionals deciding to work on two environmental building assessment schemes, the Leadership for Energy and Environmental Design (LEED) and the Green Globes (GG) scheme.

\subsection{Environmental rating and assessment schemes for commercial buildings}

The adoption and inclusion of environmental and energy rating systems in the construction and building industry is an important issue for climate change mitigation and environmental governance. Environmental and energy considerations in building construction processes are subject to a variety of governance modes, including building codes, laws and regulations. In addition to command-and-control regimes, voluntary third-party-sponsored schemes have gained momentum around the world to facilitate the transition to a more sustainable built environment.

A large number of third-party sponsored schemes have appeared both in developed and developing countries to mitigate the impact of the built environment on the natural environment. Environmental rating and assessment schemes have been developed by Green 
Building Councils (GBCs), organized in the World Green Building Council (WGBC), as well as by other commercial and non-profit organizations. Currently, 83 GBCs are in existence globally and aim to contribute to the development energy and environmental rating schemes and/or to general improvement of sustainability in the building and construction industry (WGBC, 2011). GBCs have founded in response to sustainability challenges on the initiative of building industry professionals to create common standards in the building and design process. Buildings can be awarded a certificate when a certain number of credits from a list are included in a building's design and construction process. After an audit, building owners can claim an energy and environmental certificate for the assessed building. These principles are similar for most green building VEPs.

Well-known schemes around the world include CASBEE (Japan), HK-Beam (Hong Kong), BREEAM (UK), Green Star (Australia). In this chapter, the main aim is to analyze the Leadership for Environmental Design and Energy (LEED) and the Green Globes building rating and certification programs in the US and Canada. The LEED scheme, developed by the US Green Building Council, has been adapted to a variety of country contexts in Latin America, India, Europe and Russia and North America (including Canada). The Green Globes scheme was developed by a Canadian industry-related organization and subsequently also gained some traction in the United States.

\subsection{Professional behavior and behavior change in the building industry}

The issue of behavior and behavior change in the building industry has only recently gained momentum. Many studies on the building sector have neglected to examine the way individuals and professional groups interact with each other in construction projects and how these interactions influence outcomes related to energy efficiency and sustainability.

Studies by Phua (2002), Phua (2004), Phua and Rowlinson (2004) or Anvuur (2008) suggest that research into the behavior of building and construction industry members needs to become more prominent to advance understanding and improvement of work practices in this sector.

In the PTEM tradition, change of professional practices in the building industry can be induced in several ways by introducing economic stimuli or legal instruments for green building. However, since the programs discussed in this chapter are aimed at a "voluntary" market transformation, understanding the determinants of building professionals' behavior and decisions needs to take center stage. This is not to say that professional decisions are redundant in command-and-control settings; even if economic stimuli or legal provisions are in place, compliance with rules (enforceable and unenforceable) needs to be carefully considered. Numerous studies on environmental compliance have been carried out over the 
last twenty years determining reasons for firms' compliance with environmental regulation and policies (for a detailed review see Wu, 2009 and The US Environmental Protection Agency, 2007).

Most of these studies, however, investigate firm-level determinants while behavioral studies have been less prevalent (with a few exceptions e.g. Cordano and Frieze, 2000; Cordano et al., 2005). Intervention studies aimed at improving environmental compliance were even scarcer at the moment of this review (April, 2013).

Hence, for the promotion of sustainable professional practice, the behavior change literature can offer various and different approaches on how to achieve "compliance". In particular within the social psychology literature a number of behavior change strategies and theoretical models have come to co-exist. As there is a large array of models to choose from to analyze and predict the behavior of specific interest groups, "guidelines" that help researchers and policy-makers to choose the most appropriate theoretical approaches and models have gained increasingly importance.

For instance, the PRECEDE/PROCEED model by Green and Kreuter (2005) and the Intervention Mapping Approach (Bartholomew et al., 2011) offer insight in the planning, implementation and analysis stages of behavior change programs. The challenge, however, is to find the most appropriate theory or combinations of theories to assess building professionals' decisions. Since this study focuses on determinants of behavior, the general theories approach advocated by Bartholomew et al. (2011) was used to select an appropriate determinants theory. Theories should not be eliminated from the outset and hence, a review of several models in the behavior change literature was conducted to find the most robust framework for the analysis of decisions in a professional context.

\subsection{Theoretical Framework: Reasoned Action Approach (RAA)}

Choosing a theoretical framework is a crucial step in every research project. The decision between several theoretical frameworks can be arduous since many models could be applied to the analysis of building professionals' behaviors. The literature on pro-environmental behavior (PEB) or environmentally significant behavior (ESB) is vast and diverse. Several reviews provide an excellent overview of the theoretical models and approaches available (e.g. Jackson, 2005; Darnton, 2008). Theories aimed at explaining pro-environmental and energy behaviors have included the Value-Belief-Norm (VBN) theory (Stern, 2000) or Schwartz' (1977) Norm-Activation Theory (NAT). Based on the Intervention Mapping Approach's (Bartholomew et al., 2011) recommendations and applications to energy-related behaviors, a needs analysis was carried out in this chapter to understand the problem, consequences and behaviors related to the issue of environmental building assessment. This analysis incorporates a specific focus on environmental conditions and contexts these 
behaviors and decision-making processes are embedded in. Even though many factors are likely to have an impact on the decision to work with the LEED and Green Globes schemes in the US and Canada including values, knowledge, motivation, concern, norms, attitudes, control perceptions, risk perceptions etc., the decision was taken to identify models that include intentions to act and subsequent behavior.

After an extensive literature review as depicted in Chapter 3, the Reasoned Action Approach (RAA) and its predecessors, the Theory of Reasoned Action (TRA) and the Theory of Planned Behavior (TPB), (Fishbein and Ajzen, 2010) were found to be supported by enough empirical evidence in many environmentally focused studies across a range of disciplines including psychology and management studies (e.g. Cordano and Frieze, 2000) to be applied for the purpose of this research. The TPB and RAA were found to perform better in explaining behaviors and decisions that come at a high behavioral cost (Steg and Vlek, 2009) and to have a higher explanatory power in terms of conservation behavior than most competing theoretical frameworks (Kaiser, Huebner and Bogner, 2005). The Reasoned Action Approach (RAA) suggests that the best predictor of a given behavior is the intention to perform that behavior. The intention in turn can be predicted by three other constructs: the attitude towards the behavior, subjective norms and Perceived Behavioral Control (PBC). While attitudes are an individual's assessment of the specific behavior (i.e. whether it is positive or negative), subjective norms describe the perceived social pressure to engage in that behavior. However, for the intention to act and subsequent behavior only relevant actors' opinion matters to enact that specific behavior. The third construct, PBC, measures how easy an individual perceives a given behavior is to perform.

Based on the results of the eliciation study presented in Chapter 3, the decision was taken to apply Fishbein and Ajzen's (2010) Reasoned Action Approach as a basis to test for differences in attitudes, subjective norms and self-efficacy and their effect on intention to work with the LEED and Green Globes scheme in both the US and Canada.

While the differences between adopters and non-adopters between the schemes have been a topic of interest in many studies related to the Reasoned Action Approach (e.g. Lokhorst et al., 2011), national and cultural differences have also been subject to wide- spread interest in the research arena (e.g. Triandis, 1980; Pavlou, 2002; Hooft et al., 2006). Additionally, adherence to a professional group might also play a role in the adoption of the scheme as suggested by several authors e.g, Oz (2001). The fact that the Reasoned Action Approach (RAA) and its predecessor frameworks have been tested in many studies on specific professional groups including physicians (e.g. Millstein, 1996), nurses (Feng, 2005), sales agents (e.g. Kurland, 1996) or managers (Cordano and Frieze, 2000) with slight variation in reuslts suggests implicitly that professional group affiliation may matter. Hence, it was assumed that adoption and non-adoption and their underlying socio-psychological determinants may be influenced by cultural and professional group adherence and affiliation. 


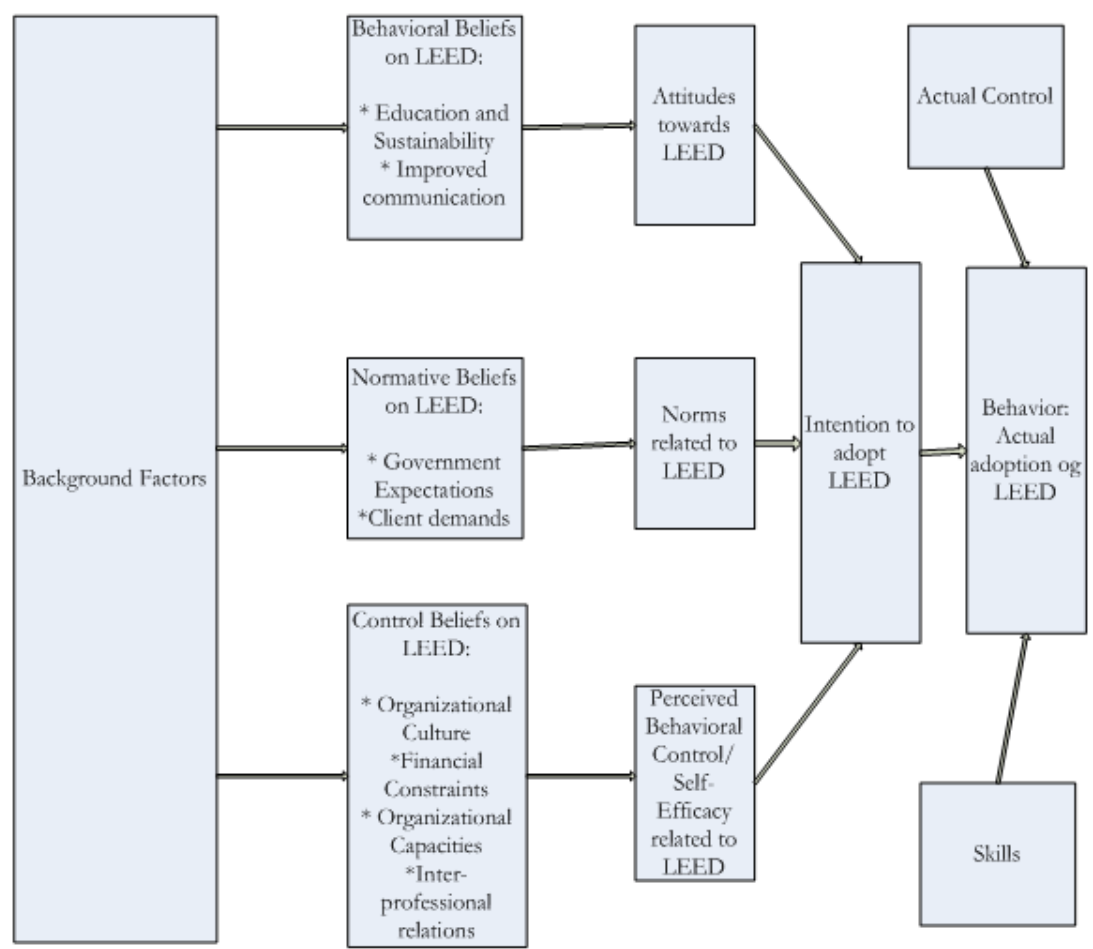

Note: Figure 4.1 depicts the Reasoned Action Approach (RAA) by Fishbein and Ajzen (2010) adapted to the LEED scheme. A representation of the Green Globes scheme would be exactly the same.

Figure 4.1: Reasoned Action Approach (Fishbein and Ajzen, 2010) adapted to LEED adoption

While these aspects are not the main aim of this study, these assumptions will be considered during data analysis and interpretation.

An additional aspect briefly mentioned in the previous section, the intention-behavior gap, will be discussed in the next section since the Reasoned Action Approach (RAA) and its predecessors, the Theory of Reasoned Action (TRA) and the Theory of Planned Behavior (TPB), have been frequently used to predict behavioral intention rather than actual behavior. Since this chapter is also interested in actual behavior, special attention was paid to a potential intention-behavior (in) consistency in the data analysis process. 


\subsection{Intention-Behavior consistency}

Behavioral change studies and programs aim to identify factors that encourage or constrain people from performing certain types of (desirable) behavior. While this is true for household behavior, these behavior change studies have been less prevalent in the field of professional and managerial behavior and practices. One of the many reasons for this lack of empirical evidence is the fact that some researchers may believe professional behaviors to be more regulated and subject to a higher number of constraints than "household" behaviors. If this is the case, intentions may be less likely to predict behaviors than in other decision scenarios and may lead to a phenomenon known as the "intention-behavior gap".

The "intention-behavior gap" is important since quite a few models in the field of social psychology, including the Theory of Reasoned Action (TRA) (Fishbein, 1980; Fishbein and Ajzen, 1975), the Theory of Planned Behavior (TPB) (Ajzen, 1985, 1991), AttitudeBehavior Theory (Triandis, 1980) or the Protection Motivation Theory (PMT) (Rogers, 1983 ) suggest that intentions can be regarded as the most predictive factor for a given behavior to be performed. Behavioral intentions in this context encompass both the direction (yes or no) and intensity (time and effort invested) of the decision to act. How well intentions predict behavior and which other factors explain this process is much debated (e.g. Sheeran, 2011). Intentions are sometimes regarded as the most important predictors of behavior but at the same time many theoretical approaches also acknowledge that behaviors may be thwarted by a lack of control over intention enactment (Ajzen, 1985, 1991; Triandis, 1980). In a meta-analysis conducted on the relation between intentions and behavior, Sheeran (2002) suggested that in the research included in this review intentions accounted only for an average of $28 \%$ in actual behavior.

A number of explanations for the gap between intentions and behaviors have been brought forward. On a methodological level, measurement errors and dichotomization may reduce correlations between intentions and behavior (Sheeran, 2002) due to a lack of compatibility between intentions and behavior in terms of action, target, context or time (Ajzen \& Fishbein, 1973, 1974); lack of correspondence between measurement scales used for intentions and behavior or a mismatch of marginal distributions of the intention and behavior measures (e.g. Sutton, 1998). Since, however, even the best estimates do not lead to a perfect match between intentions and behavior $(\mathrm{r}=1.00)$, other factors may be responsible for the discrepancy between intentions and behaviors in certain cases.

Sheeran (2002) identified several categories of factors that may lead to decreased intentionbehavior consistency: behavior types (including how much control can be exerted over a behavior), intention types (e.g. implementation intentions), properties of behavioral intentions (temporal stability, degree of intention formation, attitudinally vs. normatively controlled intentions, certainty and accessibility of intentions), personality and cognitive variables (action control, self-schemas, conflicting intentions), relationships between 
determinants of intention-behavior consistency and habit-controlled behavior (Triandis, 1980).

Additionally, respondent types can play a role in how well an intention can predict a specific behavior. Two main respondent groups can be identified that can influence intentionbehavior consistency: inclined actors (acting on their intentions), disinclined abstainers (no intentions and no action). On the other hand, participants not acting on their intentions can be regarded as the main reason for the intention-behavior gap, i.e. inclined abstainers (having intention but not acting) and disinclined actors (acting despite negative intentions) (Sheeran, 2002). This typology is important for intervention studies and behavior change programs since different respondent groups may need different approaches or program elements. The literature has suggested that the intention-behavior gap is mainly due to the inclined abstainers (Sheeran, 2002).

The aim of this chapter is to determine how the Reasoned Action Approach (RAA) constructs, attitudes, subjective norms and perceived behavioral control determine the intention and subsequently predict the actual decision to work on an environmental building rating scheme. The analysis carried out in this chapter will also investigate whether intention and behavior consistency may be an issue in the green building industry.

\subsection{Sample and Method}

After an initial pilot interview study in the North East of the United States (Chapter 3) a survey instrument was developed and administered online in both Canada and the United States among building professionals (architects, construction engineers and builders) regarding their decision to integrate the LEED and Green Globes scheme in their business practices and project plans. These two countries were chosen since they are close enough culturally and institutionally (Buhr and Friedman, 2001) and both offer the same two voluntary environmental rating programs, LEED and Green Globes.

Potential respondents were identified via the US and Canadian Green Building Councils and National Professional Accreditation boards (i.e. Architectural, Engineering, and Construction etc.). However, while professional accreditation boards should hold information on all accredited building professionals, not all contact details were available in email form appropriate for an online survey. Those building professionals were not included in the sample population. For instance, the number of architects in the United States alone is estimated by the American Institute of Architects (AIA) above 100000 licensed professionals ${ }^{2}$. Due to the vast and transitory nature of the building and construction profession, however, information for everyone in the overall population is not readily available. The

\footnotetext{
${ }^{2}$ http://www.aia.org/press/AIAS077761 (Retrieved 26 December 2013)
} 
respondents contacted for the survey presented in this chapter were randomly selected from the professional accreditation lists available.

The respondents were contacted via email invitation to participate in an online survey, based on the survey management software "Lime Survey." After sending out two reminders, the response rate was $10 \%$ in the US $(n=440)$ and $12 \%$ in Canada $(n=491)$ respectively, yielding a total of $n=931$ responses. Overall, $41 \%$ of the respondents were CEOs or Partners in their firms, with $25 \%$ senior-level and $22 \%$ middle managers. Only $10 \%$ of the respondents were at a junior level. As for job tenure, more than half (58\%) of the respondents had more than fifteen (15) years of professional experience. Another $16 \%$ of respondents had 10-15 years, $16 \%$ 5-10 years and 10\% 0-5 year's experience. Among the respondents, there were fewer females (CAN: 171/US: 107) than males (CAN: 320/US: 333), which represents the gender ratio in the building industry to a fair extent.After verifying response patterns and excluding respondents who indicated either not being active in the building industry anymore, having rescinded their accreditations etc., a total usable sample of $n=914$ responses was remained for subsequent analyses. Not all respondents, however,had worked on an environmental building rating scheme before participating in this study.The number of respondents in both the United States and Canada that have worked on LEED and Green Globes schemes respectively are listed in Table 4.1. The overview of survey respondents suggests that in both countries more building professionals had experience with the LEED scheme than the Green Globes scheme at the time of survey administration in 2011. It needs to be emphasised, however, that the LEED and Green Globes adoption is not mutually exclusive, which leads to some respondents being counted twice in Table 4.1 (but not in any further statistical analyses). More detailed information on characteristics of respondents to all LEED or all Green Globes question items can be found in Appendix C.

\subsection{Questionnaire and Measurement}

\section{Reasoned Action Approach (RAA)}

The survey instrument was constructed based on the recommendations given by Ajzen (1991) and the results of the qualitative pilot interview study (Chapter 3). After constructing the questionnaire, the survey was pre-tested with the help of five building professionals from the North East of the US, filling in the questionnaire and giving feed-back on the structure and measures of the survey items. The survey instrument was adjusted accordingly. The final instrument included the variables specified by the Reasoned Action Approach (RAA / Theory of Planned Behavior (TPB) (Fishbein and Ajzen, 2010). All questionnaire items were ranked on a 7-point rating scale. Two items were used to measure behavioral intention: "I expect that my next commercial building project will include the certification scheme" and "I intend to integrate the certification scheme in my next commercial building 


\begin{tabular}{ccccc}
\hline & \multicolumn{2}{c}{ US } & \multicolumn{2}{c}{ Canada } \\
\cline { 2 - 5 } $\begin{array}{c}\text { Adopters } \\
\text { (LEED }\end{array}$ & LEED & GG & LEED & GG \\
and GG & & & & \\
are not & & & & \\
mutually & & & & \\
exclu- & & & & \\
sive) & & & & \\
\hline Yes & 293 & 21 & 329 & 54 \\
No & 52 & 316 & 68 & 321 \\
Total & 345 & 337 & 397 & 375 \\
\hline
\end{tabular}

Table 4.1: LEED and Green Globes Adopters per country (Source: Own survey data)

project": Strongly Agree/Strongly Disagree.

Attitude was measured using four items: "Working with the scheme is/would be (Very pleasant/Very unpleasant); " The certification scheme has established clear guidelines for sustainability practices in the building industry"(Strongly Agree/Strongly Disagree); "I think that the _ scheme has educated me about sustainable building practices" (Strongly Agree/Strongly Disagree); "I think that the certification scheme has provided building professionals with a common language regarding sustainable construction practices" (Strongly Agree/Strongly Disagree).

Subjective Norms were measured with six items: "Most important people in the building industry think that I should work with the certification scheme"(Strongly Agree/ Strongly Disagree); "Most important people in the building industry work with the scheme (Strongly Agree/Strongly Disagree); "Government/City/State officials expect me to work with the scheme (Strongly Agree/Strongly Disagree); "Clients expect me to work with the scheme"(Strongly Agree/Strongly Disagree); "Co-workers expect me to work with the scheme"(Strongly Agree/Strongly Disagree); "Other building professionals expect me to work with the scheme”(Strongly Agree/Strongly Disagree).

Lastly, Perceived Behavioral Control (PBC) was measured with five items: " The decision to work with the scheme is entirely up to me"( Strongly Agree/Strongly Disagree); "It would be easy for me to integrate the certification scheme if I wanted to" (Strongly Agree/Strongly Disagree); "Organizational practices in my firm prevent me from working with the ___ scheme" (Strongly Agree/Strongly Disagree); "Financial constraints prevent me from working with the scheme” (Strongly Agree/Strongly Disagree); "Other building profes- 
sionals' decisions prevent me from working with the Disagree). The last three items were reverse-coded. scheme" ( Strongly Agree/Strongly

\section{Background variables}

Besides the Reasoned Action Approach (RAA) constructs, background variables were also included in the analysis to account for potential differences in professional and educational background, firm type, seniority in their organization, place of employment (country) and previous experience with sustainability issues in the building sector. All the variables were included in the analysis as binary dummy variables. Furthermore, binary variables that measure past experience with LEED or Green Globes schemes were introduced in the regression analyses to account for different levels of building professionals' experience with these types of schemes.

\subsection{Results}

\section{Study 1: Effect of Perceived Behavioral Control, Norms and Attitudes on Intention}

First an exploratory factor analyses using STATA 11 for Windows were performed to refine the scales. Subsequently, Cronbach's alpha for the model's constructs were determined to assess the reliability of the questions in the survey instrument. For the LEED items, intentions $(0.92)$ norms $(0.95)$, attitudes $(0.62)$ and PBC $(0.89)$ yielded reliable coefficients. For Green Globes items, intentions (0.89), attitudes (0.49), norms (0.85) and PBC (0.68), the scales for attitudes and $\mathrm{PBC}$ were found to be less reliable overall. After ascertaining the construct validity for the Reasoned Action items, descriptive statistics, correlation analyses and a hierarchical logistic regression procedure was performed.

\section{Correlation Analysis}

Subsequently, a pairwise correlation was performed. The means, standard deviations and correlations for LEED and Green Globes are listed in Table 4.2 and Table 4.3 respectively.

As can be seen from Table 4.2, the intention to adopt LEED is positively correlated with past behavior (0.36), attitudes (0.19), subjective norms (0.53) and PBC (0.39).

Overall, the pairwise correlation for LEED seems to indicate that intention is most strongly correlated with norms, then PBC, past behavior and lastly attitudes. This result could indicate that the perception of other key players' actions is the most influential factor for building professionals to adopt the LEED scheme. 


\begin{tabular}{lccccccc}
\hline & Mean & SD & 1 & 2 & 3 & 4 & 5 \\
\hline 1.Past behavior & & & 1.00 & & & & \\
2.Intention & 5.05 & 1.59 & $0.36^{*}$ & 1.00 & & & \\
3.Norms & 5.43 & 0.90 & $0.28^{*}$ & $0.53^{*}$ & 1.00 & & \\
4.Attitude & 4.68 & 0.91 & 0.04 & $0.19^{*}$ & $0.22^{*}$ & 1.00 & \\
5.PBC & 4.63 & 1.00 & $0.18^{*}$ & $0.39^{*}$ & $0.31^{*}$ & $0.31^{*}$ & 1.00 \\
\hline
\end{tabular}

Table 4.2: Pairwise correlations Reasoned Action Approach (RAA) constructs (LEED)

\begin{tabular}{lccccccc}
\hline & Mean & SD & 1 & 2 & 3 & 4 & 5 \\
\hline 1.Past behavior & & & 1.00 & & & & \\
2.Intention & 2.74 & 1.45 & $0.36^{*}$ & 1.00 & & & \\
3.Attitudes & 4.23 & 0.56 & 0.05 & $0.16^{*}$ & 1.00 & & \\
4.Norms & 3.10 & 1.13 & -0.18 & -0.05 & 0.04 & 1.00 & \\
5.PBC & 4.20 & 0.86 & $0.14^{*}$ & $0.16^{*}$ & 0.00 & $-.09^{*}$ & 1.00 \\
\hline
\end{tabular}

Table 4.3: Pairwise correlation Reasoned Action Approach (RAA) constructs (Green Globes)

When considering the pairwise correlations for the Green Globes scheme, intention was positively correlated with past behavior (0.36), attitudes (0.16) and PBC (0.16) (Table 4.3). Interestingly, correlation with subjective norms was not found to be significant. As opposed to the LEED scheme, this result suggests that Green Globes is less institutionalized and seems to depend on building professionals' favorable attitudes and perception of control instead.

However, since the pairwise correlations do not determine whether the RAA constructs (attitudes, subjective norms and perceived behavioral control) predict intentions, linear regressions for both the LEED and Green Globes certification schemes were performed.

\section{Regression analysis}

Linear regression analyses with the intention to adopt the LEED and Green Globes schemes as the dependent variable were conducted to confirm which RAA constructs influenced building professionals' intention to integrate the LEED and Green Globes schemes in building projects.

For the LEED adoption behavior (Table 4.4), the data suggests that among the demographic variables only gender, working in an engineering firm and previous sustainability classes 


\begin{tabular}{lccccc}
\hline Step & $\mathrm{R}^{2}$ & $\Delta \mathrm{R}^{2}$ & $\mathrm{RAA} \beta$ & $\beta$ after & Final $\beta$ \\
& & \multicolumn{3}{c}{ Past } \\
& & \multicolumn{3}{c}{ Behavior } \\
\hline
\end{tabular}

Step 1 : RAA

Attitude

$0.34^{* * *}$

$0.04^{*}$

$0.05^{*} \quad 0.04^{*}$

Norms

$0.25^{* * *}$

$0.22^{* * *} \quad 0.22^{* * *}$

Perceived Control

$0.17^{* * *} \quad 0.15^{* * *} \quad 0.15^{* * *}$

Step 2: Past Behavior

Past LEED (=yes)

$0.38^{* * *} \quad 0.04^{* * *} \quad 3.85^{* *} \quad 1.94^{* * *}$

Step 3: Background variables

Architect ns

Engineer

ns

Construction professional

ns
ns

Architecture firm

Engineering firm

$0.41^{* * *} \quad 0.02^{* *}$

$0.56^{*}$

Combined Arch/Eng. Firm

ns

US

ns

Canada

ns

Female

$0.46^{* *}$

Junior level (profession)

ns

Bachelor education

ns

Sustainability (=yes)

$0.45^{* *}$

${ }^{*} \mathrm{p}<0.1 ;{ }^{* *} \mathrm{p}<0.05 ;{ }^{* * *} \mathrm{p}<0.01, \mathrm{n}=649$ (Respondents to all LEED RAA questions)

Note: After the LEED regression analysis was conducted and to exclude multicollinearity issues, Variance Inflation Factors (VIF) were calculated for both explanatory variables individually and the regression equation overall. All VIFs were under 4, with an equation mean VIF of 1.81. The VIFs for RAA constructs were: norms (1.26), attitude (1.09), PBC (1.19) and past behavior (1.15). The VIF results suggest that multicollinearity is not an issue in this analysis.

Table 4.4: LEED adoption intention. Regression Analysis with Intention as the Dependent Variable 
were statistically significant at the $5 \%$ level. Females in the sample displayed a higher level of intention to integrate the LEED scheme than male respondents. In addition, professionals that had followed college-level sustainability classes overall were more in favor of integrating the LEED scheme in their building projects. No statistically significant difference was determined between the two countries (Canada and the US), professional groups or types of firms the respondents worked in.

Attitudes $(\beta=0.04, \mathrm{p}<0.1)$, subjective norms $(\beta=0.22, \mathrm{p}<0.05)$ and $\mathrm{PBC}(\beta=0.15, \mathrm{p}<0.05)$ were found to be statistically significant. Just as for the correlation results, norms was the largest coefficient, followed by perceived behavioral control. Hence, norms and PBC are more important in predicting intentions for LEED adoption than attitudes. Interestingly, past experience with the LEED scheme did strongly influence behavioral intentions. The regression model for LEED integration explained 41 per cent of the variance in intention.

For the intention to adopt the Green Globes scheme, gender and working in an engineering firm were found to be statistically significant at the $5 \%$ level. As for LEED, females overall had a higher intention level to adopt the Green Globes scheme. While country factors and professional group affiliation were not found to be significant, respondents working in integrated architecture and engineering firms as well as construction firms had higher levels of intention for adopting the Green Globes scheme. The reason for this result is no entirely clear but may be linked to the subcontractor structure in the building industry.

As Table 4.5 indicates, intention was predicted by attitudes $(\beta=0.15, \mathrm{p}<0.05)$ and $\mathrm{PBC}(\beta=$ $0.08, \mathrm{P}<0.05)$. Interestingly, subjective norms were not found to be statistically significant, a deviation from the standard Reasoned Action Approach (RAA) model and the LEED results. For the Green Globes scheme, past behavior was found to be significant $(\beta=-2.2$, $\mathrm{p}<0.01)$ but have a negative effect on intention. The model explained 24 per cent of the variance in intention to integrate the Green Globes scheme.

Interestingly, for both the LEED and Green Globes schemes different RAA constructs predicted the intention to adopt these programs. A common denominator was only that professional group affiliation and national differences did not influence adoption intentions. Similar model fits were detected in comparable studies (e.g. Lokhorst et al., 2011).

Subjective norms and PBC were found to be the strongest predictors in the RAA model, which points to the fact that the LEED scheme is so far established that respondents' attitudes may not matter as much anymore. On the other hand, the intention to integrate the less well known Green Globes scheme was found to have attitudes as the strongest RAA predictor. While PBC was found to be significant, subjective norms were not. This result indicates that the scheme's adoption was not established sufficiently at the time when the data was collected (June and July 2011). In addition, past Green Globes experience seemed to indicate a negative impact on future intentions. Whether this result was due to the fact 


\begin{tabular}{|c|c|c|c|c|c|}
\hline Step & $\mathrm{R}^{2}$ & $\Delta \mathrm{R}^{2}$ & RAA $\beta$ & $\begin{array}{l}\beta \text { after } \\
\text { Past } \\
\text { Behavior }\end{array}$ & Final $\beta$ \\
\hline \multicolumn{6}{|l|}{ Step $1:$ RAA } \\
\hline Attitude & $0.04^{* * *}$ & & $0.2^{* * *}$ & $0.16^{* * *}$ & $0.15^{* * *}$ \\
\hline Norms & & & ns & ns & ns \\
\hline Perceived Control & & & $0.1^{* * *}$ & $0.07^{* * *}$ & $0.08^{* * *}$ \\
\hline \multicolumn{6}{|l|}{ Step 2: Past Behavior } \\
\hline Past GG (=yes) & $0.17^{* * *}$ & $0.13^{* * *}$ & & $-2.73^{* * *}$ & $-2.2^{* * *}$ \\
\hline \multicolumn{6}{|l|}{ Step 3: Background variables } \\
\hline Architect & & & & & ns \\
\hline Engineer & & & & & ns \\
\hline Construction professional & & & & & ns \\
\hline Architecture firm & & & & & $\mathrm{ns}$ \\
\hline Engineering firm & $0.24^{* * *}$ & $0.06^{* * *}$ & & & $-0.99^{* *}$ \\
\hline Combined Arch / Eng. Firm & & & & & ns \\
\hline US & & & & & ns \\
\hline Canada & & & & & ns \\
\hline Female & & & & & $0.62^{* *}$ \\
\hline Junior level (profession) & & & & & ns \\
\hline Bachelor education & & & & & ns \\
\hline Sustainability (=yes) & & & & & ns \\
\hline
\end{tabular}

Note: After the Green Globes regression analysis was conducted and to exclude multicollinearity issues, Variance Inflation Factors (VIF) were calculated for both explanatory variables individually and the regression equation overall. All VIFs were under 4, with an equation mean VIF of 1.79 . The VIFs for RAA constructs were: norms (1.08), attitude (1.03), PBC (1.08) and past behavior (1.15). The VIF results suggest that multicollinearity is not an issue in this analysis.

Table 4.5: Green Globes adoption intention. Regression Analysis with Intention as the Dependent Variable

that building professionals were not satisfied with the scheme itself or due to other factors will need to be further investigated future research. 


\section{Study 2: Effect of Perceived Behavioral Control, Norms and Attitudes and Intention on LEED adoption}

As the previous study merely looked at the effects of attitudes, subjective norms and perceived behavioral control on intention, the aim in the follow-up survey was to determine how well intentions predicted actual behavior six to nine months later. To this end, all the respondents of the initial study were sent a follow-up questionnaire determining whether the building professionals had actually commenced work on one or more green building projects in the meantime.Those respondents among the original 914 survey respondents that were contacted for Study 1 and completed information on key RAA variables for LEED and/or Green Globes were contacted.

Overall, 162 building professionals that participated in Study 1 and provided complete information on Reasoned Action Approach (RAA) variables also completed the follow-up questionnaire. However, due to an error in survey administration, only questions with regards to the LEED scheme were elicited. Hence, in this section only the results of the LEED follow-up questionnaire are included in the analysis. The respondent characteristics, including professional group, firm type, country, gender, job position and job tenure, are listed in Appendix C. In order to verify whether intention did predict actual follow-up behavior, a probabilistic regression analysis was performed. Control variables and the other three RAA constructs were included in the analysis in order to test whether these would have a direct effect on actual behavior.

According to the Reasoned Action Approach (RAA) and its predecessors, intentions are the best predictor of actions. According to our model, attitudes, norms and PBC influenced intentions to work on a LEED project which in turn influenced behavior. The regression results in Study 1 in this chapter for the LEED scheme indicated that RAA constructs contributed to explaining building professionals' behavioral intentions. In the probabilistic regression analysis presented in Table 4.6, the result suggests that intention predicts subsequent LEED adoption $(\beta=0.13, \mathrm{p}<0.05)$, while none of the other constructs (i.e. attitudes, subjective norms and perceived behavioral control) seem to have direct influence on LEED adoption. This result is in line with the RAA models' predictions and no intention-behavior gap was observed for the LEED scheme uptake. However, past behavior was a direct predictor for the LEED scheme $(\beta=0.9, p<0.1)$, just as one of the background variables, gender $(\beta=0.57, p<0.01)$. In the context of LEED adoption, past behavior seems to directly influence future LEED adoption behavior, which may be due to habituation or institutionalized organisational practices. The reason why female respondents seem to be more directly involved in the adoption of the LEED scheme could be due to a more direct interest in environmentally sustainable practices and acting on these interests. As this factor was not the main interest of this chapter, this question will have to be answered in future studies. 


\begin{tabular}{|c|c|c|c|c|c|c|}
\hline Step & $\begin{array}{l}\text { Pseudo } \\
\mathrm{R}^{2}\end{array}$ & $\Delta \mathrm{R}^{2}$ & $\begin{array}{l}\text { Intention } \\
\beta\end{array}$ & RAA $\beta$ & $\begin{array}{l}\beta \text { after } \\
\text { Past } \\
\text { Behavior }\end{array}$ & Final $\beta$ \\
\hline Step 1: Intention & $0.12^{* * *}$ & & $0.18^{* * *}$ & $0.18^{* * *}$ & $0.12^{* * *}$ & $0.13^{* * *}$ \\
\hline \multicolumn{7}{|l|}{ Step 2 : RAA } \\
\hline Attitude & $0.12^{* * *}$ & 0 & & ns & ns & ns \\
\hline Norms & & & & ns & ns & ns \\
\hline Perceived Control & & & & ns & ns & $\mathrm{ns}$ \\
\hline \multicolumn{7}{|l|}{ Step 3: Past Behavior } \\
\hline Past LEED (=yes) & $0.14^{* * *}$ & $0.02^{* *}$ & & & $0.90^{*}$ & $0.90^{*}$ \\
\hline \multicolumn{7}{|l|}{$\begin{array}{l}\text { Step 4: Background } \\
\text { variables }\end{array}$} \\
\hline Architect & & & & & & ns \\
\hline Engineer & & & & & & ns \\
\hline \multicolumn{7}{|l|}{ professional } \\
\hline Architecture firm & & & & & & ns \\
\hline Engineering firm & $0.18^{* * *}$ & $0.04^{* *}$ & & & & ns \\
\hline Combined Arch / & & & & & & ns \\
\hline \multicolumn{7}{|l|}{ Eng. Firm } \\
\hline US & & & & & & ns \\
\hline Canada & & & & & & ns \\
\hline Female & & & & & & $0.57^{* * *}$ \\
\hline Junior level & & & & & & $\mathrm{ns}$ \\
\hline \multicolumn{7}{|l|}{ (profession) } \\
\hline Bachelor education & & & & & & ns \\
\hline Sustainability (=yes) & & & & & & ns \\
\hline${ }^{*} \mathrm{p}<0.1 ;^{* *} \mathrm{p}<0.05 ;{ }^{* * *}$ & $\mathrm{p}<0.01$ & & & & & $\mathrm{n}=162$ \\
\hline
\end{tabular}

Note: After the LEED as behavior probit regression analysis was conducted and to exclude multicollinearity issues, Variance Inflation Factors (VIF) were calculated for both explanatory variables individually and the regression equation overall. All VIFs were under 4 , with an equation mean VIF of 1.38. The VIFs for RAA constructs were: norms (1.63), attitude (1.14), PBC (1.15) and past behavior (1.32). The VIF results suggest that multicollinearity is not an issue in this analysis.

Table 4.6: LEED adoption. Probit Analysis with Behavior as the Dependent Variable 


\subsection{Discussion}

The results suggest that the Reasoned Action Approach (RAA) is useful to predict building professionals' intentions in the US and Canadian building industry to adopt LEED and Green Globes. The data analysis suggests that even though LEED and Green Globes are "competing schemes" in the environmental building and assessment certification market, the reason why the adoption processes may differ can be explained with the RAA constructs at hand. While the intention to implement the LEED scheme is mainly predicted by norms and $\mathrm{PBC}$, attitudes play a less prominent role.

However, the adoption of the Green Globes scheme does not entirely follow the RAA model expectations as subjective norms were not found to be significant to predict behavioral intentions. Since the Green Globes program is the less widely known scheme in the United States (even though that is not the case in Canada), respondents did not seem to perceive pressure from peers and governments to use this scheme in their design and construction projects. Past behavior was only significant for the Green Globes scheme and not for the LEED certification program.

While professional group and country affiliation overall were not significant in this study, some background variables had an influence on intentions for both the LEED and Green Globes schemes. For both LEED and Green Globes adoption, female respondents were more likely to indicate their intention to include an environmental voluntary building rating scheme in their building projects. In addition, employees in construction firms indicated that they intended to integrate the Green Globes scheme, while employment in other firm types was not found to be significant. On the other hand, having taken college-level classes in sustainability did influence the LEED adoption process, while this factor did not predict Green Globes adoption.

For actual LEED adoption, however, no background variables were found to be significant.

While neither professional affiliation nor national context did seem to matter in the context of LEED and Green Globes intention to adopt, it is quite interesting to investigate why at least at the intention stage the determinants for both schemes differ for the same sample of respondents. Even though the RAA constructs in neither case contributed the largest coefficient to predict intention, this study does suggest that these constructs influence the uptake process in different ways for different schemes.

After analyzing the adoption patterns, how can these results help the building and construction industry to move to more sustainable practices? 


\subsection{Behavior change strategies in fragmented project-based professional settings}

Behavior change strategies can only be successful if individuals have control over specific actions. In this case, the data indicated that subjective norms and perceived behavioral control was the strongest predictor of intentions for the LEED scheme. This result, however, does not answer questions on actual control over the integration of LEED in business practices. For project leaders, this decision is certainly easier to make than for subcontractors and overall building owners will have the final say in the decision to certify a building. Most of the adopters had been project leaders in a LEED project (to a lesser extent for Green Globes projects) and were either CEOs or senior partners in their firms. Due to the structure of the very fragmented building industry business owners and CEOs are likely to have more control over actions than other building professionals employed in positions lower in the firm hierarchy.

Since the building and construction industry functions on a project basis practices may not be as stable within and across organizations as in other settings and the actions of individuals in other organizations may become pivotal. Expectations and importance of other actors are likely to be stronger in situations where coordination and cooperation is necessary for behavioral enactment (see Chapter 6 and 7).

Hence, behavior change strategies in this type of fragmented professional settings may need to use very different intervention types than in other organizational and household situations. While it is debatable whether a scheme such as LEED or Green Globes is valuable enough to be promoted in behavior change interventions, this chapter indicated potential problems in similar behavioral enactment situations, i.e. green building VEP uptake.

Since environmental intervention programs have yielded mixed results in more straight forward household settings, strategies to changing behaviors and practices in voluntary governance settings may need very different approaches than previously used.

Convincing one actor will be less likely successful if other actors are not convinced as well. Persuasion and communication models such as the Elaboration Likelihood Model (ELM) (Petty \& Cacioppo, 1986) have been used in behavior change programs (see Chapter 9). Even though the high significance of norms for the more established scheme, LEED, seems to indicate that building professionals are limited by actual control, it is not quite clear to what extent they have an influence on the inclusion of the LEED scheme in cases when they are the building project leaders.

Interestingly, however, the Green Globes scheme is attitudes driven, with norms were not significant. This result could suggest that actors are more likely implement a scheme when they have a favorable opinion or when a program is still relatively new and unknown. 


\subsection{Limitations}

There are several limitations to this study. These limitations concern mainly methodological issues such as data-related problems, measurement errors and dichotomization reducing correlations between intentions and behavior (Sheeran, 2002) due to a lack of compatibility between intentions and behavior in terms of action, target, context or time (Ajzen \& Fishbein, 1973, 1974); lack of correspondence between measurement scales used for intentions and behavior or a mismatch of marginal distributions of the intention and behavior measures (e.g. Sutton, 1998). As discussed in the literature review section, several factors may account for an intention-behavior: behavior types (including how much control can be exerted over a behavior), intention types (e.g. implementation intentions), properties of behavioral intentions (temporal stability, degree of intention formation, attitudinally vs. normatively controlled intentions, certainty and accessibility of intentions), personality and cognitive variables (action control, self-schemas, conflicting intentions), relationships between determinants of intention-behavior consistency, respondent types and habit-controlled behavior (Triandis, 1980). Not all of these aspects of intention and behavior implementation were investigated in this study. Since there are also many other potential determinants of green VEP adoption, alternative explanation to the ones explored in this study will be explored in subsequent chapters.

\subsection{Conclusion}

This chapter has demonstrated that to understand building professionals' adoption of LEED and Green Globe in the United States and Canada, the Reasoned Action Approach can be a useful instrument to analyze which factors influence the adoption and the intention to adopt the schemes. In the first instance the RAA model was applied to Green Globes and LEED uptake with intention as the dependent variable in each case. In a second instance, actual behavior for the LEED scheme was included in the analysis.

For behavioral intentions as dependent variable, all of the three predictor variables were found to influence intention for LEED, with subjective norms the most dominant construct with attitudes and perception of control being less influential. Green Globes adoption, on the other hand, was predicted by attitudes, perceived behavioral control and past behavior.

Adding actual behavior for the LEED scheme followed the predictions of the RAA model: attitudes, subjective norms and perceived behavioral control predicting intentions and intentions in turn predicting actual behavior. Hence, an intention-behavior gap was not observed in this study for LEED adoption. As neither professional affiliation nor national context did seem to matter in the context of LEED and Green Globes intention to adopt, it is quite interesting to investigate why at least at the intention stage the determinants of adoption and implementation intentions for both schemes differ. 
This research has demonstrated that beyond standardized valuation techniques, and sociodemographic factors, behavioral components do influence the intention and uptake of environmental building rating and assessment schemes. While these factors may not be necessarily predominant, the differing adoption patterns suggest that two quite similar schemes, LEED and Green Globes, have different social-psychological factors that are more influential for the uptake process (norms and PBC for LEED and attitudes and PBC for Green Globes).

The knowledge generated in this study can assist issuing organizations to understand professional adoption of voluntary building rating and assessment schemes. To neglect behavioral factors altogether bears the risk of not recognizing potential for improving VEPs in the construction and building sector. 


\section{References}

Ajzen, I. (1985). From intentions to actions: A theory of planned behavior. Springer.

Ajzen, I. (1991). The theory of planned behavior. Organizational behavior and human decision processes, 50(2), 179-211.

Ajzen, I., \& Fishbein, M. (1973). Attitudinal and normative variables as predictors of specific behavior. Journal of Personality and Social Psychology, 27(1), 41.

Ajzen, I., \& Fishbein, M. (1980). Understanding attitudes and predicting social behaviour. Prentice-Hall.

Anvuur, A., \& Kumaraswamy, M. (2008). Collaborative relationships in construction: Developing frameworks and networks. In S. Smyth \& S. Pryke (Eds.), (p. 107-128). Wiley-Blackwell Oxford.

Bartholomew, L. K., Parcel, G. S., Kok, G., Gottlieb, N. H., \& Fernandez, M. E. (2011). Planning health promotion programs: an intervention mapping approach. Jossey-Bass.

Buhr, N., \& Freedman, M. (2001). Culture, institutional factors and differences in environmental disclosure between canada and the united states. Critical Perspectives on Accounting, 12(3), 293-322.

Cordano, M., \& Frieze, I. H. (2000). Pollution reduction preferences of us environmental managers: Applying ajzen's theory of planned behavior. Academy of Management Journal, 43(4), 627-641.

Cordano, M., Frieze, I. H., \& Ellis, K. M. (2004). Entangled affiliations and attitudes: An analysis of the influences on environmental policy stakeholders' behavioral intentions. Journal of Business Ethics, 49(1), 27-40.

Darnton, A. (2008). Practical guide: An overview of behaviour change models and their uses (Tech. Rep.). Government Social Research Unit. (www. gsr. gov. uk/downloads/resources/behaviour_change_review/practical_guide.pdf)

Feng, J.-Y., \& Levine, M. (2005). Factors associated with nurses' intention to report child abuse: A national survey of taiwanese nurses. Child abuse \& neglect, 29(7), 783-795.

Fishbein, M., \& Ajzen, I. (1974). Attitudes towards objects as predictors of single and multiple behavioral criteria. Psychological review, 81(1), 59.

Fishbein, M., \& Ajzen, I. (1975). Belief, attitude, intention and behavior: An introduction to theory and research. Addison-Wesley, Reading, MA.

Fishbein, M., \& Ajzen, I. (2011). Predicting and changing behavior: The reasoned action approach. New York: Psychology Press.

Green, L. W., \& Glasgow, R. E. (2006). Evaluating the relevance, generalization, and applicability of research issues in external validation and translation methodology. Evaluation \& the Health Professions, 29(1), 126-153.

Green, L. W., \& Kreuter, M. W. (2005). Health program planning: an educational and ecological approach. McGraw-Hill New York. 
Huston, S. A., Bagozzi, R. P., \& Kirking, D. M. (2010). Decision-making about the use of hormone therapy among perimenopausal women. British Journal of Health Psychology, 15(2), 231-251.

Jackson, T. (2005). Motivating sustainable consumption.a review of evidence on consumer behaviour and behavioural change. a report to the sustainable development research network (Tech. Rep.). Surrey: Centre for Environmental Strategies.

Kaiser, F. G., Hübner, G., \& Bogner, F. X. (2005). Contrasting the theory of planned behavior with the value-belief-norm model in explaining conservation behavior1. Journal of Applied Social Psychology, 35(10), 2150-2170.

Kurland, N. B. (1996). Sales agents and clients: ethics, incentives, and a modified theory of planned behavior. Human Relations, 49(1), 51-74.

Lokhorst, A. M., Staats, H., van Dijk, J., van Dijk, E., \& de Snoo, G. (2011). What's in it for me? motivational differences between farmers' subsidised and non-subsidised conservation practices. Applied Psychology, 60(3), 337-353.

Millstein, S. G. (1996). Utility of the theories of reasoned action and planned behavior for predicting physician behavior: a prospective analysis. Health Psychology, 15(5), 398.

Orbell, S., \& Sheeran, P. (1998). 'inclined abstainers': A problem for predicting healthrelated behaviour. British Journal of Social Psychology, 37(2), 151-165.

Oskamp, S. (2000). A sustainable future for humanity? how can psychology help? American Psychologist, 55(5), 496.

Oz, E. (2001). Organizational commitment and ethical behavior: An empirical study of information system professionals. Journal of Business Ethics, 34(2), 137-142.

Parker, D., Manstead, A. S., Stradling, S. G., Reason, J. T., \& Baxter, J. S. (1992). Intention to commit driving violations: An application of the theory of planned behavior. Journal of Applied Psychology, 77(1), 94-101.

Pavlou, P. A., \& Chai, L. (2002). What drives electronic commerce across cultures? across-cultural empirical investigation of the theory of planned behavior. J. Electron. Commerce Res., 3(4), 240-253.

Pertl, M., Hevey, D., Thomas, K., Craig, A., Chuinneagáin, S. N., \& Maher, L. (2010). Differential effects of self-efficacy and perceived control on intention to perform skin cancer-related health behaviours. Health education research, 25(5), 769-779.

Petty, R. E., \& Cacioppo, J. T. (1986). The elaboration likelihood model of persuasion. Springer.

Phua, F. T. (2004). The antecedents of co-operative behaviour among project team members: an alternative perspective on an old issue. Construction Management and Economics, 22(10), 1033-1045.

Phua, F. T., \& Rowlinson, S. (2003). Cultural differences as an explanatory variable for adversarial attitudes in the construction industry: the case of hong kong. Construction Management and Economics, 21(7), 777-785. 
Phua, F. T., \& Rowlinson, S. (2004). Operationalizing culture in construction management research: a social identity perspective in the hong kong context. Construction Management and Economics, 22(9), 913-925.

Phua, F. T. T. (2002, 14-17 Jan 2002). Effects of cultural differences on project participants' co-operative behavior in construction projects: the case of hong kong. In Cib international symposium on procurement systems (p. 497-513). St Augustine, Trinidad \& Tobago.

Rayner, S., \& Malone, E. L. (1998). Human choice and climate change: an international assessment. Columbus, Ohio: Battelle Press.

Rogers, R. W. (1975). A protection motivation theory of fear appeals and attitude change1. The Journal of Psychology, 91(1), 93-114.

Schwartz, S. H. (1977). Normative influences on altruism. Advances in experimental social psychology, 10, 221-279.

Sheeran, P. (2002). Intention-behavior relations: A conceptual and empirical review. European review of social psychology, 12(1), 1-36.

Steg, L., \& Vlek, C. (2009). Encouraging pro-environmental behaviour: An integrative review and research agenda. Journal of Environmental Psychology, 29(3), 309-317.

Sutton, S. (1998). Predicting and explaining intentions and behavior: How well are we doing? Journal of applied social psychology, 28(15), 1317-1338.

Triandis, H. C. (1979). Values, attitudes, and interpersonal behavior. In Nebraska symposium on motivation.

Triandis, H. C. (1989). The self and social behavior in differing cultural contexts. Psychological review, 96(3), 506.

Van Hooft, E. A., \& De Jong, M. (2009). Predicting job seeking for temporary employment using the theory of planned behaviour: The moderating role of individualism and collectivism. Journal of Occupational and Organizational Psychology, 82(2), 295-316.

$\mathrm{Wu}, \mathrm{J}$. (2009). Environmental compliance: the good, the bad, and the super green. Journal of Environmental Management, 90(11), 3363-3381. 


\title{
CHAPTER
}

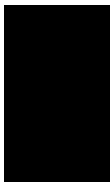

\section{What do Clients want? Commercial Real Estate Developers' views on the LEED and Green Globes certification schemes in the United States}

\footnotetext{
"What concerns me is not the way things are, but rather the way people think things are" (Epicetetus)
}

\subsection{Introduction}

\begin{abstract}
A $s$ the previous chapters have suggested, subjective norms (i.e. perceived client pressure and demands) influence building professionals' decision to adopt environmental building rating schemes. While clients in demand-driven markets have more power to determine the products and services offered to them, supply-driven markets see the producers usually dominate production (Halman, Voordijk and Reymen, 2008). In commercial real estate markets, the clients of building professionals are usually real estate development and investment firms. As Beuschel and Rudel (2010) suggest, "when real estate developers make choices about the size, location and layout of buildings, they shape [... ] landscapes for decades to come." Some building professionals seem to consider real estate developers and investors to have the final say in whether a building will be certified with an environmental rating scheme or have an eco-friendly footprint.

In this chapter, perceptions of building professionals will be contrasted with real estate developers' perceptions and decisions. Just as the previous chapters in this dissertation project, the current study was carried out in the North American context and the focus
\end{abstract}


of this chapter is on real estate developers and investors in the United States. The main aim is to further understand whether high level decision-makers in these organizations are in favor of environmental rating certification schemes and in control of the decision to implement them in new and existing building developments. Furthermore, this chapter will consider which social-psychological factors affect developers' intention to integrate two of the best known North American environmental building assessment and rating schemes in construction projects. To understand these issues, the current chapter builds on previous research on real estate development and environmentally relevant behavior and practices.

\subsection{Background}

In the context of research on green buildings and construction practices, it is a surprising fact that given their prominent role in the planning and construction industry, real estate developers and investors are understudied groups. Research studies on real estate development firms are usually generic in scope (e.g. Cohen, 2002; Bruegmann, 2005) and environmental practices of developers and investors have been mainly analyzed in the context of conflicts over ecological concerns (e.g. Rome, 2001). As Beuschel and Rudel (2010) suggest it has become a frequently voiced opinion that "developers are incorrigible from an environmental point of view $[\ldots]$, they only become green when compelled to do so by restrictive statutes and laws". If this reading of real estate developer's behavior were to be true, "voluntary" environmental rating schemes would not be apt to successfully entice real estate developers to include them in their building projects.

In one of the rate studies on green real estate development, Circo (2007) analyzed sustainable construction and green building projects in the US context. He suggests that building codes and other land use regulations have found to be effective, these measures are usually enforced at the local level and federal standards are unlikely to be implemented anytime soon. As a consequence, "voluntary" building standards have been considered as a "unifying" instrument to consolidate green building initiatives at the national level. Due to the lack of standards, voluntary compliance with enforceable standards introduced by private organizations has become the dominant green building strategy in the US (Circo, 2007). Advantages for real estate developers including green certification schemes are said to include offsetting additional development costs by higher rents, lower holding costs and lower risks due to increased demand. Additionally, developers as well as owners and occupiers may obtain tax breaks and benefits to offset initial costs (Fuerst and McAllister, 2011).

However, reviews of the property sector and its trade publications demonstrates a vivid debate on whether business case for environmental rating schemes can be made (Switzer, 2006). Some critics voice concerns that voluntary rating schemes are an elaborate form of "green washing" (e.g. Lang Ho, 2003). This concern seems to be substantiated in reports and 
studies that conclude a lack of private building sector awareness about green construction practices (Boston Task Force report, 2005). Proponents of more stringent government policy on green building and construction, however, argue that the majority of developers will not voluntarily comply with building rating standards that would require them to internalize environmental costs that are still externalities in competitors projects (Circo, 2007).

While economic incentives and legal solutions are widely discussed, real estate developers' perceptions and views on green buildings has not been analyzed extensively. Since legal frameworks, at least at the US federal level, will not be imposed anytime soon and financial incentives are less likely in the current budget-constraint economic climate, other strategies should be investigated by analyzing possible solutions to the green building conundrum and to determine real estate developers' decision-making and behavior.

Many building professionals such as architects, engineers or construction firm owners perceive their clients, i.e. real estate developers and investors as the main driver for the inclusion of environmental rating and assessment schemes in building projects. Hence, in this research, it was decided to analyze how aware respondents in real estate development firms are of environmental rating schemes and to assess the reasons for these standards are included in commercial building projects.

To this end, in addition to questions about firm-relevant actions, social-psychological elements from the Reasoned Action Approach (RAA) discussed in the previous chapters were included in the analysis to achieve theoretical and methodological consistency across the dissertation chapters.

\subsection{Literature}

The results presented in Chapter 4 suggest that the green building industry including that real estate development and investment decisions have a strong behavioral component.

Within certain research streams of academic literature, on the building industry itself and the general public, the impression may persist that real estate development and investment decisions follow a fixed formula that produces uniform assessment outcomes. More recent research, however, has suggested that this perception is inherently flawed.

Normative processes in valuation processes are discussed in more detail by Diaz (1990). In a series of studies, real estate valuers' decisions were found to differ significantly from technical valuation models. In addition, he found that more experienced valuers used different valuation methods than less experienced ones, irrespective of value model accuracy (Diaz, 1990b). Overall, real estate valuers used different numbers and types of data sources, which indicates that valuation as well as real estate investment decisions leave significant 
room for discretion.. Valuers were found to be prone to give the highest importance to information considered last (Gallimore, 1994). Additionally, real estate valuers were found to make judgments on construction project value and seek evidence to support these early judgments, a sign of confirmation bias (Gallimore, 1996). Beyond research on real estate valuers, other studies on behavior in the real estate development sector have mainly focused on lending processes. Loan officers' perception of project loan success in real estate investment firms was linked to the lender's training and professional experience (Hardin, 1997).

More detailed research studies on real estate developers and investors' behavior and attitudes were conducted by Coaicetto $(2000,2001)$ and Taylor et al. (2012). Their studies suggest that understanding private sector real estate developers' perspectives is crucial to improve environmental planning and governance processes. According to Coaicetto (2001), real estate developers' decisions and behavior are influenced by a variety of information needs, motives and objectives that translate in a number of approaches and strategies. While local factors and knowledge may influence strategies and research approaches, these factors are of relative and not of absolute importance (Logan, 1993).

To adapt to developers and investors behavior in the building and construction industry, their decisions and motives need to be further understood (Coaicetto, 2001). The complexity of real estate developers decision processes is described in further detail by Black et al (2000). Cross-disciplinary theoretical models to understand real estate developers decisions outlined in their research include social psychological approaches to advance the understanding of key players' decisions and behaviors. Gibler and Nelson (1998) outlined the value of social psychological models to real estate research, including the predecessors of the Reasoned Action Approach (RAA) such as the Theory of Planned Behavior (TPB).

Fishbein and Ajzen (2011) developed the Reasoned Action Approach to predict, explain and change human behavior. A large amount of research studies have confirmed the model in a large number of studies across numerous fields of application. Behavioral, normative and control beliefs have been found to provide a basis for attitudes towards a specific type of behavior, subjective norms and perceived behavioral control. These factors, in turn, account for a large percentage of the variance in behavioral intentions. Perceived behavioral control and intentions, again, are useful in predicting actual behavior. A more detailed description of the Reasoned Action Approach can be found in Chapter 3 and 4.

\subsection{Method}

To analyze how real estate developers evaluate the LEED scheme, a survey instrument was administered online in July 2011 to real estate developers in the United States. The aim was to collect and analyze data from a cross-sectional sample of real estate developers and 
investors to understand their perceptions of green building assessment schemes. From a member list of over 15, 000 members of in the United States Commercial Real Estate Developers association (NAIOP), a sample of 359 real estate developers was drawn. The sample resulted from excluding non-real estate developers as well as a number of small and local firms which were deemed not representative for the wider real estate community. The resulting sample included mainly publicly traded companies as well as mid-sized firms active in several markets across the United States. After sending an initial email and two follow-up reminders, twenty-nine (29) responses were obtained, representing an $8.1 \%$ response rate. While this result was certainly disappointing, the low response rate may indicate a potential lack of interest by the real estate developer community. This is in itself quite an interesting outcome that will be discussed further later in this chapter.

\section{Measurement}

\section{Reasoned Action Approach (RAA) constructs}

The survey instrument for the RAA items was constructed based on the recommendations given by Ajzen (1991) and the results of the qualitative pilot interview study (Chapter 3). After constructing the questionnaire, the survey was pre-tested with the help of five building professionals from the North East of the US, filling in the questionnaire and giving feed-back on the structure and measures of the survey items. The survey instrument was adjusted accordingly with their feedback. The final instrument included the variables specified by the Reasoned Action Approach (RAA)/ Theory of Planned Behavior (TPB). All questionnaire items were ranked on a 7-point rating scale. Two items were used to measure behavioral intention: "I expect that my next commercial building project will include the certification scheme" and "I intend to integrate the certification scheme in my next commercial building project”: Strongly Agree/Strongly Disagree.

Attitude was measured using four items "Working with the scheme is/would be (Very pleasant/Very unpleasant); "The certification scheme has established clear guidelines for sustainability practices in the building industry"(Strongly Agree/Strongly Disagree); "I think that the __scheme has educated me about sustainable building practices" (Strongly Agree/Strongly Disagree); "I think that the certification scheme has provided building professionals with a common language regarding sustainable construction practices" (Strongly Agree/Strongly Disagree).

Subjective Norms were measured with six items: "Most important people in the building industry think that I should work with the certification scheme"(Strongly Agree/Strongly Disagree); "Most important people in the building industry work with the scheme (Strongly Agree/Strongly Disagree); "Government/City/State officials expect me to work with the scheme (Strongly Agree/Strongly Disagree); "Clients expect me to work with the 
scheme"(Strongly Agree/Strongly Disagree); "Co-workers expect me to work with the scheme"(Strongly Agree/Strongly Disagree); "Other building professionals expect me to work with the scheme"(Strongly Agree/Strongly Disagree).

Lastly, Perceived Behavioral Control (PBC) was measured with five items: "The decision to work with the scheme is entirely up to me" ( Strongly Agree/Strongly Disagree); "It would be easy for me to integrate the certification scheme if I wanted to" (Strongly Agree/Strongly Disagree); "Organizational practices in my firm prevent me from working with the ___ scheme" (Strongly Agree/Strongly Disagree); "Financial constraints prevent me from working with the scheme" (Strongly Agree/Strongly Disagree); "Other building professionals' decisions prevent me from working with the Disagree). The last three items were reverse-coded scheme" ( Strongly Agree/Strongly

\section{Background and Control variables}

Aside from the Reasoned Action Approach (RAA) constructs derived from the theoretical framework, background variables were included in the analysis to account for potential differences in professional and educational background, firm type, seniority in their organization, place of employment (country) and previous experience with sustainability issues in the building sector. All the variables were included in the analysis as binary coded dummy variables. Furthermore, binary variables that measure past experience with LEED or Green Globes schemes were introduced in the regression analyses to account for different levels of building professionals' experience with these type of schemes.

\subsection{Data}

\section{Descriptive Statistics: Sample}

Invitations for participation were sent by email to 359 employees in real estate development firms across the United States. In total, 29 respondents participated in and completed the survey, yielding an overall response rate of $8 \%$. Respondents were predominantly male (22) with fewer female respondents (7) in line with actual gender ratios in the building and construction industry. Of all survey respondents, twenty-two (22) held CEO, executive or senior functions in their organization while seven (7) respondents worked in mid career positions. The majority of respondents, twenty (20) real estate professionals, had more than fifteen (15) years of work experience, while four (4) respondents had 11-15 years of experience and another five (5) respondents had 5-10 years of experience. From an education point of view, fourteen (14) respondents completed a Bachelor's degree while fifteen (15) respondents had completed a Master's degree and above. Among the respondents, twelve (12) had taken sustainability - related classes or training in college while seventeen (17) had not. 


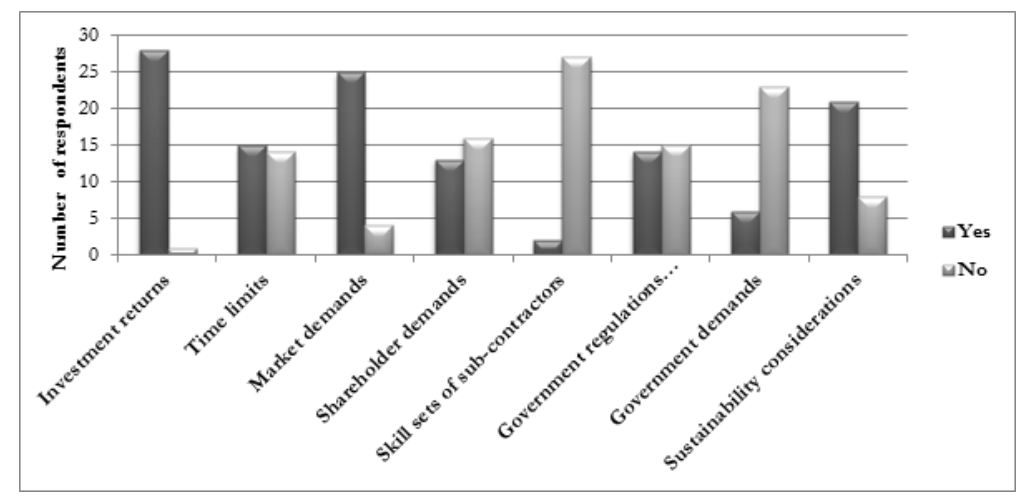

Figure 5.1: Factors influencing Real Estate Developers' investment decisions

Out of the twenty-nine (29) respondents, twenty-seven (27) had previously dealt with the LEED scheme, while only three (3) had worked on a Green Globes project before. Hence, it will be very enlightening to see whether and how building professionals' perception of what the clients (i.e. the real estate developers and investors) want aligns with the respondents working in the real estate development and investment sector. Out of twenty-nine (29) respondents, twenty-four (24) were personally involved in deciding whether a real estate project should be invested in or developed. Additionally, of twenty-nine (29) respondents, twenty-six (26) reported that their company had an overall strategy plan in place with regards to environmental sustainability. Respondent characteristics can be consulted in more detail in Appendix C.

\section{Overview descriptive statistics}

Descriptive statistics were initially used to summarize the relevant factors respondents reported with regards to green construction projects.

Figure 5.1 suggests that investment returns, market demands and general sustainability considerations were frequently part of investment and development decision-making. Government regulations were less of a concern.

Opinion on time considerations (i.e. that green building may take a longer time to be constructed) was divided. For half the respondents time was a factor for investment and development while the other half of the respondents did not consider turnaround time to be of concern. Interestingly, skill set of contractors and sub-contractors (architects, engineers or builders) did not represent a major concern for the respondents. Hence, real 


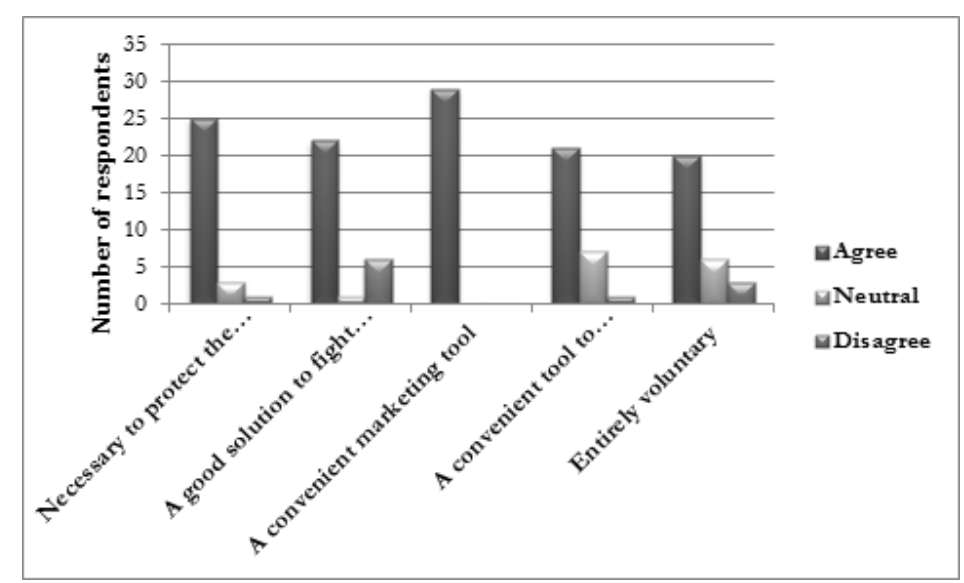

Figure 5.2: Real Estate Developers' evaluation of rating and assessment schemes

estate developers did not deem education and proficiency in green building to be a major impediment to environmentally sustainable building projects.

When specifically asked to voice their opinions on environmental building VEPs, respondents did agree that these schemes were necessary to protect the environment, were a good solution to fight climate change, a convenient tool to transform the building industry and mainly entirely voluntary for building developers. The results suggests that even though government demands are considered as a factor in the investment decision process, real estate developers still believe that the decision to engage in environmental certification schemes is up to them, at least to some extent.

The most interesting result was that all respondents agreed that environmental rating schemes are a convenient marketing tool to promote their projects. Whether the marketing aspect is a positive side effect or the main reason that real estate developers and investors choose to construct their buildings and certify them cannot be inferred from this result. However, this result does raise some concern with regards to the "greenwashing" argument purported by environmental building rating scheme critics.

\section{Descriptive analysis of responses}

Due to the small number of observations, descriptive analyses of individual survey items of interest were carried out. Before creating the summative scales for the RAA constructs, norms, attitudes and perceived behavioral control (PBC), several single question items of 


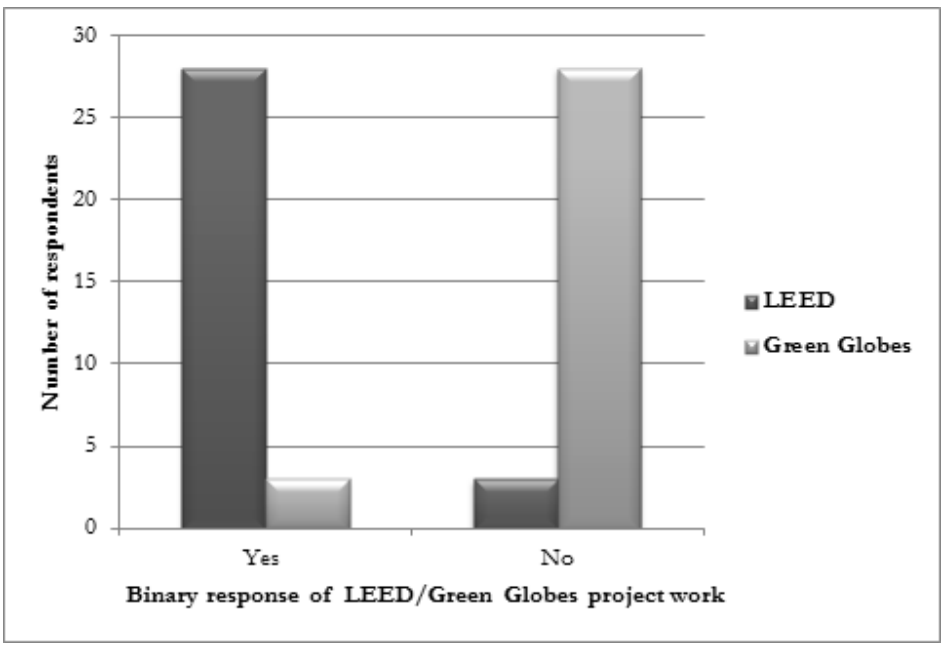

Figure 5.3: Real Estate Developers' experience with the LEED and Green Globes schemes

interest were analyzed separately to understand responses to questions in a more nuanced fashion.

As discussed above, Figure 5.3 suggests that most respondents in the sample had been working on a LEED project previously but not on a Green Globes project.

As Figure 5.4 demonstrates, most respondents indicated that they expected and intended to integrate the LEED certification schemes in one or more of their next projects. As for the Green Globes scheme, a majority of respondents were unsure or negative that their next real estate investment projects would integrate the Green Globes scheme.

Figure 5.5 represents real estate developers' experience of working with a specific scheme in the past or in absence of working on a building project that included either the LEED or Green Globes scheme, how they imagine working on either scheme would be. As most respondents did have experience with the LEED scheme but not Green Globes, the latter scheme was inquired about speculatively. The results indicate that most respondents thought their experience to be satisfactory. However, some respondents were neutral in their evaluation or even indicated that it was somewhat unpleasant having to integrate LEED in their building projects. As for the Green Globes scheme, most respondents felt neutral about it while two (2) respondents indicated the scheme would probably be a pleasant or very pleasant experience. However, as most respondents did not have professional experience working with the Green Globes scheme, their response does not allow for direct 


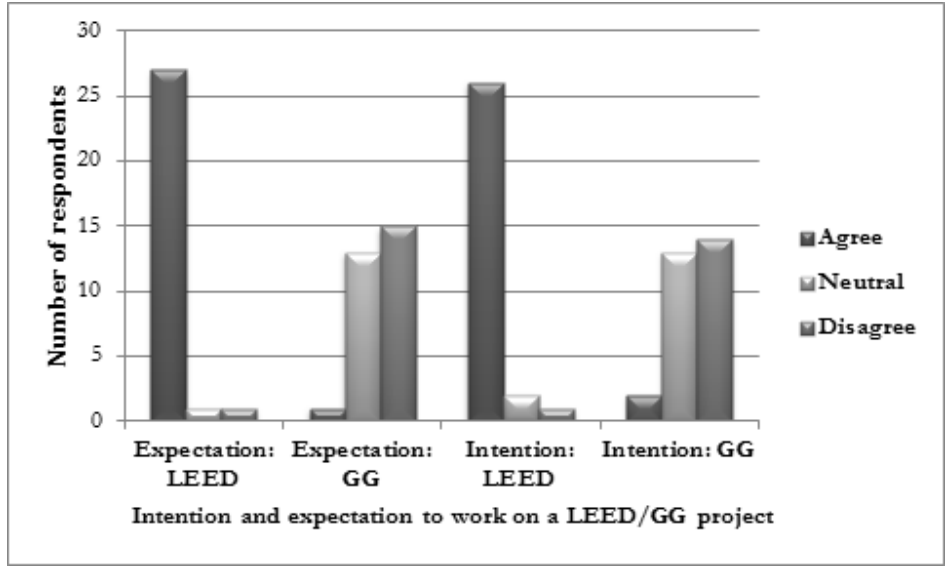

Figure 5.4: Real Estate Developers' intention and expectation to have their projects LEED and Green Globes certified

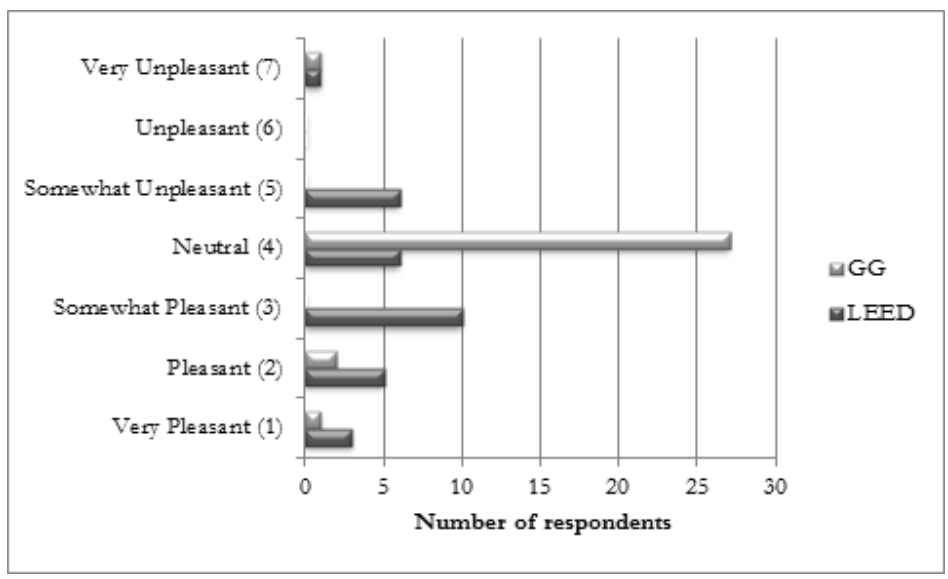

Figure 5.5: Real Estate Developers' evaluation of LEED and GG characteristics 


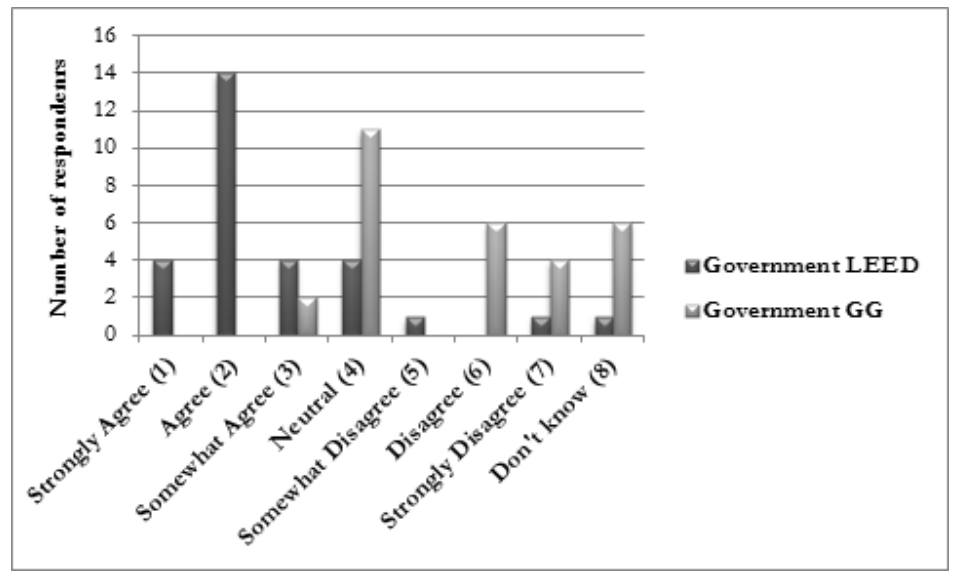

Figure 5.6: Real Estate Developers' assessment of government expectations with regards to LEED and Green Globes.

comparison with the respondents' assessment of the LEED scheme.

When it comes to government expectations, Figure 5.6 clearly shows that real estate developers perceived that governments (local, state and federal) expected them to include LEED certification in their building projects but not the Green Globes scheme. However, with the present data it is not possible to determine whether LEED inclusion is a result of perceived government expectation or vice versa.

When probed whether the decision to integrate the LEED and Green Globes scheme in their projects was entirely up to their firm, more respondents agreed that this was the case for LEED than for Green Globes.

\section{Correlation analysis}

In addition to the descriptive analysis of individual survey items, pairwise correlation analyses of the RAA constructs was performed for both the decisions to include LEED and Green Globes in real estate managers decision processes.

For the Green Globes scheme uptake, only attitudes were positively correlated with intentions, while norms and $\mathrm{PBC}$ were not found to be statistically significant. As the correlation between intentions and attitudes were positive, the data suggests that the more positive the attitude towards the Green Globes scheme, the higher the intention to integrate the Green Globes scheme in a building or construction project and vice versa. 


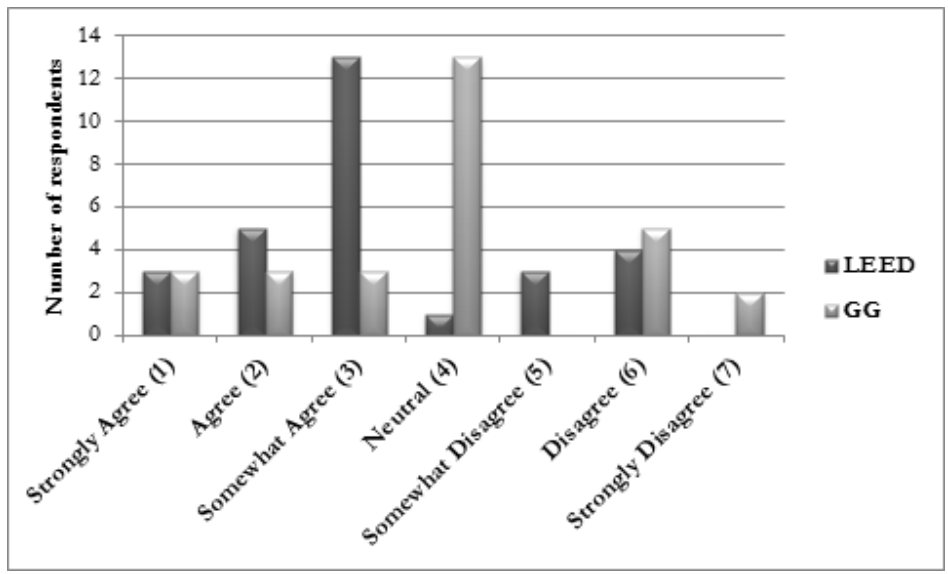

Figure 5.7: Real Estate Developers' assessment of LEED and Green Globes necessity

As for the LEED scheme, intention to include the LEED scheme in investment and development decisions was only significantly correlated with norms. As the correlation between these two constructs is positive, the stronger the perception that it is expected to integrate LEED in a building project, the stronger the intention to actually include the scheme and vice versa. In addition to the correlation between intention and norms, positive significant correlation was also found between norms and attitudes. Hence, while attitudes do not seem to be directly correlated with intentions, attitudes may indirectly, via norms, influence intentions in this case. However, due to data limitations, this hypothesis could not be tested in this chapter.

As the correlation results do not, however, indicate a direction, i.e. whether attitudes influence intention, it was decided to conduct linear regressions for both the LEED and the Green Globes scheme adoption intention as dependent variables.

\section{Regression results}

Despite the small sample size and potential reliability issues, regression analyses were tentatively performed to confirm whether the trends observed in the correlation analyses persisted. As expected, despite an overall rather disappointing model fit, the results overall confirmed the conclusions drawn from the correlation analyses for both LEED and Green Globes schemes.

As indicated in Table 5.3, from the three RAA constructs (attitudes, norms and PBC) only norms influenced the intention to integrate the LEED scheme in building projects at the 


\begin{tabular}{llllllll}
\hline & Mean & SD & 1 & 2 & 3 & 4 & 5 \\
\hline 1. Intention & 2.67 & 0.21 & 1 & & & & \\
2. PBC & 3.11 & 0.15 & 0.10 & 1 & & & \\
3. Norms & 3.00 & 0.17 & 0.35 & 0.09 & 1 & & \\
4. Attitude & 2.54 & 0.08 & $0.43^{*}$ & 0.18 & 0.26 & 1 & \\
5. Past GG project & 1.10 & 0.06 & -0.20 & 0.00 & -0.32 & -0.29 & 1 \\
\hline
\end{tabular}

Table 5.1: Pairwise correlation Reasoned Action Approach (RAA) constructs (Green Globes)

\begin{tabular}{llllllll}
\hline & Mean & SD & 1 & 2 & 3 & 4 & 5 \\
\hline 1. Intention & 3.07 & 0.24 & 1 & & & & \\
2. PBC & 3.06 & 0.17 & 0.19 & 1 & & & \\
3. Norms & 2.48 & 0.21 & $0.41^{*}$ & 0.14 & 1 & & \\
4. Attitude & 2.32 & 0.17 & 0.21 & 0.05 & $0.48^{*}$ & 1 & \\
5. Past LEED & 1.93 & 0.05 & -0.03 & 0.01 & $-0.44^{*}$ & $-0.43^{*}$ & 1 \\
project & & & & & & & \\
\hline
\end{tabular}

Table 5.2: Pairwise correlation Reasoned Action Approach (RAA) constructs (LEED)

\begin{tabular}{llllllc}
\hline Intention & Coef. & Std. Err. & $\mathbf{t}$ & $\mathbf{P}>|\mathbf{t}|$ & {$[\mathbf{9 5 \%}$ Conf. Interval $]$} \\
\hline PBC & 0.07 & 0.10 & 0.67 & 0.5 & -0.15 & 0.29 \\
Norms & $0.16^{* *}$ & 0.08 & 2.01 & 0.05 & 0.00 & 0.33 \\
Attitude & 0.05 & 0.15 & 0.37 & 0.71 & -0.26 & 0.38 \\
Past LEED experience & 0.94 & 2.15 & 0.90 & 0.37 & -2.51 & 6.39
\end{tabular}

Note: After the regression analysis, Variance Inflation Factors (VIF) were calculated for both explanatory variables individually and the regression equation overall. All VIFs were under 4, with an equation mean VIF of 1.22. The VIFs for RAA constructs were: norms (1.33), attitude (1.30), PBC (1.02). The VIF results suggest that multicollinearity is not an issue in this analysis, despite the extremely small sample size $(n=29)$

Table 5.3: Regression results- LEED 


\begin{tabular}{llllllc}
\hline Intention GG & Coef. & Std. Err. & $\mathbf{t}$ & $\mathbf{P}>|\mathbf{t}|$ & {$[95 \%$ Conf. Interval] } \\
\hline Attitude & $0.64^{* *}$ & 0.27 & 2.32 & 0.03 & 0.07 & 1.22 \\
Norms & 0.09 & 0.07 & 1.30 & 0.20 & -0.05 & 0.24 \\
PBC & 0.01 & 0.09 & 0.18 & 0.86 & -0.18 & 0.22 \\
Past GG experience & 1.79 & 1.49 & 1.20 & 0.24 & -1.30 & 4.89 \\
\hline
\end{tabular}

Note: After the regression analysis, Variance Inflation Factors (VIF) were calculated for both explanatory variables individually and the regression equation overall. All VIFs were under 4, with an equation mean VIF of 1.08. The VIFs for RAA constructs were: norms (1.08), attitude (1.11), PBC (1.04). Hence, the VIF results suggest that multicollinearity is not an issue in this analysis, despite the extremely small sample size $(n=29)$

Table 5.4: Regression results- Green Globes

$10 \%$ confidence level.

The regression results for the Green Globes scheme were also in line with the correlation outcomes. From the RAA constructs, only attitudes were found to be significant to predict intentions at the $5 \%$ confidence level.

The results from the correlation and regression analyses considered together seem to indicate that the integration of the LEED scheme in building assessment and investment decisions, at least for the respondent sample, is strongly based on perception of other key players' expectations.

As a contrast, no normative dimension was found for the Green Globes scheme. For the integration of this environmental assessment scheme, the most important predictor for intentions seems to be attitudes, i.e. whether decision-makers are positive about the scheme and the results for their projects.

\subsection{Discussion}

In this chapter, several contributions to advance the understanding of behavioral intentions of real estate developers and investors were made.

The descriptive analysis suggests that investment returns, market demands and sustainability considerations drive real estate development and investment decisions. This result was to be expected considering the previous literature and assumptions of real estate assessment as a straight forward and standardized process.

Environmental rating and assessment schemes overall were considered to be necessary to protect environment, a good solution to climate change, and to transform building industry. However, some possible evidence for "green-washing" was found as well, given that all 
respondents deemed these certification schemes to be convenient marketing tools for their building projects. In this context, $60 \%$ of the respondents considered environmental rating schemes to be entirely voluntary. For those respondents who considered the scheme to be involuntary, there were no indications made which other stakeholders beyond government pressure influenced their decisions. While it can be assumed that shareholders may also have a say in these matters, no evidence was found to substantiate this assumption.

To get a more detailed picture of some of the issues touched upon previously, several survey items were analyzed separately. The questions distinguished between two prominent environmental building rating and assessment schemes: LEED and Green Globes. As most respondents (with the exception of three participants) had experience with the LEED scheme but not the Green Globes scheme, the responses trended towards the "neutral" position for Green Globes. This trend was also visible in the intentions to work with the LEED scheme in the future. Generally, most respondents were ready to include the LEED scheme in their next building schemes again. When the respondents were probed whether they would consider the Green Globes scheme in the future, most respondents remained neutral or negative.

While it could be simple market demand determining LEED scheme certification in new building schemes, the fact that the respondents at the same time confirmed the voluntary character offers some interesting research opportunities in the future. In addition, the question of habituation arises: Real estate developers choose a certification scheme and stick with it. However, the habituation hypothesis as a direct determinant of behavior irrespective of intentions has been rejected in the literature, most notably by Ajzen (2002) in the context of the Reasoned Action Approach (RAA). Habituation as such has not been empirically confirmed in the context of unstable, complex decision and behavior contexts (Ajzen, 2002).

With mere habituation being an unlikely explanation, the RAA constructs were analyzed in more detail. In both pairwise correlation and linear regression analyses, attitudes were found to be significantly related to intentions for Green Globes while intentions to integrate the LEED scheme were positively correlated with intentions.

These results indicate that the intention to integrate an environmental assessment scheme in green building projects is not a straight forward process: attitudes were the determining factor for the Green Globes scheme while intentions for the LEED scheme were correlated with subjective norms.

Hence, intentions to integrate environmental rating and assessment schemes (potentially as a function of perceived social acceptability) are determined by different factors for each scheme. While this result is not entirely reliable due to data limitations, it suggests that real estate developers' perception of schemes influences their decision to work integrate these schemes in their building projects. 
When considering building professionals' perception that real estate developers and investors are in control and decide relatively freely whether a project will be certified, the results from this study neither confirm nor completely refute this hypothesis. While a substantial number of professionals in real estate development consider environmental rating schemes to be voluntary, the more detailed analysis suggests that this assessment is environmental scheme specific. Despite LEED considered to be mainly voluntary, the less known Green Globes scheme triggered mainly neutral responses.

Hence, even though subjective norms are positively correlated with the intention to adopt the LEED scheme, building professionals themselves suggest that they decide relatively freely with regards to the integration of this scheme. On the other side, while attitudes seem to determine the Green Globes scheme, real estate developers are not sure at this stage how voluntary the working with the scheme would be.

\subsection{Limitations}

As indicated above, several factors limit the conclusions presented in this chapter. First, the low response rate is very likely to have introduced a bias towards real estate developers and investments interested in sustainability oriented topics. Hence, the small sample size and response bias limits the validity of the statistical analyses performed. Specifically the regression results can be assumed to be relatively unreliable due to the small number of respondents.

As this study deals with sustainability and environmentally significant behaviors, social desirability bias (i.e. the tendency to respond in a way to present the participant in a favorable light) is a significant risk. However, self-administered web-based surveys, overall, are less susceptible to this specific bias than interviewer administered surveys (Kreuter et al., 2008).

In addition, due to the higher prevalence of the LEED scheme in the US, comparing it to the Green Globes scheme directly may not be the most valid choice. Previous research has suggested that market dominance and familiarity can introduce bias to favor the existing and more known assessment scheme.

\subsection{Conclusion}

As other building professionals previously indicated (Chapter 4) that real estate developers and investors have the final say in including environmental rating and assessment schemes in building construction projects, the aim of this chapter was to investigate the perceptions and attitudes of said developers towards two prominent certification schemes in the US market, LEED and Green Globes. 
Previous research on real estate developers focused on valuation methods and biases but this chapter suggests that social-psychological variables can contribute significantly to a better understanding of real estate developers' assessment of environmental building assessment and rating schemes. The results suggest that social psychological models, such as the Reasoned Action Approach (RAA) can enhance understanding as to why real estate developers and investors include an environmental rating and assessment scheme in their building projects.

In this chapter, clients' perspective (i.e. real estate developers and investors) on voluntary environmental building rating schemes was the main focus of analysis. As subjective norms and perceived behavioral control were found to be strong predictors for one of the main rating and assessment schemes, LEED, in Chapter 4 investors' perspective on these schemes was considered of importance. The results demonstrate that real estate developers consider LEED to be an important marketing tool; the environmental aspect was deemed to be important but less of concern. Interestingly not all investors thought rating schemes to be entirely voluntary. This result could indicate that perceived pressure from either government or shareholders could influence the practices of some real estate development and investment firms to consider voluntary building certification.

Additionally, an additional analysis based on the Reasoned Action Approach (RAA) was undertaken. As in previous chapters, intention to include the Green Globes scheme was predicted by attitudes while LEED was mainly predicted by norms. In either case, perceived behavioral control was not found to be statistically significant for real estate developers and investors' intention to include voluntary environmental building assessment programs.

Real estate developers and investors, as other key players in the building industry, via their decisions influence urban and rural development, and consequently influence urban systems' ecological footprint. If their decision-making processes and behavior can be better understood, policy instruments and planning methods can be adapted to influence decisionmakers to integrate sustainability issues and environmental matters more consistently in their projects. 


\section{References}

Beuschel, V., \& Rudel, T. K. (2009). Can real-estate developers be "green"?: Sprawl, environmental rhetoric, and land use planning in a new jersey community. Society and Natural Resources, 23(2), 97-110.

Black, R. T., Brown, G. M., Diaz, J., Gibler, K. M., \& Grissom, T. V. (2000). Behavioral research in real estate: a search for the boundaries. Journal of Real Estate Practice and Education, 6(1), 85-112.

Bruegmann, R. (2006). Sprawl: A compact history. University of Chicago press.

Circo, C. J. (2008). Using mandates and incentives to promote sustainable construction and green building projects in the private sector: a call for more state land use policy initiatives. Penn State Law Review, 112, 731-776.

Cohen, L. (2004). A consumers' republic: The politics of mass consumption in postwar america. Random House LLC.

Coiacetto, E. (2001). Diversity in real estate developer behaviour: A case for research. Urban Policy and Research, 19(1), 43-59.

Coiacetto, E. (2006). Real estate development industry structure: Consequences for urban planning and development. Planning, Practice \& Research, 21(4), 423-441.

Coiacetto, E. J. (2000). Places shape place shapers? real estate developers' outlooks concerning community, planning and development differ between places. Planning Practice and Research, 15(4), 353-374.

Diaz, J. (1990). How appraisers do their work: a test of the appraisal process and the development of a descriptive model. Journal of Real Estate Research, 5(1), 1-15.

Diaz III, J. (1990). The process of selecting comparable sales. The Appraisal Journal, 58(4), 533-540.

Force, B. G. B. T. (2004). Green building task force report executive summary.4-7 (Tech. Rep.). Author. (available at http://www.bostongreenbuilding.org/)

Fuerst, F., \& McAllister, P. (2011). Green noise or green value? measuring the effects of environmental certification on office values. Real Estate Economics, 39(1), 45-69.

Gallimore, P. (1994). Aspects of information processing in valuation judgement and choice. Journal of Property Research, 11(2), 97-110.

Gallimore, P., \& Wolverton, M. (1997). Price-knowledge-induced bias: a cross-cultural comparison. Journal of Property Valuation and Investment, 15(3), 261-273.

Gibler, K. M., \& Nelson, S. L. (1998). Consumer behavior applications to real estate. In American real estate society meeting.

Halman, J. I., Voordijk, J. T., \& Reymen, I. M. (2008). Modular approaches in dutch house building: an exploratory survey. Housing Studies, 23(5), 781-799.

Hardin III, W. G. (1997). Heuristic use, credit constraints and real estate lending. Journal of Property Valuation and Investment, 15(3), 245-255. 
King, N. J., \& King, B. J. (2004). Creating incentives for sustainable buildings: a comparative law approach featuring the united states and the european union. Virginia Environmental Law Journal, 23, 397.

Kreuter, F., Presser, S., \& Tourangeau, R. (2008). Social desirability bias in cati, ivr, and web surveys the effects of mode and question sensitivity. Public Opinion Quarterly, $72(5), 847-865$.

Lang Ho, C. . (2003). Building: Might not be all they're made out to be. Architecture, 31.

Logan, J. (1993). Cycles and trends in the globalization of real estate. Prentice-Hall.

Morton, T. A., Bretschneider, P., Coley, D., \& Kershaw, T. (2011). Building a better future: An exploration of beliefs about climate change and perceived need for adaptation within the building industry. Building and Environment, 46(5), 1151-1158.

Rome, A. (2001). The bulldozer in the countryside. Cambridge University Press.

Switzer, T. (2006). Opportunistic or altruistic? savvy developers of green bbuilding reduce energy costs. National Real Estate Investor, 105-106.

Taylor, B. M., Harman, B. P., Heyenga, S., \& McAllister, R. R. (2012). Property developers and urban adaptation: conceptual and empirical perspectives on governance. Urban Policy and Research, 30(1), 5-24. 



\title{
Environmental Building Rating and Assessment Schemes and Inter-firm Cooperation: an application of Social Interdependence Theory in the US, the UK and Canada
}

\begin{abstract}
"In this world there are things that you can only do alone, and things you can only do with somebody elese. It is important to combine the two in just the right amount" (Haruki Murakami, After Dark)
\end{abstract}

\subsection{Introduction}

$\mathrm{V}$

oluntary green building rating and assessment programs have become prominent instruments to reduce the environmental impact of buildings, promote energy efficiency and decrease water usage. Green building councils (GBCs) and similar organizations have emerged in many countries to develop or adapt Voluntary Environmental Programs (VEPs) in the construction and building domain to local conditions. Certification is usually awarded to building projects if certain sustainability criteria are fulfilled both in countries with existing mandatory building codes and countries where less stringent regulations and codes are in place. Though mainly developed by non-profit organizations such as Green Building Councils (GBCs), governmental units have endorsed and integrated voluntary rating schemes in their urban planning and environmental policy mix to enhance eco-innovations in certain industrial sectors developing appliances and materials for sustainable building construction. The establishment of GBCs and the development and inclusion of VEPs has been also increasingly promoted in developing countries as market-based and informational mechanisms for green growth. Since GBCs 
aim to transform the construction and building industries, it may be that participation in these schemes could enhance cooperation in these industries, which has been traditionally a problem in this sector as defined by the United Nations: "Sustainable development in the building and construction sector remains hampered by limited coordination and cooperation between different stakeholders throughout a building's life span" (UNEP/ SBCI, 2011). Even before the development of green building practices project stakeholder cooperation has been an issue, due to encrusted professional practices. Innovative practices could potentially shake-up traditional ways of production and construction.

While GBCs as an innovative form of building governance can potentially contribute to increased sustainability awareness in the building profession and improve cooperation between building professionals, this assumption has not been tested so far. Since the individuals involved in GBCs mainly hail from the building industry, the attitudes and perceptions by building professionals need to be strongly examined to test whether adoption of green building VEPs does indeed lead to stakeholder cooperation.

Hence, this chapter aims to determine (1) which socio-psychological factors influence inter-firm cooperation and (2) whether membership in GBCs and GBC-like organizations (i.e.previous experience working on green building VEPs) has an impact on cooperative behavior.

\subsection{Green Building Councils}

Even though a numerous organizations have developed building VEPS globally, the most dynamic development has occurred within the Green Building Council (GBC) movement. Green Building Councils (GBCs) are third party and mainly not-for-profit organizations consisting of industry and public officials which state as their goal to provide "a prosperous and sustainable future for our nation through cost-efficient and energy-saving green buildings" (USGBC, $2015^{1}$ ), "to radically improve the sustainability of the built environment"

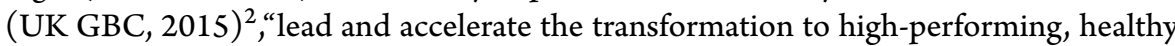
green buildings, homes and communities" (CA GBC, 2015) ${ }^{3}$ and "sustainable property industry and drive the adoption of green building practices through market-based solutions" (GBCA, 2011) ${ }^{4}$.

Many of the national GBCs are organized in an umbrella organization, the World Green Building Council (WGBC). The World Green Building Council (WGBC) aims "to be the global voice for Green Building Councils and to facilitate the global transformation

\footnotetext{
${ }^{1} \mathrm{http}: / /$ www.usgbc.org/organizations/us-green-building-council (Accessed 9 June 2015)

${ }^{2}$ http://www.ukgbc.org/about-us/why-we-do-it (Accessed 9 June 2015)

${ }^{3} \mathrm{http}: / /$ www.cagbctoronto.org/cagbc-toronto/about-us (Accessed 9 June 2015)

${ }^{4} \mathrm{http}: / /$ www.gbca.org.au (Accessed 9 June 2015)
} 
of the building industry towards sustainability" (WGBC, 2015) 5 . There are currently 20 established, 9 emerging, 26 prospective and 27 associated GBCs with different membership statuses worldwide.

To ascertain its importance, the WGBC also forged partnerships with international organizations such as UNEP SBCI, Sustainable Buildings Alliance (SBA) and the International Union of Architects (IUA). The WGBC, however, has been set up relatively recently and many major VEPs were developed outside the GBC realm. In some countries, GBCs have been in "competition" with other national groups developing green building schemes, as it is the case in the United Kingdom with the BREEAM scheme developed by BRE Assessment, another building industry-related organization. Similar situations occurred in Japan and Canada where later established GBCs either endorse the existing scheme, choose to develop a new program or import a VEP from other countries.

\section{Voluntary Rating and Assessment Schemes and the Construction Industry}

Most schemes follow the same processes and principles:From a list with certain criteria, a number of them need to be integrated in a building projects and are credited with points, after an audit in some cases. If a minimum number of points is reached, certification for a building can be obtained. This system is very similar for the most influential schemes around the world, LEED (US), BREEAM (UK), Green Star (Australia), BOMA BEst (Canada), CASBEE (Japan), HK-BEAM (Hong-Kong) and DNGB (Germany). To achieve these credits for certification, the relevant aspects need to be implemented along the building life-cycle from design to construction completion.

Since the building industry is one of the most fragmented sectors with members from various professions (Real Estate Developers, Architects, Engineers, Commissioners, Constructors and procurement officers etc.) working on a project basis, many stakeholders are needed to coordinate and collaborate to achieve satisfactory (and sustainable) outcomes. Cooperation can, however, be a sensitive issues, due to the nature of building professions and assumed expertise. Since sustainable construction in many cases means to break with established routines, cooperation and collaboration between the different interest and stakeholder groups becomes even more important.

Cooperation in the building industry, as in other project-based industries, depends on multipartner collaboration, willingness to communicate and knowledge integration. In a review of literature on multi-partner collaboration three main results of successful cooperation in the construction industry were identified by the authors: (1) project success, (2) learning and innovation and (3) commitment to future collaborations (Dietrich et al., 2010).

\footnotetext{
${ }^{5}$ http://gpc.brandtologie.com/index.php/homePage/infoPage/2/3/304 (Accessed 9 June 2015)
} 


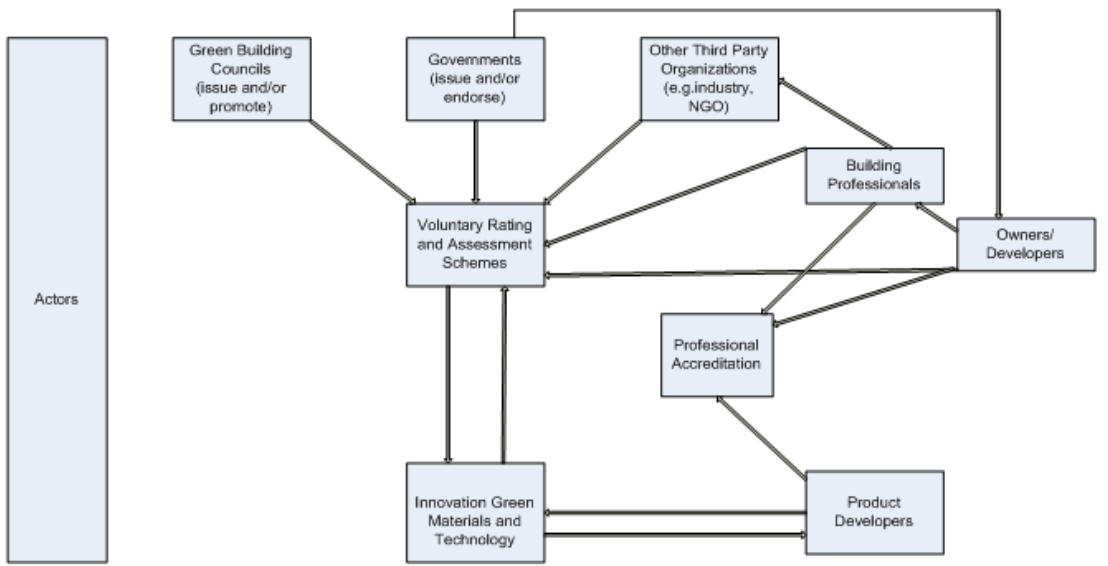

Figure 6.1: A brief overview of actors involved in the construction process (Source: Author)

Given the complexities of the building industry (depicted in Fig.6.1), and building professionals' cooperation mechanisms, GBCs and GBC-like organizations (and by extension their certification schemes) face a difficult task to transform the industry. Research on the linkage between institutional arrangements, different types of governance modes and subsequent behavior by the building and construction professionals is scarce (with the exception being a study by Feldman and Perez (2009)). Due to this lack of knowledge, only little is known about building professionals' perceptions of green building VEPs and whether they may improve cooperation.

\subsection{Pro-environmental behavior in building and construction literature}

Literature on energy efficient building is divided in disciplinary research traditions including economics, psychology, management and sociology. While the major focus has been on domestic energy consumption, conservation and energy efficiency, studies on the design and construction phase have been neglected to a large extent. In addition, many households only rent premises and are not able to alter significantly existing energy consumption patterns. Social and cognitive psychology have identified a multitude of potential variables that influence pro-environmental and energy efficient behavior in cases where volitional 


\begin{tabular}{ll}
\hline External factors & Internal factors \\
\hline $\begin{array}{l}\text { - Institutional factors (e.g. Clark } \\
\text { et al., 2003) }\end{array}$ & - Motivations (e.g. Tarbernero and \\
- Economic factors (e.g. Clark et & - Intentandez, 2010) \\
$\begin{array}{ll}\text { al., 2003) } \\
\text { - Social and Cultural factors (e.g. }\end{array}$ & - Knowledge (e.g. Tilikidou, 2006) \\
Laroche, 1996) & Hernandez, 2010) \\
- Demographic factors (e.g. Kahn. & - Awareness (e.g. Gough, 2002) \\
2002) & - Attitudes (e.g. Stewart, 2001) \\
& - Emotions (e.g. Duran et al., 2007) \\
& - Values (e.g. Nordlund and Garvill, 2002) \\
& - Habit (e.g. Dahlstrand, 1997) \\
& - Norms (Stem et al., 1999) \\
& - Risk perception (Fischhoff et al., 1997) \\
& \\
\hline
\end{tabular}

Table 6.1: Overview of variables influencing pro-environmental behavior (Source: Author's review)

control is possible and have focused on environmental values, knowledge, information processing, attitudes, norms, control perceptions, habits (Table 6.1):

In addition to social and psychological factors, demographic, economic, institutional, political and cultural aspects have been found to influence energy-efficient behavior and decision-making (see Figure 3 ). The link between pro-environmental attitudes and energy efficient behavior has been subject to much discussion (e.g. Cook and Berenberg, 1981; Ritchie et al., 1981; Axelrod and Lehman, 1993) and it is suggested that these are influenced by "external" structural variables (i.e. such as country or professional characteristics). However, less is known about the determinants of cooperative behavior in the building industry for VEP implementation. With VEPs being new to many construction and industry professionals, the issue of cooperative learning needs to be fully considered. A theoretical framework for analyzing cooperative learning is Social Interdependence Theory (SIT) (Johnson and Johnson, 1989).

\subsection{Theoretical framework: Social Interdependence Theory}

The theoretical framework in this chapter adapts Social Interdependence Theory (SIT) (Deutsch, 1949; Johnson and Johnson, 1989) to the issue of cooperation in the building and construction industry within the context of green building VEPs in the United States, United Kingdom and Canada. 
Just as research on pro-environmental behavior, literature on cooperation and cooperative learning is diverse and of interest in various disciplines such as political science, economics, anthropology, sociology and psychology, organization studies and management science. As a consequence, many definitions of what exactly cooperation entails exists in research investigating cooperative processes. Most definitions, however, emphasize the processes by which "individuals, groups and organizations interact and form psychological relationships for mutual gain or benefit" (Smith et al., 1995). While several forms of cooperation can co-exist within organizations and across professional groups, the most basic distinction is usually made between informal and formal cooperation. While formal cooperative arrangements are usually determined by some form of contractual obligation, informal cooperation is determined mainly by behavioral processes (Smith et al., 1995).

Despite this distinction, formal cooperation arrangements can turn into more informal arrangements over time and vice versa (Ring and Van de Ven, 1994). In the building and construction industry contractual arrangements often determine the scope for cooperation but informal cooperation is said to be more scarce. SIT can contribute to understand why this may be the case.

Social Interdependence Theory, based on Lewin's analysis of group interdependence, suggests that group members are interdependent through goals. Deutsch $(1949,1962)$ extended Lewin's work by distinguishing positive and negative social interdependence. Hence, participants' goals determine their interaction which in turn determines cooperative outcomes. While positive interdependence assumes that individuals perceive their goals to be positively correlated with other individuals' goals, negative interdependence assumes a perceived negative correlation between these goals. When individuals perceive that their goals are unrelated to others' objectives, no interdependence is assumed (Johnson and Johnson, 1989; Johnson, 2003).

An exhaustive review of research on organizational and inter-organizational processes is beyond the scope of this chapter. Some of the research reviews offering greater detail include Hillebrand and Biemans (2003) and Smith et al. (1995) for cooperation in an organizational context.

Social Interdependence Theory is very well suited for analyzing aspects of intrapersonal, interpersonal, intragroup, and intergroup processes (Deutsch, 2006). In the realm of organizational research Tjosvold $(1984,1986,1988)$ applied social interdependence theory to the measurement of cooperative dimensions within organizational and inter-organizational contexts to analyze patterns of cooperative behaviors. Some of the cooperative dimensions brought forward in this analysis include (1) information, ideas and other resources exchange, (2) assistance giving, (3) constructive problem/conflict discussion, and (4) mutual support and encouragement (Tjosvold, 1988). These cooperative dimensions were 
further developed into scales and operationalized for survey research in managerial and organizational contexts by Thompson and Phua (2005).

Organizational behavior literature reinforces the link between different cooperation forms. In their review of the literature, Hillebrand and Biemans (2003) examine the link between internal and external organizational cooperation. The authors suggest that despite being treated as separate concepts, internal and external cooperation in the organizational context are intrinsically linked. Their article identifies five perspectives on inter-and intraorganizational cooperation: (1) involvement of external and internal parties, (2) communication patterns (3) organizational learning (4) organizational norms and (5) internal cooperation as a coordination mechanism. First, the result of their analysis suggests that effective external cooperation can only occur if effective internal cooperation is guaranteed (Langerak, 1997). Second, boundary persons between the organizations were found to be a success factor to facilitate cooperation between organizations (e.g. Katz and Tushman, 1979). Third, organizational learning theory (Huber, 1991) postulates that internal cooperation will start a continuous learning cycle interpreting outcomes of external cooperation while preparing for new external cooperation. Fourth, organizational norms may act as a determinant of external cooperation as individual cooperation is shaped by institutionalized social guidelines (e.g. Campbell, 1994; 1998; Lusch and Brown, 1996). Fifth, as a coordination mechanism, cooperation needs be coordinated internally to be able to prosper externally (Biemans, 1991). In all five research perspectives, the need for internal cooperation as a guarantor of external cooperation is highlighted. Hence, intra-firm cooperation will be thoroughly examined as a potential predictor of inter-firm cooperation in building sector VEP adoption. While the organizational behavior literature is silent on the issue of inter-professional and intra-professional cooperation, reality in the construction and building industry as well as evidence on professional group importance (see Chapter 7) make the assumption reasonable that these two constructs should also be included as potential determinants for inter-firm cooperation.

In this chapter, the measures suggested by Tjosvold (1988) and their operationalization by Thompson and Phua (2005) will be used to determine (1) whether past experience with working on a voluntary environmental building rating project affects inter-firm cooperation in (sustainable) building projects among building stakeholders across four dimensions (inter-professional, intra-professional, inter-firm and intra-firm), (2) to investigate the effect of self-perceptions of building professionals towards energy efficiency and sustainability on inter-firm cooperation among building professionals and (3) to determine the effect of other forms of cooperation within the building and construction industry on inter-firm cooperation.

The perceptions building professionals have of other project stakeholders were measured in a questionnaire survey. Even though some studies on collaborations in the building sector were carried out in the past (Phua, 2004; Thompson and Phua, 2005), measuring 


\begin{tabular}{ll}
\hline Variables & Definition \\
\hline Firm-level & Country (multinominal) \\
& Firm Type (architecture, engineering or construction) \\
\hline Demographics & Age (in age group) \\
& Sex (male, female) \\
& Profession (architect, engineer, construction professional) \\
& Education (Apprenticeship, Bachelor, Master, PhD) \\
& Seniority (job) (in years) \\
\hline Cooperation & Intra-professional cooperation (7 point Likert scale) \\
& Intra-firm cooperation (7 point Likert scale) \\
& Inter-professional cooperation (7 point Likert scale) \\
\hline Perception of & Self-Perception (7 point Likert scale) \\
Sustainability & \\
\hline
\end{tabular}

Table 6.2: Determinants of Inter-firm and Inter-professional cooperation

stakeholder perceptions are crucial since they will determine behavior and decisions to design buildings in a more environmentally friendly way. Gorse and Emmitt (2009) emphasized the importance of cooperation through informal interactions in construction progress meetings and their impact on behaviors. The authors suggested that adversarial behavior in construction processes, including with regards to energy and environmentally determined issues may be due to a lack of socio-emotional interactions to engage in and build effective relationships.

In this line of reasoning, Phua (2004) suggested that co-operative behavior in construction project teams is a function of socio-psychological factors influencing individual behavior. In addition, Thompson and Phua (2005) also proposed that under certain circumstances cultural dimensions can influence cooperation between building project team members. This aspect has been supported by the literature on cultural dimensions of decision-making and behavior (Fiske et al., 1997).

Barriers to green project cooperation in the building industry stem from a variety of sources and include institutions, markets, organizational as well as behavioral barriers (Weber, 1997). Policy measures implemented to reduce legal and economic barriers were reviewed by Elliott (2003). These, however, will not be sufficient to improve energy efficiency and sustainability since these decisions are inherently predicted by social processes and impacted by building stakeholders' behavioral characteristics (Cooke et al., 2007). Andreu and Oresczczyn (2004) affirm that enhanced cooperation between building project stakeholders is necessary since "design decisions strongly influence building in-use energy and environmental impacts”. 


\subsection{Method and Data}

The aim of this study is to analyze whether VEPs and by extension GBCs and GBC-like organizations can influence and improve cooperation between building project stakeholders. For this purpose, data was collected in three countries (UK, US, CAN) from both GBC members and non-members. The main results reported in this study result from a quantitative survey study conducted in early 2011, administered by the author. The survey instrument is based not only on a systematic review of the literature but also on a qualitative elicitation study conducted before constructing the questionnaire and the results of the interview study will be briefly summarized below. ${ }^{6}$

\section{Qualitative Study: Interviews with building project stakeholders}

The elicitation study was conducted in April and May 2010 in the North East of the United States, with architects and engineers as respondents. The participants were identified and selected via the US Green Building Council Member Database and the National Professional Accreditation Boards. From the combined databases consisting of 300 entries, 40 building professionals were randomly selected.

The respondents were first contacted by email in order to make an appointment for a subsequent face-to-face interview. From the selected sample of 40 building professionals, 14 agreed to an extensive face-to-face expert interview. Fourteen interviews were conducted that lasted between 30 to 60 minutes. In total, ten architects ( 8 male and 2 female) and four engineers ( 4 male) participated in the study. Their average age was 52.3 years and 12 interviewees held senior positions (CEO or partner) in their companies. During the interviews cooperation in building projects were repeatedly named are a key aspect to energy efficient and sustainable construction.

"You have to have everyone on board with the same mindset. This is why it is hard to get a sweeping effort together" (Respondent 11, architect).

GBCs and voluntary environmental building schemes were mentioned during the interviews as contributing to an improved cooperation process.

"One of the good things .... [is the] consensus process where there are stakeholders from all sides of the building industry" (Respondent 3, engineer).

The interviews confirmed that stakeholder cooperation for sustainability in the building construction and design process needs to be carefully considered. Whether GBCs play a major role, however, was not clearly ascertained during the interview study. As a result, it

\footnotetext{
${ }^{6}$ The data described in this chapter partially overlaps with data used in other chapters of this dissertation. For further description of the surveys conducted and the data collected, please refer to the Appendix.
} 
was decided to further analyze the question of GBC membership enhancing cooperation in green building projects with a survey study in the US, Canada and the UK. These countries were chosen since they are quite close on cultural and linguistic dimensions. The main difference between these three countries is the status of the GBCs: While the US Green Building Council (USGBC) has a major role in the building sustainability discussion, the local GBC in Canada is gaining momentum but has less importance to this point while the UK Green Building Council (UK GBC) is of least importance compared to other sustainable construction organizations.

\section{Quantitative Study: Survey study in the US, Canada and the UK}

\section{Sample, procedure and response}

The data was collected in the United States, Canada and the United Kingdom between July and August 2011. The respondents were selected both from the national professional accreditation board registration lists and Green Building Council membership lists, creating a judgment sample on which the analysis was performed.After sending out the survey links individually to potential respondents and two follow-up reminders, 212 building professionals from the United States, 258 building professionals from Canada and 143 building and construction professionals (with the majority architects) from the United Kingdom decided to participate in this study.

The sample and respondents in the UK only included architects, while in Canada and the US several building professions, including architects and engineers, responded to the survey. The average respondent had more than 15 years of professional experience and held the position of CEO or business partner. ${ }^{7}$ In all three countries, respondents from all regions (UK), provinces (CAN) or states (US) were contacted to guarantee variance in responses. The response rate was around $10 \%$ for all three countries studied. Table 6.3 outlines the major professional groups of respondents from the United States, United Kingdom and Canada for respondents included in subsequent analyses. For more detailed information on respondents retained for subsequent statistical analysis compared to all respondents, please refer to Appendix C.

\section{Questionnaire development and measures}

\section{Cooperation measures}

In this study, the cooperative dimensions developed by Tjosvold (1988) based on Social Interdependence Theory (Johnson and Johnson, 1989) of (a) information and ideas ex-

\footnotetext{
${ }^{7}$ Architects in the private sector are in many cases self-employed or work in design firms that are organized in a similar fashion as law firms.
} 


\begin{tabular}{lllll}
\hline & UK & CAN & US & $\begin{array}{l}\text { Total (All } \\
\text { respon- } \\
\text { dents) }\end{array}$ \\
\hline Architect & 141 & 138 & 80 & 359 \\
Engineer & $\begin{array}{l}1 \text { (Archi- } \\
\text { tect by } \\
\text { training) }\end{array}$ & & 19 & 58 \\
Construction professional & 0 & 43 & 77 & 120 \\
Landscape architect & 0 & 11 & 12 & 23 \\
Interior Designer & 0 & 8 & 0 & 8 \\
Commissioning professional & 0 & 3 & 0 & 3 \\
Other & 1 (Archi- & 17 & 24 & 42 \\
& tect by & & & \\
training) & & & \\
\hline Total & 143 & 258 & 212 & 613 \\
\hline
\end{tabular}

Table 6.3: Professional Groups in the UK, US and CAN

change (b)assistance giving (c) constructive problem discussion and (d) mutual support were applied to measure intra-firm, inter-firm, inter-professional and intra-professional cooperation in the building and construction sector. Four 4-item scales were developed based on the scales developed by Thompson and Phua (2005). For all four cooperation forms, respondents were asked to score on a 7-point interval measure ( $1=$ strongly disagree, $7=$ strongly agree) on following questions: In building projects you are (a) keen to help colleagues from [own firm/other project firms/your professional group/other professional groups], (b) willfully contribute ideas and opinions to colleagues from [ your firm/other project firms/ your professional group/other professional groups], (c) volunteer time and effort to colleagues from [your firm/other project firms/your professional group/other professional groups], (d) actively assist colleagues from [ your firm/other project firms/ your professional group/other professional groups] in solving difficult problems.

Membership in GBCs and similar organizations was measured by past experience working on a green building VEP developed by these organizations. This decision was taken to investigate whether GBC membership will influence inter-firm cooperation during (green) building project development and implementation.

Since the concepts of inter-firm cooperation, intra-firm cooperation, inter-professional cooperation and intra-professional cooperation consist of four items each; an internal scale reliability score was calculated. The results for Cronbach's alpha can be found in Table 6.4: As the data shows, all items were found to be reliable indicators for the cooperation con- 


\begin{tabular}{lllll}
\hline & Intra-Firm & Inter-Firm & Inter-Professional & $\begin{array}{l}\text { Intra- } \\
\text { Professional }\end{array}$ \\
\hline US & 0.98 & 0.97 & 0.97 & 0.9 \\
CAN & 0.83 & 0.83 & 0.82 & 0.86 \\
UK & 0.9 & 0.88 & 0.87 & 0.86 \\
\hline
\end{tabular}

Table 6.4: Cronbach's alpha for cooperation constructs

structs to be measured.

\section{Control variables}

To control for confounding demographic effects, control variables including sex, age, job tenure, education level, firm type, regional location and previous sustainability education and personal sustainability attitudes were included in the regression analysis. All control variables were dummy coded. In addition, personal attitude towards sustainability and energy efficiency practices in building design and construction was introduced to control for individual differences in sustainability orientation: "To engage in sustainable design and construction practices is an important part of who I am”. The perception variable was coded on a 7 -point Likert-scale type ( $1=$ Strongly Disagree to $7=$ Strongly Agree). Additionally, the perception of sustainability of other actor's actions was included as a predictor variable measured by the questions "Most of my co-workers engage in sustainable building practices" and "Most people in my professional group engage in sustainable construction practices" ( $1=$ Strongly Disagree to $7=$ Strongly Disagree).

In order to account for overall cooperative behavior, three other cooperative behavior types, inter-firm and inter-professional and intra-professional, were also included as determinants for inter-firm cooperation, the main outcome variable.

\subsection{Results}

\section{Bivariate correlation}

In all three countries (United States, Canada and the United Kingdom) inter-firm cooperation was positively correlated with inter-professional correlation, intra- professional cooperation and intra-firm cooperation. The correlation coefficient strength followed the same order. Past experience working on a green building rating and assessment scheme was not found to be correlated with inter-firm cooperation at the $5 \%$ significance level. The results for all three correlations can be found in Tables 6.6, 6.7 and 6.8. 


\begin{tabular}{lll}
\hline Construct & Mean & $\mathrm{SD}$ \\
\hline Inter-professional cooperation US & 5.99 & 1.09 \\
Inter-professional cooperation CAN & 5.69 & 1.42 \\
Inter- professional cooperation UK & 5.92 & 1.01 \\
\hline Intra-professional cooperation US & 5.78 & 0.98 \\
Intra-professional cooperation CAN & 5.50 & 1.05 \\
Intra-professional cooperation UK & 5.73 & 0.97 \\
\hline Inter-firm cooperation US & 5.87 & 1.02 \\
Inter-firm cooperation CAN & 5.77 & 1.16 \\
Inter-firm cooperation UK & 5.72 & 1.02 \\
\hline Intra-firm cooperation US & 6.91 & 0.78 \\
Intra-firm cooperation CAN & 6.67 & 0.83 \\
Intra-firm cooperation UK & 6.08 & 0.88 \\
\hline 7- point Likert Scale (Strongly Agree/ Strongly Disagree)
\end{tabular}

Table 6.5: Cooperation constructs: Means and Standard Deviation

\begin{tabular}{lllllll}
\hline & 1 & 2 & 3 & 4 & 5 & 6 \\
\hline 1. Interprof. Cooperation US & 1 & & & & & \\
2. Intraprof. Cooperation US & $0.73^{*}$ & 1 & & & & \\
3. Interfirm Cooperation US & $0.61^{*}$ & $0.60^{*}$ & 1 & & & \\
4. Intrafirm Cooperation US & $0.37^{*}$ & $0.42^{*}$ & $0.44^{*}$ & 1 & & \\
5. Self-perception & 0.07 & -0.10 & -0.10 & $-0.22^{*}$ & 1 & \\
6. Previous project experience & 0.06 & $0.13^{*}$ & $0.16^{*}$ & $0.16^{*}$ & -0.06 & 1 \\
\hline
\end{tabular}

Table 6.6: Pairwise correlation for Social Interdependence Constructs (US)

\begin{tabular}{lllllll}
\hline & 1 & 2 & 3 & 4 & 5 & 6 \\
\hline 1. Interprof. Cooperation UK & 1 & & & & & \\
2. Intraprof. Cooperation UK & $0.65^{*}$ & 1 & & & & \\
3. Interfirm Cooperation UK & $0.63^{*}$ & $0.60^{*}$ & 1 & & & \\
4. Intrafirm Cooperation UK & $0.17^{*}$ & $0.27^{*}$ & $0.44^{*}$ & 1 & & \\
5. Self-perception & -0.15 & $-0.23^{*}$ & -0.02 & -0.05 & 1 & \\
6. Previous project experience & 0.00 & 0.07 & $0.18^{*}$ & $0.18^{*}$ & -0.06 & 1 \\
\hline
\end{tabular}

Table 6.7: Pairwise correlation for Social Interdependence Constructs (UK) 


\begin{tabular}{lllllll}
\hline & 1 & 2 & 3 & 4 & 5 & 6 \\
\hline 1. Interprof. Cooperation CAN & 1 & & & & & \\
2. Intraprof. Cooperation CAN & $0.66^{*}$ & 1 & & & & \\
3.Interfirm Cooperation CAN & $0.61^{*}$ & $0.51^{*}$ & 1 & & & \\
4.Intrafirm Cooperation CAN & $0.20^{*}$ & $0.31^{*}$ & $0.23^{*}$ & 1 & & \\
5. Self-perception & -0.07 & -0.09 & -0.08 & $-0.28^{*}$ & 1 & \\
6. Previous project experience & 0.06 & 0.10 & 0.02 & 0.09 & -0.06 & 1 \\
\hline
\end{tabular}

Table 6.8: Pairwise correlation for Social Interdependence Constructs (CAN)

\section{Determinants of inter-firm cooperation in sustainable building design and construction.}

\section{United Kingdom}

Among UK respondents, inter-professional cooperation $(\beta=0.47)$, intra-firm $(\beta=0.21)$ and intra-professional cooperation $(\beta=0.18)$ were found to be statistically significant determinants of inter-firm cooperation. In addition, the data suggests that self-perception with regards to sustainability is a significant predictor for inter-firm cooperation in the UK construction industry. In the United Kingdom, architects were the only respondent group. Hence, the determinants of inter-firm cooperation were found to be slightly different than for the US and Canada. Past LEED project engagement was not found to be significant, neither were demographic or other background variables. For discussion and comparability of results, it is important to keep in mind, however, that the number of respondents in the UK was lower than in the US and Canada and building practices are somewhat different to the two North American countries.

\section{Canada}

The analysis of the Canadian data suggests that inter-professional cooperation $(\beta=0.52)$ and intra-professional cooperation $(\beta=0.20)$ were significant determinants of inter-firm cooperation in the building and construction industry. As opposed to the United Kingdom, neither intra-firm cooperation nor sustainability self-perception influenced inter-firm cooperation. Just as in the United Kingdom, however, previous work on an environmental building ratings and assessment scheme assessed project did not matter for improved inter-firm cooperation. 


\begin{tabular}{|c|c|c|c|c|c|}
\hline Step & $\mathrm{R}^{2}$ & $\Delta \mathrm{R}^{2}$ & $\begin{array}{l}\text { Social Inter- } \\
\text { dependency } \\
\beta\end{array}$ & $\begin{array}{l}\beta \text { after Past } \\
\text { Behavior and } \\
\text { Self-identity }\end{array}$ & Final $\beta$ \\
\hline \multicolumn{6}{|l|}{ Step 1 : Social } \\
\hline \multicolumn{6}{|l|}{ Interdependency } \\
\hline Interprofessional cooperation & $0.54^{* * *}$ & & $0.48^{* * *}$ & $0.48^{* * *}$ & $0.47^{* * *}$ \\
\hline Intraprofessional cooperation & & & $0.17^{* *}$ & $0.18^{* *}$ & $0.18^{* *}$ \\
\hline Intrafirm cooperation & & & $0.22^{* * *}$ & $0.21^{* * *}$ & $0.21^{* * *}$ \\
\hline \multicolumn{6}{|l|}{ Step 2: Past Behavior } \\
\hline Past LEED (=yes) & $0.57^{* * *}$ & $0.03^{* * *}$ & & ns & ns \\
\hline Self- identity & & & & $0.25^{* * *}$ & $0.27^{* * *}$ \\
\hline \multicolumn{6}{|l|}{ Step 3: Background variables } \\
\hline Architect & $0.59^{* * *}$ & 0.02 & & & ns \\
\hline Engineer & & & & & $\mathrm{ns}$ \\
\hline Construction professional & & & & & ns \\
\hline Architecture firm & & & & & ns \\
\hline Engineering firm & & & & & ns \\
\hline Combined Arch/Eng. Firm & & & & & ns \\
\hline US & & & & & $\mathrm{ns}$ \\
\hline Canada & & & & & ns \\
\hline Female & & & & & ns \\
\hline Junior level (profession) & & & & & ns \\
\hline Bachelor education & & & & & $\mathrm{ns}$ \\
\hline Sustainability (=yes) & & & & & $\mathrm{ns}$ \\
\hline${ }^{*} \mathrm{p}<0.1 ;{ }^{* *} \mathrm{p}<0.05 ;{ }^{* * *} \mathrm{p}<0.01$ & & & & & $\mathrm{n}=143$ \\
\hline
\end{tabular}

Note: After the regression analysis for the UK data, Variance Inflation Factors (VIF) were calculated for both explanatory variables individually and the regression equation overall. All VIFs were under 4, with an equation mean VIF of 1.59 The VIFs for SIT constructs were: past behavior (1.08), selfidentity (1.13), intraprofessional cooperation (1.95), interprofessional cooperation (1.16), intrafirm cooperation (1.43). Hence, the VIF results suggest that multicollinearity is not an issue in this analysis.

Table 6.9: Regression Analysis with Inter-firm cooperation as the Dependent Variable (UK) 


\begin{tabular}{|c|c|c|c|c|c|}
\hline Step & $\mathrm{R}^{2}$ & $\Delta \mathrm{R}^{2}$ & $\begin{array}{l}\text { Social } \\
\text { Interdepen- } \\
\text { dency } \\
\beta\end{array}$ & $\begin{array}{l}\beta \text { after Past } \\
\text { Behavior and } \\
\text { Self-identity }\end{array}$ & Final $\beta$ \\
\hline \multicolumn{6}{|l|}{ Step 1 : Social } \\
\hline \multicolumn{6}{|l|}{ Interdependency } \\
\hline $\begin{array}{l}\text { Interprofessional } \\
\text { cooperation }\end{array}$ & $0.40^{* * *}$ & & $0.51^{* * *}$ & $0.51^{* * *}$ & $0.52^{* * *}$ \\
\hline $\begin{array}{l}\text { Intraprofessional } \\
\text { cooperation }\end{array}$ & & & $0.19^{* * *}$ & $0.19^{* * *}$ & $0.20^{* * *}$ \\
\hline Intrafirm cooperation & & & 0.19 & 0.19 & 0.15 \\
\hline \multicolumn{6}{|l|}{ Step 2: Past Behavior } \\
\hline Past LEED (=yes) & $0.41^{* * *}$ & 0.01 & & ns & $\mathrm{ns}$ \\
\hline Self- identity & & & & ns & ns \\
\hline \multicolumn{6}{|l|}{$\begin{array}{l}\text { Step 3: Background } \\
\text { variables }\end{array}$} \\
\hline Architect & $0.42^{* * *}$ & 0.01 & & & ns \\
\hline Engineer & & & & & ns \\
\hline Construction & & & & & ns \\
\hline \multicolumn{6}{|l|}{ professional } \\
\hline Architecture firm & & & & & ns \\
\hline Engineering firm & & & & & ns \\
\hline Combined Arch/Eng. & & & & & ns \\
\hline \multicolumn{6}{|l|}{ Firm } \\
\hline US & & & & & ns \\
\hline Canada & & & & & ns \\
\hline Female & & & & & ns \\
\hline Junior level (profession) & & & & & ns \\
\hline Bachelor education & & & & & ns \\
\hline Sustainability (=yes) & & & & & ns \\
\hline${ }^{*} \mathrm{p}<0.1 ;{ }^{* *} \mathrm{p}<0.05 ;{ }^{* * *} \mathrm{p}<$ & 0.01 & & & & $\mathrm{n}=258$ \\
\hline
\end{tabular}

Note: After the regression analysis for the Canadian data, Variance Inflation Factors (VIF) were calculated for both explanatory variables individually and the regression equation overall. All VIFs were under 4, with an equation mean VIF of 1.70 The VIFs for SIT constructs were: past behavior (1.08), self-identity (1.17), intraprofessional cooperation (1.95), interprofessional cooperation (1.89), intrafirm cooperation (1.22). Hence, the VIF results suggest that multicollinearity is not an issue in this analysis.

Table 6.10: Regression Analysis with Inter-firm cooperation as the Dependent Variable (CAN) 


\begin{tabular}{|c|c|c|c|c|c|}
\hline Step & $\mathrm{R}^{2}$ & $\Delta \mathrm{R}^{2}$ & $\begin{array}{l}\text { Social Inter- } \\
\text { dependency } \\
\beta\end{array}$ & $\begin{array}{l}\beta \text { after Past } \\
\text { Behavior and } \\
\text { Self-identity }\end{array}$ & Final $\beta$ \\
\hline
\end{tabular}

Step 1 : Social

Interdependency

Interprofessional cooperation

Intraprofessional cooperation

$0.47^{* * *}$

$0.55^{* * *}$

$0.55^{* * *}$

$0.51^{* * *}$

Intrafirm cooperation

$0.22^{* *}$

$0.23^{* *}$

$0.27^{* *}$

$0.25^{* * *}$

$0.24^{* * *}$

$0.23^{* * *}$

Step 2: Past Behavior

Past LEED (=yes)

$0.47^{* * *}$

ns

ns

Self- identity

ns

ns

Step 3: Background variables

Architect

$0.50^{* * *}$

ns

Engineer

ns

Construction professional

ns

Architecture firm

ns

Engineering firm

ns

Combined Arch/Eng. Firm

ns

US

ns

Canada

ns

Female

ns

Junior level (profession)

ns

Bachelor education

ns

Sustainability (=yes)

ns

${ }^{*} \mathrm{p}<0.1 ;{ }^{* *} \mathrm{p}<0.05 ;{ }^{* * *} \mathrm{p}<0.01$

$\mathrm{n}=212$

Note: After the regression analysis for the US data, Variance Inflation Factors (VIF) were calculated for both explanatory variables individually and the regression equation overall. All VIFs were under 4, with an equation mean VIF of 1.59 The VIFs for SIT constructs were: past behavior (1.12), selfidentity (1.06), intraprofessional cooperation (2.41), interprofessional cooperation (2.35), intrafirm cooperation (1.43). Hence, the VIF results suggest that multicollinearity is not an issue in this analysis.

Table 6.11: Regression Analysis with Inter-firm cooperation as the Dependent Variable (US) 


\section{United States}

The data collected in the United States suggests that inter-professional cooperation ( $\beta=$ $0.51)$ and intra-professional cooperation $(\beta=0.27)$ were statistically significant as predictors of inter-firm cooperation. As opposed to Canada and in line with UK data, intraprofessional cooperation $(\beta=0.23)$ determined inter-firm cooperation in building projects in the US. Neither sustainability self-perception nor past experience on building rating and assessment schemes influenced perceived inter-firm cooperation.

\subsection{Discussion}

Different patterns of cooperation type significance, sustainable self-perception and previous environmental building and assessment project work were identified for the United Kingdom, Canada and the United States.

In all three countries surveyed, past experience working on sustainable building schemes, and by extension being influenced by Green Building Councils and similar organizations, did not influence inter-firm cooperation among respondents. However, inter-firm cooperation in all three countries was influenced by inter-professional cooperation and intra-professional cooperation to varying degrees. It does seem that professional cooperation in this context takes precedence over organizational (i.e. across project firms) cooperation.

Intra-firm cooperation was found to be non-significant in Canada, which may strengthen this point of view. Sustainable self-perception influenced inter-firm cooperation in the construction and building industry in the UK, i.e. among architects, but not in the other two countries.

While intra-professional cooperation was less significant predicting inter-firm cooperation in the United Kingdom than intra-firm cooperation, the situation was reversed for the United States. In other words, in the UK established cooperation within a professional group was more important for inter-firm cooperation in a building project than having established cooperation within the respondents' organization while the opposite was true for respondents in the US. This phenomenon can be partly explained by sample composition: The UK respondents belong to only one professional group, i.e. architects working mainly in pure architectural firms, with "integrated" architecture and engineering firms non-existent among respondents. However inter-professional cooperation between architects was found to be more predominant than in the US, which comprised a mixed sample and more integrated cross-disciplinary firms in which intra-firm cooperation may be more important than intra-professional cooperation.

The reason for intra-firm cooperation not being significant in Canada is more difficult to explain. A potential explanation is that intra-firm cooperation itself may be less of an issue 
within the context of the Canadian building industry due to different industrial relations and hence only the other forms of cooperation will influence inter-firm cooperation. While some evidence suggests that parts of the building and construction industry may be indeed more cooperative than their US counterparts (Arku, 2012) this fact alone does not explain this difference entirely.

Sustainability self-perception was only found to be significant in the United Kingdom (i.e. the architect sample) for explaining inter-firm cooperation. It may seem intuitive that a strong sense of self-identity in terms of sustainability could positively influence inter-firm cooperation processes within the fragmented building industry as promoting sustainable change may be a higher goal than obtaining advantages for the own firm. However, in the United States and Canada sustainable self-perception was not found to be statistically significant. The influence of sustainable self-perception and identity, therefore, needs to be considered in further detail in future research studies. A more detailed research project on the role of social identity is detailed in Chapter 7 outlining the potential influence of intergroup perceptions, group norms and group identification on cooperative behavior in green building projects.

The results raise some important questions: Why are inter-professional and intra- professional cooperation strong predictors for inter-firm cooperation? How come sustainability self-perception is only significant in the UK while intra-firm cooperation is only insignificant only in Canada? And finally, and most importantly, if previous experience with environmental building rating and assessment schemes will not improve inter-firm cooperation, are these programs missed opportunities, given the fact that that one of their major goals is to improve cooperation and thereby facilitate change for sustainable building practices? These questions should be addressed in future research as they indicate that cooperation may have to be addressed by locally adaptable green building VEPs.

\subsection{Limitations}

The above conclusions need to be set against the limitations of the small and restricted sample on which the results are based. This particular research suffers drawbacks from using a convenience sampling approach and the potential number of biases introduced. While efforts have been made to reduce social desirability bias often observed in socially contentious issues such environmental protection, occurrence of these biases cannot be fully excluded. Despite the use of previously tested measurement scales and survey instruments and verifying reliability in the context of this study, measurement errors may have influenced the results discussed above. Cooperation is a complex issue and while experimental approaches may allow for better control over participants, self-reports are sometimes the most accessible way to obtain data from groups that would not be very 
approachable for the purpose of a lab study. Further experimental research, where possible, could allow for better control on the determinants of inter-firm, inter-professional, intra-professional and intra-firm behavior with a larger number of building professionals. The exact path of influence, i.e. the way which intra-professional, inter-professional and intra-firm cooperation may influence inter-firm cooperation needs to be investigated further to identify reasons for cooperation or absence thereof.

\subsection{Conclusion}

While environmental building ratings and assessment schemes can contribute to create significant awareness in sustainability matters, they depend on high levels of stakeholder cooperation due to their voluntary nature. Even though training building industry professionals in building sustainability and promoting consensus-based processes are commendable initiatives and aim in the right direction, it may not be sufficient to assume that cooperation can be significantly improved by encouraging building professionals to work on VEP projects.

Cultural and country influences, especially beyond the Anglo-Saxon cultural sphere, may be influential in cooperation readiness (Thompson and Phua, 2005) and cooperation patterns. Even though the US, Canada and the UK are part of the same Anglo-Saxon cultural sphere, green building VEP uptake does not follow the same patterns. Behavioral factors can be influenced by structural effects (building policies, building industry composition and structural effects) and are likely to influence cooperative measures.

While cooperation between building projects stakeholders is one green building VEPs main aims, research and experience has so far not been able to demonstrate improved cooperative behavior. As a result, the aim of GBCs and their associated rating and assessment schemes to radically improve sustainability in the building sector does not seem to fulfill the expectations at this stage. 


\section{References}

Andreu, I. C., \& Oreszczyn, T. (2004). Architects need environmental feedback. Building Research \& Information, 32(4), 313-328.

Axelrod, L. J., \& Lehman, D. R. (1993). Responding to environmental concerns: What factors guide individual action? Journal of environmental psychology, 13(2), 149-159.

Biemans, W. G. (1991). User and third-party involvement in developing medical equipment innovations. Technovation, 11(3), 163-182.

Campbell, A. (1994). The influence of intra-firm coordination in inter-firm cooperation. paper presented at the 10th imp annual conference.

Campbell, A. J. (1998). Do internal departmental relationships influence buyers' expectations about external supply partnerships? Journal of Business \& industrial marketing, 13(3), 199-214.

Clark, C. F., Kotchen, M. J., \& Moore, M. R. (2003). Internal and external influences on pro-environmental behavior: Participation in a green electricity program. Journal of environmental psychology, 23(3), 237-246.

Cook, S. W., \& Berenberg, J. L. (1981). Approaches to encouraging conservation behavior: A review and conceptual framework. Journal of Social Issues, 37(2), 73-107.

Cooke, R., Cripps, A., Irwin, A., \& Kolokotroni, M. (2007). Alternative energy technologies in buildings: Stakeholder perceptions. Renewable Energy, 32(14), 2320-2333.

Council, U. G. B. (2013). Online USGBC http://www.usgbc.org/About.

Dahlstrand, U., \& Biel, A. (1997). Pro-environmental habits: Propensity levels in behavioral change1. Journal of Applied Social Psychology, 27(7), 588-601.

Deutsch, M. (1949). An experimental study of the effects of co-operation and competition upon group process. Human relations, 2, 199-231.

Deutsch, M. (1949b). A theory of cooperation and competition. Human Relations, 2, 129-151.

Dietrich, P., Eskerod, P., Dalcher, D., \& Sandhawalia, B. (2010). The dynamics of collaboration in multipartner projects. Project Management Journal, 41(4), 59-78.

Elliott, D. (2002). Energy, society and environment. Routledge.

Feldman, Y., \& Perez, O. (2009). How law changes the environmental mind: An experimental study of the effect of legal norms on moral perceptions and civic enforcement. Journal of Law and Society, 36(4), 501-535.

Fischhoff, B., Bostrom, A., \& Quadrel, M. J. (1993). Risk perception and communication. Annual review of public health, 14(1), 183-203.

Fiske, A. P., Kitayama, S., Markus, H. R., \& Nisbett, R. E. (1998). Handbook of social psychology. In (p. 915-981). McGraw-Hill.

Gorse, C. A., \& Emmitt, S. (2007). Communication behaviour during management and design team meetings: a comparison of group interaction. Construction Management and Economics, 25(11), 1197-1213. 
Gough, A. (2002). Mutualism: a different agenda for environmental and science education. International Journal of Science Education, 24(11), 1201-1215.

Harland, P., Staats, H., \& Wilke, H. A. (1999). Explaining proenvironmental intention and behavior by personal norms and the theory of planned behavior1. Journal of applied social psychology, 29(12), 2505-2528.

Hillebrand, B., \& Biemans, W. G. (2003). The relationship between internal and external cooperation: literature review and propositions. Journal of Business Research, 56(9), 735-743.

Huber, G. P. (1991). Organizational learning: The contributing processes and the literatures. Organization science, 2(1), 88-115.

Johnson, D. W. (2003). Social interdependence: interrelationships among theory, research, and practice. American Psychologist, 58(11), 934.

Johnson, D. W., \& Johnson, R. T. (1989). Cooperation and competition: Theory and research. Interaction Book Company.

Kahn, M. E. (2002). Demographic change and the demand for environmental regulation. Journal of Policy Analysis and Management, 21(1), 45-62.

Katz, R., \& Tushman, M. (1979). Communication patterns, project performance, and task characteristics: An empirical evaluation and integration in an r\&d setting. Organizational behavior and human performance, 23(2), 139-162.

Langerak, F., Peelen, E., \& Commandeur, H. (1997). Organizing for effective new product development: an exploratory study of dutch and belgian industrial firms. Industrial Marketing Management, 26(3), 281-289.

Laroche, M., Toffoli, R., Kim, C., \& Mutter, T. E. (1996). The influence of culture on proenvironmental knowledge, attitudes, and behavior. a canadian perspective. Advances in Consumer Research, 23(1), 196-202.

Lusch, R. F., \& Brown, J. R. (1996). Interdependency, contracting, and relational behavior in marketing channels. The journal of Marketing, 60, 19-38.

Nordlund, A. M., \& Garvill, J. (2002). Value structures behind proenvironmental behavior. Environment and Behavior, 34(6), 740-756.

Ring, P. S., \& Van de Ven, A. H. (1994). Developmental processes of cooperative interorganizational relationships. Academy of management review, 19(1), 90-118.

Ritchie, J. B., McDougall, G. H., \& Claxton, J. D. (1981). Complexities of household energy consumption and conservation. Journal of Consumer Research, 8, 233-242.

Smith, K. G., Carroll, S. J., \& Ashford, S. J. (1995). Intra-and interorganizational cooperation: Toward a research agenda. Academy of Management journal, 38(1), 7-23.

Stern, P. C., \& Dietz, T. (1994). The value basis of environmental concern. Journal of social issues, 50(3), 65-84.

Stewart, A. M., \& Craig, J. L. (2001). Predicting pro-environmental attitudes and behaviors: A model and a test. Journal of Environmental Systems, 28(4), 293-317. 
Tabernero, C., \& Hernández, B. (2011). Self-efficacy and intrinsic motivation guiding environmental behavior. Environment and Behavior, 43(5), 658-675.

Tanner Jr, J. F. (1999). Organizational buying theories: a bridge to relationships theory. Industrial Marketing Management, 28(3), 245-255.

Thompson, E. R., \& Phua, F. T. (2005). Are national cultural traits applicable to senior firm managers? British Journal of Management, 16(1), 59-68.

Tjosvold, D. (1984). Cooperation theory and organizations. Human Relations, 37(9), 743-767.

Tjosvold, D. (1986). The dynamics of interdependence in organizations. Human Relations, 39(6), 517-540.

Tjosvold, D. (1988). Cooperative and competitive dynamics within and between organizational units. Human Relations, 41(6), 425-436.

UK Green Building Council (UKGBC). (2013). Online www.ukgbc.org/membership.

UNEP. (2013). United nations environment program.2013. focus area: Sustainable buildings (Tech. Rep.). Author.

Weber, L. (1997). Some reflections on barriers to the efficient use of energy. Energy Policy, 25(10), 833-835.

Wilson, E. J. (1999). Research practice in business marketing: A comment on response rate and response bias. Industrial Marketing Management, 28(3), 257-260. 



\title{
Constructing Green: Social Identity, Professional and Organizational Group Affiliation in the US and Canadian Building and Construction Industry
}

\begin{abstract}
"What were needed were not words and promises but the steady accumulation of small realities" (Haruki Murakami, South of the Border, West of the Sun)
\end{abstract}

\subsection{Introduction}

W

ith the climate change and the overuse of natural resources by an ever increasing world population, green construction has been identified as a potential pathway to reduce ecological footprint and greenhouse gas emissions in urban and rural settings. While technical solutions for sustainable construction are being developed and promising inventions for better building insulation, reduced water consumption and better energy efficiency are showcased internationally, human factors are still less widely considered in the architecture, engineering and construction (AEC) industry. Technical solutions are crucial for a sustainable economy, however, the interaction of consumers and professionals with technical solutions and programs need to be more thoroughly understood. Studies on ergonomics and the interaction of people with technological systems in buildings have become widespread (e.g. how tenants use energy meters to reduce their consumption). However, research focused on professionals in AEC industries is far less common. Greening building practices by changing building professionals' behaviors has become an emerging topic of interest. 
In the area of environmental management and governance, voluntary schemes have become an important instrument to promote more environmentally beneficial practices. In this chapter, the main focus is on the acceptance and adoption of voluntary rating and assessment schemes for green design and construction as a function of professional and organizational affiliation and intergroup perceptions in the United States and Canada. Professional acceptance is a key factor for long lasting change in AEC practices and the road towards a more sustainable built environment. In order to advance organizational and industry-level change in the AEC industry, the determinants leading professionals to adopt environment-oriented rating schemes need to be understood. Studies on environmental professionals including engineers and biologists have concluded that professional identities and organizational affiliation may influence work practices and subsequent courses of action in the environmental protection process (e.g. Mieg, 2008). While understanding individual-level factors and motivations is necessary, as can be seen in the previous chapters, the effect of perceived properties of group affiliation in the adoption process needs to be further analyzed to understand cooperative processes. Hence, this chapter will be based on both elements from both the sociology of professions as well as psychology-based social identity and self-categorization theories to analyze the way group affiliations of AEC professionals in the US and Canada affects uptake of voluntary environmental building rating schemes.

\subsection{Environmental Building Rating Schemes uptake in the US and Canadian AEC industry}

Voluntary building rating and assessment schemes regarding environmental and energy sustainability have become increasingly prominent when it comes to greening the building sector. In some instances, the main aim of the schemes is to provide a third party, nongovernmental form of governance and transform building and design practices. Programs have been developed by a variety of organizations including Green Building Councils (GBCs) and other industry or NGO-affiliated organizations.

Buildings for which specific points and aspects of environmental and energy sustainability have been integrated in the design and construction process can obtain a bronze, silver, gold or platinum certification. Two of the most common schemes worldwide are the Leadership for Energy and Environmental Design (LEED) and Green Globes schemes following similar principles. While the Green Globes scheme is more known in Canada where it was originally developed and adapted from the BREEAM scheme (common in the United Kingdom), the LEED program is now the most known voluntary environmental building rating and assessment scheme in the United States (and potentially around the world). 
Due to green building VEP design and construction requirements that can be quite different from usual processed and practices, some of the organizations administering the programs also issue professional accreditation schemes to train building professionals for the application of their scheme. ${ }^{1}$

Voluntary accreditations, particularly when related to additional dimensions in professional practice such as sustainability are less common in the green building literature. It has not been evaluated to this point whether LEED and Green Globes adoption practices differ among professional groups in the building sector and which underlying factors may contribute, if this were the case. Diverging professional practices and identities may hinder the implementation of common procedures in the AEC industry. Studies have demonstrated that common professional identities (e.g. Mieg, 2008) and cooperation are necessary for advancing professional sustainability practices. Cooperation as discussed in Chapter 6 is linked not only to personal but also social identity, i.e. professional and organizational group affiliation.

\subsection{Theoretical Perspectives: Sociology of Professions, Social Identity and Self-Categorization Theories}

Examining the adoption and subsequent use of green building VEPs, literature on both sociology of professions and social identity theory/self-categorization can yield valuable insights to understand program uptake. With sociology of professions sheds light on the macro-environment perspective in which decision-makers are embedded in, the sociopsychological social-identity and self-categorization approach offers explanations as to the perceptions and actions of individual professional actors (e.g. Hotho, 2008; Mieg, 2008).

\section{Sociology of Professions}

Professions, as opposed to other occupations, have been defined in numerous studies as privileged occupational groups controlling specific and narrowly defined types of work such as medicine, law, accountancy, architecture or engineering (Mieg, 2008). The nature of professions and the control they exert in the wider society has been extensively studied in the field of sociology (e.g. Freidson, 1994; Abbott, 1988, Reed, 1996). The topic has become so popular that it is widely known as the "sociology of professions". Major areas of interest in this field of research are the concepts of social power and control. Historically, regulated professional groups have been attributed exceptional status and power and therefore can shape societal practices and understandings (Reed, 1996). This aspect of sociology of professions is useful for in-depth understanding of environmental practices in the AEC industry by different professional groups (such as architects and engineers).

\footnotetext{
${ }^{1}$ Professional accreditation schemes in green building VEPs will be analyzed in more detail in Chapter 8 .
} 
In the sociological approach to studying professions, specialized and expert knowledge (Reed, 1996) enable professions, as opposed to other occupations, to legitimate societal interventions (Hotho, 2008). Social control, generally, is maintained by tightly regulating access, education and training as well as professional licensure and accreditation (Macdonald, 1995, 1999). These actions thereby have created a system which builds the foundation for professional legitimacy (Freidson, 1994) and shapes the behavior and identity of individual professionals within (Hotho, 2008). Sociological approaches, however, have been criticized as being too abstract and presenting professions as "monolithic entities" (Hotho, 2008) as sociological perspectives on professions in general have been less concerned with the experiences of individuals within a social system. However, it also seems clear that group phenomena and structural norms are likely to influence professionals' perceptions, attitudes and behaviors. According to Hotho (2008), neither macro (sociological) nor micro (psychological) approaches are fit to explain the professional identities and practice on their own. Resulting from this argument is that social phenomena need to be considered as the result of a constant interplay between social structures and human action (Hotho, 2008). Some theoretical frameworks in the social-psychological literature have adapted elements from both areas.

This chapter adapts concepts from social identity and self-categorization theories as proposed by Tajfel and Turner (1988) and Terry and Hogg (1996) to explore the influence of perceived group characteristics on individual decisions in the building industry to become more environmentally sustainable.

\section{Social Identity and Self-Categorization}

\section{Application of Social Identity concepts to the AEC industry}

It is widely accepted that identification with a specific group can significantly influence an individual's attitudes, decisions and behaviors. While high levels of group identification (e.g. within an organizational context) can be positive and allow for more effective cooperation, over-identification may also lead to adopting in-group practices without further reflection or criticism (Hornsey, 2008). In the AEC industry, many professional groups need to collaboratively work on an ad-hoc basis. Especially when it comes to changing and adopting new professional practices which may favor a more sustainable approach to construction, group affiliation may play a central role. Only if all professional groups accept new sustainability practices, such as the LEED scheme, can profound change occur. While evidence suggests that affiliation with Green Building Councils (GBCs) by itself does not lead to increased cooperation between professional groups in the building sector (see Chapter 6), group norms, group identification and intergroup perceptions may be influential in the adoption of the LEED and Green Globes. 
The Social Identity Approach (SIA) (comprising Social Identity Theory (SIT) and SelfCategorization Theory (SCT)) is a frequently applied approach of group processes and inter-group relations. The social identity approach has evolved significantly over the last thirty years (Tajfel, 1978; Tajfel and Turner, 1979; Turner et al., 1987; Hogg and Abrams, 1988). Social identity theory is based on the work of Tajfel et al. (1971)'s work on the minimal group paradigm, which investigated how social context influences intergroup relations and competitive group behavior. Results from experiments conducted in this research field have become the foundation of the SIT (Tajfel, 1978; Tajfel and Turner, 1979). Based on work on social cognition (e.g. Tajfel and Wilkes, 1963), Tajfel (1978) argued that category distinctions will enhance perceived similarities within a group while reinforcing perceived differences with outside groups. Hence, Tajfel (1978) suggested that human behavior is influenced by both interpersonal and intergroup relations. Social categories, such as professional affiliation, influence the way individuals relate to each other and SIT focuses on individual behavior as a function of group membership and the perceptions of in-group traits as opposed to out-group traits. The motivating principle driving competitive group behavior is to create a secure and positive self-concept (Hornsey, 2008).

An extension of the Social Identity Theory (SIT), Social Categorization Theory (SCT) focuses specifically on the group categorization processes at the heart of SIT. However, SCT refines the interpersonal vs. intergroup relations spectrum and defines identity as comprising several levels of self-categorization: human identity, social identity and personal identity. Additionally, sub-group identities have also been explored over the recent years (Hornsey and Hogg, 2000). In the SCT realm, categorization and self-categorization results from how well social categories are perceived to reflect social reality and intragroup norms provide essential information as to how an individual within that group should feel or act (Hornsey, 2008). Over-identification with a specific group, such as professions, can lead to depersonalization processes in which group norms are so deeply internalized that agreement among group members becomes implicit (Turner, 1991). Power mechanisms and influence can be a result from categorization and power can shape rhetoric over social issues and to control over resources (Turner, 2005). Based on SCT, professional cooperation in the building and construction industry may be a result of social identification and selfcategorization processes.

In addition to comparing other groups to one's own group, self-categorization changes self-perception. However, merely belonging to a professional group cannot be assumed to determine an individual's attitudes, norms and behavior towards adopting certain professional standards. Individuals will necessarily have different levels of association with groups and can be located on a sliding spectrum with preferences from interpersonal to intergroup interaction (Hornsey, 2008). In individuals with a preference for interpersonal interactions, the self-concept will be dominated by personal attitudes, norms and behaviors that make up the "personal identity". Hence, some AEC professionals may base interactions 
and decisions to engage in certain building practices on their own attitudes and interests. However, individual's self-concepts can also be dominated by their "social identity" which is derived from group affiliation. In this case, an AEC professional may decide only to adopt the LEED AP scheme if this practice is acceptable in the group context.

In short, both SIT and SCT (Turner et al., 1987) are valuable tools to understand building professionals' affiliations and actions in terms of group affiliation.

\section{Professional vs. Organizational identities}

In previous sections, it was explained how the acceptance of voluntary professional schemes may differ as a result of professional affiliations. However, it needs to be emphasized that professionals can and may have to incorporate multiple professional identities at the same time, i.e. the predominant group may be the profession or the employing organization (Johnson et al., 2006). Research on organizational identification has thrived (e.g. Ashforth and Saks, Mael and Ashforth, 1992) and SIT and SCT have both been applied to these issues over the last decade (e.g. Ashforth and Johnson, 2001). Organizational identification in this context is defined as the "psychological attachment that occurs when members adopt the defining characteristics of an organization as defining characteristics of themselves" (Dutton, Dukerich and Harquail, 1994). Work-related identities have been found to influence selfconcepts in certain circumstances more than ethnicity or gender (Hogg and Terry, 2001; Johnson et al, 2006).

While certain individuals may hold allegiance to their professional group, others may feel that their affiliation with an organization or organizational sub-groups may be stronger (Ashforth \& Johnson, 2001). In some occasions, individuals may hold several professional identities. Hogg and Terry (2001) suggested that identities can become more salient because of contextual cues but that some will be more important than others overall.

While organizational identities have been suggested to be stronger than professional group affiliation due to the fact that organizations provide financial incentives and a work place, many of the "traditional" professions, including architects, engineers, doctors or lawyers are dominated by "self-employed" individuals. If these professionals work for organizations, such as firms, their social identification may be influenced by whether their organization's mission is consistent with their profession (Johnson et al., 2006). According to Wallace (1995) , in some organizational contexts "the majority of the members are professionals, the professional content of the work is central to the mission of the organization, and the goals of the organization are largely consistent with those of the professionals it employs". However, individuals also work in organization where their professional group is a minority of overall employees or their professional expertise may not be at the center of organizational goals. In this case, professional affiliation can take on the function as the "in-group". 
Brewer (1991) suggests that when it comes to choosing groups to identify with, individuals frequently select those that allow for maintaining a distinct status. In work-related contexts, professionals have been found to either select their profession, or their organization, both or neither (Hornsey, 2008).

The differentiation between the influence of professional and organizational affiliations is very important for the AEC industry. Demarcation lines can be the different professional groups (i.e. architects, engineers, planners) working together on a project, but also firms. Both "discipline-oriented" (i.e. engineering firms or architecture firms) as well as "integrated" firms employing different professional groups while integrating several project functions have become more common. Hence, this chapter will determine whether professional groups will have a more distinct influence on the decision to integrate the LEED and Green Globes schemes than organizational (i.e. firm) group perceptions and influences.

\section{Integration of SIT and SCT and Reasoned Action Approach (RAA)}

To analyze the potential contribution of SIT and SCT to the adoption of green building VEPs, the concepts derived from these frameworks will be added to the Reasoned Action Approach (RAA) (Fishbein and Ajzen, 2010) model to behavior change. The Reasoned Action Approach (RAA) has become one of the most commonly used frameworks of determining and influencing change across a range of different types of behavior classes.

The RAA is a social-psychological framework that evaluates both internal and external factors that shape decisions and lead to a specific behavior. This model has frequently been used for studies on pro-environmental behavior and proven to be a very useful tool for understanding beliefs, intentions and subsequent behavior. Even though its "pure form" has been mostly applied to decisions of individuals in a private decision context, such as household recycling behavior, it has also been used in the past to studies on decisions in a professional role and environmental management practices (e.g. Cordano and Frieze, 2000; Martin-Pena, 2010).

The RAA builds on two predecessor models, the Theory of Reasoned Action (Fishbein and Ajzen, 1975) and the Theory of Planned Behavior (Ajzen, 1985). The Theory of Reasoned Action (Fishbein and Ajzen, 1975) suggests that under volitional control, the behavior of the individual is determined by behavioral intention which is jointly determined by the attitude towards the specific behavior and subjective norms. These intentions to perform a behavior are in many cases good predictors of behavior even though there are some cases to which this assumption does not apply (Perkins, 2007). Attitudes refer to an individual's perceptions of the inconveniences and advantages of performing a behavior while subjective norms are related to what an individual perceives to be important to other people around them. The strength of these perceptions is then complemented by the motivation to comply. 


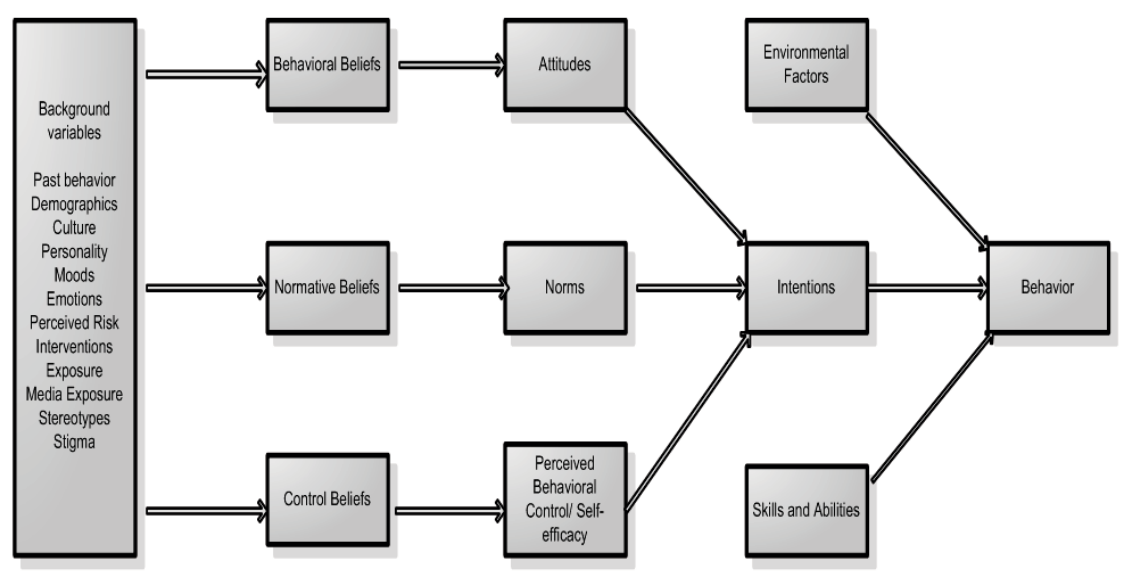

Figure 7.1: Reasoned Action Approach (Adapted from Fishbein, 2008)

Since, however, not every behavior is under volitional control, Ajzen (1985) added the variable of Perceived Behavioral Control (PBC) and altered the name to "Theory of Planned Behavior" (TBP). PBC refers to 'the person's belief as to how easy or difficult performance of the behavior is likely to be' (Ajzen \& Madden, 1986) and has an effect on behavioral intention and thereby on a specific behavior. The concept of Perceived Behavioral Control builds on the concept of Self-Efficacy established by Bandura (1994). The reasoned action approach builds on the assumption that behaviors can be predicted from behavioral intentions. In addition to the elements above, Fishbein and Ajzen (2010) have added environmental factors and skills and abilities to the model to explain variance between intentions and subsequent behavior (see Fig.7.1). Social identity and self-categorization concepts have frequently found to offer useful contributions to explaining intentions and behaviors within the RAA approach and its predecessor models (e.g. Terry et al., 1999; Fekadu and Kraft, 2000; White et al., 2002; Johnston et al., 2003; Norman et al., 2005; White et al., 2009). SIT and SCT address professionals' group selection by investigating group norms, group identification, perception of intergroup context and perceived power differentials.

\subsection{Method}

The data presented in this chapter were collected by administering a survey instrument online to building professionals in the United States and Canada in July 2011. Previous research on social identity and intergroup behavior is dominated by experimental methods, 
starting with research by Tajfel et al.s (1971) work on the minimal group paradigm. While social identity is still used frequently in experimental or quasi-experimental settings, applied research in organizational and work contexts has also resorted increasingly to survey methods to collect data (e.g. Fielding et al., 2008).

\section{Measurement of SIT and SCT constructs}

Measurement of SIT and SCT key concepts overall has proven rather difficult and have received mixed empirical support (e.g. Brewer and Miller, 1996; Deaux, 1996; Messick and Mackie, 1989). However, as Hornsey (2008) suggested, these issues may be due to the fact that SIT and SCT are quite broad in nature, resulting in numerous conceptual definitions and operationalization of social identity terms. The scales developed over the last decades are quite different in scope, depending on whether authors empirically adhered to a uni-dimensional view of social identity (e.g. Brown et, al., 1986), two-dimensional (e.g. Karasawa, 1991) or even four-dimensional (Luthanen and Crockers, 1992). Research is divided as to how social identity should be conceptualized, how many dimensions the concept has and how those dimensions relate to each other. As a consequence this chapter will focus on scales that have been used in previous studies on similar behavior, i.e. environmental and professional decisions.

In order to understand whether professional affiliation determines the adoption of LEED and Green Globes schemes, measures from SIT and SCT were adapted in a survey instrument distributed among AEC professionals in the US and Canada. The scales, developed by Terry and Hogg (1996) and White et al. (1994), were used for group norms, assessing the respondent's perceptions of the reference group norms (e.g. "How many people in your professional group/organization engage in green building practices?” (1=very few; $7=$ most), "How likely is it that people in your professional group/ organization engage in green building practices during projects?" ( $1=$ unlikely; $7=$ very likely), "How much agreement is there in your professional group/ organization to engage in green building practices?"( $1=$ very little,' $7=$ a great deal of agreement)).

Measures of group identification were obtained by adapting five items used by Brown et al. (1986), Hogg et al. (1993) and Hogg and Hains (1996) designed to assess strength of identification with the reference group (e.g. "How much do you identify with your professional group/ organization"; $1=$ not very much to $7=$ very much), as well as feelings of belonging to the group (e.g. In general, how well do you feel you fit into your professional group/ organization; $1=$ not very much to $7=$ very much).

Seven items measured key aspects of perceptions of the intergroup context. Two statements tapped perceptions of professional groups and organizations in the area of green construction practices (e.g. "It feels we are all on the same side in my professional group/ 
organization when it comes to environmental construction practices" ( $1=$ Strongly Disagree to $7=$ Strongly Agree); " There is a sense that professional groups/ organizations in the AEC industry are split in many different camps" $1=$ Strongly Disagree to $7=$ Strongly Agree). These items were adapted from Gaertner, Dovidio, Anastasio, Bachman, and Rust (1993) and assessed the salience of the intergroup context. Perceived power differentials between professional groups (1) on the one hand and between professional groups and organizations (2) on the other hand were measured by two items with subitems for professions and organizations. These were: "Green construction practices are mainly determined by ___ professions/ organizations”, "All AEC professional groups have ample input into green construction practices”, “ (AEC professions list) have little influence on green construction practices"). Legitimacy of power differentials was assessed with two items: "The professional groups/ organizations who determine green construction practices in the AEC industry have little understanding of these practices", "The professional groups/ organizations who determine green construction practices in the AEC industry have enough knowledge and expertise in this respect". The first two items were rated from $1=$ Strongly Disagree to $7=$ Strongly Agree, while the last item was responded to on a seven point scale from $1=$ Not at all to $7=$ A lot.

In addition to tapping in theoretical aspects of the intergroup context, the items also reflected dimensions of intergroup relations that emerged from interviews with AEC professionals from the same population as the present study. All questions with regards to group norms, perceptions of intergroup context, group identification, perceived power differentials and legitimacy thereof were asked in an array format requiring answering for both identification with professional groups and their organization/firm. This way, the aim was to identify whether professional or organizational affiliation perception influences LEED and Green Globes adoption intentions.

\section{Measurement of Reasoned Action Approach constructs ${ }^{2}$}

The RAA part of the survey instrument was constructed based on the recommendations given by Ajzen (1991) and the results of the qualitative pilot interview study (Chapter 3). After constructing the questionnaire, the survey was pre-tested with the help of five building professionals from the North East of the US, filling in the questionnaire and giving feed-back on the structure and measures of the survey items. The survey instrument was adjusted accordingly. The final instrument included the variables specified by the Reasoned Action Approach/ Theory of Planned Behavior. All questionnaire items were ranked on a 7-point rating scale. Two items were used to measure behavioral intention: "I expect that my next commercial building project will include the certification scheme" and "I intend

\footnotetext{
${ }^{2}$ The measurements in this chapter are in line with the measurements described in earlier chapters, most notably Chapter 4.
} 
to integrate the certification scheme in my next commercial building project": Strongly Agree/Strongly Disagree.

Attitude was measured using four items: "Working with the scheme is/would be (Very pleasant/Very unpleasant); " The certification scheme has established clear guidelines for sustainability practices in the building industry"(Strongly Agree/Strongly Disagree); "I think that the _scheme has educated me about sustainable building practices" (Strongly Agree/Strongly Disagree); "I think that the certification scheme has provided building professionals with a common language regarding sustainable construction practices" (Strongly Agree/Strongly Disagree).

Subjective Norms were measured with six items: "Most important people in the building industry think that I should work with the certification scheme"(Strongly Agree/ Strongly Disagree); "Most important people in the building industry work with the scheme (Strongly Agree/Strongly Disagree); "Government/City/State officials expect me to work with the scheme (Strongly Agree/Strongly Disagree); "Clients expect me to work with the scheme"(Strongly Agree/Strongly Disagree); "Co-workers expect me to work with the scheme"(Strongly Agree/Strongly Disagree); "Other building professionals expect me to work with the scheme"(Strongly Agree/Strongly Disagree).

Lastly, Perceived Behavioral Control (PBC) was measured with five items: " The decision to work with the scheme is entirely up to me"( Strongly Agree/Strongly Disagree); "It would be easy for me to integrate the certification scheme if I wanted to" (Strongly Agree/Strongly Disagree); "Organizational practices in my firm prevent me from working with the ___ scheme" (Strongly Agree/Strongly Disagree); "Financial constraints prevent me from working with the scheme" (Strongly Agree/Strongly Disagree); "Other building professionals' decisions prevent me from working with the scheme" ( Strongly Agree/Strongly

Disagree). The last three items were reverse-coded.

\section{Control and Background variables}

To control for confounding demographic effects, control variables including sex, age, job tenure, education level, firm type, regional location and previous sustainability education and personal sustainability attitudes were included in the regression analysis. All control variables were dummy coded.

\subsection{Data}

The data were collected between April and July 2011 in a survey administered in the US and Canada. The two countries were chosen as they share several similar characteristics such as similar cultural background and the same environmental building rating schemes. The 
invitations were emailed to a building professionals in each country selected from National Professionals Accreditation boards and Green Building Council databases.

After an initial elicitation interview study, described in Chapter 3, the questionnaire was programmed in Lime Survey software and tested with AEC building professionals in the North-East of the United States. After sending out the survey with a link provided to the hosting website and two email reminders, 341 AEC professionals answered the survey in total. Of these respondents, 232 were from Canada and 109 respondents from the United States. The response rate overall was $7 \%$.

Architects accounted for $57 \%$ of the respondents, with engineers representing $24 \%$ of the respondent sample. The third most common professional group was construction professionals (e.g. builders, construction workers etc.) with $10 \%$ of respondents falling in this category. The remaining other $9 \%$ of respondents belonged to various other professional groups from across the AEC industry.Architects and engineers were retained in the sample as self-standing categories due to sufficient respondent numbers while the remaining professionals were grouped and coded as "other" for subsequent between-group analysis. As for the firm types, $51 \%$ of the respondents worked in architecture firms, $18 \%$ of the respondents were employed in engineering firms while $14 \%$ respondents worked in combined architectural and engineering firms. A further $14 \%$ of respondents were employed in construction and commissioning firms. The remainder of respondents worked for various types of AEC organizations such as planning firms or real estate developers. Females represented $31 \%$ and males represented $69 \%$ of the respondent group, which is in line with the demographic composition in the AEC industry.

As for the professional level overall within the organization, $11 \%$ of all respondents occupied a junior-level position, while $24 \%$ worked in a mid-career position, $31 \%$ were employed in a senior-level position and 33\% of respondent sample occupied CEO, executive and partner-level positions. Most respondents held a post-secondary qualification, with 50\% at the Bachelor level while 39\% held a Master's qualification. The remaining $11 \%$ of respondents held a number of vocational qualifications related to the AEC industry. During their post-secondary education, $41 \%$ of the respondent sample had taken classes with some sustainability component while $59 \%$ had not followed any such courses. A further $2 \%$ could not remember whether their courses had included sustainability elements. Of the respondent sample, $83 \%$ had worked on a LEED project while only $11 \%$ of respondents had worked on a Green Globes project.

After excluding respondents that had not provided answers to all required key variables, 215 building professional were retained to determine factors for LEED adoption, while 71 respondents were retained to analyse determinants of Green Globes adoption. The difference in respondent numbers can be explained by lower numbers of respondents that provided all answers for key variables needed for the Green Globes analysis. As adoption 


\begin{tabular}{lccc}
\hline & Architects & $\begin{array}{l}\text { Construction } \\
\text { professionals }\end{array}$ & Engineers \\
\hline $\begin{array}{l}\text { Percentage of the respondents on the } \\
\text { AGREE spectrum ("Strongly Agree", "Agree” }\end{array}$ & $62 \%$ & $50 \%$ & $66 \%$ \\
$\begin{array}{l}\text { or "Somewhat Agree") as a percentage of } \\
\text { ALL respondents in survey }\end{array}$ & & & \\
\hline Source: Author's own data (2011). & & &
\end{tabular}

Table 7.1: Perceived influence of professional groups in the building and construction industry (as percentage of respondents)

of LEED and Green Globes are not mutually exclusive, the potential for respondents being included in both response samples was permitted. For more detailed information on LEED and Green Globes respondent characteristics, please refer to Appendix C.

\subsection{Results}

\section{Descriptive analysis of professional groups and sustainability}

In the first instance, frequency analysis was performed on several individual question items to get an initial understanding of group perceptions in the building and construction industry. The responses to the items were categorized according to the three major AEC industry groups in the sample, architects, construction professionals and engineers.

As Table 7.1 demonstrates, $66 \%$ of the responding engineers stated that all professional groups in the building industry have ample input into sustainability practices in the building industry more than architects $(62 \%)$ and construction professionals $(50 \%)$ considered being the case.

When prompted about which professional groups were thought to have little influence in the building and construction industry (Table 7.2), less than a quarter (architects: $21 \%$, construction professionals: $21 \%$, engineers: $20 \%$ ) of each professional group thought that their own group was not able to influence the sustainability debate significantly. As for rating other building professionals, construction professionals varied most in their assessment of influence of other AEC industry associated groups: Only $11 \%$ of construction sector respondents considered landscape architects to have little influence on sustainability practices while $28 \%$ of construction sector respondents thought urban planners were not in a position to have an impact on environmentally friendly construction.

In line with the previous summary, the overall agreement (i.e. "Strongly agree" and "Agree" answer options) with sustainability practices was found to be quite high for all three major 


\begin{tabular}{lccc}
\hline & Architects & $\begin{array}{c}\text { Construction } \\
\text { professionals }\end{array}$ & Engineers \\
\hline Architects & $21 \%$ & $28 \%$ & $24 \%$ \\
Constructors & $16 \%$ & $21 \%$ & $18 \%$ \\
Engineers & $19 \%$ & $21 \%$ & $20 \%$ \\
Interior Designers & $16 \%$ & $14 \%$ & $26 \%$ \\
Landscape & $19 \%$ & $11 \%$ & $18 \%$ \\
Architects & & & \\
Real Estate & $17 \%$ & $25 \%$ & $19 \%$ \\
Developers & & & \\
City Officials & $22 \%$ & $28 \%$ & $26 \%$ \\
Commissioners & $17 \%$ & $28 \%$ & $19 \%$ \\
Urban Planners & $18 \%$ & $28 \%$ & $21 \%$ \\
\hline
\end{tabular}

Source: Author's own data (2011).

Table 7.2: Professional groups with perceived limited influence in the building and construction industry ( as percentage of respondents)

\begin{tabular}{lccc}
\hline $\begin{array}{l}\text { Agreement } \\
\text { with... }\end{array}$ & Architect & Construction & Engineer \\
\hline Total & $65 \%$ & $73 \%$ & $67 \%$ \\
\hline Source: Author's own data (2011). & &
\end{tabular}

Table 7.3: Agreement with environmental sustainability practices in the building and construction industry (as percentage of respondents)

AEC industry professions surveyed (Table 7.3).

Interestingly, construction professionals were most content with current sustainability practices $(73 \%)$, while engineers $(67 \%)$ and architects $(65 \%)$ were so to a lesser extent. As construction professionals overall have the reputation of being less open to environmental innovation overall, the agreement of the construction professionals with current practices may hinder the advancement green construction this professional group.

The assumption that interest levels in sustainability across the AEC industry differ across professional groups is substantiated in Table 7.4: Less than 10\% of respondents from each of the three major building groups thought that all groups in the building industry had the same level of interest for sustainable building practices.

When prompted which of the AEC professional groups were most likely to engage in sustainable building practices (Table 7.5), however, architects considered their own group 


\begin{tabular}{lccc}
\hline & Architects & Construction & Engineers \\
\hline Total & $8 \%$ & $7 \%$ & $10 \%$ \\
\hline Source: Author's own data (2011). & &
\end{tabular}

Table 7.4: Perceived interest in sustainability practices by professional groups in the building and construction industry (as percentage of respondents)

\begin{tabular}{lccc}
\hline & Architects & Engineers & Constructors \\
\hline Architects & $73 \%$ & $59 \%$ & $66 \%$ \\
Engineers & $48 \%$ & $62 \%$ & $54 \%$ \\
Constructors & $11 \%$ & $22 \%$ & $36 \%$ \\
Commissioner & $17 \%$ & $19 \%$ & $18 \%$ \\
Urban Planners & $28 \%$ & $18 \%$ & $27 \%$ \\
Interior Designers & $20 \%$ & $18 \%$ & $24 \%$ \\
Landscape architects & $46 \%$ & $25 \%$ & $39 \%$ \\
\hline
\end{tabular}

*The answer format was included as a multiple choice item with several choice options to be selected. Source: Author's own data (2011).

Table 7.5: Likelihood of professional groups in the building and construction industry to engage in sustainable building practices (as percentage of respondents)*

to be most likely to engage in green construction (73\%), a higher percentage than engineers (48\%) and landscape architects (46\%). Engineers also considered their own professional group to be most environmentally sustainable ( $62 \%$ of the respondents in the sample), just before architects (59\%) with other building professions faring much worse.

Interestingly, construction professionals seemed to be more self-conscious on their environmental record with only $36 \%$ of respondents thinking of their own professional group as the most environmentally savvy. From their perspective, architects (66\%), engineers (54\%) and landscape architects (39\%) were more likely to have a better environmental record.

However, when directly prompted whether more people from their own professional group engaged in sustainable building practices than from other professional groups (Table 7.6), the percentage numbers of respondents who either strongly agreed or agreed with this statement were markedly lower: Only $44 \%$ of architects, $40 \%$ of engineers and $13 \%$ of construction professionals subscribed to this point of view. In Table 7.5, building professionals were requested to name the groups that are most likely to adopt environmental building rating schemes. However, directly probing the respondents seemed to make them more reluctant to name their own professional group as the most sustainably conscious.

The descriptive analysis above suggests that in rating themselves and other professional 


\begin{tabular}{lccc}
\hline & Architect & Engineers & Constructors \\
\hline Total & $44 \%$ & $40 \%$ & $13 \%$ \\
\hline
\end{tabular}

Source: Author's own data (2011).

Table 7.6: Perception of respondens' own professional group and its sustainability practices in the building and construction industry (as percentage of respondents)

groups, there seems to be a perceived differential in environmental engagement across professions in the building and construction industry. However, the perceptions of other groups in this section is merely an indicator that intergroup perceptions and group norms may play a role in the adoption of environmental building rating and assessment schemes such as LEED and Green Globes. In addition, individual items analyzed only dealt with professional groups and did not include organizational group perceptions. However, this differentiation between professional and organizational group identity was introduced in the correlation and regression analysis.

\section{Correlations}

In line with the statements described in the measurement section, pairwise correlations were performed for the Reasoned Action Approach (attitudes, subjective norms and perceived behavioral control) and Social Identity constructs (group norms, group identity and intergroup perception) for both the LEED (Table 7.7) and Green Globes (Table 7.8) schemes following Terry et al. (1999) and Fielding et al. (2008).

The intention to adopt the LEED scheme was positively correlated with norms (0.53), perceived behavioral control $(0.35)$, attitudes $(0.25)$, professional group norms $(0.25)$, organizational group norms $(0.22)$, professional group identity $(0.24)$, organizational group identity (0.17), professional intergroup perception (0.16) and organizational intergroup perception (0.19). At the same time, the intention to adopt the LEED scheme was positively correlated with norms $(0.74)$, perceived behavioral control (0.16), attitudes $(0.37)$, professional intergroup perception $(0.14)$ and organizational intergroup perception $(0.18)$.

\section{Regression analysis}

After the preliminary frequency and correlation analyses, linear regressions were performed with the intention to work on a LEED and/or Green Globes scheme within the next months as the dependent variable. The Reasoned Action Approach (RAA) constructs, as explained in Chapters 2-4 were complemented derived from social identity and self-categorization frameworks as well as demographic background information. The approach developed by 


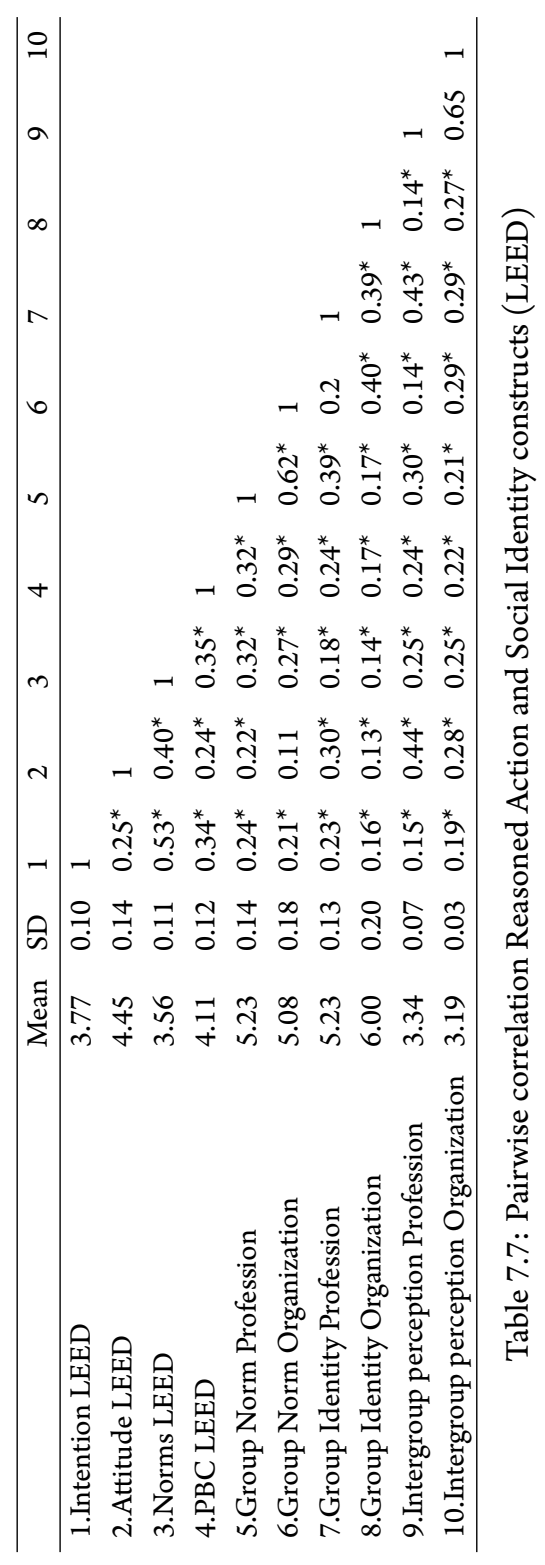




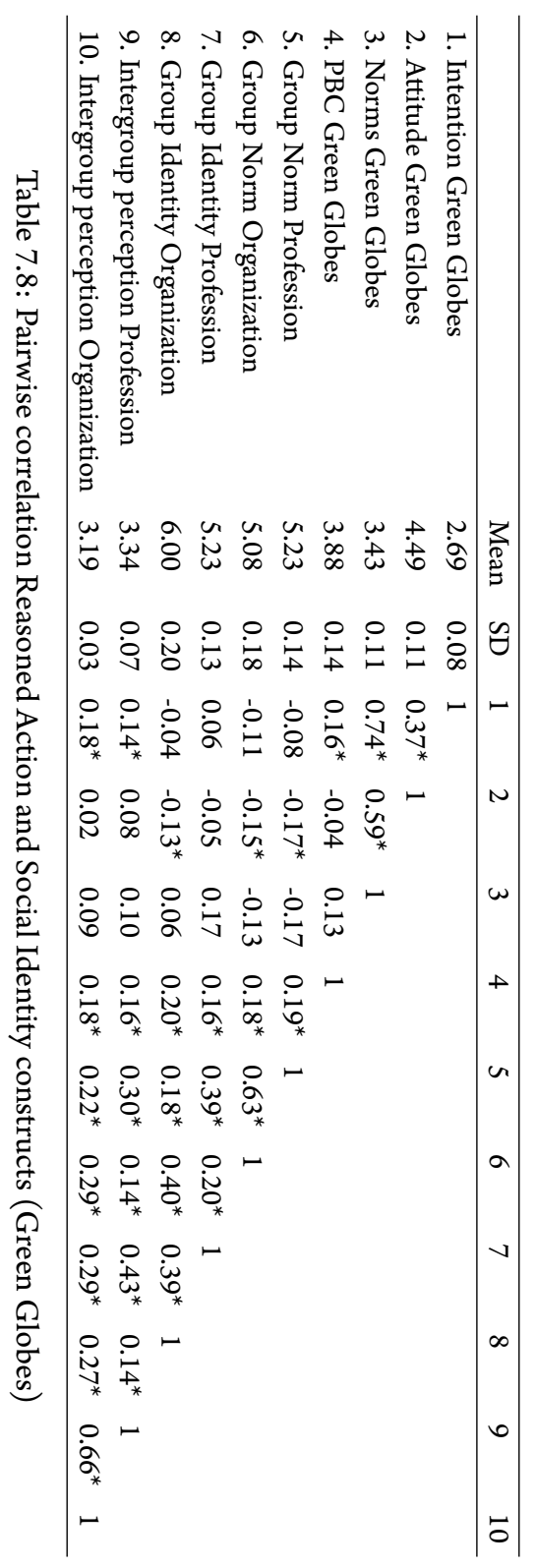


Fielding and et al. (2008) as well as Terry et al. (1999) was adapted for the purpose of this analysis.

\section{Linear regression: Intention to work on a LEED project}

As the results presented in Table 8.3 suggest, the intention to integrate the LEED scheme was found to be predicted at the $95 \%$ level by attitudes $(\beta=0.1)$, subjective norms $(\beta=0.17)$ and perceived behavioral control $(\beta=0.1)$. In addition, having worked on a LEED project in the past also heightened the probability of intending to work on a LEED scheme in the future, in line with the results presented in previous chapters. Interestingly, none of the SIT variables was found to be significant for the LEED scheme.

\section{Linear regression: Intention to work on a Green Globes project}

As the results presented in Table 7.10 suggest, the intention to integrate the Green Globes scheme was predicted at the $95 \%$ level by subjective norms $(\beta=0.26)$. From the set of social identity constructs, organizational intergroup perception had a positive effect on the intention to work with the Green Globes scheme while professional intergroup perception was not found to influence behavioral intention. This result suggests that perceiving other organizations positively may be more important, at least for some behaviors, in the fragmented and project-based building and construction industry. An explanation why this variable was found to be significant for the Green Globes scheme could be that for lesser known scheme positive perceptions of contract partners may be more crucial than for more established activities. None of the background variables was found to be significant.

\subsection{Discussion and Limitations}

As the descriptive, correlations and regression analyses suggest, constructs derived from the social identity theory (SIT) can be very useful when analyzing intentions and behavior to work on a green building VEP. In line with previous research, constructs from SIT added to other models predicting intention and behavior can add further to explaining variance in behavior (e.g. Fielding et al., 2008).

However, the influence does not seem to be straight forward. While the pairwise correlation analyses demonstrate significance between intentions to work on a LEED or Green Globes scheme and social identity constructs, no significant effect was detected when controlled for in regression analyses beyond the importance of organizational intergroup perceptions for Green Globes uptake. The social identity constructs, however, were not found to be statistically significant for the more well-known LEED program. Hence, in this case cooperation as discussed in Chapter 6 and the present study seems to be difficult to measure and detect both theoretically and empirically due to its multidimensional nature. 


\begin{tabular}{|c|c|c|c|c|c|c|}
\hline Step & $\mathrm{R}^{2}$ & $\Delta \mathrm{R}^{2}$ & $\begin{array}{l}\text { RAA } \\
\beta\end{array}$ & $\begin{array}{l}\beta \text { after } \\
\text { Past } \\
\text { Behavior }\end{array}$ & $\begin{array}{l}\beta \\
\text { after } \\
\text { SIT }\end{array}$ & $\begin{array}{l}\text { Final } \\
\beta\end{array}$ \\
\hline \multicolumn{7}{|l|}{ Step $1:$ RAA } \\
\hline Attitude & $0.32^{* * *}$ & & $0.09^{* * *}$ & $0.10^{* * *}$ & $0.10^{* * *}$ & $0.10^{* * *}$ \\
\hline Norms & & & $0.19^{* * *}$ & $0.18^{* * *}$ & $0.17^{* * *}$ & $0.17^{* * *}$ \\
\hline Perceived Control & & & $0.11^{* * *}$ & $0.11^{* * *}$ & $0.10^{* * *}$ & $0.10^{* * *}$ \\
\hline \multicolumn{7}{|l|}{ Step 2: Past Behavior } \\
\hline Past LEED (=yes) & $0.37^{* * *}$ & $0.03^{* * *}$ & & $1.52^{* * *}$ & $1.52^{* * *}$ & $1.43^{* * *}$ \\
\hline Step3: Social Identity & $0.39^{* * *}$ & 0.01 & & & ns & ns \\
\hline Group norms professional & & & & & ns & ns \\
\hline Group norms organizational & & & & & ns & ns \\
\hline Group identity professional & & & & & ns & ns \\
\hline Group identity organisational & & & & & ns & ns \\
\hline Intergroup perception professional & & & & & ns & ns \\
\hline Intergroup perception organizational & & & & & ns & ns \\
\hline Step 4: Background variables & $0.40^{* * *}$ & 0.01 & & & & ns \\
\hline Architect & & & & & & ns \\
\hline Engineer & & & & & & ns \\
\hline Construction professional & & & & & & ns \\
\hline Architecture firm & & & & & & ns \\
\hline Engineering firm & & & & & & ns \\
\hline Combined Arch/Eng. Firm & & & & & & ns \\
\hline US & & & & & & ns \\
\hline Canada & & & & & & ns \\
\hline Female & & & & & & ns \\
\hline Junior level (profession) & & & & & & ns \\
\hline Bachelor education & & & & & & ns \\
\hline \multicolumn{7}{|l|}{ Sustainability (=yes) } \\
\hline *nดn 1,**n & (N) & nses) & & & & \\
\hline
\end{tabular}

Note: After the LEED regression analysis, Variance Inflation Factors (VIF) were calculated for both explanatory variables individually and the regression equation overall. All VIFs were under 4 , with an equation mean VIF of 2.25. The VIFs for SIT constructs were: past behavior (1.18), self-identity (1.25), attitude (1.52), norms (1.51), PBC (1.34), group norms organization (2.23), group norms profession (2.41), intergroup organization (2.36), intergroup profession (2.07), group identity organization (1.93) and group identity profession (1.73), Hence, the VIF results suggest that multicollinearity is not an issue in this analysis.

Table 7.9: LEED adoption intention. Regression Analysis with Intention as the Dependent Variable 


\begin{tabular}{|c|c|c|c|c|c|c|}
\hline Step & $\mathrm{R}^{2}$ & $\Delta \mathrm{R}^{2}$ & $\begin{array}{l}\text { RAA } \\
\beta\end{array}$ & $\begin{array}{l}\beta \text { after } \\
\text { Past } \\
\text { Behavior }\end{array}$ & $\begin{array}{l}\beta \text { after } \\
\text { SIT }\end{array}$ & $\begin{array}{l}\text { Final } \\
\beta\end{array}$ \\
\hline \multicolumn{7}{|l|}{ Step 1: RAA } \\
\hline Attitude & $0.50^{* * *}$ & & ns & ns & ns & ns \\
\hline Norms & & & $0.29^{* * *}$ & $0.26^{* * *}$ & $0.25^{* * *}$ & $0.25^{* * *}$ \\
\hline Perceived Control & & & ns & ns & ns & ns \\
\hline \multicolumn{7}{|l|}{ Step 2: Past Behavior } \\
\hline \multirow[t]{2}{*}{ Past GG (=yes) } & $0.55^{* * *}$ & $0.05^{* * *}$ & & $-1.80^{* * *}$ & - & - \\
\hline & & & & & $1.70^{* * *}$ & $1.60^{* * *}$ \\
\hline \multicolumn{7}{|l|}{ Step3: Social Identity } \\
\hline Group norms professional & $0.64^{* * *}$ & $0.09^{* * *}$ & & & ns & ns \\
\hline Group norms organizational & & & & & ns & ns \\
\hline Group identity professional & & & & & ns & ns \\
\hline Group identity organisational & & & & & ns & ns \\
\hline Intergroup perception professional & & & & & ns & ns \\
\hline Intergroup perception organizational & & & & & $0.28^{* * *}$ & $0.27^{* * *}$ \\
\hline \multicolumn{7}{|l|}{ Step 4: Background variables } \\
\hline Architect & $0.70^{* * *}$ & 0.05 & & & & ns \\
\hline Engineer & & & & & & ns \\
\hline Construction professional & & & & & & ns \\
\hline Architecture firm & & & & & & ns \\
\hline Engineering firm & & & & & & ns \\
\hline Combined Arch/Eng. Firm & & & & & & ns \\
\hline US & & & & & & ns \\
\hline Canada & & & & & & ns \\
\hline Female & & & & & & ns \\
\hline Junior level (profession) & & & & & & ns \\
\hline Bachelor education & & & & & & ns \\
\hline Sustainability (=yes) & & & & & & ns \\
\hline${ }^{*} \mathrm{p}<0.1 ;{ }^{* *} \mathrm{p}<0.05 ;{ }^{* * *} \mathrm{p}<0.01$ & Full resp & onses) & & & & \\
\hline
\end{tabular}

Note: After the Green Globes regression analysis, Variance Inflation Factors (VIF) were calculated for both explanatory variables individually and the regression equation overall. All VIFs were under 4, with an equation mean VIF of 2.61 The VIFs for SIT constructs were: past behavior (1.56), self-identity (1.42), attitude (1.90), PBC (1.67), norms (2.07), group norms organization (3.34), group norms profession (2.84), intergroup organization (2.80), intergroup profession (1.95), group identity organization (2.30) and group identity profession (2.25),. Hence, the VIF results suggest that multicollinearity is not an issue in this analysis.

Table 7.10: Green Globes adoption intention. Regression Analysis with Intention as the Dependent Variable 
In line with other chapters in this dissertation, the data suggests that different environmental building rating and assessment schemes need to be considered as separate sets of behaviors instead of standardized schemes that will follow similar adoption patterns. A hypothesis that can be derived from this chapter, however, is that, in the case of Green Globes the positive perception of project partners can positively influence the decision to engage in a lesser known environmental program.

As the descriptive analysis has demonstrated, professional groups in the building industry are perceived differently in terms of environmental engagement and sustainability practices of other project partners. While professional groups may be the intuitive demarcation line, research in organizational group identity and affiliation needs to be advanced further to understand the influence of organizational practices on environmental sustainability in the building and construction industry.

This chapter faces two main categories of limitations: theoretical and empirical. On the theoretical side, despite its broad influence, the Social Identity Approach (SIA) has not been without critics (e.g. Rabbie et al., 1989; Turner and Reynolds, 2001). At a time when there is growing attention given to subgroup identities, cross-cutting identities, relational identities, out-group identification, and the complex intersection of personal and collective identity, the relationships between variables proposed in the original SCT model can appear rigid and over-simplified (Abrams \& Hogg, 2004). Other critics ascertain that, with its focus on individual processes and social cognition, the human model it proposes is too reductionist and individualistic-focused (Farr, 1996). Finally, there are repeated claims that the Social Identity Approach (SIA) is more comfortable explaining in-group favoritism than out-group problems and inter-group conflicts (Brewer, 1979; Brown, 1995). While group norms and intergroup relations are extremely influential for individuals, the role of the individual in shaping these group norms has been less discussed in the SIA (both for SIT and SCT) (Hornsey, 2006; Postmes \& Jetten, 2006; Postmes, Spears, Lee, \& Novak, 2005). This reversed relationship of influence was out of scope for the purpose of this study and should be investigated more thoroughly in the future.

From an empirical point of view, the survey approach, necessitated by geographical restrictions has imposed additional limitations on this study. While it could be argued that there is a significant self-selection bias in the responses (i.e. AEC professionals with an interest in environmental issues are more likely to respond and be more positive about environmental programs), this assumption has not been and cannot be confirmed. It can be argued that this is the case due the AEC industry not seeing their primary concern as environmental in nature but to construct buildings that are stable and functional. While voluntary schemes such as LEED deal with environmental and sustainability issues, the overall discourse is not emotional but rather pragmatic. 


\subsection{Conclusion}

In this chapter, the aim was to further analyze cooperative behavior in the building industry. To do this, elements from Social Identity Theory were introduced to the analysis of green building VEP adoption and integrated with the Reasoned Action Approach (RAA) (Fishbein and Ajzen, 2011) described in previous chapters. To analyze whether group norms, intergroup perceptions and group identity can influence building professionals' intention to adopt environmental building rating and assessment schemes, such as LEED and Green Globes. The building and construction industry with a large number of professional groups and organizations working together on a project is a great example of how group norms, intergroup perceptions and group identity can influence project outcomes. However, the results of the analysis carried out in this chapter suggest that the Social Identity Theory may be more appropriate in, cases when a behavior is less known and standardized. In the context of this chapter, only intergroup perceptions with regards to organizations were found to be significant to influence the adoption intention of the lesser known Green Globes scheme.

While not part of social identity constructs, demographic variables also pointed towards organizational effects influencing environmental building rating scheme uptake: For both the LEED and Green Globes scheme, respondents working in cross-professional organizations (i.e. combined architecture and engineering firms) displayed higher intention levels in terms of working on a project integrating these schemes.

Reasoned Action Approach (RAA) constructs emerged as significant predictors of intentions of working on LEED and Green Globes projects. While Perceived Behavioral Control (PBC) mattered for LEED adoption but not Green Globes, the strongest predictor in both cases was subjective norms. Group norms in this study were not found to be significant for either behavior. However, intergroup perceptions were found to be significant only for the Green Globes scheme, and only on the organizational dimension. Despite the common assumption that professional group affiliation and perception will be more significant in the fragmented building industry, perception of organizations seems to be more significant in certain contexts. This outcome relates to the fact that in work contexts most people have multiple identities (e.g. Ashfort and Johnson, 2001; Johnson et al., 2006), and organizations as the "salary provider" may offer more (direct or indirect) incentives for identification.

Based on social identity concepts, it was predicted that individuals that perceive more positive intergroup relations will be more likely to participate in behaviors that include out-groups (Fielding et al., 2008). In line with previous research (Fielding et al., 2008), the importance of intergroup perceptions for environmental decision-making is highlighted. Further investigations are needed to develop the contributions of the Social Identity Approach (SIA) in the analysis of normative influences in the building industry, green VEP uptake and behavior change interventions. 


\section{References}

Abbott, A. (1988). The system of professions: An essay on the division of expert labor. University of Chicago Press.

Ashforth, B. E., \& Johnson, S. A. (2001). Which hat to wear? the relative salience of multiple identities in organizational contexts. In (Vol. 31, p. 31-48).

Ashforth, B. E., \& Mael, F. (1989). Social identity theory and the organization. Academy of management review, 14(1), 20-39.

Ashforth, B. K., \& Saks, A. M. (1996). Socialization tactics: Longitudinal effects on newcomer adjustment. Academy of management Journal, 39(1), 149-178.

Brown, R., Condor, S., Mathews, A., Wade, G., \& Williams, J. (1986). Explaining intergroup differentiation in an industrial organization. Journal of Occupational psychology, 59(4), 273-286.

Cordano, M., \& Frieze, I. H. (2000). Pollution reduction preferences of us environmental managers: Applying ajzen's theory of planned behavior. Academy of Management Journal, 43(4), 627-641.

Dutton, J. E., Dukerich, J. M., \& Harquail, C. V. (1994). Organizational images and member identification. Administrative science quarterly, 39(2), 239-263.

Fekadu, Z., \& Kraft, P. (2002). Expanding the theory of planned behaviour: The role of social norms and group identification. Journal of health psychology, 7(1), 33-43.

Fielding, K. S., Terry, D. J., Masser, B. M., \& Hogg, M. A. (2008). Integrating social identity theory and the theory of planned behaviour to explain decisions to engage in sustainable agricultural practices. British Journal of Social Psychology, 47(1), 23-48.

Fishbein, M. (2008). A reasoned action approach to health promotion. Medical Decision Making, 28(6), 834-844.

Fishbein, M., \& Ajzen, I. (1975). Belief, attitude, intention and behavior: An introduction to theory and research. Reading, MA.: Addison-Wesley.

Fishbein, M., \& Ajzen, I. (2011). Predicting and changing behavior: The reasoned action approach. Psychology Press.

Freidson, E. (1994). Professionalism reborn: Theory, prophecy, and policy. University of Chicago Press.

Gaertner, S. L., Dovidio, J. F., Anastasio, P. A., Bachman, B. A., \& Rust, M. C. (1993). The common ingroup identity model: Recategorization and the reduction of intergroup bias. European review of social psychology, 4(1), 1-26.

Hogg, M. A., \& Abrams, D. (1990). Social identity theory: Constructive and critical advances. In D. Abrams \& M. Hogg (Eds.), (chap. Social motivation, self-esteem and social identity). New York: Springer Verlag.

Hogg, M. A., \& Hains, S. C. (1996). Intergroup relations and group solidarity: Effects of group identification and social beliefs on depersonalized attraction. Journal of Personality and Social Psychology, 70(2), 295-309. 
Hogg, M. A., \& Smith, J. R. (2007). Attitudes in social context: A social identity perspective. European Review of Social Psychology, 18(1), 89-131.

Hornsey, M. J. (2008). Social identity theory and self-categorization theory: A historical review. Social and Personality Psychology Compass, 2(1), 204-222.

Hotho, S. (2008). Professional identity-product of structure, product of choice: linking changing professional identity and changing professions. Journal of Organizational Change Management, 21(6), 721-742.

Johnson, M. D., Morgeson, F. P., Ilgen, D. R., Meyer, C. J., \& Lloyd, J. W. (2006). Multiple professional identities: examining differences in identification across work-related targets. Journal of Applied Psychology, 91(2), 498-506.

Johnston, K. L., \& White, K. M. (2003). Binge-drinking: A test of the role of group norms in the theory of planned behaviour. Psychology and Health, 18(1), 63-77.

Macdonald, K. M. (1995). The sociology of the professions. Sage.

Mael, F., \& Ashforth, B. E. (1992). Alumni and their alma mater: A partial test of the reformulated model of organizational identification. Journal of organizational Behavior, 13(2), 103-123.

Martin-Pena, M. L., Diaz-Garrido, E., \& Sanchez-Lopez, J. M. (2010). Relation between management's behavioural intentions toward the environment and environmental actions. Journal of Environmental Planning and Management, 53(3), 297-315.

Mieg, H. A. (2008). Professionalisation and professional identities of environmental experts: the case of switzerland. Environmental sciences, 5(1), 41-51.

Norman, P., Clark, T., \& Walker, G. (2005). The theory of planned behavior, descriptive norms, and the moderating role of group identification. Journal of Applied Social Psychology, 35(5), 1008-1029.

Rabbie, J. M., Schot, J. C., \& Visser, L. (1989). Social identity theory: A conceptual and empirical critique from the perspective of a behavioural interaction model. European Journal of Social Psychology, 19(3), 171-202.

Reed, M. I. (1996). Expert power and control in late modernity: an empirical review and theoretical synthesis. Organization studies, 17(4), 573-597.

Styhre, A. (2012). Identification work in the construction industry: Ideal selves, project performance, and disidentification. Leadership \& Organization Development Journal, $33(7), 632-645$.

Tajfel, H. (1978). Differentiation between social groups: Studies in the social psychology of intergroup relations. Academic Press.

Tajfel, H. (1981). Intergroup behavior. In J. Turner \& H. Giles (Eds.), (pp. 144-167). Oxford, UK.: Blackwell.

Tajfel, H., \& Billic, M. (1974). Familiarity and categorization in intergroup behavior. Journal of Experimental Social Psychology, 10(2), 159-170.

Tajfel, H., Billig, M. G., Bundy, R. P., \& Flament, C. (1971). Social categorization and intergroup behaviour. European journal of social psychology, 1(2), 149-178. 
Tajfel, H., \& Turner, J. C. (1979). The social psychology of intergroup relations. In (Vol. 33, p. 33- 47). Monterey, CA.: Brooks/Cole.

Tajfel, H., \& Wilkes, A. L. (1963). Classification and quantitative judgement. British Journal of Psychology, 54(2), 101-114.

Terry, D. J., \& Hogg, M. A. (1996). Group norms and the attitude-behavior relationship: A role for group identification. Personality and Social Psychology Bulletin, 22(8), 776-793.

Thorbjørnsen, H., Pedersen, P. E., \& Nysveen, H. (2007). ” this is who i am”: Identity expressiveness and the theory of planned behavior. Psychology \& Marketing, 24(9), 763-785.

Turner, J. C., \& Reynolds, K. J. (2001). Blackwell handbook of social psychology: Intergroup processes. In (Vol. 4, pp. 133-152). Blackwell Oxford, England.

Van Knippenberg, D. (2000). Work motivation and performance: A social identity perspective. Applied psychology, 49(3), 357-371.

White, K. M., Hogg, M. A., \& Terry, D. J. (2002). Improving attitude-behavior correspondence through exposure to normative support from a salient ingroup. Basic and Applied Social Psychology, 24(2), 91-103.

White, K. M., Smith, J. R., Terry, D. J., Greenslade, J. H., \& McKimmie, B. M. (2009). Social influence in the theory of planned behaviour: The role of descriptive, injunctive, and in-group norms. British Journal of Social Psychology, 48(1), 135-158. 


\title{
Voluntary Professional Accreditation for Sustainability: An application of Self-Determination Theory to LEED AP professional accreditation in the United States and Canada.
}

\author{
"Any explanation or logic that explains everything so easily has a hidden trap in \\ it" (Haruki Murakami, Sputnik Sweetheart)
}

\subsection{Introduction}

\begin{abstract}
$Y$ reen building design has been repeatedly brought forward as a means to reduce $\mathrm{CO} 2$ emissions and other pollutants. However, green buildings can only be constructed (1) the political, legal and economic environment favors the development of green construction practices and (2) if building stakeholders are learning and implementing techniques and principles for sustainable building and design. Organizational practices and other constraints can prevent building professionals from applying their knowledge to industry practice. While actual control professionals can exert over the decision to work on Voluntary Environmental Programs (VEPs) is unknown, individuals have more control over taking professional accreditation exams, independent of whether they will subsequently apply the skills gained in building projects. Personal motivations may be irrelevant when external circumstances prevent building professionals from applying their knowledge. However, analyzing motivations to acquire additional green knowledge can be useful to determine whether industry practices are the result of individuals' intrinsic or extrinsic motivations.
\end{abstract}


Green construction professional credentials have become increasingly popular and multiple schemes have appeared around the Globe. In the context of green building VEP uptake, some credentialing schemes include the LEED accredited professional (LEED AP), Green Globes professional program and Green Advantage Certified Practitioner. The first two accreditation programs are associated with the two most commonly known green building VEPs, LEED and Green Globes.

These licensing programs integrate education about sustainable design and construction principles, but mainly aim to train professionals in the specific use of building rating and assessment schemes they are associated with (Tucker et al., 2012).

In this chapter, the focus is on the type of motivation what will predict the decision to obtain the LEED AP accreditation, an examination associated with Leadership in Environmental and Energy Design (LEED) in the United States and Canada. Motivations for obtaining the credentials will be assessed via both qualitative and quantitative data collected in the United States and Canada based on Self-Determination Theory (SDT) (Deci and Ryan, 2002).

\subsection{Third-party professional accreditation schemes in the building sector: The LEED AP scheme}

Voluntary building rating and assessment schemes, targeting improving environmental and energy sustainability, have become increasingly prominent when it comes to greening the building sector. Schemes are developed by a variety of organizations including Green Building Councils (GBCs) and other industry or NGO-affiliated organizations. According to Tucker et al.(2012), there are close to 30 other green building credentialing programs in the United States. While some of these schemes only apply to certain professions (e.g. Real estate developers or commercial valuers), others aim to appeal to a broader range of professions, such as the LEED AP scheme.

The LEED AP scheme is not the only voluntary professional accreditation scheme in the US and Canada. For instance, in the US the Green Advantage, Green Globes AP or the Certified Energy Efficiency Professional (CEEP) schemes were developed to train building professionals in sustainability practices. In the US, the Association of Energy Engineers (AEE) has developed energy accreditation programs such as the AEE Certified Energy manager (CEM) credential while the US department of Energy has commissioned Certified Energy Auditors (CEA) and Certified Building Commissioning Professional (CBCP) programs. None of these schemes are mandatory. In Canada, the Green Roof professional accreditation has become fairly popular. All of these professional accreditation programs, however, are aimed at professionals that had previous experience with environmental and energy issues. 
Buildings for which specific points and aspects of environmental and energy sustainability have been integrated in the design and construction process can obtain a bronze, silver, gold or platinum certification. Since the way green building VEPs operate can be quite different from usual practices, some of the organizations (i.e. GBCs) issuing voluntary building rating and assessment schemes also develop professional accreditation schemes to train building professionals for the application of their program. The aim of the LEED AP program, according to the issuing organization, the US GBC and the Green Building Certification Institute (GBCI) is:

"LEED Professional Credentials demonstrate current knowledge of green building technologies, best practices, and the rapidly evolving LEED Rating Systems. They show differentiation in a growing and competitive industry, and they allow for varied levels of specialization. A LEED Professional Credential provides employers, policymakers, and other stakeholders with assurances of an individual's level of competence and is the mark of the most qualified, educated, and influential green building professionals in the marketplace"(GBCI, 2011).

Voluntary accreditation and its mandatory equivalent, licensing, is common in the building sector. Many of the professions involved such as architects or engineers need to become part of a national registration body and take qualifying exams in order to be able to practice.

\subsection{Literature on professional accreditation schemes}

Non-compulsory accreditation has been neglected in the literature on environmental sustainability in the building and construction sector.

Lester (2000) suggested that individual accreditation by professional bodies and other organizations serve numerous purposes such as the creation of a measure of confidence, responding to client demands, creating additional legitimacy, setting service standards and protecting clients (Waddington, 1985).

The importance of accreditation ranges from being legally required (e.g. medical field or law) to recognition-providing with hardly any impact on employment opportunities (Lester, 2000). In between are semi-controlled professions in which practitioners need accreditation or licensing for certain tasks (e.g architecture or accountancy) or where additional accreditation may not be required but can have a positive effect on career trajectories (Lester, 2000). Certification and professional accreditation has gained importance in many professions and occupational areas (Harris \& Barnhart, 2001; Moran, 1996; Pare, 1999; Wiley, 1995).

From a building professionals' point of view accreditation can attest competency, enhance and change professional practices and promote desirable behaviors (Kleiner, 2006; Livingood \& Auld, 2001; Raymond, 2001), and may be used for job promotion, to garner power 
and prestige. Fertig et al. (2009) and Gioia and Carley (2002) call this issue "being good" versus "looking good". Collins (2007) criticizes that focusing overly on the "looking good" aspect of voluntary professional accreditation can undermine potential value and intended impact of the accreditation program.

Most accreditation schemes are based on very simple behavioral assumptions; theoretical knowledge assessment plays a major role (Bines, 1992). Not surprisingly, very few studies have focused on behavioral aspects of accreditation processes. Wiley $(1992,1995,1999)$ is a notable exception focusing on certification and accreditation in the Human Resources (HR) field.

In order to distinguish different motives and motivations responsible for accreditation efforts, Fertig et al. (2009) suggest the use of Self-Determination Theory (SDT) to test the motivation structure underlying the adoption of third-party certification schemes. Applied to the "being good" and "looking good" dichotomy (even though certainly a combination of both is possible), intrinsic motivations represent the "being good" while extrinsic motivations represent the "looking good" side of the spectrum.

Fertig et al. (2009) propose that professionals obtaining accreditation for intrinsic motivations will less likely use the accreditation as a symbol to gain advantages. Results from intrinsic motivations will also be more stable even if organizations mainly aim to establish legitimacy with stakeholders for image purposes (DiMaggio \& Powell, 1983). Hence, in the building and construction industry intrinsic motivation would point to less opportunistic behavior, and more reliable cooperation. It has been proposed that many accreditation programs testing procedures do not have absolute predictive validity over outcomes. As a result the sources of motivations become more crucial to identify whether professionals use schemes to improve their practices or merely as an positive image-creating tool. Even though extrinsic motivations may be predominant in occupational settings, intrinsic motivations can tell more about long-term success in practice transformation and behavior change (Fertig et al, 2009).

Previous research has considered the effectiveness of accreditation for career enhancement (Bruce et al., 2009). Generally, these studies found that accreditation overall had little effect on salaries or opportunities for climbing up the corporate ladder. However, recognition and associated prestige motivations within and across organizations was found to be significant. While this result may confirm extrinsic value for being accredited, this result does not provide whether extrinsic motivation played a major factor in the adoption procedures (Bruce et al., 2009).

One study that evaluated green building professional accreditation was conducted by Tucker et al. (2012) comparing the LEED Green Associate and the Green Globes professional scheme. While broadly differentiating between intrinsic and extrinsic motivations, their study is based on the rational actor model and does not differentiate between different levels 
of intrinsic and extrinsic motivation as well as amotivation and the potential to predict green professional accreditation decisions.

In the literature on pro-environmental behavior, intrinsic motivations have found to be preferable and better predictors of behavior than extrinsic motivations since the effects are usually longer lasting and stable (e.g. Osbaldiston and Sheldon, 2003).

\subsection{Theoretical framework: Self-Determination Theory (SDT)}

To investigate the contributions of intrinsic and extrinsic motivation to the analysis of green building VEP associated professional licensing, the present chapter is based on the Self-Determination Theory (SDT) analyzing human assimilation and adaption to social environments (Deci and Ryan, 1985; Ryan and Deci, 2002). This theoretical approach identifies several types of motivations that trigger actions. While basic distinctions in the realm of motivations are frequently made between intrinsic and extrinsic motivations, SDT refines these concepts further.

SDT is closely linked to processes of learning at the individual level. Cognitive structures represent higher levels of learning that define the context in which new experiences are interpreted. As a consequence of these new experiences, the cognitive structures are modified to integrate additional experiences in order to establish coherence (Deci and Ryan, 2002). Social situations, however, can either support or undermine an individual's tendency towards assimilation.. As a result, several motivational processes can be identified (Ryan, 1995). Intrinsic motivation, for instance, cannot be controlled by external stimuli and subjected to rewards (Deci, Koestner and Ryan, 2001; Deci, Ryan and Koestner, 2001; Ryan, 1995; Ryan and Deci, 2000b).

Self-determination Theory (SDT) is a meta-concept that includes four main sub-theories including (1) Cognitive Evaluation Theory (CET) describing the impact of psychological and social conditions on the propensity to perform behaviors out of intrinsic motivations (Deci, 1971); (2) Organismic Integration Theory (OIT) evaluating the degree of internalization along a continuum of extrinsically motivated behavior (Deci and Ryan, 2002); (3) Causality Orientations Theory (COT) investigating personality differences and their link to self-determined or controlled behaviors (Deci and Ryan, 2002) and (4)Basic Needs Theory (BNT) determining the importance of competence and autonomy with regards to motivation and well-being (Deci and Ryan, 2002).

Even though all sub-theories are interesting for analysis, in this study two SDT sub-theories (Cognitive Evaluation Theory (CET) and Organismic Integration Theory (OIT)) will be applied to the decision to obtain professional accreditation schemes in the building industry aiming to explain the influence of both extrinsic and intrinsic motivations. Hence, the chapter focuses on the adaptation of Cognitive Evaluation Theory (CET) (Deci and 


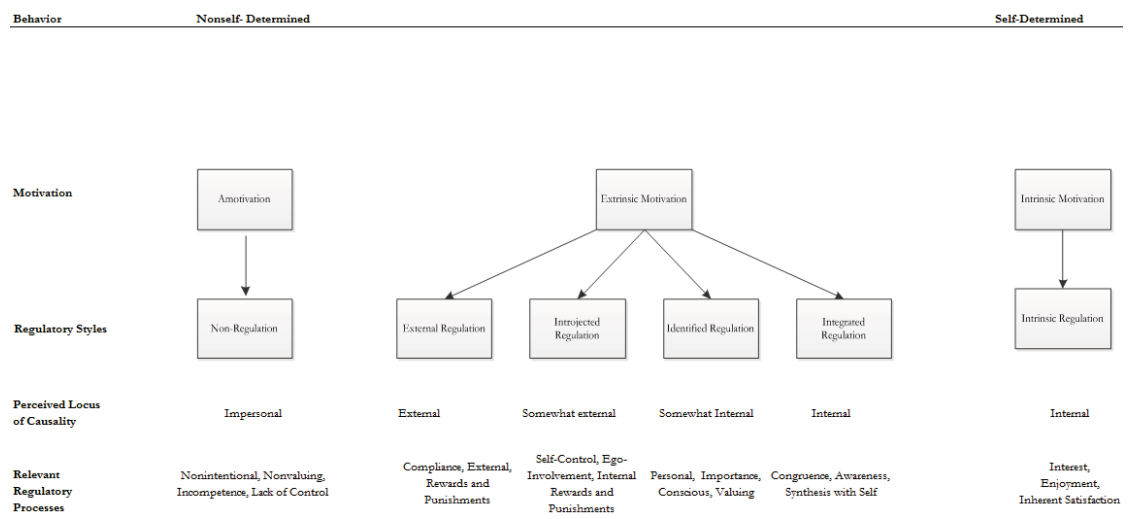

Figure 8.1: The motivational continuum according to Self-Determination Theory (SDT) (Deci and Ryan, 2000)

Ryan, 2002) focusing on intrinsic motivation and analyses the way social and external factors influence favor or bar intrinsic motivations.

To measure extrinsic motivation, which is stipulated by external sources, this chapter includes elements from the Organismic Integration Theory (OIT), as developed by Deci and Ryan (2002), a sub-theory explaining the ways in which extrinsically motivated behavior is regulated. OIT investigates the different types of extrinsic motivations and their origins. Within the OIT, four types of extrinsic motivations are specified which vary in terms of relative autonomy. "Externally regulated behavior" is performed because of external demands and potential rewards. In this case, the locus of control is perceived to be external. As for voluntary rating scheme accreditation, this could happen if a building professional does not perceive to have a choice in the adoption of an AP scheme. "Introjected regulation" of behavior does integrate external demands in cognitive processes while not fully accepting them as one's own.

"Regulation through identification" is more autonomy-based type of extrinsic motivation and includes valuing a goal or regulation to accept that behavior as personally important. "Integrated regulation", lastly, is the most autonomous kind of extrinsic motivation and occurs in situations when regulations and demands are fully assimilated with self and included in personal beliefs. This characteristic is shared with intrinsic motivations but since the sources of motivation are still extrinsic and not related to enjoyment and interest in tasks, this category needs to be differentiated from intrinsic motivations for analytical purposes. 
Motivations can be differentiated as followed, moving along a spectrum from fully external influences to fully internal reasons:

- Amotivation: In this case building professionals do not seek to obtain professional accreditation for sustainable design

- External regulation: In this case building professionals seek certification for rewards (e.g. promotion) only and not to improve knowledge or better performance.

- Introjected regulation: When building professionals seek LEED accreditation due to introjected regulations, the professional may wish to appear "valuable, genuine, hardworking, and interested" but not necessarily want to have these characteristics themselves (Lewis \& Neighbors, 2005, p. 471). Professionals in this category may obtain professional accreditation to keep up with their colleagues and peers. Hence, acting due to introjected regulation is a more internalized process but is still mainly dominated by external influences.

- Identified regulation: Building professionals seeking LEED AP accreditation or a comparable scheme may seek to obtain accreditation because they deem them to be important but not fully integrated with other aspects of their work environments and their self-perception.

- Integrated regulation: The most internalized form of extrinsic motivation is integrated regulation since behaviors are experienced as coherent with an individual's values. When seeking professional accreditation, not only benefits but also enhanced competencies and improving knowledge is considered to be of value, irrespective of rewards. While similar to intrinsic motivation, the stimulus for motivation emanates from external sources (e.g. group norms, etc.)

- Intrinsic motivations: Performing a behavior because it is perceived to be inherently interesting and important even without any external rewards. In this case, it is likely that LEED AP scheme is seen as advancing environmental sustainability in the building sector.

Many environmentally relevant human behaviors have been found not to be intrinsically motivated (Osbaldiston and Sheldon, 2003; Ryan, 1995). Humans have learned to adhere to the rule of law and to respect social norms. In some instances behavior can be a result of the desire to exist in social relationships without conflict (Ryan, 1995). This process can occur during internalization, when external behavioral regulations are assimilated into own cognitive structures and accepted as one's own (Deci and Ryan, 1990; Ryan, 1995: Ryan and Deci, 2002).

Self-Determination Theory (SDT) determines factors within the social context that support internalization processes and can also be applied to intervention programs. Frequency and variety of pro-environmental behaviors have been found to correlate mainly with self-determined motivation and less frequent when regulated externally (Green-Demers, 
Pelletier and Menard, 1997; Pelletier, 2002; Pelletier et al., 1998; Seguin, Pelletier and Hunsley, 1999). Interestingly, incentives, rewards and punishments are not a successful means to promote long-lasting behavioral effects (Pelletier, 2002) for certain environmentally relevant behaviors.

While fostering and preserving intrinsic behaviors is an important goal, further understanding determinants of extrinsic motivations is equally important. As suggested, extrinsic motivations according to SDT can be quite distinct and have very different effects on intentions and behaviors. Some forms of extrinsic motivations can be surprisingly similar to intrinsic motivations in terms of agency and autonomy (Ryan and Deci, 2000).

During the internalization process of behavioral regulations (Deci and Ryan, 1985), an individual adopts values or external regulations and integrates these by transforming them into their own. The result of this process includes a higher level of commitment to an activity and a more positive self-perception when engaging in that action (Ryan and Deci, 2000). Thus, if a person internalizes and assimilates reasons to enact specific behavior, extrinsic regulations can increasingly seem self-determined to that individual. As a result, integrated regulation can appear to have several commonalities with intrinsic motivations in terms of the perception of autonomy and self-determination. It is important to emphasize that these are still extrinsic motivations due to the behavior being outcome oriented (Ryan and Deci, 2000).

Applied to green professional accreditation professionals should ideally adopt it out of intrinsic motivation or its closes relative along the extrinsic spectrum, or integrated external regulation for long-lasting changes in pro-environmental behavior and cooperation. If the majority of building professionals engages in this type of scheme only due to external regulation, then accreditation will not be suitable to change behavior and induce more environmentally conscious professional practices.

\subsection{Measures and method}

\section{Self-Determination Theory (SDT) measurement}

Motivations as determinants of professional accreditation were investigated via an online administered survey instrument among building professionals in the United States and Canada. The measures in this chapter focus on both extrinsic and intrinsic behavior along a continuum. While intrinsic motivation was measured via the Intrinsic Motivation Inventory (IMI) developed by Ryan (1982), extrinsic motivation along a continuum was adapted from the Motivation Towards Environment Scale (MTES) adapted from Pelletier et al. (1998). All items were measured on a 7 point Likert type scale ( $1=$ Strongly disagree; $7=$ Strongly Disagree). The MTES scale includes the original OIT constructs (1) external 
regulation,(2) interjected motivation,(3) identified regulation and (4) integrated regulation plus (5) amotivation. While MTES also includes questions on intrinsic motivation, these elements are not very diverse so that the decision was taken to include items from the Intrinsic Motivation Inventory (IMI) developed by Ryan (1982) that provides a more detailed account of intrinsic motivation as stipulated by Cognitive Evaluation Theory (CET).

The items for CET from the IMI included items concerning interest, perceived competence, effort, perceived choice and value usefulness, subscales of intrinsic motivation. Each of the subscale was measured with one item respectively.

After questions on profession, firm type, country, sex, job tenure, years of professional experience, education level and sustainable classes in college, three general questions on voluntary accreditation schemes were asked: (1)I find it difficult to assess which voluntary AP schemes are really necessary" (Strongly Agree-Strongly Disagree), (2) "which voluntary AP scheme for sustainable construction have you passed?" and (3) "Voluntary AP schemes can promote professionalism and professional prestige, distinguish professionals from peers, improve income prospects and stabilize job security" (Strongly Agree/ Strongly Disagree).

Cognitive Evaluation Theory (Deci and Ryan, 1980) was measured by seven items measuring intrinsic motivation via six subscales of (1) interest/enjoyment, (2) perceived competence, (3) effort/ importance, (4) pressure/ tension, (5) perceived choice and (6) value/ usefulness. These items were adapted from the Intrinsic Motivation Inventory (IMI): (1) “Achieving accreditation was boring”(interest/ enjoyment); (2)“I think I did pretty well on the test" ( perceived competence); (3) "I did not put much energy into taking the exam" and (4)"It was important to me to do well at the exam" (effort/ importance); (5)“I felt pressured while taking the test" (pressure/ tension); (6) "I did take the exam because I wanted to" (perceived choice); (7)“I think that taking the exam is/was an important activity"(value/usefulness). All items were measured on a seven-point Likert-type scale.

Organismic Integration Theory (OIT)'s extrinsic motivation items were adapted from the Motivation Towards the Environment Scale (MTES): While amotivation could be interpreted as non-adopters' behavior the construct was measured according to two MTES items: (1) "Taking the exam was a waste of time" and (2) "I cannot see what I am getting out of taking the exam" (Strongly Agree/Strongly Disagree). The four extrinsic motivation constructs (external regulation, introjected motivation, identified regulation and integrated regulation) were measured via 2 items each in the survey. External regulation was measured by two items: (1)“Taking the exam means getting recognition from colleagues" and (2) "the accreditation scheme was chosen for me by my organization" (Strongly Agree/ Strongly Disagree). Introjected motivation was measured with two items: (1)" Taking the Accredited Professional (AP) exam avoids criticism from colleagues" and (2) "Taking the __ exam was a sign of my professional attitude towards sustainable construction practices” (Strongly 
Agree/Strongly Disagree). Identified regulation was measured via two items: (1)“Taking the exam was a sensible thing to do" and (2) "It was a good idea to take the exam". Integrated regulation was measured via two items: (1)“Taking the exam was a natural thing to do professionally" and (2) “To take the Accredited Professional (AP) exam to demonstrate adherence to sustainable building practices is an important part of who I am".

\section{Background variables}

To control for confounding demographic effects, control variables including sex, age, job tenure, education level, firm type, regional location and previous sustainability education and personal sustainability attitudes were included in the regression analysis. All control variables were dummy coded.

\subsection{Data}

\section{Qualitative Data}

Before developing and administering the survey questionnaire, the results from a qualitative elicitation study performed in Chapter 2, the North East of the United States (Chapter 3) were used to examine opinions of the LEED scheme. In this elicitation study fourteen (14) building professionals voiced their opinions about the LEED AP scheme. The elicitation study was conducted in April and May 2010 with architects and engineers as interview respondents. The participants were identified and selected via the US Green Building Council Member Database and the yellow pages to avoid bias towards building professionals holding positive perceptions and beliefs towards LEED. From this database consisting of 300 entries, 40 building professionals were randomly selected.

They were first contacted by email in order to make an appointment for a subsequent faceto-face interview. From the selected sample of 40 building professionals, 14 agreed to an extensive face-to-face expert interview. Fourteen interviews were conducted that lasted between 30 to 60 minutes. In total, ten architects ( 8 male and 2 female) and four engineers (4 male) participated in the study. Three of the interviewees were not LEED accredited while the other eleven had taken the LEED AP test and were involved in LEED projects in the past. The average age was 52.3 years and 12 interviewees held senior positions (CEO or partner) in their companies.

Professional accreditation was mentioned by most professionals interviewed. However, it was suggested that LEED professional accreditation was not as important as having experience in sustainable building practices: 
"If I was leading a team, I would much rather have a team of people that have gone through a $L E E D$ project previously than a room full of LEED APs that have never done it" (Respondent 2, engineer)

"I do not think that clients would notice if some of our collaborators were LEED accredited though" (Respondent 4, architect)

"Because everyone could become LEED AP it did not mean anything anymore. I am LEED AP, but what does that really mean? "(Respondent 9, architect)

"The more important thing probably is the history of the firm in terms of working on green projects and demonstrating knowledge in actual practice than having the personal accreditation" (Respondent 3, engineer). Even though the interviews presented a rather critical assessment of voluntary professional accreditation in the building sector, it was not entirely clear why building professionals overall chose to become accredited. Hence, it was decided to investigate the motivations underlying the LEED scheme by testing Self-Determination Theory in in a subsequent questionnaire study.

\section{Survey data}

A a small pilot survey study among five building professionals from the North East United States carried out after qualitative elicitation resulted in reformulation of questions and adaptation of the survey. After a adjustment of the items, the questionnaire was sent to building professionals based in the United States and Canada. The building and construction professionals were identified via Green Building Council (GBC) membership lists and professional licensing registration lists. After two reminders, responses from 268 Canadian and 333 US building professionals were collected, yielding an overall number of 603 respondents. Overall, $41 \%$ of the respondents were CEOs or Partners in their firms, with $25 \%$ senior-level and $22 \%$ middle managers. Only $10 \%$ of the respondents were at a junior level. As for job tenure, $58 \%$ of the respondents had more than 15 years of professional experience, with $15 \% 10-15$ years, $15 \% 5-10$ years and $10 \%$ 0-5 years' experience. Among the respondents, female respondents represented around $30 \%$ of survey respondents, which represents the gender ratio in the building industry to a fair extent. After the exclusion of missing observations, 224 respondents from Canada and 216 respondents from the United States were retained for subsequent analysis, providing an overall sample of 440 respondents. Fore more detailed information on these respondent characteristics please refer to Appendix C. 


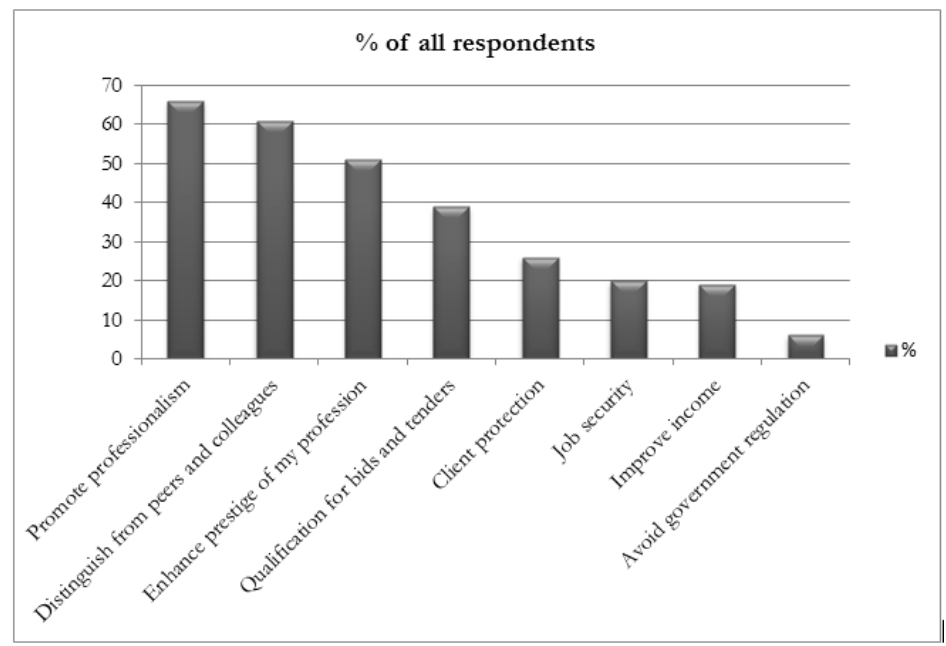

Figure 8.2: Factors for LEED AP accreditation (Source: Own data)

\subsection{Results and discussion}

\section{Descriptive summary}

In order to verify which reasons given in the elicitation study for becoming accredited with a green building professional accreditation were also named in the current research, several answer options were presented to respondents.

As the data suggests, professionalism promotion (66\%) and distinguishing oneself from peers and colleagues $(61 \%)$ were most frequently selected. Furthermore, just over half of the 603 respondents (51\%) indicated that they included green building assessment schemes to their service portfolio to enhance the prestige of their profession. Engaging in qualification for bids and tenders (39\%) and client protection (26\%) were named by fewer respondents as a major factor.

Interestingly, job security (20\%) and improved income (16\%) were not frequently selected options. Avoidance of government regulation was only selected by $6 \%$ of respondents.

However, the reasons given do not explain which type of motivation were predominant for becoming LEED AP accredited. For this reason, further analysis was conducted including several types of intrinsic and extrinsic motivations along a continuum as postulated by Self-Determination Theory (SDT). 


\begin{tabular}{|c|c|c|c|c|c|c|c|c|c|c|}
\hline & Mean & SD & 1 & 2 & 3 & 4 & 5 & 6 & 7 & 8 \\
\hline $\begin{array}{l}\text { 1.Past LEED } \\
\text { project }\end{array}$ & 0.16 & 0.01 & 1 & & & & & & & \\
\hline $\begin{array}{l}\text { 2.Intention to work } \\
\text { on a LEED project }\end{array}$ & 5.11 & 0.06 & $0.38^{*}$ & 1 & & & & & & \\
\hline 3.Amotivation & 4.63 & 0.07 & 0.00 & 0.01 & 1 & & & & & \\
\hline $\begin{array}{l}\text { 4.Introjected } \\
\text { regulation }\end{array}$ & 4.38 & 0.07 & -0.05 & -0.08 & 0.00 & 1 & & & & \\
\hline $\begin{array}{l}\text { 5.Identified } \\
\text { regulation }\end{array}$ & 3.83 & 0.09 & -0.06 & $-0.13^{*}$ & $-0.17^{*}$ & $0.38^{*}$ & 1 & & & \\
\hline $\begin{array}{l}\text { 6.External } \\
\text { regulation }\end{array}$ & 3.71 & 0.07 & -0.07 & -0.06 & -0.06 & $0.17^{*}$ & $0.28^{*}$ & 1 & & \\
\hline $\begin{array}{l}\text { 7.Integrated } \\
\text { regulation }\end{array}$ & 5.04 & 0.05 & $0.16^{*}$ & $0.15^{*}$ & 0.06 & $0.23^{*}$ & $0.26^{*}$ & 0.00 & 1 & \\
\hline $\begin{array}{l}\text { 8.Intrinsic } \\
\text { motivation }\end{array}$ & 4.26 & 0.04 & -0.04 & 0.05 & $0.14^{*}$ & -0.07 & -0.08 & -0.08 & 0.00 & 1 \\
\hline
\end{tabular}

Table 8.1: Pair-wise correlation Self-Determination Theory (SDT) constructs

\section{Correlation analysis}

Coming back to the Self-Determination Theory (SDT), pairwise correlation analyses between the theories' constructs were performed. The results are shown in Table 8.1. The correlation suggest that LEED AP accreditation is positively (albeit weakly) correlated with LEED scheme adoption and the intention to integrate the LEED scheme to construction projects in the United States and Canada.

Additionally, the pairwise correlation determined that being a LEED AP accredited professional was weakly negatively correlated with external regulation and weakly positively correlated with integrated regulation. This result points towards two separate streams of accreditation processes: internally (despite not fully intrinsic) driven and externally driven adoption mechanisms.

As indicated in the theory section, integrated regulation is closest (from a self-identity point of view) to intrinsic motivations, in that building professionals may have integrated the principles of the LEED AP scheme, while an external incentive is still present. Beyond intrinsic motivation, integrated regulation is the most "desirable" form of motivation, as actions and learning are not dependent on external rewards and temporally stable. The second result, a weak negative correlation of LEED AP accreditation with external regulation indicates that LEED AP accreditation is lower when extrinsic motivation is higher and 
vice versa. Hence, individuals that are purely external rewards driven may be less likely to become LEED AP accredited.

To test whether these results persist a logistic regression analysis was performed subsequently to determine the effect of intrinsic and extrinsic motivations on the decision to become LEED AP certified.

\section{Regression analyses}

\section{Logistic regression analysis LEED AP accreditation}

From the control variables only country and education level were found to impact LEED AP accreditation. Canadian building professionals were overall more likely than their US counterparts to become LEED AP accredited while a Bachelor education reduced the likelihood of achieving the accreditation than Master or $\mathrm{PhD}$ educated professionals. Interestingly, past LEED work experience did not seem to influence LEED AP accreditation. Potential explanations include that (1) that professionals aim to achieve the accreditation prior to working on a LEED scheme or that it may be compulsory in their organization to do so or (2) that becoming LEED AP accredited may be seen as an independent scheme overall from the associated LEED building certification scheme.

Among the motivational constructs, the results suggest that integrated regulation was the strongest predictor for building professionals becoming LEED AP accredited. While intrinsic motivation was found to be statistically significant, the effect on accreditation was weaker than for integrated regulation. Interestingly, the correlation effect of external regulation was not replicated in the logistic regression analysis.

Hence, the data suggests that beyond ranking higher on integrated regulation and intrinsic motivation scales is associated with a higher likelihood of being LEED AP accredited. This outcome demonstrates the importance of further distinguishing between different types of extrinsic motivations along a continuum.

An extrinsic motivations have been found to be the most significant predictor for LEED professional accreditation, but the extrinsic motivation that matters the most is actually one closest to intrinsic motivation and does not require external pressure or significant rewards.

Opposed to some previous studies that suggest that environmentally significant behavior in workplace contexts is not commonly intrinsically motivated. In the present study this was not the case as intrinsic motivation for LEED AP accreditation had a significant positive effect on it.

Beyond merely determining which types of motivations are determinants of LEED AP accreditation, a second analysis was conducted to determine whether motivations to be- 


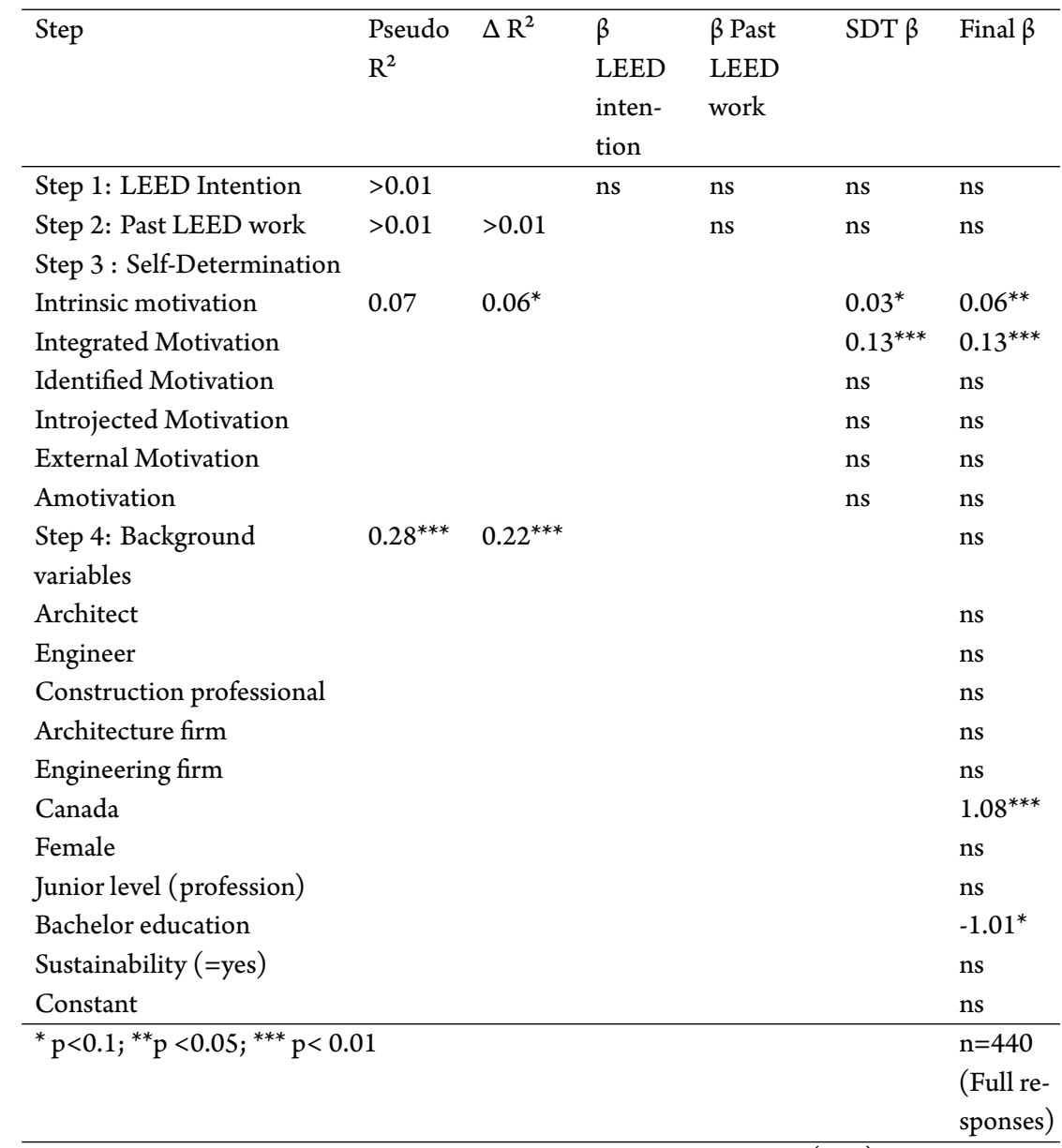

Note: After conducting the regression analysis, Variance Inflation Factors (VIF) were calculated for both explanatory variables individually and the regression equation overall. All VIFs were under 4, with an equation mean VIF of 1.44. The VIFs for SDT constructs were: intention LEED (1.32), past behavior (1.35), intrinsic motivation (1.11), integrated motivation (1.21), external motivation (1.15), identified motivation (1.39), introjected motivation (1.22) and amotivation (1.11). ). Hence, the VIF results suggest that multicollinearity was not an issue in this analysis.

Table 8.2: LEED AP accreditation. Logistic regression analysis with LEED AP accreditation as the dependent variable 
come an accredited professional translated in intentions to integrate the LEED building certification scheme in a new construction project.

\section{Linear regression analysis intention to work with LEED}

To determine whether the LEED AP motivations also predict the intention to work on a LEED building certification program, a linear regression analysis was conducted.

While it seems unclear whether "motivational spill-over" (Mata et.al. 2009) can occur within the SDT context, general motivational transference has been promoted in frameworks such as the hierarchical model of motivation ( Vallerand, 1997; Vallerand and Ratelle, 2002).

The results show that being LEED AP accredited does not have a statistically significant effect on the intention of working on a LEED project. Having worked on a LEED project in the past was found to be predictive, which indicates that the LEED program and the LEED AP professional accreditation, despite being are not considered as such by building professionals.

The only demographic variables found to be significant included gender, with female respondents having higher intention levels than their male colleagues to work on a LEED scheme, in line with previous chapters' results. Integrated and identified regulation, closest to intrinsic motivations along the SDT continuum was found to be significant for LEED program uptake. However, intrinsic motivations were not found to be relevant for integrating the green building VEP in a construction project. Intrinsic motivations seem to matter more for personal and professional accreditation than more "abstract" building certification. Respondents that ranked higher on integrated motivation (for being LEED AP) accredited have a higher intention level for working on a LEED project.

Surprisingly, however, respondents with a higher score on the identified regulation construct displayed lower intention levels with regards to working on a LEED building certification project.

Identified and integrated regulations are the closest to intrinsic motivation, but the change between negative effect (identified regulation) and a positive effect (integrated regulation) on intention for LEED project work is difficult to explain but may have occurred in the transition between acceptance to the self-assimilation of the target behavior.

\subsection{Discussion and limitations}

As Self-Determination Theory (SDT) has been frequently used to analyze learning and behavior change processes, the approach offers a useful framework for understanding building 


\begin{tabular}{|c|c|c|c|c|c|c|}
\hline Step & $\mathrm{R}^{2}$ & $\Delta \mathrm{R}^{2}$ & $\begin{array}{l}\beta \\
\beta \\
\text { LEED } \\
\text { AP }\end{array}$ & $\begin{array}{l}\beta \text { Past } \\
\text { LEED } \\
\text { work }\end{array}$ & SDT $\beta$ & Final $\beta$ \\
\hline $\begin{array}{l}\text { Step 1: LEED AP } \\
\text { Certification }\end{array}$ & $>0.01$ & & ns & ns & ns & ns \\
\hline $\begin{array}{l}\text { Step 2: Past LEED work } \\
\text { Step } 3 \text { : Self-Determination }\end{array}$ & $0.15^{* * *}$ & $0.14^{* * *}$ & ns & $3.45^{* * *}$ & $3.25^{* * *}$ & $3.51^{* * *}$ \\
\hline Intrinsic motivation & $0.20^{* * *}$ & $0.05^{* *}$ & & & ns & \\
\hline Integrated Motivation & & & & & $0.24^{* * *}$ & $0.24^{* * *}$ \\
\hline Identified Motivation & & & & & $\begin{array}{l}- \\
0.12^{* * *}\end{array}$ & $-0.12^{* *}$ \\
\hline Introjected Motivation & & & & & ns & ns \\
\hline External Motivation & & & & & ns & ns \\
\hline Amotivation & & & & & $\mathrm{ns}$ & ns \\
\hline $\begin{array}{l}\text { Step 4: Background } \\
\text { variables }\end{array}$ & & & & & & ns \\
\hline Architect & $0.22^{* * *}$ & 0.02 & & & & ns \\
\hline Engineer & & & & & & ns \\
\hline Construction professional & & & & & & ns \\
\hline Architecture firm & & & & & & ns \\
\hline Engineering firm & & & & & & ns \\
\hline Canada & & & & & & ns \\
\hline Female & & & & & & $0.64^{* *}$ \\
\hline Junior level (profession) & & & & & & ns \\
\hline Bachelor education & & & & & & ns \\
\hline Sustainability (=yes) & & & & & & ns \\
\hline Constant & & & & & & ns \\
\hline${ }^{*} \mathrm{p}<0.1{ }^{* *} \mathrm{p}<0.05 ;^{* * *} \mathrm{p}<0.0$ & & & & & & $\begin{array}{l}\mathrm{n}=440 \\
\text { (Full re- } \\
\text { sponses) }\end{array}$ \\
\hline
\end{tabular}

Table 8.3: LEED adoption intention. Regression Analysis with Intention as the Dependent Variable 
and professionals' decisions to obtain a third party professional accreditation. By defying the too often simplified view on motivations, SDT postulates that individuals do have different levels of motivation and, most importantly, can be in different motivational states along a continuum (Ryan and Deci, 2000). Using SDT theoretical approaches, Cognitive Evaluation Theory (CET) and Organismic Integration Theory (OIT), this chapter demonstrates that different types of motivations can be present, even simultaneously, when forming intentions to act.

In line with previous research extrinsic motivations are significant but not just any kind: Integrated regulation, closest to intrinsic motivation, contributes to LEED AP accreditation decisions. Intrinsic motivation itself also is a significant predictor, albeit weaker in significance.

Interestingly, however, in subsequent analysis, integrated regulation with regards to LEED $\mathrm{AP}$ accreditation has a direct influence on the intention integrating the LEED building certification scheme in a case of "motivational spill-over"; the actual act of being LEED AP certified, however, does not have an effect at all. A more puzzling result included the significant, but negative effect of identified regulation, the closest motivational "neighbor" to integrated regulation along the SDT continuum. While this effect is difficult to explain, it may point towards an individuals' dependency on organizational policies in terms of LEED $\mathrm{AP}$ and LEED program uptake. If motivation for LEED AP accreditation was imposed from the outside, i.e. by professional or organizational norms, certain resistance mechanisms may have been activated to reduce LEED program uptake intentions.

While these results have certainly shed a light on building professionals' motivations for becoming LEED AP certified, several limitations can be identified (1) related to the field of application, (2) theoretical and (3) empirical in nature.

First, from an application point of view, it is not really clear whether the fact of becoming LEED AP accredited can be considered to be a pro-environmental behavior. While becoming accredited could be interpreted as a signal to demonstrate sustainability knowledge, some building professionals doubt whether these types of professional accreditations schemes represent sustainability expertise.

Second, on a theoretical level, the effect of the SDT motivational constructs with regards to LEED AP accreditation was used to determine intention to integrate the LEED building scheme in a construction project. So-called "motivational spill-over" could explain this phenomenon, i.e. motivations for one behavior that influence another, closely related behavior. While research supports this phenomenon (e.g. Vallerand, 1997; Mata, 2009), in this context it does not seem clear whether "becoming LEED AP accredited" and "integrating LEED in a building project" can be considered closely linked behaviors. Becoming LEED $\mathrm{AP}$ accredited, despite being dependent on organizational support, is a more autonomous behavior than LEED certification integration, in which many stakeholders take decisions. 
At the same time, the data limitations did not allow for measuring actual subsequent LEED adoption but only the intention to integrate LEED, while LEED AP certification was measured as actual steps undertaken to become accredited. These empirical limitations influenced the results obtained and the data interpretation.

Third, as most studies, this chapter is subject to usual biases in measurement and response. While frequently used and validated measurement scales were used in this project and the questionnaire had been tested by building professionals before administration, measurement errors cannot be excluded. As it is often the case with environmentally related studies, answering to comply with social desirability criteria cannot be fully excluded. Similarly, while precautions were taken place to have both respondents with and without LEED AP certification in this study, a relatively low response rate overall may have introduced additional measurement-related biases.

\subsection{Conclusion}

In conclusion, this chapter demonstrated that beyond attitudes, norms and perceived behavioral control, as demonstrated in previous chapters, different types of motivations can contribute to explain VEP adoption among building and construction professionals.

Intrinsic motivation is essential for creating sustainable environmentally relevant change. Behaviors driven by internalized motivation are not only temporally more stable but individuals also enjoy performing these behaviors more (Osbaldiston and Sheldon, 2003). However, intrinsic motivation can by definition not be achieved by external interventions. Influence on relevant behaviors can, however, achieve integrated and identified motivations in which respondents gradually accept external values and stimuli as their own. To address issues with extrinsic motivations, however, it needs to be known which types are present in the intentions for and actual uptake of green building VEPs.

This chapter also addressed another important issue: The effect of motivational spill-over from one behavior to the next. While in this chapter only the effect of self-determination constructs with regards to LEED AP accreditation on LEED project intention was measured, a statistically significant effect was found for integrated and identified regulation. The overall potential of integrating self-determination in other theoretical constructs such as the Theory of Planned Behavior (Ajzen, 1991) is well documented (e.g. Chatzisarantis and Biddle, 1998; Hagger et al., 2002; Hagger et al., 2006), but in the case of "motivational spill-overs" more knowledge may be needed.

The respondents who were more likely to adopt the LEED AP scheme were mainly driven by intrinsic motivation and integrated regulation. As explained above, intrinsic motivation cannot be easily influenced in most cases. However, integrated regulation can be. If the aim is to promote the uptake of these professional accreditation schemes in the hope that the 
building and construction industry will become more environmentally sustainable, further research could investigate how to achieve this goal (see Chapter 12). Similar to the experimental research carried out by Koestner and Houlfort (2001), studies could determine effect of experimental intervention studies that aim to promote integrated behavior towards LEED AP accreditation in building and construction professionals.

There are risks associated with promoting this type of professional accreditation schemes. As this chapter suggests, becoming professionally accredited does not determine eventual uptake of the relevant behavior (i.e. intention to work on a LEED building project). Additionally, becoming LEED AP accreditation cannot be necessarily be described as a pro-environmental behavior, as suggested by some building professionals. Hence, if interventions are developed in the building and construction industry to promote sustainable behavior, the type of behavior to be changed needs to be considered closely. 


\section{References}

Ajzen, I. (1991). The theory of planned behavior. Organizational behavior and human decision processes, $50(2), 179-211$.

Burns, R. L. (1985). Understanding testing in occupational licensing. In J. Fortune \& Associates (Eds.), (pp. 15-44). San Francisco: Jossey-Bass.

Chatzisarantis, N. L., \& Biddle, S. J. (1998). Functional significance of psychological variables that are included in the theory of planned behaviour: a self-determination theory approach to the study of attitudes, subjective norms, perceptions of control and intentions. European Journal of Social Psychology, 28(3), 303-322.

Chatzisarantis, N. L., \& Hagger, M. S. (2009). Effects of an intervention based on selfdetermination theory on self-reported leisure-time physical activity participation. Psychology and Health, 24(1), 29-48.

Chirkov, V., Ryan, R. M., Kim, Y., \& Kaplan, U. (2003). Differentiating autonomy from individualism and independence: a self-determination theory perspective on internalization of cultural orientations and well-being. Journal of personality and social psychology, 84(1), 97.

Cole, R. J. (2006). Shared markets: coexisting building environmental assessment methods. Building Research \& Information, 34(4), 357-371.

Deci, E. L. (1975). Intrinsic motivation. Plenum Press.

Deci, E. L., \& Ryan, R. M. (1985). Intrinsic motivation and self-determination in human behavior. Plenum, New York.

Deci, E. L., \& Ryan, R. M. (2000). The" what” and" why” of goal pursuits: Human needs and the self-determination of behavior. Psychological inquiry, 11(4), 227-268.

Fertig, J., Zeitz, G., \& Blau, G. (2009). Building internal motivation for worker competency certifications: a critique and proposal. Human Resource Development Review, 8(2), 197-222.

Gagné, M., \& Deci, E. L. (2005). Self-determination theory and work motivation. Journal of Organizational behavior, 26(4), 331-362.

Hagger, M. S., \& Chatzisarantis, N. L. (2009). Integrating the theory of planned behaviour and self-determination theory in health behaviour: A meta-analysis. British Journal of Health Psychology, 14(2), 275-302.

Hagger, M. S., Chatzisarantis, N. L., \& Biddle, S. J. (2002). A meta-analytic review of the theories of reasoned action and planned behavior in physical activity: Predictive validity and the contribution of additional variables. Journal of sport \& exercise psychology, 24(1), 3-32.

Hagger, M. S., Chatzisarantis, N. L., \& Harris, J. (2006). From psychological need satisfaction to intentional behavior: Testing a motivational sequence in two behavioral contexts. Personality and social psychology bulletin, 32(2), 131-148. 
Hamm, M. (1996). What are the building blocks of good certification and accreditation programs. Gale Research.

Kane, M. (2004). Certification testing as an illustration of argument-based validation. Measurement, 2(3), 135-170.

Koestner, R., Houlfort, N., Paquet, S., \& Knight, C. (2001). On the risks of recycling because of guilt: an examination of the consequences of introjection1. Journal of Applied Social Psychology, 31(12), 2545-2560.

Lavergne, K. J., Sharp, E. C., Pelletier, L. G., \& Holtby, A. (2010). The role of perceived government style in the facilitation of self-determined and non self-determined motivation for pro-environmental behavior. Journal of Environmental Psychology, 30(2), 169-177.

Mata, J., Silva, M. N., Vieira, P. N., Carraça, E. V., Andrade, A. M., Coutinho, S. R., ... Teixeira, P. J. (2009). Motivational "spill-over" during weight control: Increased self-determination and exercise intrinsic motivation predict eating self-regulation. Health Psychology, 28(6), 709-716.

Miller, J. G. (1997). Motivation and culture. In J. F. S. . A. C. C. D. Munro (Ed.), (chap. Cultural conceptions of duty: Implications for motivation and morality.). Routledge.

Naquin, S. S., \& Wilson, J. (2002). Creating competency standards, assessments, and certification. Advances in Developing Human Resources, 4(2), 180-187.

Osbaldiston, R., \& Sheldon, K. M. (2003). Promoting internalized motivation for environmentally responsible behavior: A prospective study of environmental goals. Journal of Environmental Psychology, 23(4), 349-357.

Pelletier, L. G., Baxter, D., \& Huta, V. (2011). Personal autonomy and environmental sustainability. In Human autonomy in cross-cultural context (pp. 257-277). Springer.

Pelletier, L. G., Dion, S., Tuson, K., \& Green-Demers, I. (1999). Why do people fail to adopt environmental protective behaviors? toward a taxonomy of environmental amotivation1. Journal of Applied Social Psychology, 29(12), 2481-2504.

Pelletier, L. G., \& Sharp, E. (2008). Persuasive communication and proenvironmental behaviours: How message tailoring and message framing can improve the integration of behaviours through self-determined motivation. Canadian Psychology/Psychologie canadienne, 49(3), 210-217.

Pelletier, L. G., Tuson, K. M., Green-Demers, I., Noels, K., \& Beaton, A. M. (1998). Why are you doing things for the environment? the motivation toward the environment scale (mtes) 1. Journal of Applied Social Psychology, 28(5), 437-468.

Ryan, R. M. (1982). Control and information in the intrapersonal sphere: An extension of cognitive evaluation theory. Journal of personality and social psychology, 43(3), 450.

Ryan, R. M. (1993). Agency and organization: Intrinsic motivation, autonomy, and the self in psychological development. In Nebraska symposium on motivation: Developmental perspectives on motivation. University of Nebraska Press. 
Ryan, R. M. (1995). Psychological needs and the facilitation of integrative processes. Journal of personality, 63(3), 397-427.

Ryan, R. M., \& Deci, E. L. (2000a). Intrinsic and extrinsic motivations: Classic definitions and new directions. Contemporary educational psychology, 25(1), 54-67.

Ryan, R. M., \& Deci, E. L. (2000b). Self-determination theory and the facilitation of intrinsic motivation, social development, and well-being. American psychologist, 55(1), 68-78.

Ryan, R. M., \& Deci, E. L. (2006). Self-regulation and the problem of human autonomy: Does psychology need choice, self-determination, and will? Journal of personality, 74(6), 1557-1586.

Ryan, R. M., Patrick, H., Deci, E. L., \& Williams, G. C. (2008). Facilitating health behaviour change and its maintenance: Interventions based on self-determination theory. The European Health Psychologist, 10(1), 2-5.

Seguin, C., Pelletier, L. G., \& Hunsley, J. (1999). Predicting environmental behaviors: The influence of self-determined motivation and information about perceived environmental health risks1. Journal of Applied Social Psychology, 29(8), 1582-1604.

Vallerand, R. J. (1997). Advances in experimental social psychology. In M. P. Zanna (Ed.), (p. 271-360). New York: Academic Press.

Vallerand, R. J., \& Ratelle, C. F. (2002). The motivation and self-determination of behavior: Theoretical and applied issues. In E. L. D. . R. M. Ryan (Ed.), (chap. Intrinsic and extrinsic motivation: A hierarchical model). University of Rochester Press.

Vansteenkiste, M., Niemiec, C. P., \& Soenens, B. (2010). The development of the five mini-theories of self-determination theory: An historical overview, emerging trends, and future directions. Advances in motivation and achievement, 16, 105-165.

Villacorta, M., Koestner, R., \& Lekes, N. (2003). Further validation of the motivation toward the environment scale. Environment and Behavior, 35(4), 486-505. 



\section{Voluntary Green Building Rating principles in Environmental Preferential Purchasing: Lessons from the Advocacy Coalition Framework and the Elaboration Likelihood Model}

"If you want everything to be nice and straight all the time, the go live in a world made with a triangular ruler". (Haruki Murakami, Kafka on the Shore)

\subsection{Introduction}

$\mathrm{V}$

oluntary green building rating and assessment schemes have become a prominent instrument to reduce the environmental impact of buildings, promote energy efficiency and reduce water usage. Green Building Councils (GBCs) and similar third party organizations have appeared in many countries, and either developed voluntary environmental building rating and assessment schemes or adapted existing schemes to local conditions. Certification is usually awarded to building projects if certain sustainability criteria are fulfilled. Though mainly issued by non-profit organizations, governmental units have endorsed and integrated voluntary rating schemes in their urban planning and environmental policy mix. Additionally, in some countries, local governments and municipalities have become interested in adding them to their sustainable procurement policies (Trisolini, 2010). Specifically cities and towns have begun to integrate voluntary environmental schemes as criteria for the construction of municipal buildings. 
The inclusion of voluntary green rating schemes in procurement policies can, if properly endorsed by all stakeholders, enhance eco-innovations in certain industrial sectors developing appliances and materials for sustainable building construction.

However, the inclusion of voluntary building rating schemes in public procurement practices needs to be investigated carefully. It is likely that the integration of building rating schemes in Environmentally Preferable Purchasing (EPP) policies will depend on a multitude of factors such as the goals of the organization issuing the scheme and the geographic region in which these schemes have been developed and are applied to. Most importantly, the attitudes and perceptions by policy-makers and public procurement professionals involved in the process to develop and apply these schemes also need to be taken into account. This aspect has been frequently left out in previous research studies. Hence, this chapter presents two frameworks that can explain and promote the inclusion of voluntary building ratings schemes among policy-makers and procurement professionals, the Advocacy Coalition Framework (ACF) developed by Sabatier and Jenkins-Smith (1988) and the Elaboration Likelihood Framework by Petty and Cacioppo (1986).

\subsection{Green Building Councils and Voluntary Assessment Schemes}

Even though a number of organizations are in involved in the process of developing voluntary building rating and assessment schemes, the most dynamic development occurs these days within the global Green Building Council (GBC) movement.

\section{Green Building Councils and World Green Building Council}

Green Building Councils (GBCs) are third party and mainly not-for-profit organizations consisting of industry and public officials which state as their goal to provide "a prosperous and sustainable future for our nation through cost-efficient and energy-saving green buildings" (USGBC, 2011), "to radically improve the sustainability of the built environment" (UK GBC, 2011),"lead and accelerate the transformation to high-performing, healthy green buildings, homes and communities" (CA GBC, 2011) and "sustainable property industry and drive the adoption of green building practices through market-based solutions" (GBCA, 2011)

Numerous national GBCs are organized in an umbrella organization, the World Green Building Council (WGBC). The World GBC aims "to be the global voice for Green Building Councils and to facilitate the global transformation of the building industry towards sustainability" (WGBC, 2011). There are currently 20 established, 9 emerging, 26 prospective and 27 associated GBCs with different membership statuses, namely:

established GBCs which have full member status 
emerging GBCs which work towards full member status

prospective GBCs which are the group officially recognized by the WGBC as the group establishing a GBC in their country and working towards emerging member status and associated GBCs which are recognized as the group or entity establishing a GBC in their country and working towards prospective member status.

To ascertain its importance, the $\mathrm{WGBC}^{1}$ has developed partnerships with international organizations such as UNEP SBCI ${ }^{2}$, Sustainable Buildings Alliance (SBA) ${ }^{3}$ and the International Union of Architects (IUA) ${ }^{4}$.The WGBC, however, has been established only relatively recently and many major building rating schemes have been developed outside the GBC realm. In some countries, GBCs have been in "competition" with other national groups developing green building schemes, as it is the case in the United Kingdom with the BREEAM scheme not developed by the UKGBC but BRE Assessment, another building industry-related organization. In other countries such as Japan or Canada, the prominent schemes were developed by non-GBC third party organizations and GBCs either endorsed the existing scheme, chose to develop a new program or imported an existing rating scheme from other countries.

The main developers of voluntary schemes, both GBCs and other third party organizations have been actively exporting their programs abroad, mainly to developing countries. The export and development of voluntary rating schemes has been endorsed by some international organizations such as UN HABITAT $(2010)^{5}$, which promotes the adoption of voluntary building rating schemes in African countries.

\section{Voluntary Rating and Assessment Schemes and the construction industry}

Most schemes worldwide function according to the same principle: From a list with certain criteria, a number of them need to be fulfilled and are credited with points. If a minimum number of points is reached, certification can be obtained.The most influential schemes around the world have been LEED (US), BREEAM (UK), Green Star (Australia), BOMA BEst (Canada), CASBEE (Japan), HK-BEAM (Hong-Kong) and DNGB (Germany). In the US, the national GBC, however, has established the dominant scheme, the "Leadership in Environment and Energy scheme" (LEED) which has been successful both on the national and international level. The USGBC has claimed that there are currently 16, 000 member companies and organizations, and more than 160, 000 LEED AP holders in the United States (USGBC, 2011).

\footnotetext{
${ }^{1}$ http://www.worldgbc.org/

${ }^{2} \mathrm{http}$ ://www.unep.org/sbci/

${ }^{3}$ http://www.sballiance.org/

${ }^{4}$ http://www.uia.archi/en

${ }^{5}$ http://unhabitat.org/
} 


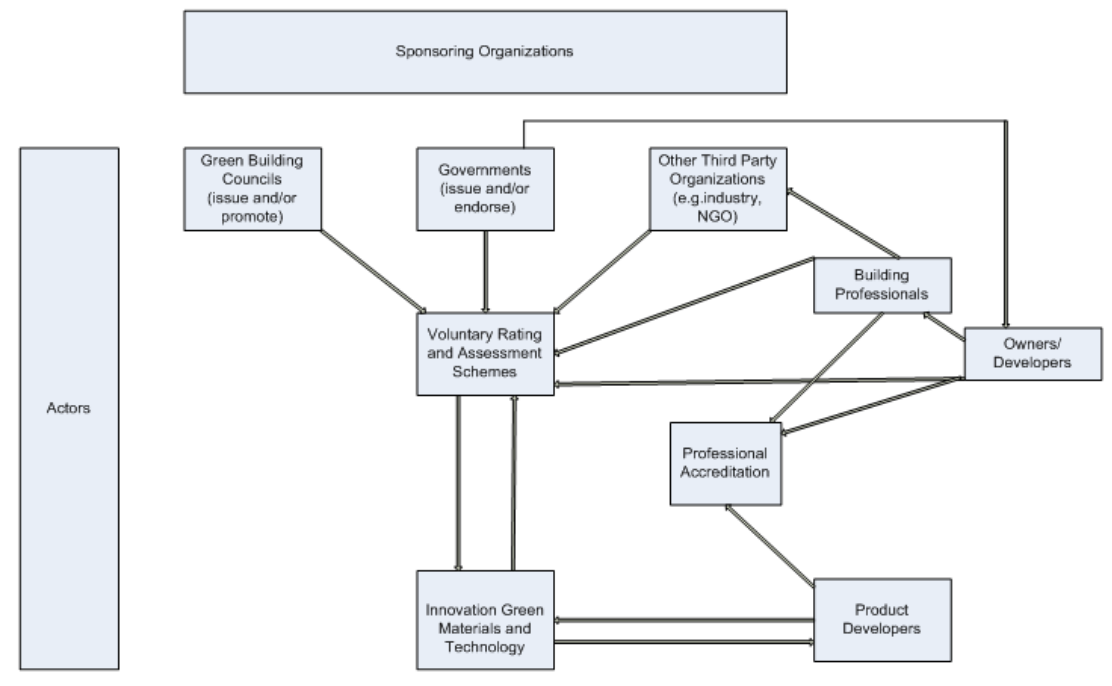

Figure 9.1: Actors involved in the construction process and voluntary rating scheme application (Source: Author's representation)

Since the building industry is one of the most fragmented sectors with members from various professions (Real Estate Developers, Architects, Engineers, Commissioners, Constructors and procurement officers etc.) working on a project basis, many stakeholders are involved to coordinate and collaborate to achieve satisfactory (and sustainable) outcomes. This cooperation can, however, be problematic. Since sustainable construction in many cases means to break with established routines, cooperation and collaboration between the different interest and stakeholder groups becomes even more important when it comes to procurement practices and negotiations. Policy-makers and procurement professionals will need to be convinced of the benefits of integrating green building VEP criteria in EPP policies. As in previous chapters, the focus is on cooperation necessary for successful VEP implementation. Yet, according to UNEP (2010), "sustainable development in the building and construction sectors is still hampered by limited coordination and cooperation between different stakeholders throughout a building's life span”.

As Fig. 9.1 shows, governments, GBCs, NGOs, owners, developers, architects, engineers and product developers for energy efficient appliances are involved in the process. Hence, the adoption and promotion of a voluntary rating and assessment scheme can be influenced by many different actors and stakeholders. It can be assumed that the direction of influence goes both ways: 
Government officials can influence owners, real estate firms, product developers and the building profession to adopt a voluntary rating scheme, while these professions in turn can exert influence on government officials to endorse a specific rating scheme (via the GBC, professional associations or other communication forums)

In order to understand the dynamics of adoption, the channels of communication influencing behavior and patterns of interaction to include voluntary schemes in procurement practices are of major importance. Before the decision and behavior in public procurement processes is reviewed, it will be useful to turn first to the literature on Environmentally Preferential Purchasing (EPP) to determine the contextual factors influencing decision and behavioral outcomes.

\subsection{EPP: Barriers and Opportunities}

The literature on determinants of green purchasing in the private sector is vast and diverse. Examples of "green" purchasing are reduction of packaging and waste, developing ecofriendly products, resorting to environmentally less damaging transport or environmental criteria for suppliers (Walker et al., 2008).

A thorough overview of the relevant literature can be found in Walker et al. (2008) and Srivastava (2007).

\section{EPP: Private and public procurement in the construction sector}

As mentioned in the literature, governments (local, regional and state) use sustainable procurement to improve environmental quality and foster eco-innovation (Charter et al., 2001). Some local governments in the US for instance have imposed for municipal and commercial projects to be certifiable with the LEED or other local green building schemes (Local Leaders for Sustainability, 2009). The development and choice of appliances is frequently up to the owners and building professionals involved which in turn make the selection from products presented by product manufacturers. Hence, private sustainable procurement between firms takes place directly when real estate developers and building owners purchase directly energy and water efficient appliances from product manufacturers and suppliers in order to be able to achieve rating and assessment scheme certification. Supply and procurement chains are long and intertwined in the construction sector (Bon and Hutchinson, 2000). Real estate developers and owners need to make decisions whether to include sustainability criteria in their projects, while judging costs and benefits. Depending on their location, they will face more (some European Union countries) or less stringent (e.g. some parts of the United States or developing countries) requirements and laws.

However, it is not clear why and in which ways specific voluntary rating schemes are integrated in public EPP policies and tendering procedures. It can be assumed that these 


\begin{tabular}{ll}
\hline Drivers & Barriers \\
\hline - Regulatory Pressures (e.g. Min and Galle; & - Costs (e.g. Wycherley, 1999) \\
2001) and proactive regulatory & - Lack of training (Bowen et al., \\
compliance (e.g. Bowen et al., 2001a, b) & 2001a, b) \\
- Customer pressure (e.g. Hall, 2001) & - Lack of legitimacy (Greer and \\
- Marketing pressures (e.g. Zhu and Sarkis, & Bruno, 1996) \\
2006) and Publicity (Wycherley, 1999) & - Regulations (Porter and van den \\
- Competitive Advantage (e.g. Sarkis, 2003; & Linde, 1995) \\
Noori and Chen, 2003) & Poor supplier commitment \\
- Improve firm performance (e.g. & (Wycherley, 1999) \\
Gonzalez-Benito, 2005) & and Sarkis, 2006) \\
- Stakeholder pressure (Sharma and & \\
Vredenburg, 1998) & \\
- Pressure by environmental groups (Hall, & \\
2001) & \\
- Supply integration (e.g. Vachon and & \\
Klassen, 2006) & \\
- Organizational factors such as owner & \\
values or employee values (New et al., & \\
2000; Hanna et al., 2000; Carter and & \\
Dresner, 2001) &
\end{tabular}

Figure 9.2: Factors influencing Environmentally Preferential Purchasing (EPP) processes.

decisions are made as a compromise between different interest groups. While the efficiency of using VEPs for environmental outcomes has not been ascertained since data on voluntary rating schemes has been patchy at best, certain municipalities seem convinced that including VEP principles in public procurement strategies is advantageous. Behavior and decision-centered approaches are crucial to understand the integration of green building VEPs in EPP as well as building professionals and product developers' decisions to promote these schemes to public agencies.

In the public sector, green procurement has been used to promote environmental initiatives (Varnaes et al., 2009) and suggested to influence suppliers, change the market for environmental technologies and foster eco-innovation. However, inertia and problems are frequently caused by time constraints, high costs as well as technical issues (Gluch et al., 2009). Public procurement has been the focus of tax payer organizations and business interests which frequently argue that tight environmental criteria could lead to higher costs and unfair competition (Varnaes et al., 2009). In the context of these schemes, building 
industry-related organizations in many countries create and promote voluntary schemes as "pre-emptive regulation" or "self-regulation" (Lyon, 2003, Lyon and Maxwell, 2004).

\section{Voluntary Rating and Assessment schemes as Eco-labels}

Several dynamics may influence the integration of third party rating and assessment schemes in the EPP mix. Environmental attributes include energy efficiency, recycled content, recyclability, water efficiency, resource conservation, reduction of greenhouse gas emissions, waste prevention, no toxic material content, packaging and reduced impact of transport (US EPA, 2000). These are the same criteria that many voluntary environmental rating schemes specify, e.g. the US LEED scheme.

Green building VEPs can be seen close relatives of eco-labels with the difference being that they certify a more complex product (i.e. an entire building). As Fuerst and McAllister (2011) have suggested, labels provide information to the users of a given scheme and is aimed at providing influencing their choices, suppliers production hence reduce emissions and waste. In addition, monitoring costs are said to be reduced. Several other arguments in favor of the establishment of eco-labels have been brought forward (e.g. Franzitta et al., 2010).

Opponents of eco-labeling frequently point out that these schemes are green-washing strategies and that firms use certification schemes for purely public relations and strategic reasons (e.g. Zaman et al., 2010). In addition, Dosi and Moretto (2001) have pointed out that eco-labels can cause environmental harm since they may create a higher level of consumption. A well-known example is the study conducted by Teisl et al. (2002) which has shown that tuna consumption increased after the introduction of a dolphin-safe label. In a similar fashion, Fuerst et al. (2011) argue that the same effect might be in certified buildings since occupants might be less strict with saving energy and water due to the image of a building being "green". There are many other arguments against the use of eco-labels (e.g. Grolleau et al., 2009; Ibanez and Grolleau, 2008). For a more extensive review of literature on eco-labels generally see Gallastegui (2002).

However, eco-label research has mainly focused on behavioral aspects related consumer decisions to purchase eco-labeled products (e.g. Thogersen, 2000; Leire and Thidell, 2005). Less has been written on the determinants of decisions and behavior of professionals in a public procurement process and the choices made to integrate specific VEPs in the EPP mix. An exception is Thai (2001), investigating the role of interest groups with different objectives and beliefs involved in the public procurement processes. Since procurement is a very complex system with conflicting interests, procurement programs frequently emerge as a compromise between those interest groups and policy-makers. 


\subsection{Sustainable Procurement and Voluntary Rating and Assessment Schemes: Social and Cognitive factors}

This section will review evidence from studies on factors influencing decision and behavior outcomes that can be applied to the integration of voluntary rating schemes in EPP policies.

The human dimension has been frequently left out of the picture in research on procurement processes. Neither the green building nor the public procurement literature have been strong on analyzing social and psychological dimensions. While the literature has shown that sustainable procurement can be limited by budget constraints, technological limitations and legislation (e.g. Walker et al., 2008; Walker and Preuss, 2008 and Preuss, 2009), cognitive and social factor research with regards to EPP is rather limited.

There are some exceptions. Preuss and Walker (2011) have focused on psychological barriers to green public sector procurement and suggested in a qualitative study on local government authority officials in the UK that along with organizational factors and external adaptation processes, individual cognitive and affective factors are important aspects of sustainable purchasing decisions. Gelderman et al. (2006) found in a survey among Dutch procurement officials that familiarity with procurement rules, perceived inefficiency of procurement procedures and organizational incentives were potential causes for new procurement processes to fail.

Unethical purchasing behavior has been studied extensively over the last ten years, also because the damage to an economic system can be very high. Deviant behavior from public procurement officials can significantly reduce environmental outcomes since purchasing behavior is closely linked to attitudes, social norms and organizational factors (Kelley and Dorsch, 1991; Robertson and Rymon, 2001). Deviant purchasing behavior includes accepting bribes or gifts but also 1 omission of information etc. over correct procurement policy-making and implementation processes (Badenhorst, 1994). In a study conducted in the US state of Arizona, public procurement officials were found to engage in practices such as allowing vendors to change quotes or visiting vendor plants and offices at company expense (Forker, 1990) on a regular basis.

Additional complexity added by including VEPs to the procurement mix might open the door to corruption and reduce any pro-environmental effect intended significantly. Lack of compliance (De Boer and Telgen, 1998) has been an issue in many developed countries (e.g. Eyaa and Oluka, 2011), which also can be seen as a warning sign not to export VEP schemes without caution considering potentially detrimental side-effects (De Boer and Telgen, 1998).

Decision and behaviors with regards to public procurement practices have been studied mainly after a specific procurement policy has been adopted. In addition, most empirical 
studies have neglected interaction patterns between different professional groups in the public procurement process. Even though there are new forms of cooperation to public procurement (Lawther and Martin, 2005), which have changed the traditional procurement roles to some extent, the interaction between the different groups involved in green building procurement processes need to be well understood.

Convincing public procurement officials to consider principles derived from voluntary environmental building schemes in EPP services in construction-related processes (e.g. building construction or lease selection for own purposes or the provision of third party building approvals) is a challenging task.

As EPP decisions in the public sector are the consequence of both policy decisions (i.e. the consequence of budget processes and political decisions to promote sustainable principles in the procurement processes), a theoretical framework is needed combining the policy decision processes and a pathway to persuade policy decision-makers to consider VEP processes for EPP criteria inclusion.

For this purpose, this chapter combines the Advocacy Coalition Framework (ACF) ( Sabatier, 1988) with the Elaboration Likelihood Model (ELM) developed by Petty and Cacioppo (1986).

As the ELM is an individual-level model while the ACF has a focus on policy coalitions, these frameworks have not been integrated to this point for the purpose of studying environmental cognition. The only other research project with a similar approach was carried out by Henry and Dietz (2012) studying common properties of the Advocacy Coalition Framework (ACF) and the Value-Beliefs-Norm (VBN) theory developed by Stern (2000).

\subsection{Policy Learning and Advocacy Coalition Frameworks}

Policy learning and policy processes have been investigated from a large number of perspectives. One of the predominant frameworks to understand policy processes has been the Advocacy Coalition Framework (ACF) developed by Sabatier (1988). Within the ACF, the main focus lies on policy subsystems consisting of actors from a variety of private and public organizations concerned with a policy issue. These actors in turn are organized in coalitions that share a set of normative and causal beliefs as well as engage in coordinated activity over time (Sabatier, 1998). Three sets of beliefs influencing outcomes are: (1) deep core beliefs (ontological and normative beliefs), (2) policy core beliefs (fundamental value priorities) and (3) secondary beliefs (e.g. seriousness of an issue). According to ACF coalitions adopt strategies to alter behavior of institutions to realize policy objectives. While studies have been conducted on coalition composition, behavior and subsystems, some researchers have also focused on the individual and their belief system structure (Sabatier, 1998). Specific policy preferences are assumed to be endogenous to the behavior to be explained and while 


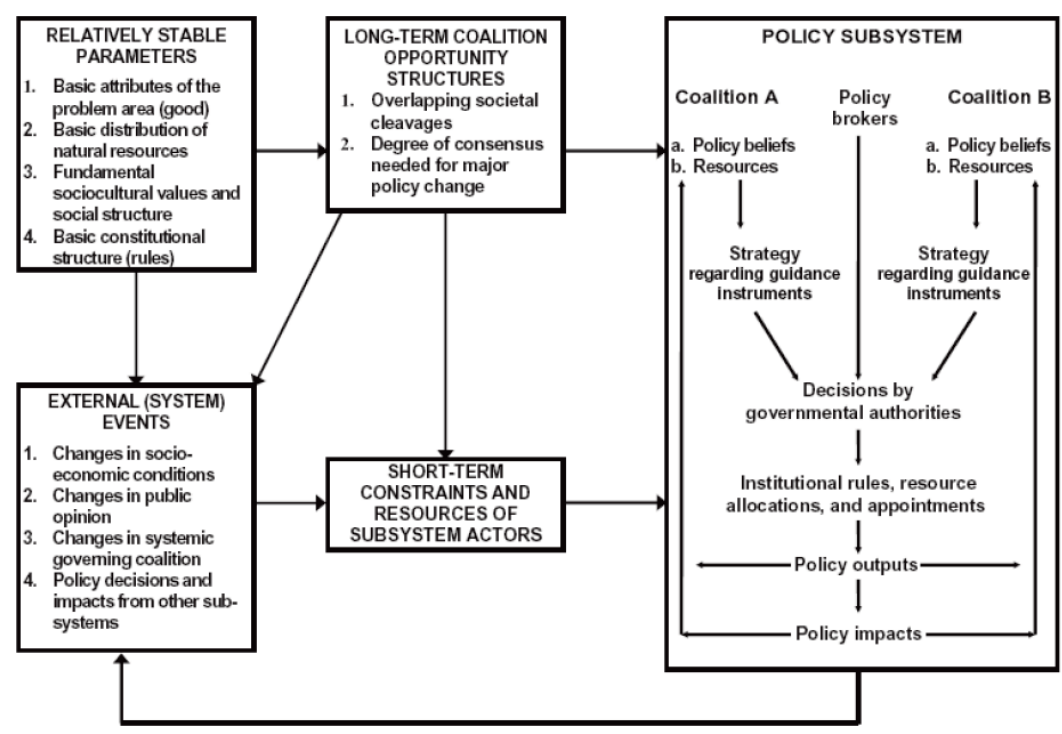

Figure 9.3: Advocacy Coalition Framework as represented by Weible et al. (2009)

policy core beliefs can change over time, deep rooted beliefs are often seen as a given. While the ACF framework has been mainly used to study national policy processes, it has also been scarcely applied to the adoption of third party schemes (Elliott and Schlaepfer, 2001).

The ACF was developed to explain the decisions and behaviors made by actors in policy coalitions (Sabatier \& Jenkins-Smith, 1999). The basis for the ACF is the assumption that policy networks and coalitions are determined by belief systems homophily and actors tend to form coalitions with individuals with similar policy beliefs (Henry, Lubell \& McCoy 2011). Complementary to these micro-level interactions are macro-level dynamics that produce several coalitions of policy actors (Henry, 2011b).

Literature in the management and the social psychology field has suggested that professionals construct belief structures which are simplified representations of their external environment (March and Simon, 1958). Daft and Weick (1984) have suggested that these beliefs prevent decision-makers from being overwhelmed by their decision tasks.

Additionally, information theories(e.g. Argyris and Schon, 1996), predicts that the way information is processed, framed and assessed is of major importance to understand the transfer of ideas and policies. Policy learning processes are "relatively enduring alterations of thought or behavioral intentions that result from experience and which are concerned 
with the attainment or revision of the precepts of the belief system of individuals or of collectivities" (Jenkins-Smith and Sabatier, 1993). In this respect, organizations learn when relevant individuals in organizations change their values, attitudes or beliefs. Hence, in the discussion of voluntary rating schemes inclusion in EPP strategies, communication, processing, assessment and utilization of information need to be a major focus.

However, the role of the interaction between groups and the step from policy beliefs to strategy formation and end result within the ACF cannot be easily tested. If a policy decision has been made, this usually means that one side was able to convince the other at least partially to achieve a consensus. The use of information and messages is likely to differ in negotiation processes between municipalities in which a voluntary rating scheme has been included in EPP policies and in those in which this did not happen. The ACF does, however, not posit how these processes in and between actors occur. Hence, to account for these shortfalls, the ACF can be complemented with additional frameworks and elements from models based on social cognitive theory developed by Bandura (1985) and the Elaboration Likelihood Model (ELM) (Petty and Cacioppo, 1986).

\subsection{Social and strategic cognition as a basis for persuasion}

Social cognition focuses on how social information is processed and how these mental processes affect social perceptions and behavior (Lepgold and Lamborn, 2001). Two research traditions have influenced this area of investigation: social psychology and cognitive psychology. While cognitive psychology has focused on mental processes outside contextual factors, social psychological studies have traditionally focused on the influence of social relationships on thoughts and behavior. Social cognition bridges these two approaches and examines the mediating role of cognitive mechanisms between these two dimensions. Hence, social cognition describes how individuals draw inferences and categorize social events by creating simplified mental images. Purposive choice can be strategic or nonstrategic with the former being the results of interdependent actions while the latter focuses on non-interdependent actions. Since projects in the building industry imply many professional groups and level of decision-making, public procurement decisions are likely to be strategic in nature.

\subsection{The Elaboration Likelihood Model (ELM)}

Advocacy takes place via strategic information transmission. Groups aim to persuade each other to adopt their respective viewpoints. Since in an inter-group context one coalition/group tries to convince the other and find a common ground, the elaboration likelihood model can be used to analyze this situation. Even though this model has been used mainly in social psychology research on behavior change, it can also be applied to the analysis 
of conditions under which negotiation partners can influence each other with persuasive communication (i.e.cause belief, attitude or behavior change in their negotiation partners).

The Elaboration Likelihood Model (ELM) is linked to the social cognition literature and research on attitudinal change. In this dual-process model, beliefs can be changed due to "persuasion". Elaboration is the extent to which stakeholders think about "issue-relevant arguments in a message" (Petty and Cacioppo, 1986). High elaboration is the result of individuals engaging in issue-relevant thinking while low elaboration occurs when this process does not happen. Both motivation and ability are relevant factors in this process. Petty and Cacioppio (1986) note two important aspects of the model: If the issue is closely linked to a person's core values they might be unwilling to process a message and if a message is repeated to frequently, the same result might occur. In the ELM, two routes to persuasion are possible, central and peripheral. Under conditions of high elaboration, individuals change their beliefs either through a complex central process or by attention to a peripheral cue. The central route may lead to a long-lasting change in beliefs while low elaboration leads to weak and short-lived belief change (peripheral route).

If a compromise in a negotiation is reached between negotiation parties, this could indicate in an ELM context that two sides have changed their beliefs at least in a peripheral way, i.e. secondary beliefs (in the ACF framework) have been modified. However, these changes cannot be used to predict future behavior and strategies employed by a group or coalition as these tend to be short-lived.

Secondary beliefs and peripheral attitudes can be changed according to the ELM model if one of the conditions is fulfilled:

- The groups involved are not motivated to take communication and messages into account but face peripheral cues; or

- The groups are motivated but do not have an ability to process these messages while facing peripheral cues; or

- In addition to peripheral cues, the groups are motivated and have the ability to process the message but the nature of cognitive processes are neutral and neither framed positively nor negatively.

If peripheral cues are not present, the initial attitude prevails and no substantial change takes place. This, in turn, can lead to enduring or unfruitful negotiations.

Applied to ACF, this means that in a negotiation process between different coalitions to integrate a voluntary rating scheme in the procurement process, policy beliefs are only likely to change if the above outlined conditions are met. 


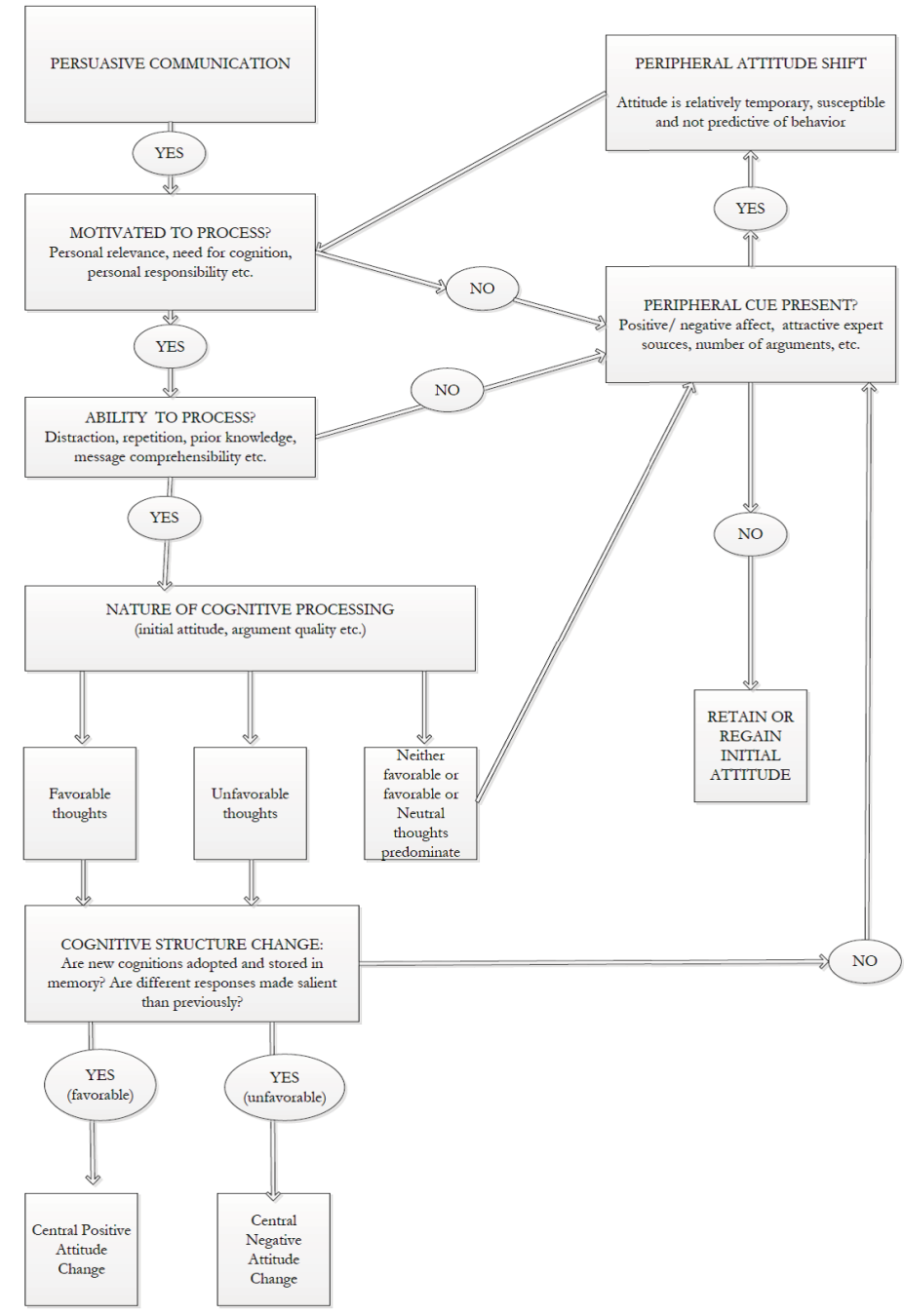

Figure 9.4: Elaboration Likelihood Model (ELM) by Petty and Cacioppo (1986) 


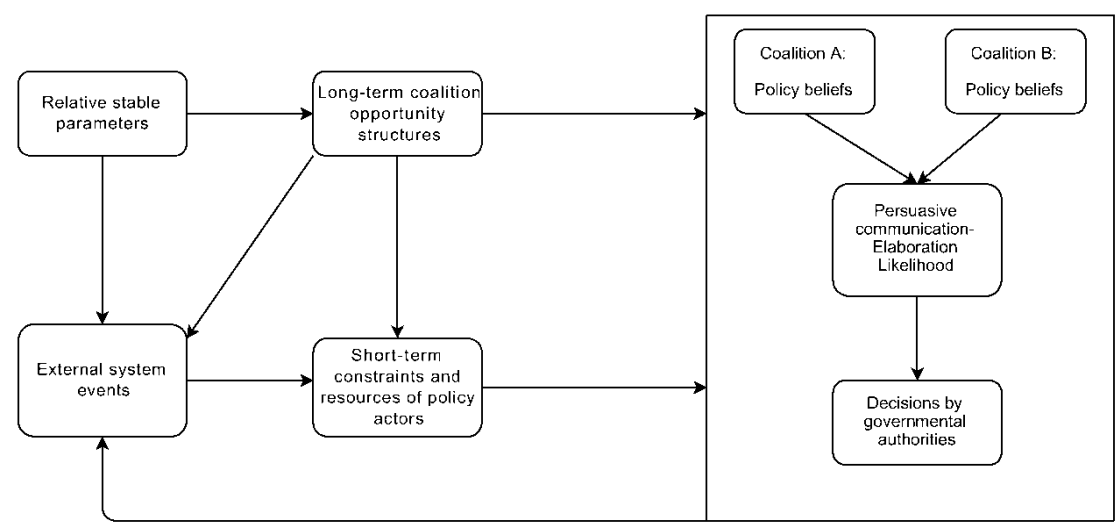

Figure 9.5: Elaboration Likelihood Model (ELM) in the Advocacy Coalition Framework (ACF) (Source: Author's representation)

\subsection{A strategy to influence policy-makers to integrate VEPs in their decision processes}

As indicated in the previous sections, public policy innovation within the Advocacy Coalition Framework (ACF) suggests that change occurs as a function of beliefs about policy issues (e.g. the reduction of environmental problems) and likely solutions. These policy beliefs changes can occur when a new policy coalition comes to power or actors in existing dominant coalitions change their core policy beliefs.

While external change has been suggested to be the main reason for changes in policy beliefs, internal change within the system due to learning can also occur (Sabatier and Weible, 2007; Weible, et al., 2009) as the ACF focuses on policy actors' behavior to influence policy outcomes (Henry and Dietz, 2012). An overview of how policy brokerage could be explained by the ELM and at the same time serve as a basis for strategies employed by policy actors within the ACF and ELM to push their agenda can be seen in Figure 9.5.

Promoting environmentally relevant behaviors such as convincing policy actors that green building principles need to be further considered in policy-making processes could be achieved by changing the policy coalition's stance (i.e. their members). 


\subsection{Limitations and Conclusion}

As a conclusion, it can be said that green building VEPs have become increasingly popular, at least partly a result of their promotion by Green Building Councils (GBCs). International organizations such as UN Habitats' 2010 " Conference on Green Building Rating in Africa” have brought forward strategies to promote sustainable building in the southern hemisphere. Even though some developed countries have endorsed these schemes for quite some time, evidence on their effectiveness is still scarce and widely debated. In addition, the reasons for which building professionals, public procurement officials and product developers opt for these schemes is not well understood, which has created a procedural "black box". The concepts of green building and environmental public purchasing processes can be very different economically, technologically, culturally and sociologically across countries.

While some proponents of voluntary building rating schemes have promoted them as a good instrument to foster sustainable urban environments, the debate is still open whether this is really the case. The inclusion of a VEP in EPP policies is the result of several dynamics. On the international level, some countries determine the agenda with their schemes being exported to third countries. Within that country, however, there have been most likely conflicts between organizations such as the GBCs and other rating schemes developing bodies. Also, within the WGBC which seems to promote the US-based LEED scheme, and individual GBCs are active discussions about which scheme is most appropriate to the local context. Additionally, certain professional groups within the building and construction industry will benefit more from certain schemes than others and try to influence public officials (such as procurement officers) to push their agenda.

Then, importantly, policy-makers at the local, state and national level will have very different conceptions of what a "green" building and an acceptable environmental footprint should be and how to address issues appropriately by either voluntary or compulsory regulatory instruments. Public purchasing and procurement processes finally are subject to external constraints such as budgetary processes, environmental policy and individual decisions.

If principles from third party developed environmental building rating schemes were to be included in the overall assessment processes, adopting elements from different social science approaches, such as the ACF and ELM, can substantially contribute to explain the way by which policy-makers could be influenced either by a third party or each other to determine the environmental and energy policy agenda. 


\section{References}

Argyris, C., \& Schön, D. A. (1996). Organizational learning: Theory, method, and practice. Reading, MA.: Addison-Wesley.

Badenhorst, J. (1994). Unethical behaviour in procurement: a perspective on causes and solutions. Journal of Business Ethics, 13(9), 739-745.

Bandura, A. (1985). Social foundations of thought and action. Englewood Cliffs, NJ Prentice Hall.

Berry, J. W. (1984). Multicultural policy in canada: A social psychological analysis. Canadian Journal of Behavioural Science/Revue canadienne des sciences du comportement, 16(4), 353.

Boer, L., \& Telgen, J. (1998). Purchasing practice in dutch municipalities. Journal of Supply Chain Management, 34(2), 31-36.

Bon, R., \& Hutchinson, K. (2000). Sustainable construction: some economic challenges. Building Research \& Information, 28(5-6), 310-314.

Bowen, F. E., Cousins, P. D., Lamming, R. C., \& Faruk, A. C. (2001). Horses for courses:explaining the gap between the theory and practice of green supply. Greener Management International, 2001(35), 41-60.

Breton, E., \& De Leeuw, E. (2011). Theories of the policy process in health promotion research: a review. Health promotion international, 26(1), 82-90.

Carter, C. R., \& Dresner, M. (2001). Purchasing's role in environmental management: Cross-functional development of grounded theory. Journal of Supply Chain Management, 37(3), 12-27.

Charter, M., Young, A., Kielkiewicz-Young, A., \& Belmane, I. (2001). Integrated product policy and eco-product development. Sustainable Solutions: Developing Products and Services for the Future, 1(92), 98-116.

Daft, R. L., \& Weick, K. E. (1984). Toward a model of organizations as interpretation systems. Academy of management review, 9(2), 284-295.

Dolowitz, D. P., \& Marsh, D. (2000). Learning from abroad: The role of policy transfer in contemporary policy-making. Governance, 13(1), 5-23.

Dosi, C., \& Moretto, M. (2001). Is ecolabelling a reliable environmental policy measure? Environmental and Resource Economics, 18(1), 113-127.

Dowding, K. (1995). Model or metaphor? a critical review of the policy network approach. Political Studies, 43(1), 136-158.

Elliott, C., \& Schlaepfer, R. (2001). The advocacy coalition framework: application to the policy process for the development of forest certification in sweden. Journal of European Public Policy, 8(4), 642-661.

Eriksson, P. E., \& Westerberg, M. (2011). Effects of cooperative procurement procedures on construction project performance: a conceptual framework. International Journal of Project Management, 29(2), 197-208. 
Evans, K. R., \& Schultz, R. J. (1997). Toward an understanding of public purchaser and salesperson interaction activities: a public purchaser's perspective. Journal of Nonprofit \& Public Sector Marketing, 4(4), 55-75.

Eyaa, S., \& Oluka, P. (2011). Explaining non-compliance in public procurement in uganda. International Journal of Business and Social Science, 2(11).

Fenger, M., \& Klok, P.-J. (2001). Interdependency, beliefs, and coalition behavior: A contribution to the advocacy coalition framework. Policy sciences, 34(2), 157-170.

Forker, L. B., \& Janson, R. L. (1990). Ethical practices in purchasing. Journal of Purchasing and Materials Management, 26(1), 19-26.

Franzitta, V., La Gennusa, M., Peri, G., Rizzo, G., \& Scaccianoce, G. (2011). Toward a european eco-label brand for residential buildings: Holistic or by-components approaches? Energy, 36(4), 1884-1892.

Fuerst, F., \& McAllister, P. (2009). An investigation of the effect of eco-labeling on office occupancy rates. The Journal of Sustainable Real Estate, 1(1), 49-64.

Fuerst, F., \& McAllister, P. (2011a). Eco-labeling in commercial office markets: Do leed and energy star offices obtain multiple premiums? Ecological Economics, 70(6), $1220-1230$.

Fuerst, F., \& McAllister, P. (2011b). Green noise or green value? measuring the effects of environmental certification on office values. Real Estate Economics, 39(1), 45-69.

Galarraga Gallastegui, I. (2002). The use of eco-labels: a review of the literature. European Environment, 12(6), 316-331.

Gelderman, C. J., Paul, W. T., \& Brugman, M. J. (2006). Public procurement and eu tendering directives-explaining non-compliance. International Journal of Public Sector Management, 19(7), 702-714.

Gluch, P., Brunklaus, B., Johansson, K., Lundberg, Ö., Stenberg, A.-C., \& Thuvander, L. (2010). Performance improvement in construction management. In B. Atkin \& J. Borgbrant (Eds.), (chap. Environmental attitudes, management and performance). London: Taylor and Francis.

González-Benito, J., \& González-Benito, Ó. (2005). Environmental proactivity and business performance: an empirical analysis. Omega, 33(1), 1-15.

Greer, J., \& Bruno, K. (1996). Greenwash: The reality behind corporate environmentalism. Third World Network (Penang, Malaysia.

Grolleau, G., Ibanez, L., \& Mzoughi, N. (2009). Too much of a good thing? why altruism can harm the environment? Ecological Economics, 68(7), 2145-2149.

HABITAT. (2010). Conference on promoting green building rating in africa. paper presented at the conference on promoting green building rating in africa..

Hall, J. (2001). Environmental supply-chain innovation. Greener Management International, $35,105-119$.

Hanna, M. D., Newman, W. R., \& Johnson, P. (2000). Linking operational and environmental improvement through employee involvement. International Journal of Operations 
\& Production Management, 20(2), 148-165.

Henry, A. D. (2011). Belief-oriented segregation in policy networks. Procedia-Social and Behavioral Sciences, 22, 14-25.

Henry, A. D., Lubell, M., \& McCoy, M. (2011). Belief systems and social capital as drivers of policy network structure: The case of california regional planning. Journal of Public Administration Research and Theory, 21(3), 419-444.

Ibanez, L., \& Grolleau, G. (2008). Can ecolabeling schemes preserve the environment? Environmental and Resource Economics, 40(2), 233-249.

Karjalainen, K., Kemppainen, K., \& Van Raaij, E. M. (2009). Non-compliant work behaviour in purchasing: An exploration of reasons behind maverick buying. Journal of Business Ethics, 85(2), 245-261.

Kelley, S. W., \& Dorsch, M. J. (1991). Ethical climate, organizational commitment, and indebtedness among purchasing executives. Journal of Personal Selling \& Sales Management, 11(4), 55-66.

Lawther, W. C., \& Martin, L. L. (2005). Innovative practices in public procurement partnerships: The case of the united states. Journal of Purchasing and Supply Management, 11(5), 212-220.

Leire, C., \& Thidell, A. (2005). Product-related environmental information to guide consumer purchases-a review and analysis of research on perceptions, understanding and use among nordic consumers. Journal of Cleaner Production, 13(10), 1061-1070.

Lepgold, J., \& Lamborn, A. C. (2001). Locating bridges: connecting research agendas on cognition and strategic choice. International Studies Review, 3(3), 3-29.

Luthans, F., Stajkovic, A. D., \& Ibrayeva, E. (2000). Environmental and psychological challenges facing entrepreneurial development in transitional economies. Journal of World Business, 35(1), 95-110.

Lyon, T. P. (2004). Corporate environmentalism and public policy. Cambridge University Press.

Lyon, T. P., \& Maxwell, J. W. (2003). Self-regulation, taxation and public voluntary environmental agreements. Journal of Public Economics, 87(7), 1453-1486.

March, J. G., \& Simon, H. A. (1958). Organizations.

Milfont, T. L., \& Duckitt, J. (2010). The environmental attitudes inventory: A valid and reliable measure to assess the structure of environmental attitudes. Journal of Environmental Psychology, 30(1), 80-94.

Min, H., \& Galle, W. P. (2001). Green purchasing practices of us firms. International Journal of Operations \& Production Management, 21(9), 1222-1238.

New, S., Green, K., \& Morton, B. (2000). The business of greening. In (pp. 33-53). Routledge.

Noori, H., \& Chen, C. (2003). Applying scenario-driven strategy to integrate environmental management and product design. Production and Operations Management, 12(3), $353-368$. 
Petty, R. E., \& Cacioppo, J. T. (1986). The elaboration likelihood model of persuasion. Springer.

Porter, M. E., \& Van der Linde, C. (1995). Green and competitive: ending the stalemate. Harvard business review, 73(5), 120-134.

Preuss, L. (2009). Addressing sustainable development through public procurement: the case of local government. Supply Chain Management: An International Journal, 14(3), 213-223.

Preuss, L., \& Walker, H. (2011). Psychological barriers in the road to sustainable development: evidence from public sector procurement. Public Administration, 89(2), 493-521.

Robertson, D. C., \& Rymon, T. (2001). Purchasing agents' deceptive behavior: A randomized response technique study. Business Ethics Quarterly, 11(3), 455-479.

Sabatier, P. A. (1988). An advocacy coalition framework of policy change and the role of policy-oriented learning therein. Policy sciences, 21(2-3), 129-168.

Sabatier, P. A. (1998). The advocacy coalition framework: revisions and relevance for europe. Journal of European public policy, 5(1), 98-130.

Sabatier, P. A., \& Jenkins-Smith, H. C. (1993). Theories of the policy process. In P. A. Sabatier (Ed.), (chap. Policy change and learning: An advocacy coalition approach). Boulder, Co.: Westview Press.

Sabatier, P. A., \& Jenkins-Smith, H. C. (1999). Theories of the policy process. In P. A. Sabatier (Ed.), (Vol. 118, p. 117-166). Westview Press Boulder, CO.

Sabatier, P. A., \& Weible, C. M. (2007). Theories of the policy process. In P. A. Sabatier (Ed.), (Vol. 2, pp. 189-220). Westview Press Boulder.

Sarkis, J. (2003). A strategic decision framework for green supply chain management. Journal of Cleaner Production, 11(4), 397-409.

Schlager, E. (1995). Policy making and collective action: Defining coalitions within the advocacy coalition framework. Policy sciences, 28(3), 243-270.

Sharma, S., \& Vredenburg, H. (1998). Proactive corporate environmental strategy and the development of competitively valuable organizational capabilities. Strategic Management Journal, 19(8), 729-753.

Sporrong, J., \& Bröchner, J. (2009). Public procurement incentives for sustainable design services: Swedish experiences. Architectural Engineering and Design Management, 5(1-2), 24-35.

Srivastava, S. K. (2007). Green supply-chain management: a state-of-the-art literature review. International journal of management reviews, 9(1), 53-80.

Stacey, R. (2000). The emergence of knowledge in organization. Emergence, A Journal of Complexity Issues in Organizations and Management, 2(4), 23-39.

Stern, P. C. (2000). New environmental theories: toward a coherent theory of environmentally significant behavior. Journal of social issues, 56(3), 407-424. 
Stone, D. (2000). Non-governmental policy transfer: the strategies of independent policy institutes. Governance, 13(1), 45-70.

Teisl, M. F., Roe, B., \& Hicks, R. L. (2002). Can eco-labels tune a market? evidence from dolphin-safe labeling. Journal of Environmental Economics and Management, 43(3), 339-359.

Thai, K. V. (2001). Public procurement re-examined. Journal of Public Procurement, 1(1), 9-50.

Thorngate, W. (2001). The social psychology of policy analysis. Journal of Comparative Policy Analysis: Research and Practice, 3(1), 85-112.

Trisolini, K. A. (2009). All hands on deck: local governments and the potential for bidirectional climate change regulation. Stanford, 62, 669-746.

Ürge-Vorsatz, D., Koeppel, S., \& Novikova, A. (2006). Improving energy-efficiency in buildings: opportunities, promises, challenges and solutions. Center for Policy Studies, Central European University.. (Available: $<$ http://web. ceu. hu/envsci/projects/IPCC/ipcc\% 20site\% 20folders/publications/UrgeVorsatz_EnergyEfficiencyPotentials_Seoul.pdf)

Vachon, S., \& Klassen, R. D. (2006). Extending green practices across the supply chain: the impact of upstream and downstream integration. International Journal of Operations \& Production Management, 26(7), 795-821.

Varnäs, A., Faith-Ell, C., \& Balfors, B. (2009). Linking environmental impact assessment, environmental management systems and green procurement in construction projects: lessons from the city tunnel project in malmö, sweden. Impact Assessment and Project Appraisal, 27(1), 69-76.

Walker, H., Di Sisto, L., \& McBain, D. (2008). Drivers and barriers to environmental supply chain management practices: Lessons from the public and private sectors. Journal of Purchasing and Supply Management, 14(1), 69-85.

Walker, H., \& Preuss, L. (2008). Fostering sustainability through sourcing from small businesses: public sector perspectives. Journal of Cleaner Production, 16(15), 1600-1609.

Weible, C. M. (2005). Beliefs and perceived influence in a natural resource conflict: An advocacy coalition approach to policy networks. Political Research Quarterly, 58(3), 461-475.

Weible, C. M., Sabatier, P. A., \& McQueen, K. (2009). Themes and variations: Taking stock of the advocacy coalition framework. Policy Studies Journal, 37(1), 121-140.

Wycherley, I. (1999). Greening supply chains: the case of the body shop international. Business Strategy and the Environment, 8(2), 120-127.

Zafonte, M., \& Sabatier, P. (1998). Shared beliefs and imposed interdependencies as determinants of ally networks in overlapping subsystems. Journal of theoretical politics, 10(4), 473-505.

Zaman, A. U., Miliutenko, S., \& Nagapetan, V. (2010). Green marketing or green wash?: A comparative study of consumers' behavior on selected eco and fair trade labeling in 
sweden. Journal of Ecology and the Natural Environment, 2(6), 104-111.

Zhu, Q. \& Sarkis, J. (2006). An inter-sectoral comparison of green supply chain management in china: drivers and practices. Journal of cleaner production, 14(5), 472-486. 



\section{0}

\section{ISO 14001 Certification of Environmental Management Standards - Comparing the Netherlands and Germany}

\footnotetext{
"You don't have to judge the world by your own standards. Not everyone is like you, you know". ( Haruki Murakami, The Elephant vanishes)
}

\subsection{Introduction}

$\mathrm{R}$ educing the environmental impact of business on the natural environment has been a long standing issue in environmental law and policy-making as well as a prominent issue in academic research. Laws, regulations and other forms of policy choice have been tried and implemented in order to understand which governance forms and policy instruments work best to reduce the damage inflicted by economic growth on the global environmental system. Even though there are several approaches to environmental policy (e.g. command-and-control mechanisms), voluntary management schemes have frequently been favored by politicians and business leaders. Despite doubts from policy and academia, these schemes continue to be extremely popular. Explaining behavioral factors that lead to the adoption of these systems have been neglected until rather recently, when social scientists took up the challenge to investigate which determinants within a firm affect the adoption of Environmental Management Systems and Certification Schemes.

An increasing number of environmental and energy management schemes target essentially the same firms. Hence, understanding the adoption process of these schemes and analyzing why some of them are preferred by decision-makers is crucial. This chapter seeks to determine (1) which factors influence managers' decisions to adopt a specific environmental 
management scheme and (2) potential differences in characteristics and behavior of professionals involved in EMS certification schemes in Germany and the Netherlands. The latter point has not been investigated at this point, even though there are some indications that business managers facing an increasing decision load with regards to sustainability may be confused by the wide array of certification programs related to the natural environment.

In this chapter, research on the diffusion of innovation and technology will be applied to the adoption process of the ISO 14001 (environmental management scheme) in the Netherlands and Germany. When it comes to environmental management, the Netherlands and Germany are interesting cases since the choices made by governments (in terms of environmental policies) place the countries as two of the most innovative around the world. Knowledge on these processes will help policy-makers, researchers but also business managers to better understand and apply the decision and implementation processes of EMS certification programs. In both countries decision-makers in companies are surveyed and their decisions linked to behavioral factors that may influence EMS uptake.

\subsection{Standards for Environmental Protection: the Development of Standards}

Many standards bodies have been established around the world, with the most predominant being the International Standardization Organization (ISO). International standards have largely replaced national standards and certification schemes related to almost any business activity exist nowadays. ISO is composed of national standards bodies (NSBs) and is a nontreaty international organization (ANSI, 2012) with members being both governmental and non-governmental entities. However, increasingly private international standards organizations such as ASTM International or SAE International have developed sectorspecific standards aimed at regulating business activities.

In addition to international standards bodies, regional organizations such as the European Committee for Standardization (CEN), the Pacific Area Standards Congress (PASC), the Pan American Standards Commission (COPANT) or the African Organization for Standardization (ARSO) have started to develop and issue business certification schemes. For instance, CEN's schemes are recognized as "European Standards" as laid down in Directive 98/34/EC (European Commission, 2000). As a result of this standards proliferation, large number of standard developing organizations (SDOs) in most countries; in some economies such as the United States, several hundreds of SDOs have come to co-exist.

Since the focus of this chapter is on standards for environmental management, this study will first analyze the most commonly used voluntary standard for environmental management systems in the Netherlands and Germany, the ISO 14001 management certification. 


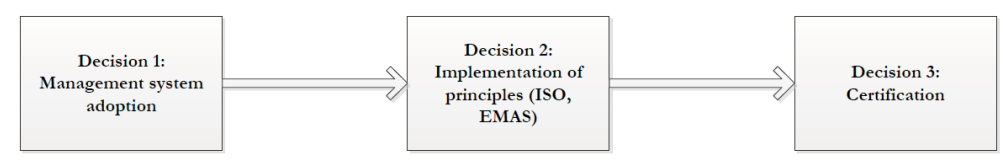

Figure 10.1: Adoption Process of a Certified Management System (CMS) (Source: Author)

Environmental management generally encompasses many diverse definitions which have been narrowed down for the purpose of creating certifiable environmental management systems. Environmental Management Systems can be defined as a "set of processes and practices that enable an organization to reduce its environmental impacts and increase its operating efficiency" (US Environmental Protection Agency, 2012). The implicit assumption underlying EMS systems is that streamlined control will eventually lead to an improvement of a firm's environmental score. EMS will not prescribe a specific level of environmental performance and offers the possibility for each company to define its own environmental targets (US Environmental Protection Agency, 2012). This leaves a very wide range of interpretation what should be included in an EMS system; certain common elements usually found are the:

- Review of the company's environmental goals;

- Analysis of environmental impacts and legal requirements;

- Setting of environmental objectives and targets to reduce environmental impacts and comply with legal requirements;

- Establishment of programs to meet these objectives and targets;

- Monitoring and measurement of progress in achieving the objectives;

- Ensuring employees' environmental awareness and competence; and the

- Review of the progress of the EMS and subsequent improvements

As Figure 11.1 demonstrates, Environmental Management System (EMS) adoption is not a single-step or uniform process but includes several stages including adoption, implementation and certification. Costs of EMS implementation include set up fees, employee time, training and external assistance. Potential benefits that have been mentioned extend to improved environmental performance, enhanced legal compliance, exploration of new market opportunities, a reduction of operation costs, an improved public image as well as an improvement of employee awareness (US Environmental Protection Agency, 2012). These costs and benefits are not present in all cases or business contexts and may vary from sector to sector and cross-country. The same principles apply for EMS certification schemes such as ISO 14001 and EMAS. While standardization in the private sector has gained momentum due to hypothesized efficiency gains and increased benchmarking (e.g. the quality 
management field and the widespread success of the ISO 9001 series), standardization is much more difficult in the environmental arena due to limitations of data availability and environmental indicators.

While firms' main adoption logic is often linked to business opportunities or the imitation of other firms, these reasons alone do not suffice to explain different patterns of adoption nationally or internationally.

\section{The ISO 14001 vs. EMAS: theory and empirical evidence}

To better understand the discussion about voluntary energy management systems certification, the debate and literature on the ISO 14001 and EMAS contributes valuable insights. Most standardization bodies and management standards essentially target the same firms. In the European Union, both the international ISO 14001 and the European Eco-Management and Audit Scheme (EMAS) have come to gain enormous popularity.

The ISO 14001 program is part of a set of 16 standards within the ISO 14000 group that was designed to contribute to firms reducing their environmental impact (Federal Facilities Council Report 1999). This standard does not impose absolute performance requirements but serves as guidelines to assist companies in influencing their own environmental management system.

Even though the standard is voluntary, it can support organizations to comply with their country's environmental regulations and legislations. Participating organizations are hence responsible for setting their own environmental performance targets using the standard as a tool to monitor and measure these subsequently (International Organization for Standardization, 2012). Hence firms with different sets of goals and targets can comply with the ISO 14001 standards. The ISO 14001 standard has been therefore described as a rather generic management system certification scheme that can be applied to any kind of organization, sector and every level within a firm (International Organization for Standardization, 2012).

Studies on the ISO 14001 scheme are abundant within the compliance and environmental governance literature. Studies cover a wide range from comparative to national-level, industry and firm-level projects including a variety of methods dominated by interview and survey studies. Since the issue of environmental management systems and their certifications are intrinsically linked, five streams of literature are of particular interest in this matter:

1. The literature on determinants of Environmental Management System (EMS) adoption (e.g. Watson and Emery, 2004; Guest and Teplitzky, 2010; Slinn et al., 2007); and

2. The adoption of a ISO 14001 certified environmental management system ( e.g. Gonzalez-Benito and Gonzalez-Benito, 2005; Babakri et. al., 2003; Potoski and 
Prakash, 2005; ${ }^{1}$ Rondinelli and Vastag, 2000; Darnall, 2006; Darnall, 2003; Arimura et al., 2011; Schylander , 2007; Melnyk et al., 2003, Delmas, 2000; King et al., 2005; Boiral, 2007); and

3. The adoption of an EMAS certified environmental management systems (Perkins and Neumayer, 2004; Pedersen, 2007; Tinsley and Pillai, 2007; Strachan, 1999; Honkasalo, 1998; Glachant et al., 2002); and

4. Research on the comparison of the ISO 14001 and EMAS standard and determinants of some firms choosing one scheme over the other. In most cases, the empirical literature in this respect has focused on factors such as global competitiveness or institutional factors prevalent within a country that determines this choice (e.g. Freimann and Walther. 2002; Oluoch-Wauna, 2001; Morrow and Rondinelli, 2002; Kolln and Prakash, 2002; Watzold and Bueltmann, 2001); and

5. Evidence related to determinants and outcomes of EMS adoption and certification are numerous. The common consensus of most studies is that EMS certification may be beneficial to companies (e.g. in obtaining finance, creating better market access, having a better standing with investors and the government) and the wider society under specific circumstances, depending on the business and institutional environment.

The impact of these factors in the business environment on the decision to adopt and certify an EMS and subsequent managerial behavior has only recently garnered interest. Since institutional, financial and economic determinants have been the main focus within the literature on management systems adoption, studies focusing on behavioral determinants underlying Environmental Management System and adoption are scarce. Research on behavioral factors in the analysis of environmental management systems includes studies by Cordano and Frieze (2000), Marshall et al. (2005), Ramus and Killmer (2007), Boiral (2009) and Hoffman and Bazerman (2007). Nevertheless, none of the above mentioned papers analyzes the behavioral drivers underlying Environmental Management System adoption and certification behavior. According to Orsato (2006), the range of possibilities for corporate environmental management is quite diverse and leaves quite a few managers confused which approach to take.

\footnotetext{
${ }^{1}$ As an example, a search on the JSTOR (Journal Storage) online search engine produced more than 239 results in academic peer reviewed journals alone with "ISO 14001" in the search title, while the Google Scholar engine resulted in 2039 hits with "ISO 14001" in the title of the paper. Likewise, the search on EMAS literature on Google Scholar produced more than 1.570 results with EMAS included in the article title. In addition, International Organizations and national agencies (e.g. OECD, 2003 or U.S. Environmental Protection Agency, 2007) produced reports on the use of Environmental Management Systems and certification schemes while general research articles on Environmental Management systems (without specifically mentioning ISO 14001 or EMAS) returned 2.150 responses. The journals in which these articles were published belong mostly to the Management, Policy or Law field with some studies in the Technology and Sociology field.
} 
The answer as to underlying factors for environmental management systems adoption is intrinsically linked to the literature on environmental management in the private sector.

Studies on the link between financial performance and environmental management have been advanced with meta-analyses carried out by Klassen and Laughlin (1996) and Azorin et al.(2009). Klassen and Laughlin (1996) found that environmental performance, through both market gains and cost savings, affected firm financial performance. Molina-Azorin et al. (2009) were more cautious in their conclusion. The authors suggest mixed results with a general trend of a positive association between financial performance and environmental management generally. Their definition of environmental management, however, was not limited to environmental management systems but overall green firm initiatives.

In this line of thinking several research studies have focused on the overall link between environmental initiatives and firm benefits. Orsato (2006) as well as Ambec and Lanoie (2007) investigated the question whether and when it pays for a company to be green. Ambec and Lanoie (2007) propose that environmental management is not always a burden on a firm and that financial and economic burden can be offset by gains on other areas including better access to certain markets, improved risk management and stakeholder relations, reduced cost of capital or cost of labor. Orsato (2006) also analyzed potential reasons for environmental management but focused more on strategic choices and internal firm policies. However, he also emphasizes the problems with environmental management procedures: Managers overwhelmed with different models, techniques, tools and standards and while awareness has been on the increase "managers have been left wondering what they should do first, and why. Should they invest in EMS certification? Should they develop a life cycle analysis for a specific line of products? Should they subscribe to an eco-label program? Should they develop an eco-brand? Many firms do "a bit of everything" and spend precious resources without any sound rationale” (Orsato, 2006). The importance of managerial and employee understanding of environmental management issues and systems has been confirmed in other studies (e.g. Sharma, 2000).

While most of the literature focused on EMS as a "good" strategy to reduce environmental impact, increasingly researchers have also voiced criticism in relation to EMS adoption and certification. For instance, Könnölä and Unruh (2007) argued that the focus on EMS as the ultimate standard inhibits the development and of better solutions and superior innovations.

\section{ISO 50001 vs. EN 16001 : Energy Management Systems}

While studies on ISO 14001 and EMAS have had their momentum in the late 90s and early 2000s, results are inconclusive on whether EMS systems are beneficial for firms, the community and finally the natural environment. The conclusions are dependent on the specific context within which the management standard adoption is studied. With energy resources, 
mainly from oil and gas sources becoming scarcer, energy efficiency has gained momentum in the business sector. The tendency to increased environmental management and energy efficiency has led to a new trend in the standards practice: energy management standards have emerged and complement the existing environmental management standards. The EN 16001, launched in 2009 by CEN and CENELEC is a European standard targeted at effective management of energy within business firms. While the systems can be integrated with other environmental management (such as ISO 14001 or EMAS) or quality (such as ISO 9001) standards, it was advertised also to be used independently. The scheme has been devised in order to enable firms to develop an energy policy, identify the appropriate areas for reduction and engage in reductions of these targets. EN 16001 was specifically devised as a means to comply with future regulations and legislation on greenhouse gas emissions and energy efficiency targets.

At the same time, ISO developed their ISO 50001 standard for energy management published in early 2011. Similarly to the EN 16001 standard, established a tool for firms to manage and regulate their energy use focusing on compatibility with the other ISO developed standards such as ISO 9001 or ISO 14001. The aim of the standard is to improve the use of existing energy use, benchmarking and reporting the improvements in energy intensity and their impact on GHG emissions as well as encouraging good energy management practices as well as giving priority to the use of new energy-efficient technologies.

When it comes to explaining the "battle" between different standards aimed at the same issue, in this case environmental and energy management systems, this competition has not been targeted sufficiently by the relevant literature. As mentioned above, the comparison of the ISO 14001 and EMAS schemes contrasts the EU-backed EMAS with the industry sponsored ISO 14001 scheme and derives explanations in adoption behavior from this (see Table 10.1).

That being said, the decision on whether a standard will be successful depends on a sufficient mass of firms making the decision to adopt this standard. Hence, the beliefs, intentions and perceptions of decision-makers are of utmost importance in this respect. Bracke and Albrecht (2007) suggested that managers of firms wanting to implement a management system always have to decide between national, European and an International standard (mostly ISO related). While purely national standards have lost most of their importance, the difference in adoption between the ISO 14001 and EMAS standards, for instance, has been very different across Europe (Glachant et al., 2002). While institutional development certainly matters, differences in cognition and perception need to be more subject to scrutiny. The reaction to environmental and energy standards therefore needs to take into account both the question of sponsorship, and acceptance of these schemes. Patterns detected on the ISO 14001 standard and EMAS might contribute to the better understanding and prediction of the EN 16001 and ISO 50001 standard adoptions. Assuming that EMSs certification schemes are to attain their goal and contribute to a cleaner environment, they 


\begin{tabular}{llll}
\hline SCHEME & Field of Application & Issuing Organization & $\begin{array}{l}\text { Date of } \\
\text { Publica- } \\
\text { tion }\end{array}$ \\
\hline ISO 14001 & $\begin{array}{l}\text { Environmental } \\
\text { Management }\end{array}$ & $\begin{array}{l}\text { International Organization for } \\
\text { Standardization (ISO) }\end{array}$ & 1996 \\
$\begin{array}{l}\text { Eco-Management } \\
\text { and Audit Scheme }\end{array}$ & $\begin{array}{l}\text { Environmental } \\
\text { EMAS) }\end{array}$ & European Union & 1995 \\
ISO SCOO1 & Energy & $\begin{array}{l}\text { International Organization for } \\
\text { Standardization (ISO) }\end{array}$ & $\begin{array}{l}\text { Early } \\
\text { Eanagement }\end{array}$ \\
EN 16001 & $\begin{array}{l}\text { Energy } \\
\text { Management }\end{array}$ & $\begin{array}{l}\text { Standardization (CEN) } \\
\text { Jul-09 }\end{array}$ \\
\hline
\end{tabular}

Table 10.1: Overview of the main EMS certification schemes

still will be efficient only if managers and their organizations implement EMS (and certify them). Whether this occurs due to compliance or pro-active, environmental management on a voluntary basis only will make sense if a critical mass of firms can be reached.

\subsection{Environmental Management Systems and Governance: the case of the Netherlands and Germany}

So far this chapter has touched upon different dimensions of environmental management and the role of managerial assessment in the adoption of EMSs and their certification schemes. However, national preferences and policy decisions may also play a role in EMS adoption and certification of schemes.

Two aspects may influence manager's decisions: Whether environmental management systems are generally endorsed by national governments as a preferred method of environmental management and which certification schemes have been promoted at the national level.

From a policy perspective, EMS systems can be used in many innovative ways to advance environmental policy goals. According to Pezzoli (2000), EMS systems were introduced in the environmental policy debates as responses to limits in functional, structural and political factors inherent in "first generation environmental policy" allowing for more flexible regulation and industry-government co-regulation.

As mentioned by Glachant et al. (2002), deregulation has played a significant role in the corporate sector. Environmental goals have been used instead of detailed rules when it 
comes to environmental monitoring. Since a memorandum with industry from to 1989 , certified environmental management systems have been part of covenants used for initiating integrated and yet simple permits for business operations (Glachant et al., 2002). The adoption and competition process of ISO 14001 and EMAS in the Netherlands has been analyzed by Glachant et al. (2002). They suggest that the Netherlands decided early on to set up a body that interpreted the ISO 14001 standard (SCCM), which should follow the EMAS interpretation. The only additional requirement of EMAS (on top of the ISA 14001 defined regulations) therefore was the publication of an audited environmental statement. Hence, the ISO 14001 standard turned out to be more demanding for adoption in the Netherlands as opposed to other countries (Lulofs, 2000). The Netherlands does not offer subsidies to EMAS nor ISO 14001 registered firms while regulatory relief neither is automatically granted for participating firms, whether EMAS or ISO 14001 certified. Germany made very different choices in their promotion of environmental management schemes. While the Netherlands focused closely on ISO 14001, Germany promoted EMAS to a larger extent. However, the ISO 14001 is also widespread in German industry.

Kolln and Prakash (2002) studied the adoption of ISO 14001 and EMAS in Germany. According to their analysis, business associations in Germany which include overall up to $90 \%$ of all firms and act as an information exchange mechanism were involved in the process of choosing a national guideline for EMSs.

Initially, both German industry and the German government opposed EMAS in the European Council due to the higher stringency of German environmental laws. Despite the controversy, EMAS was more widely accepted by industry when regional chambers of commerce were seen to act initially as a registration body while a new law company was formed to accredit third party auditors (Waskow, 1997) owned by industry associations and overseen by government representatives, trade unions, environmental groups, etc. The involvement of industry groups certainly helped the promotion of EMAS but Kollman and Prakash (2002) fail to explain why the industry associations did not endorse ISO 14001 in a similar fashion. Hence, the decision to focus on EMAS from a governance point of view most likely shifted business attention to EMAS rather than the ISO competitor, even though the ISO 14001 standard was endorsed by industry as well, albeit on a much smaller scale.

The country cases of the Netherlands and Germany are interesting in their difference, as the governments of two countries at similar level of development, and large trading partners geographically close to each other, already choose to focus on different management systems. Even though there is no "obligation" in either country to choose a specific scheme, this national institutional support for a certain system will most likely increase client demand for these systems, and thus drive the choice of companies for one specific EMSs certification programs. 


\subsection{Theoretical perspectives: Diffusion of Innovation and Technology Acceptance literature}

Coleman's (1986) model of micro-macro relations provides the foundation for our conceptual framework. The model underscores the mediating role of individuals in linking macro-level variables such as social structure and the behavior of the social system.Three types of relations are included: (1) macro-level variables such as social structure that affect the psychological states (beliefs, desires, opportunities, etc.) of individuals (link 1); (2) psychological states that affect individual action (link 2); and (3) combined individual action that affects macro-level variables such as the behavior of the social system (link 3 ). The social system construct refers to both social and natural systems (Berkes et al., 2000) and contains both individual and corporate actors (Coleman 1986). Information systems are an important but inadequately understood weapon in the arsenal of organizations in their quest for environmental sustainability by enabling new practices and processes in support of belief formation, action formation, and outcome assessment.

While EMS systems have been around for quite some time, their extensions and new uses have to be adopted and integrated in firm processes in more innovative ways than before. Particularly energy management systems can still be regarded as an innovation, due to their relative novelty factor. Innovations can occur on the policy level (new ways of regulating environmental management and the endorsement of new practices), system-level (the diffusion of new practices among organizations), firm-level (the adoption of new practices for a firm) as well as on the individual level (the individuals practices to deal with a new system or practice) (Rogers, 1995). Particularly the last two dimensions (firm level and individual level) are of relevance for this chapter.

Additionally, innovations on a systems level are not immediate; even after a certain amount of time, a certain product or scheme can be "new" and "innovative" for an organization or an individual. The focus on "first movers" and the advantages for them may be too narrow a concept to reflect reality. Hence, EMS will be new for certain firms, and may still pose very specific issues in the adoption process, irrespective of experiences of other firms. Again, the decisions and perceptions of managers firms will be the focus of this chapter since their understanding of the systems and system certification will determine final outcomes.

Rogers' (1995) Diffusion of Innovations framework is adapted to EMS adoption to analyze whether environmental and energy management systems certification are still perceived as innovations and assess the underlying managerial behavioral reasons for adopting them.

Several academic fields such as Economics, Sociology and Psychology have focused on explaining which factors affect the adoption of a new product or business practice. There are three major streams within this field that analyze adoption, acceptance and diffusion of innovations and technologies. According to Zaltman and Lin (1971), innovation is 
"any idea, practice, or material artifact perceived to be new to the relevant adopting unit "with adoption being "the acceptance and continued use of a product, service, or idea. The adoption process refers to " a series of mental and behavioral states that a person passes through leading to the adoption or rejection of an innovation" (Howard and Moore, 1982). According to them, diffusion "is the spread of an innovation throughout a social system" (Howard and Moore, 1982). Within this field of research, both macro-level theories focus on adoption and diffusion within the system on the national or industry-level while micro-level theories analyze the individual adopters and specific innovations (Carr, 1999). Generally, diffusion models aim to explain the time and rating of an innovation, while adoption models focus on the individuals or firms and their adoption decision. This chapter will use the latter category, models of adoption and acceptance. Hence, this chapter will focus on the Rogers' (1995) diffusion of innovation model to investigate the determinants of ISO 14001 and EMAS adoption. While Rogers's (1995) model is named "diffusion of innovation" it covers the underlying reasons for adoption (that in a later stage lead to diffusion). In this chapter, we will focus on these adoption stages in the model of the Diffusion of Innovations framework.

As can be seen from the Figure 10.2, the diffusion process has several stages that affect the adoption of an innovation. The present chapter focuses on the first three sections, including the receiver variables, social systems variables and the perceived characteristics of innovations.

The receiver variables are based on the manager characteristics and their perceptions of environmental management systems certification, while the social system links to firm and country level characteristics and respective environmental management system practices. The perceived characteristics of innovations, as depicted by Rogers' (1995) model actually link to the managerial perception of certifications' schemes attributes:

- Relative Advantage: the degree to which an innovation is perceived as being better than its precursor;

- Compatibility: the degree to which an innovation is perceived as being consistent with the existing values, needs, and past experiences of potential adopters;

- Complexity: the degree to which an innovation is perceived as being difficult to use;

- Observability: the degree to which the results of an innovation are observable to others;

- Triability: the degree to which an innovation may be experimented with before Adoption.

Based on the previous considerations, the analysis was conducted on how respondent variables and the perception of the relative advantage, compatibility, triability, complexity and observability are linked to ISO 14001 adoption in the Netherlands and Germany.

Rogers (2003) proposed five phases in the adoption decision-making process: 


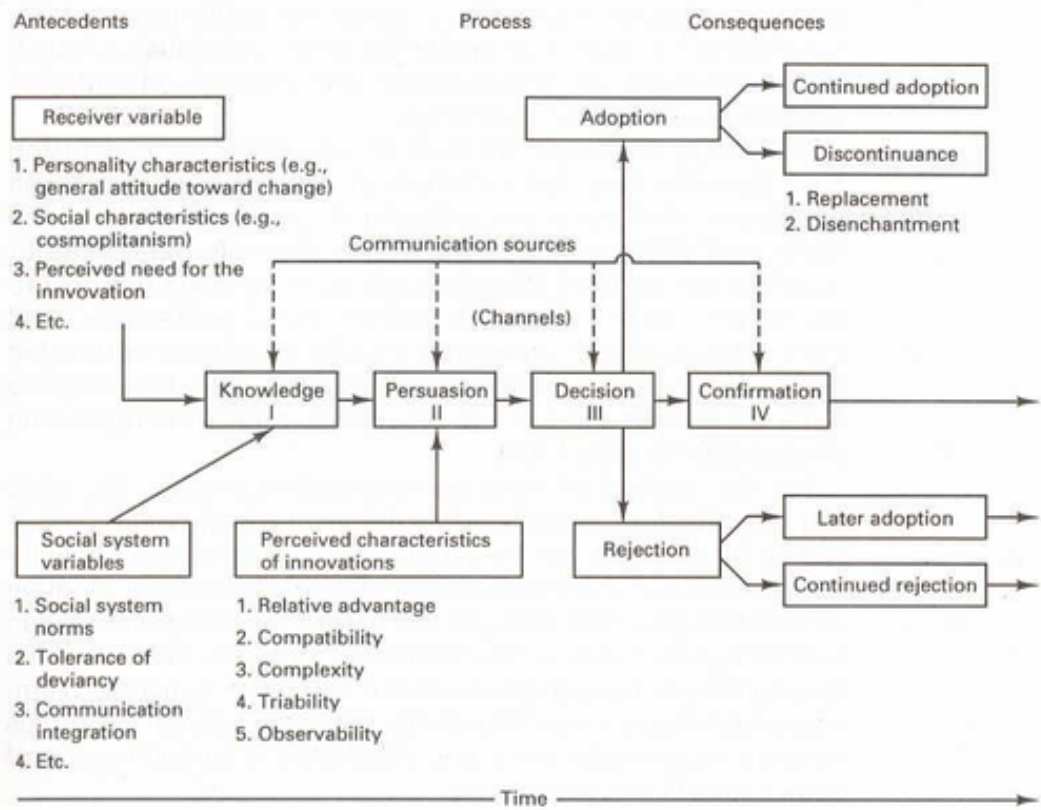

Figure 10.2: Diffusion of Innovation, Rogers (1995)

1. Obtaining knowledge about the idea or innovation;

2. Becoming persuaded to form an attitude with regards to it;

3. Deciding on adoption or rejection of the innovation;

4. Implementing the innovation; and

5. Confirmation or rejection of the decision.

\section{Knowledge of Environmental management systems and decision}

The behavioral aspect is captured in the boxes of knowledge and persuasion. The degree of knowledge a respondent has on environmental management systems certification will influence the decision. It can be expected that decision makers with more specialized knowledge on EMS, with an education in either environmental of energy studies, and with more interest in the systems to be more likely to adopt the ISO 14001 certification. Similarly, managers that perceive to have more information on the systems (irrespective if that matches with prior studies or job experience) may feel comfortable that they understand what the certification is about and what the choice options are, and will be more likely to be able to 
convince management to invest in the systems. Equally, companies that have implemented a certification system before will have more knowledge on these systems in general and on the implementation procedure, so we also expect those companies to certify sooner.

Of course, these factors are based on actual knowledge of a decision maker, but also the perceptions of the manager of their own knowledge. Moore and Benbasat (1991) developed measures of Relative Advantage, Compatibility, Complexity, Triability and Observability that are included in Rogers' (1995) model. In this chapter, their measurements were adapted to the specific EMS certification context. In many previous studies, Rogers' (1995) concepts are linked to the perception of the innovation itself, and not on the perceptions of using the innovation (Moore and Benbasat, 1991). The measures of these variables are listed in Appendix B.

However, an issue related to the analysis of innovation acceptance and diffusion is the difference between the general attitude towards an innovation and the attitude of actually using an innovation (Ajzen and Fishbein, 1980). Since innovations diffuse because of the decisions of individuals to adopt them, the perception of using them seems to be more important than the perception of the scheme under consideration itself. Moore (1987) suggests that research should focus on the perception of usage instead of the perception of the innovation itself. Thus, following this advice, in this study the predictor variables were tested in terms of the adopters perceptions of the Relative Advantage, Compatibility, Complexity, Triability and Observability of ISO 14001 adoption.

\subsection{Methodology}

This study will examine the adoption of innovation by means of a survey instrument. According to Voellink et al. (2002), there are no agreed measurements to the concepts developed by Rogers and it has been frequently mentioned that the operationalization of items should differ according to innovation characteristics (Rogers, 1995; Zaltman et al., 1984). Even though some the questions in the survey instrument were adapted from other studies, they were customised to the adoption of voluntary management standards, ISO 14001.

A methodological difficulty of this study is linked to the definition of behavior. The adoption of a management system certification depends on a five-stage process:

- Management System Adoption Decision

- EMS implementation

- Decision to certify the System

- Implementing the principles

- Certification of the System 
In this study, the focus is on the last behavior, the certification decision, since it implies that the previous steps have been followed as an EMS can only be certified if it has been implemented previously.

\subsection{Questionnaire}

The questionnaire, based on the theoretical framework, Rogers' (1995) Diffusion of Innovation model as operationalized by Taylor and Todd (1995), was sent to firms based in the Netherlands and Germany. The addresses were retrieved from two major sources: The address data base owned by the Dutch Institute for Normalization (NEN) for the Netherlands and Chamber of Commerce information for both Netherlands and Germany.

\section{Variables}

The first section of the questionnaire focused on background and control variables such as the number of employees in the respondents' organization, city, business sector, company age and organizational form. For the respondent themselves, data on professional roles, job tenure, educational achievement and age group were collected.

Predictor variables included perceptions of innovativeness, importance of certification, other firms actions, importance of the schemes, voluntariness, barriers to certification, skills importance, relative advantage, compatibility, complexity, observability and trialability, the five constructs from Rogers' (1995) diffusion model.

Each of Roger's (1995) five constructs was measured by one item each: "The advantages of ISO 14001 certification are greater than the disadvantages" (perceived relative advantage), "I think that ISO 14001 can be/is well integrated in this company" (compatibility), "I think that I can explain to other people what the results of ISO 14001 certification are/will be" (complexity), "Implementing an environmental management system can be seen as a test phase for ISO 14001 certification"(triability), "In my organization ISO 14001 is visible in major operational processes"(observability). The constructs were rated by respondents on a 7- point Likert-scale from Strongly Disagree $(=1)$ to Strongly Agree $(=7)$

\section{Questionnaire administration}

The questionnaires were programmed and administered online in the "Limesurvey" software. The invitations to participate in this study were sent by the NEN (in the Netherlands) and by the researchers themselves for Germany. While the different forms of data administration may lead to different response rates, this was the only way to obtain responses in both country contexts due to data collection arrangements made prior to questionnaire development and administration. 
As for the study administered by the NEN, 1989 emails were sent out to firms that had contacted the NEN in the past about the potential to become ISO 14001 certified. However, not all firms decided to obtain this certification. Hence, the sample consisted of four types of firms: (1) those that did certify with the ISO 14001 scheme, (2) which chose not to certify (3) currently in the process of certification and (4) which are undecided. After a first email invitation, 104 responses were collected and after a reminder, 69 additional responses were returned; due to administrative procedures at the NEN, the responses could only be sent to the 613 addresses that had opened the email before. After a total of 173 responses, the response rate was $9 \%$. Previous studies conducted by the NEN had yielded a similar response rate (Personal Communication Dick Hortensius, NEN). After excluding respondents that provided incomplete sets of information for key variables, 89 respondents remained in the final Dutch sample.

The same questionnaire was administered in a German language version to firms from a list collected from Chamber of Commerce records. Similar to the Dutch survey, the firms covered all sectors of industry and firms of all sizes. From 769 email invitations sent out, 114 responses were obtained. The overall response rate was $17 \%$, which is consistent with other studies having managers as participants (Baruch, 1999). After excluding respondents that provided incomplete sets of information for key variables, 85 respondents remained in the final German sample. As the sampling method was different for both countries and each of the resulting convenience samples suffered from different biases, the decision was taken to analyze the two data sets separately.

An overview of respondent characteristics retained for subsequent statistical analysis, please refer to Appendix C.

\subsection{Data}

\section{Descriptive Statistics}

In this section, the descriptive results of the survey responses are briefly presented. Even though the main focus of this chapter is on the ISO 14001 Environmental Management Systems certification, responses in relation to the EMAS scheme, the ISO 50001 and EN16001 schemes are also presented. The respondents characteristics are only listed for respondents who provided relevant information. Discrepancies in some categories to overall response numbers may occur for both countries due to question responses not being compulsory for survey progression. 


\section{The Netherlands: Respondent characteristics}

The following summary of survey participant characteristics refer to all Dutch respondents to the survey, i.e.173 observations.An overview of respondent characteristics (i.e. 89 observations) retained for subsequent statistical analysis, please refer to Appendix C.

In the Netherlands, the respondents were mainly environmental (55 respondents) and quality managers (92 respondents) with additionally thirteen (13) heads of department and thirteen (13) CEOs. The remaining respondents belonged to several other professional groups.Only 6 respondents had job tenure below 5 years; 54 respondents had professional experience between 6 and 15 years while 113 respondents had worked in their profession 16 years or more. While 51 respondents had worked with their current employers for 5 years or less, 78 respondents had worked with their current firm between 6 and 20 years with 43 respondents working in the same firm for 20 years or more.

The firm size varied between respondents in SMEs (53), medium-sized (101) and big firms with over 500 employees (15). Most respondents worked in the headquarters of a Dutch company (94 respondents), a branch of an international firm (43 respondents) and the headquarters of an international firm (27). Out of all respondents, 101 firms had an environmental management system installed, with 30 firms not having implemented one. For the firms of which managers reported having implemented en environmental management system only half reported to have an energy management system as well. Overall, a majority of respondents had implemented an environmental management system also certified this one with ISO 14001, while a low number had certified with EMAS (only 2 in the overall sample) and 17 chose not to certify their environmental management system.

As for the environmental management system certification, $51 \%$ of the respondent's firms were ISO 14001 certified while $49 \%$ were not. While $25 \%$ of the firms with an environmental management system reported to have an energy management system as well, this number fell to $3 \%$ for those firms without an environmental management system installed. Of the firms having certified their environmental management system with ISO 14001, only $22 \%$ of firms reported to have an energy management system while $15 \%$ of firms without ISO 14001 certification did report not to have an energy management system.

Surprisingly, none of the respondent's firms (which may be overall more interested in environmental management than the average) certified with either ISO 50001 or EN 16001. While this may be due to the fact that these schemes are relatively new, there seems to be confusion or a lack of knowledge and interest in these issues at the current time.

While most respondents correctly identified environmental management systems and $97 \%$ of the respondents deemed ISO 14001 to be the more efficient scheme (not surprising given the Dutch government's choice to promote ISO14001 at the time of study and the fact that the address database was provided by NEN used for he survey, owning the ISO standards 
in the Netherlands), 56\% of the respondents assumed ISO 14001 to be the superior energy management system, even though ISO 14001 is not developed as energy management system. Still, EN 16001 (28\%), EMAS (8\%) and ISO 50001 (8\%) falling far behind in view of the respondents. Interestingly, even for those identifying energy management standards correctly, being the EN 16001 and ISO 50001 systems, EN 16001 and not the ISO 50001 standard were more present in their mind and probably better known. Since ISO 14001 is the more widely known and used standard in the Netherlands, it was assumed that managers would be more aware of a product from the same issuer, i.e. the NEN.

This pattern was reinforced when asked whether ISO 50001 or EN 16001 adoption would be positive for the respondent's firms. In both cases over $70 \%$ of the respondents claimed not to know whether this would be the case. The same response pattern could be found across all other dimensions of Roger's diffusion of innovation concept tested in the survey. Hence, the decision was taken to conduct primary data analysis with ISO 14001 response as the main dependent variable in this analysis due to data quality and relevance.

Barriers to ISO 14001 certification mentioned by respondents included financial restrictions (4\%), time constraints (13\%), organizational constraints (14\%), lack of knowledgeable employees (4\%), and economic uncertainty (3\%). Even though financial restrictions and economic uncertainty have been found in the relevant literature to constitute a barrier, time and organizational constraints were found to be more important in this study. As mentioned above questions related to EMAS, ISO 50001 and EN 16001were either not answered in large enough numbers or answered by choosing the "don't know" category to yield conclusive results.

\section{Germany: Respondent Characteristics}

The following summary of survey participant characteristics refer to all German respondents to the survey, i.e.114 observations.An overview of respondent characteristics (i.e.85 observations) retained for subsequent statistical analysis, please refer to Appendix C.

In Germany, the respondents were mainly environmental (78) managers with additionally fourteen (14) heads of department and fifteen (15) CEOs. The remaining seven (7) respondents either did not provide additional information or worked in other functions within the firm. Only three (3) respondents had job tenure below 5 years; 35 respondents had professional experience between 6 and 15 years while 76 respondents had worked in their profession 16 years or more. While 10 respondents had worked with their current employers for 5 years or less, 86 respondents had worked with their current firm between 6 and 20 years with 38 respondents working in the same firm for 20 years or more. The education level was diverse with 26 respondents in apprenticeship professions, six (6) respondents with a Bachelor's degree, 61 respondents with a Master's degree, $16 \mathrm{PhD}$ title holders and 
21 respondents with a German Diploma (Diplom). The firm size varied between respondents in SMEs (28), medium-sized (40) and big firms with over 500 employees (46). Most respondents worked in the headquarters of a German company (80) or a branch of a German firm (15). Only four(4) respondents worked at the German headquarters of an international firm while five (5) respondents worked at a German branch of an international firm. Hence, overall the German employer profile was less international than in the Dutch respondent sample.

Out of all respondents, 92 firms had an environmental management system installed, with 1 firm not having implemented one. Only 29 respondents (22\%) reported to have an energy management system while over $60 \%$ did not have one in place at the time of survey completion. However, this question was met with low response rate overall (93 respondents).

Overall, 62 (48\%) respondent firms had implemented an environmental management system certified with ISO 14001, while EMAS was chosen in 86 firms (66.47\%). All of the respondent firms had certified their systems in the response sample with several firms obtaining both ISO 14001 and EMAS certification, a remarkable difference compared to the Dutch sample.

Of the respondent's firms (which may be overall more interested in environmental management than the average) one (1) was certified with ISO 50001 while five firms (5) chose to certify with EN 16001. While this may be due to the fact that these schemes are relatively new, there seems to be confusion or a lack of knowledge and interest in these issues at the current time.

While respondents correctly identified the environmental management systems and $13 \%$ of the respondents deemed ISO 14001 to be the superior scheme while EMAS was deemed superior in 71 respondent firms (55\%). This is a marked difference to the Dutch practices. EMAS was also seen as the superior energy management scheme (25\%) compared with ISO 14001 (5\%). Interestingly, ISO 50001 and EN 16001 were considered among German respondents as far beyond ISO 1001 with 17\% (ISO 50001) and 15\% (EN 16001) respectively.

\section{Probit Regression Analysis}

In order to determine which factors contribute to EMS ISO certification in the Netherlands and Germany, probabilistic regression analyses were performed for both countries. As there were not enough responses in relation to EMAS, the ISO 50001 and EN16001 energy management certification schemes, these were not included in the probit regression analyses. 


\begin{tabular}{lllllll}
\hline & Coef. & Std. Err. & $\mathrm{z}$ & $\mathrm{P}>|\mathrm{z}|$ & {$[95 \%$ Conf. Interval $]$} \\
ISO14001 certification & & & & & & \\
\hline Department Head & 0.56 & 1.01 & 0.56 & 0.57 & -1.42 & 2.54 \\
Environmental Manager & $2.20^{* *}$ & 0.80 & 2.75 & 0.00 & 0.64 & 3.78 \\
International Firm & -0.04 & 0.38 & -0.11 & 0.91 & -0.79 & 0.71 \\
Sector (Manufacturing) & -0.20 & 0.48 & -0.41 & 0.67 & -1.16 & 0.75 \\
Age Group (under 30 years) & 0.00 & 0.45 & 0.01 & 0.99 & -0.88 & 0.88 \\
Education level (Master & $1.08^{* *}$ & 0.61 & 1.76 & 0.07 & -0.12 & 2.28 \\
degree and above) & & & & & & \\
Firm size (small) & 0.07 & 0.42 & 0.18 & 0.85 & -0.75 & 0.90 \\
Work experience & -0.50 & 0.49 & -1.03 & 0.30 & -1.47 & 0.45 \\
Importance of EMS adoption & -0.34 & 0.30 & -1.12 & 0.26 & -0.94 & 0.25 \\
Importance of EMS & $0.77^{* *}$ & 0.35 & 2.17 & 0.03 & 0.08 & 1.48 \\
certification & & & & & & \\
Triability (baseline=yes) & -0.11 & 0.17 & -0.67 & 0.50 & -0.46 & 0.22 \\
Visibility (baseline=yes) & -0.08 & 0.17 & -0.49 & 0.62 & -0.42 & 0.25 \\
Complexity 1 (baseline=yes) & $0.55^{* *}$ & 0.28 & 1.93 & 0.05 & 0.00 & 1.12 \\
Complexity 2 (baselin=yes) & -2.33 & 1.94 & -1.20 & 0.23 & -6.15 & 1.48 \\
Compatibility (baseline=yes) & -0.40 & 0.34 & -1.16 & 0.24 & -1.08 & 0.27 \\
Relative Advantage & 0.01 & 0.20 & 0.09 & 0.93 & -0.38 & 0.41 \\
(baseline=yes) & & & & & & \\
cons & -2.33 & 1.90 & -1.20 & 0.23 & -6.15 & 1.48 \\
\hline
\end{tabular}

Table 10.2: Regression ISO 14001 adoption (the Netherlands)

\section{The Netherlands: ISO 14001}

Statistically significant results at the $5 \%$ confidence level are indicated by a double asterisk in Table 10.2. The data collected in the Netherlands included in the statistical analysis are based only on observations with full responses $(n=89)$ for the variables of interest.Table 10.2 demonstrates the results of the probit analysis, indicating which factors increase the likeliness of ISO14001 certification.

As the results demonstrate several variables had an impact on ISO 14001 certification: Job position, education level, the perception of EMS certification and the perception of EMS adoption complexity.

Environmental managers were more likely than other respondents to work in firms with ISO 14001 certification in the Netherlands. A likely explanation is that firms with a higher level of environmental commitment are likely to be more active in environmental matters and also create specific job roles related to the environment that deal with it. As for educa- 
tion, respondents with higher education levels, i.e. Master's degree and above, were more likely to work in firms with EMS certification. Since most environmental managers are working in higher level roles with substantial responsibilities, this result is not surprising. Similarly, respondents who considered EMS certification to be an important asset for their firm were more likely to work in ISO 14001 certified firms. Whether firms that are more environmentally active influence their staff to have similar attitudes or whether the presence of environmentally conscious employees will influence a firm to be more likely to obtain ISO14001 certification, however, could not be verified in this study.

When it comes to the Diffusion of Innovation variables, only perceived complexity, a variable in Rogers' (1995) Diffusion of Innovation framework described in Figure 10.2, was found to be significant in the Dutch respondent sample. Compared to those respondents that considered ISO 14001 to be an easy process, respondents who disagreed were still more likely to work in firms with ISO 14001 certification. This result may seem counter-intuitive but indicates that ISO 14001 certification has become such a necessity for some firms that perception of complexity does not influence actual adoption rates. In the Netherlands ISO 14001 certification does seem to be an important requirement for firms these days, however, reducing complexity may be another crucial factor for additional certification schemes developed for energy management and sustainable development.

\section{Germany}

Just as with the Dutch data, a probabilistic regression analysis was performed to investigate the factors influencing ISO 14001 adoption for German respondents. Statistically significant results at the $5 \%$ confidence level are indicated by a double asterisk in Table 10.3.The data collected in Germany included in the statistical analysis are based only on observations with full responses $(n=85)$ for the variables of interest.

As for the respondent variables, the sector in which the respondents' firm is in was found to be significant along with education level. Just as in the Netherlands, respondents with higher education levels, i.e. Master degrees and above, were more likely to work in ISO 14001 certified firms. In Germany respondents working for manufacturing firms were more likely to be ISO 14001 certified than those in service oriented firms.This result is different from the Netherlands where the economic sector of the firms from which the respondents hailed was not found to be statistically significant.

As for the Diffusion of Innovation (Rogers, 1995) variables, perception of triability and perception of compatibility were found to be significant in the analysis. Respondents who did not consider EMS adoption to be a good preparation for EMS certification were more likely to work in firms that were ISO 14001 certified than those who agreed with that statement. Hence, results seem to indicate that adoption and certification of EMS are two 


\begin{tabular}{llllllc}
\hline & Coef. & Std. Err. & $\mathrm{z}$ & $\mathrm{P}>|\mathrm{z}|$ & {$[95 \%$ Conf. Interval] } \\
ISO 14001 certification & & & & & & \\
\hline Department Head & 2.37 & 4.65 & 0.51 & 0.61 & -6.75 & 11.5 \\
Environmental Manager & 0.63 & 1.77 & 0.36 & 0.72 & -2.80 & 4.10 \\
International Firm & 9.33 & 6.19 & 1.51 & 0.13 & -2.80 & 21.47 \\
Sector (Manufacturing) & $2.80^{* *}$ & 1.39 & 2.01 & 0.04 & 0.07 & 5.53 \\
Age Group (under 30 years) & -2.24 & 2.00 & -1.10 & 0.26 & -6.21 & 1.73 \\
Education Level (Master & $3.22^{* *}$ & 1.66 & 1.94 & 0.05 & -0.03 & 6.48 \\
degree and above) & & & & & & \\
Work experience (in years) & 4.53 & 11.89 & 0.38 & 0.70 & -18.71 & 27.78 \\
Firm size (small) & -0.86 & 1.10 & -0.78 & 0.43 & -3.02 & 1.29 \\
Importance of EMS adoption & -1.47 & 1.39 & -1.06 & 0.29 & -4.20 & 1.25 \\
Importance of EMS & $1.62^{*}$ & 1.01 & 1.61 & 0.1 & -0.34 & 3.6 \\
certification & & & & & & \\
Triability (baseline=yes) & $1.89^{* *}$ & 1.03 & 1.84 & 0.06 & -0.12 & 3.91 \\
Visibility (baseline=yes) & -0.05 & 0.04 & -1.15 & 0.25 & -0.15 & 0.04 \\
Complexity 1 (baseline=yes) & 0.00 & 0.02 & -0.21 & 0.83 & -0.05 & 0.04 \\
Complexity 2 (baseline=yes) & -0.08 & 0.10 & -0.82 & 0.41 & -0.30 & 0.12 \\
Compatibility (baseline=yes) & $3.22^{* *}$ & 1.56 & 2.00 & 0.03 & 0.16 & 6.28 \\
Relative Advantage & 0.06 & 0.06 & 1.09 & 0.27 & -0.05 & 0.18 \\
(baseline=yes) & & & & & & \\
cons & -16.52 & 7.01 & -2.35 & 0.01 & -30.28 & -2.76 \\
\hline
\end{tabular}

Table 10.3: ISO 14001 adoption (Germany)

very different processes in the minds of the respondents in German firms or that some respondents had negative experiences in the adoption process.

Similarly, respondents who did not consider the ISO 14001 certification scheme to be naturally compatible with their firms' operational processes were more likely to work in ISO 14001 certified firms than those who thought the scheme was compatible with their firms' business processes. This result demonstrates that the ISO 14001 scheme seems to have become a necessary component of firm management in Germany, due to legal and economic requirements. However, it also attests to ISO 14001 not always being an easy path with employees in certified firms being critical of compatibility issues.

In addition to the perception of ISO 14001 features, the features of a competitor scheme, the EMAS certification, may influence ISO 14001 certification. As it is the case in consumer goods, the existence of alternative products can influence the uptake of an EMS certification schemes. 


\subsection{Discussion and Limitations}

This study has several implications that should be addressed. In both countries, different factors contributing to the ISO 14001 certification and perception thereof were identified. In the Netherlands, if respondents deemed certification to be important, they were more likely to work in firms that were certified. Perceived complexity of the ISO 14001 scheme was also found to be significant: Respondents that considered the ISO 14001 scheme to be overly complex also more likely to work in ISO 14001 certified firms. Similar results were found for Germany with regards to compatibility and triability: Even if the ISO 14001 scheme was not found to be naturally compatible with the firms' processes, or a good preparation for certification, respondents were more likely to work in ISO 14001 certified firms.

This result indicates that the respondents are at the "confirmation" stage of Rogers' (1995) framework, either after ISO 14001 adoption or certification. However, the results points towards an important aspect that should be made with regards to innovation diffusion: While the framework distinguishes between continuation and discontinuation of an innovation at the confirmation stage, the situation may arise that the adopter is not content with the innovation but maintains it nonetheless. Despite this result being surprising for a VEP, it may indicate that as the ISO 14001 scheme is so widespread at this stage, it has become de-facto compulsory and firms may be locked in their decision (either perceived or in reality).

Several aspects of this study limit the validity of the present study. First, the data collection process was skewed in favor of respondents interested in the ISO 14001 scheme in both countries. The procedures of data administration conducted in cooperation with an external organization in the Netherlands additionally put pressures on the statistical validity of the results obtained. Self-reports in data collection are usually considered to be less reliable in various ways, as social desirability biases can be easily introduced. This concern was lessened to some extent as even in firms that were already certified respondents did not necessarily speak out in favor of the scheme; the answers were quite mixed in terms of positive and negative assessment. The data did not reflect a desirability bias in responses since many respondents admitted to lack of knowledge or to uncertainty about environmental and energy management system certification benefits.

A certain issue in this aspect is the time dimension. Since the data is cross-sectional, no changes in perceptions over time could be analyzed from the mid-nineties to today. Additionally, the respondents were not in all cases participating or had participated in the environmental management decisions that led to adoption of ISO 14001 in their organization. However, $82 \%$ of the respondents had a professional experience of eleven years or more and $50 \%$ of the respondents have worked more than eleven years with their current employer. Hence, it seems reasonable to assume that many respondents were with 
their current employer when the decision regarding environmental management system certification in some relevant capacity.

\subsection{Conclusion}

While the factors influencing ISO 14001 certification in both the Netherlands and Germany can considered to be different between the two countries, the overall result can be considered as similar. Respondents in both countries assessed ISO 14001 certification quite critically in terms of perception of ISO 14001 adoption complexity, triability, relative advantage, visibility and compatibility. However, it also emerges from the data that even those who responded negatively were still likely to work in firms with ISO 14001 certification. Hence, ISO 14001 seems to have become a de-facto reality for most firms, particularly in Germany, independent of respondents' actual assessment of the certification schemes.

While schemes such as Energy Management Systems adoption and certification have become the new frontier for firms, it seems that Environmental Management Systems adoption and certification has crossed the border of "Innovativeness" and established. EMS certification can be considered to be a success story if even criticism of the ISO 14001 certification scheme does not prevent firms to engage in certification processes.

However, the critical tones of many respondents towards the complexity or compatibility of the ISO 14001 scheme in both countries also means that additional Management Systems certifications, e.g. Energy Management schemes, need to be carefully designed to prevent opposition to environmental and energy management issues in firms. 


\section{References}

Ambec, S., \& Lanoie, P. (2007). When and why does it pay to be green? (Tech. Rep.). CIRANO.

ANSI. (2012). Ansi international procedures. Retrieved from http://publicaa.ansi.org/ sites/apdl/Documents/Standards\%20Activities/International\%20Standardization/ 2012_ANSI_International_Procedures.pdf

Arimura, T. H., Darnall, N., \& Katayama, H. (2011). Is iso 14001 a gateway to more advanced voluntary action? the case of green supply chain management. Journal of Environmental Economics and Management, 61(2), 170-182.

Babakri, K. A., Bennett, R. A., \& Franchetti, M. (2003). Critical factors for implementing iso 14001 standard in united states industrial companies. Journal of Cleaner Production, 11(7), 749-752.

Berkes, F., Folke, C., \& Colding, J. (2000). Linking social and ecological systems: management practices and social mechanisms for building resilience. Cambridge University Press.

Boiral, O. (2007). Corporate greening through iso 14001: a rational myth? Organization Science, 18(1), 127-146.

Boiral, O. (2009). Greening the corporation through organizational citizenship behaviors. Journal of Business Ethics, 87(2), 221-236.

Boiral, O. (2011). Managing with iso systems: Lessons from practice. Long Range Planning, 44(3), 197-220.

Bracke, R., \& Albrecht, J. (2007). Competing environmental management standards: how iso 14001 outnumbered emas in germany, the uk, france, and sweden. Environment and Planning C, 25(4), 611.

Bressers, H., Bruijn, T. d., \& Lulofs, K. (2009). Environmental negotiated agreements in the netherlands. Environmental Politics, 18(1), 58-77.

Carr Jr, V. (1999). Technology adoption and diffusion (Tech. Rep.). The Learning Center for Interactive Technology.

Coleman, J. S. (1986). Social theory, social research, and a theory of action. American journal of Sociology, 91(6), 1309-1335.

Commission, E. (2000). Standardization mandate addressed to cen, cenelec and etsi in the field of electrotechnology, information technology and telecommunications. industry directorate general (Tech. Rep.). European Commission- Industry Directorate General. (http:// ec.europa.eu/enterprise/sectors/rtte/files/mandates/m305_en.pdf Retrieved 16 December 2013)

Cordano, M., \& Frieze, I. H. (2000). Pollution reduction preferences of us environmental managers: Applying ajzen's theory of planned behavior. Academy of Management Journal, 43(4), 627-641.

Darnall, N. (2002). Motivations for participating in a us voluntary environmental initiative: the multi-state working group and epa's ems pilot program. Research in Corporate Sus- 
tainability: The evolving theory and practice of organizations in the natural environment, 123-154.

Darnall, N., \& Edwards, D. (2006). Predicting the cost of environmental management system adoption: the role of capabilities, resources and ownership structure. Strategic Management Journal, 27(4), 301-320.

de Bruijn, T., \& Lulofs, K. (2005). The dutch policy program on environmental management: Policy implementation in networks. Industrial Transformation: Environmental Policy Innovation in the United States and Europe, 203.

Delmas, M. (2001). Stakeholders and competitive advantage: the case of iso 14001. Production and Operations Management, 10(3), 343-358.

Fishbein, M., \& Ajzen, I. (2011). Predicting and changing behavior: The reasoned action approach. Taylor \& Francis.

Freimann, J., \& Walther, M. (2001). The impacts of corporate environmental management systems. Greener Management International, 36, 91-103.

Glachant, M., Schucht, S., Bültmann, A., \& Wätzold, F. (2002). Companies' participation in emas: The influence of the public regulator. Business Strategy and the Environment, 11(4), 254-266.

González-Benito, J., \& González-Benito, Ó. (2005). Environmental proactivity and business performance: an empirical analysis. Omega, 33(1), 1-15.

Guest, D. W., \& Teplitzky, A. L. (2010). High-performance environmental management systems: Lessons learned from 250 visits at leadership facilities. Environmental Quality Management, 20(1), 25-38.

Hoffman, A. J., \& Bazerman, M. H. (2007). Changing practice on sustainability: Understanding and overcoming the organizational and psychological barriers to action. Organizations and the Sustainability Mosaic. Crafting Long-Term Ecological and Societal Solutions, 84-105.

Honkasalo, A. (1998). The emas scheme: a management tool and instrument of environmental policy. Journal of Cleaner Production, 6(2), 119-128.

Howard, J., \& Moore, W. (1982). Changes in consumer behavior over the product life cycle. Readings in the Management of Innovation, 1(1), 128.

Huang, A. Y.-J., \& Liu, R.-H. (2008). Learning for supplying as a motive to be the early adopter of a new energy technology: A study on the adoption of stationary fuel cells. Energy Policy, 36(6), 2143-2153.

King, A. A., Lenox, M. J., \& Terlaak, A. (2005). The strategic use of decentralized institutions: Exploring certification with the iso 14001 management standard. Academy of management journal, 48(6), 1091-1106.

Klassen, R. D., \& McLaughlin, C. P. (1996). The impact of environmental management on firm performance. Management science, 42(8), 1199-1214.

Kolln, K., \& Prakash, A. (2002). Ems-based environmental regimes as club goods: examining variations in firm-level adoption of iso 14001 and emas in uk, us and germany. 
Policy Sciences, 35(1), 43-67.

Könnölä, T., \& Unruh, G. C. (2007). Really changing the course: the limitations of environmental management systems for innovation. Business Strategy and the Environment, $16(8), 525-537$.

Lulofs, K. (2000). Implementation of emas in the netherlands. European Project IMPOLThe Implementation of EU Environmental Policies: Efficiency Issues, Research Paper.

Melnyk, S. A., Sroufe, R. P., \& Calantone, R. (2003). Assessing the impact of environmental management systems on corporate and environmental performance. Journal of Operations Management, 21(3), 329-351.

Molina-Azorín, J. F., Claver-Cortés, E., López-Gamero, M. D., \& Tarí, J. J. (2009a). Green management and financial performance: a literature review. Management Decision, 47(7), 1080-1100.

Molina-Azorín, J. F., Claver-Cortés, E., López-Gamero, M. D., \& Tarí, J. J. (2009b). Green management and financial performance: a literature review. Management Decision, 47(7), 1080-1100.

Moore, G. C., \& Benbasat, I. (1991). Development of an instrument to measure the perceptions of adopting an information technology innovation. Information systems research, 2(3), 192-222.

Morrow, D., \& Rondinelli, D. (2002). Adopting corporate environmental management systems: : Motivations and results of iso 14001 and emas certification. European Management Journal, 20(2), 159-171.

Oliver, R. L., \& Bearden, W. O. (1985). Crossover effects in the theory of reasoned action: A moderating influence attempt. Journal of Consumer Research, 12(3), 324-340.

Oluoch-Wauna, L. O. (2001). Emas and iso 14001: a comparison. Environmental Policy and Law, 31(4), 237-249.

Orsato, R. J. (2006). When does it pay to be green? California management review, 48(2), 128.

Pedersen, E. R. (2007). Perceptions of performance: how european organizations experience emas registration. Corporate Social Responsibility and Environmental Management, 14(2), 61-73.

Perkins, R., \& Neumayer, E. (2010). Geographic variations in the early diffusion of corporate voluntary standards: comparing iso 14001 and the global compact. Environment and Planning A, 42(2), 347-365.

Pezzoli, K. (1999). Environmental management systems (emss) and regulatory innovation. Cal. WL Rev., 36, 335.

Potoski, M., \& Prakash, A. (2005). Covenants with weak swords: Iso 14001 and facilities' environmental performance. Journal of policy analysis and management, 24(4), 745-769.

Ramus, C. A., \& Killmer, A. B. (2007). Corporate greening through prosocial extrarole behaviours-a conceptual framework for employee motivation. Business Strategy and 
the Environment, 16(8), 554-570.

Rogers, E. M. (1995). Diffusion of innovations. Simon and Schuster.

Rogers, E. M. (2003). Diffusion of innovations. Simon and Schuster.

Rondinelli, D., \& Vastag, G. (2000). Panacea, common sense, or just a label?: The value of iso 14001 environmental management systems. European Management Journal, 18(5), 499-510.

Schylander, E., \& Martinuzzi, A. (2007). Iso 14001-experiences, effects and future challenges: a national study in austria. Business Strategy and the Environment, 16(2), $133-147$.

Sharma, S. (2000). Managerial interpretations and organizational context as predictors of corporate choice of environmental strategy. Academy of Management journal, 43(4), 681-697.

Shimp, T. A., \& Kavas, A. (1984). The theory of reasoned action applied to coupon usage. Journal of consumer research, 11(3), 795-809.

Slinn, P., Handley, J., \& Jay, S. A. (2007). Connecting eia to environmental management systems: lessons from industrial estate developments in england. Corporate social responsibility and environmental management, 14(2), 88-102.

Strachan, P. A. (1999). Is the eco-management and audit scheme (emas) regulation an effective strategic marketing tool for implementing industrial organisations? EcoManagement and Auditing, 6(1), 42-51.

Sunder, S. (2002). Regulatory competition among accounting standards within and across international boundaries. Journal of Accounting and Public Policy, 21(3), 219-234.

Taylor, S., \& Todd, P. A. (1995). Understanding information technology usage: A test of competing models. Information systems research, 6(2), 144-176.

Tinsley, S., \& Pillai, I. (2006). Environmental management systems: understanding organizational drivers and barriers. Routledge.

Tornatzky, L. G., \& Klein, K. J. (1982). Innovation characteristics and innovation adoptionimplementation: A meta-analysis of findings. Engineering Management, IEEE Transactions on, 29(1), 28-45.

Triandis, H. C. (1979). Values, attitudes, and interpersonal behavior. In Nebraska symposium on motivation.

Völlink, T., Meertens, R., \& Midden, C. J. (2002). Innovating "diffusion of innovation" theory: innovation characteristics and the intention of utility companies to adopt energy conservation interventions. Journal of Environmental Psychology, 22(4), 333-344.

Waskow, S. (1994). Betriebliches umweltmanagement: Anforderungen nach der auditverordnung der eg und dem umweltauditgesetz: ein leitfaden über die eg-verordnung zum umweltmanagement und zur umweltbetriebsprüfung. CF Müller.

Watson, M., \& Emery, A. R. (2004). Environmental management and auditing systems: the reality of environmental self-regulation. Managerial Auditing Journal, 19(7), 916-928. 
Wätzold, F., \& Bültmann, A. (2000). The implementation of emas in europe: a case of competition between standards for environmental management systems. UFZ.

Zaltman, G., \& Lin, N. (1971). On the nature of innovations. American Behavioral Scientist, $14(5), 651-673$. 


\title{
11
}

\section{Information source choice and Environmental Management Systems (EMSs) certification in the Netherlands and \\ Germany}

\begin{abstract}
"They weren't fact. They were possibility. Nothing more, nothing less, but the force of possibility was shattering". (Haruki Murakami. Dance Dance Dance)
\end{abstract}

\subsection{Introduction}

he adoption and certification procedures of environmental management information systems (EMS) have been analyzed from many different angles and perspectives. However, information-seeking before and during EMS adoption and certification has not been the subject of extensive inquiry, even though the information obtained in this process is likely to contribute to project success. Understanding the decision processes of decision-makers with regards to environmental management systems, including information collection, decision, adoption and implementation, are crucial so that firms are able to fully evaluate EMS performance. Additionally, the use of information and knowledge resources also determines organizational strategy and performance. One of the major challenges an organization faces relates to information management and the ability to obtain the right resources when needed for decision-making (Huber, 1991).

Within organizational contexts, information-seeking and use has been widely studied from a procedural perspective analyzing the different stages of the information-seeking process, while information source selection has received less attention. Previous studies have shown 
that in many contexts information-seekers display a preference for information provided by other individuals (Hertzum and Pejtersen, 2000; Pinelli, 1991). Specific sources of information may provide specific types of information, and may lead to very different decisions outcomes, if the information is retained. The present chapter analyzes information source selection of decision-makers in Dutch and German firms with regards to the adoption and certification of environmental management systems. This research builds on the largely interdisciplinary information-seeking and environmental scanning literature, applying them to the largely technical-focused EMS adoption and certification processes. In this study survey data collected from Dutch and German private sector professionals is analyzed to determine information source preferences in EMS selection processes. To answer this question, a survey study was conducted among decision-makers in Dutch and German firms having adopted and/or certified an EMS system, and thus experienced information-seeking and information source selection processes.

\subsection{Background Literature}

To answer the research question, two main streams of literature analyzing information behavior and information-seeking were reviewed: Environmental scanning and information behavior models.

\section{Information-seeking and environmental scanning in firms: EMS adoption relevance}

To understand information-seeking and more specifically information source choice within a business decision-making process, the environmental scanning literature offers interesting insights. Managers and employees in high-level professional roles regularly deal with situations in which they face too many- and sometimes contradictory - bits of information. With information overload an issue for many individuals involved in decision-making processes, decision-makers need to be pre-selective and limit the amount and type of information to be considered. As postulated by the bounded rationality literature (Simon, 1991), decisions are frequently "satisficing" as decision-makers tend to use a solution that is deemed to be sufficient, not necessarily perfect.

Work at the managerial level is known to be information-intensive (Auster and Choo, 1993). Hence, managers face the enormous task of selecting information from a wide range of sources and use this information to make crucial decisions and to define long-term organizational goals and strategies.

Mintzberg (1973) suggests that "it is the informational roles that tie all managerial work together". With access to information sources available internally and externally, managers overall face higher information processing tasks than other employees. Information-seeking 
in firms has been investigated in the management literature in relation to the concept of environmental scanning. According to Choo and Auster (1993) environmental scanning is "the acquisition and use of information about events and trends in an organization's external environment, the knowledge of which would assist management in planning the organization's future courses of action". Given the changes in business environments including competition, technology and innovations, environmental scanning becomes more and more important.

Environmental scanning literature has focused mainly on a set of three issues within organizations: The first approach includes studying types and characteristics of environmental scanning (e.g. Hambrick, 1981; Daft and Weick, 1984; Yasai-Ardekani and Nystrom, 1996) examining its detailed processes (May, Stewart and Sweo, 2000). The second stream of research analyzes mainly the impact (both direct and indirect) of environmental scanning on organizational goals (e.g. Hambrick, 1982; Jennings and Lumpkin, 1992; Thomas et al., 1993; Garg et al., 2003). A third stream of research determines factors that favor or hinder environmental scanning activities in firms (e.g. Daft et al., 1988; Sawyer, 1993; Boyd and Fulk, 1996; Elenkov, 1997; Ebrahimi, 2000).

When complex decisions are made within an organization, such as the adoption and certification of an Environmental Management System (EMS), ambiguity is usually inherent in these processes. Decision ambiguity includes the elements of uncertainty and equivocality (Daft et al., 1986; Daft et al., 1981 and Weick, 1979). When uncertainty is the absence of information (e.g. Huber, 1982) as well as the inability to make fully informed choices or predict future outcomes, an individual aims to fill the gap between information needed and the information available. "Equivocality" relates to a lack of information due to a poor understanding of the nature of a problem. In the latter case, a manager may not be entirely sure which questions need to be answered and how to frame the issue at hand (Zimmer et al., 2008). Uncertainty has been found to lead to information gathering but equivocality will make individuals seek to define a certain issue and resolve ambiguity in terms of the nature of the problem (Daft et al., 1987).

Both uncertainty and equivocality play a role in organizational information processes, particularly when assessing an issue that can involve the assessment of ambiguous information, such as environmental management. Many information sources are available for decisionmakers these days, enhanced by the almost unlimited possibilities for information-gathering that electronic media have provided. Previous studies have shown that CEOs overall have access to and use a wide range of sources (Choo, 1994 and Fulk, 1993) including personal contacts and published material (on the web and elsewhere).

Correia and Wilson (2001) have categorized the research on environmental scanning in a slightly different fashion differentiating individual and organizational scanning activities. Due to the focus on individual decision-makers in this study, the individual scanning 
literature identified by these authors has been deemed most appropriate for the EMS adoption and certification process analysis. From their point of view, four main areas of interest can be identified within the environmental scanning literature:

a) the identification of the information sources used (Aguilar 1967; Keegan 1974; Smeltzer et al. 1988 and Choo, 1993); and

b) the environmental sectors scanned (Aguilar 1967; Kefalas \& Schoderbeck, 1973; Hambrick, 1979; Ghoshal 1985; Lester \& Walters, 1989 and Choo, 1993); and

c) the scanning mode and methods (Aguilar, 1967; Keegan, 1974; Fahey \& King, 1977; and Thomas, 1980); and

d) the influence of the job position and the tasks performed upon the scanning activity (Aguilar, 1967; Kefalas \& Schoderbeck, 1973; Keegan, 1974; Hambrick, 1979; and Choo 1993).

For the purpose of this study, the first category, (i,.e the identification of information sources used), will be the main focus. The environmental scanning literature suggests that personal sources are more important than impersonal sources (Aguilar, 1967) while outside sources are often more valued than inside sources (Keegan, 1974). Generally, Daft et al. (1988) found that chief executives used more sources when they perceived higher environmental uncertainty. Two main forms of information and learning behavior have been identified by Zimmer et al. (2008): learning directly from the environment and learning from other individuals (Levitt and March, 1988).

Research in this field identified three dimensions within information-seeking and source choice: (a) information source-oriented (i.e. how an information source is chosen and the attributes of this source), (b) the amount of information chosen (i.e. why some informationseekers seek out more information than others as a function of context and seeker personality) and (c) the process of information-seeking (i.e. as a function of cognitive processes and following specific stages) (Xu et al., 2006).

It has to be kept in mind that information source is a different concept from information content. Similar information can be obtained from several information sources (i.e. in environmental management, similar information may be obtained from relational, semirelational and non-relational sources) and one source may be overall better in providing a certain kind of information over another. Similarly, one information source can also provide different types of information (Xu et al., 2006).

Research studies on information source selection in consumer decisions (e.g. Gershoff et al., 2001) suggests that individuals tend to leave parts of the information search to more experienced and knowledgeable actors. While firms tend to be more comprehensive in their information selection process than consumers, aspects of information source selection 
may be the same as seeking guidance from experts (or those perceived to be) (e.g Feick and Price 1987, Reingen and Kernan 1986), such as consultants and auditors.

Properties of information sources have been found to be relevant in previous research just as subjective evaluations and beliefs underlying information source choice. Beliefs also play an important role in topic and information source selection (e.g. Bock et al., 2006; Desouza et al., 2006; Gray and Durcikova, 2005; Kankanhalli et al., 2005; He and Wei, 2009).

In decision scenarios certain information sources will be selected over others due to beliefs about the source characteristics and the topic that needs to be decided on. Information sources can be sought out based on beliefs about their utility and value to a certain decision process. Hence, the perceived value of the EMSs themselves could potentially influence the source of information chosen. If an EMS does not seem to be very valuable itself but is merely seen as a means to an end, the information source chosen may be the least demanding one to gain access to.

A main difference between information sources is based on their relational or non- relational characteristics (Rulke et al., 2000; Bunn and Clopton, 1993, Colbert et al., 2005). While relational sources are based on contact with other individuals in or outside of the company, non-relational sources do not require direct interactions with another specific individual. Some results of prior information and knowledge-seeking research suggest that professionals in organizations tend to prefer direct contact with other people over the use of printed materials (Allen, 1984). One of the main reasons is that people are able to explain the importance and background of specific information and can estalish a relationship that is more trusted than formal resources. While accessibility and quality of an information source selection is a factor for information-seeking processes (e.g. Culnan, 1983), these aspects are out of scope for the purpose of this research.

As information source characteristics will define project outcomes, this study investigates which factors contribute to decision-makers selecting specific information sources and their relational properties (Rulke et al., 2000).

In the context of EMSs adoption and certification, decision-makers in firms can resort to a wide array of potential information sources ranging from other managers (i.e.relational) to public authorities (i.e. non-relational). However, Rulke et al. (2000)'s binary classification system seems limited given the fact that in the context of EMSs adoption and certification other information sources are significant as well.

A number of organizations and individuals in the EMS adoption and certification game such as environmental consultants or auditors do not have the legal authority of a governmental institution but have potentially more legitimacy than purely relational information sources. In order to account for this group of organizations and individuals, an additional category was introduced in this study and named "semi-relational" to account for this status. 
While relevant sections from the environmental scanning literature have been reviewed in this section, it is time to include the information studies perspective. The informationseeking and behavior literature offers various interesting insights about general information behavior by individuals. As decision-makers' information source choice may deviate from "official" company policies, a few of information behavior models will be reviewed in the following section.

\section{Models of Information Behavior}

Research has investigated information behavior, seeking, processing and use from several perspectives. Even though properties of information systems have long been the main focus of research, user-centered approaches and individuals' actions with regards to information and information sources have become a main approach in the study of information over the last decades (Pettigrew et al., 2001).

Decisions are in many instances based on a specific need or problem at hand (Wilson, 1999). Several disciplines have contributed crucial insight into individuals' dealing with information. Even though information science has been the traditional realm in which information seeking is dealt with, numerous studies have been conducted in research areas such as consumer behavior, personality psychology, innovation research, health communication or organizational decision-making (Wilson, 1997). Due to the interdisciplinary character of individuals' interaction with information, a considerable number of theoretical models and frameworks co-exist in the information science literature. Most of the research in this area has been summarized under the broad definition of "information behavior" (Wilson, 1997; Pettigrew et al., 2001). While there is a debate over the accurate naming of the concept since information "does not behave; only people do" (Pettigrew, 2001), the term has been widely accepted as the totality of human behavior in relation to information sources and channels including active and passive information seeking, information searching and information use (Wilson, 2000).

Models on information-seeking behavior include such varied approaches as Uncertainty Reduction Theory (Berger and Calabrese, 1975), Sense-Making Theory (Dervin et al., 1982), Anxiety/Uncertainty Management (Gudykunst, 1995) or Theory of Motivated Information Management (Afifi and Weiner, 2004). More detailed overviews are presented by Wilson (1997), Pettigrew et al. (2001) and Afifi and Weiner (2004).

The user-centered literature on individuals' information behavior can be broadly categorized in three main approaches:

- Cognitive approaches (e.g. Ford, 2004; Verplanken et al., 1992).

- Social and contextual approaches (e.g. Courtright, 2007; Cross et al., 2001).

- Multifaceted approaches (e.g. Pettigrew et al., 2001). 


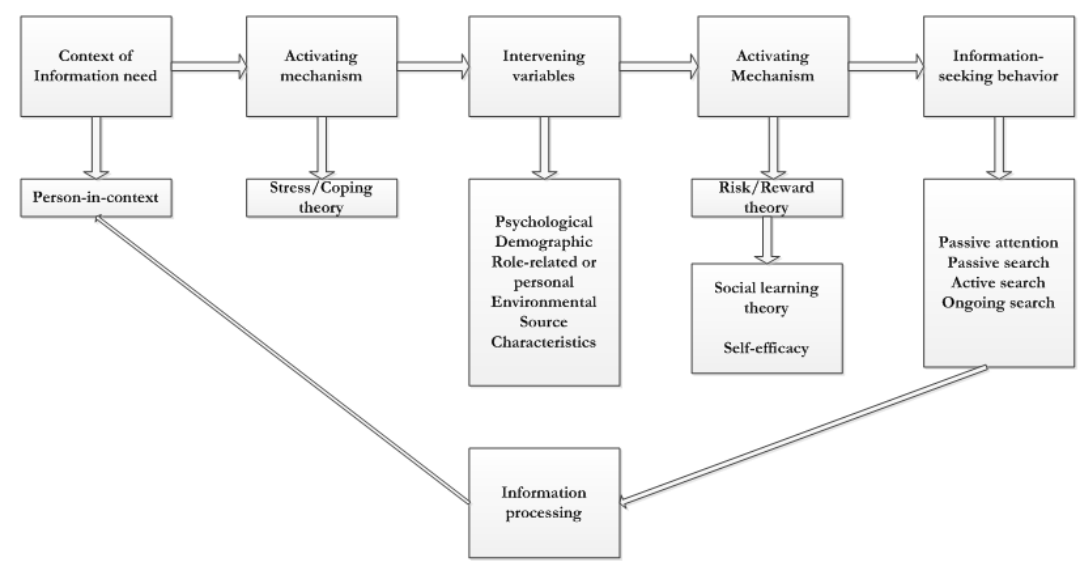

Figure 11.1: General model of information behavior by Wilson (1997)

While all of these approaches are "user-centered" (i.e., based on the analysis of individuals' handling of information), the role of the decision-maker within these models is quite different. While cognitive approaches tend to focus on cognitive processes involved in seeking of and dealing with information, social and contextual approaches tend to focus on the social context these individuals are embedded in (Pettigrew et al., 2001). In recognizing that both personal characteristics and contextual factors are crucial elements in information-seeking, processing and use, multifaceted approaches have tried to integrate a number of factors such as personal characteristics, types of information need, economic circumstances, social and interpersonal relations, environmental and situational settings as well as information source characteristics (Wilson, 1997).

To account for these different perspectives, a general multifaceted model of information behavior was developed by Wilson (1997) integrating previous elements from cognitive and situational approaches (see Figure 11.1).

Wilson (1997)'s model incorporates context of information need, intervening variables (such as psychological, demographic, role-related and source characteristics) and resulting information-seeking behavior as well as information processing and use. Since the overall model is difficult to test, this study we specifically investigates the relationships between the "intervening" variables with a main focus on psychological, demographic, role-related factors and information source characteristics. The details and adaptation of this model for the purpose of this study will be discussed further in the next two sections.

As information source selection is frequently overlooked in studies on decision processes, 
the main interest of this research is to analyze decision-makers information source choice and how their choice is affected by perceptual and situational variables as postulated by the General Model of Information Behavior (Wilson, 1997).

\subsection{Theoretical Framework: General Model of Information Behavior}

In this study, the elements from the environmental scanning literature and information behavior literature were selected. The Information Behavior Model proposed by Wilson (1997) will be used to investigate the relation between the perceptual and situational variables. While the model is generic and has not been specifically developed for selection of information sources, it can be applied to a range of situations. In choosing this model as a starting point, it is possible to analyze how information source characteristics interact with other variables that are usually supposed to merely have an "intervening" character. Even though Wilson (1999) suggests that his framework is a model of "macro-behavior", i.e. "intervening" variables that may determine "micro-behavior", i.e. information source selection, need to better understood. Hence, a secondary aim of this chapter is to contribute to theoretical model developments by discussing the role of assumed "intervening" variables and their relationship in the context of information source selection for EMS adoption and certification. Despite Wilson (1999) suggesting that intervening variables have been "extensively" discussed, their interaction and specifically effects on information source selection has not been a focus of prior research studies. Based on Wilsons' (1997) General Model of Information Behavior as well as literature on information source selection (Xu et al., 2006), information source characteristics (Rulke et al., 2000) and environmental scanning (Correia and Wilson, 2001) discussed above, the framework presented in Figure 11.2 has been subsequently developed and will form the basis of this study.

As Wilson's (1997) theoretical model is generic and can be adapted to a range of contexts and decision scenarios, the "intervening variables" section was selected as a analysis framework for the purpose of this study.

Testing the role of the activating mechanisms (Stress/Coping theory as well as Risk/Reward theory and Social learning theory) as well as type of other elements of Wilson's (1997) model of information-seeking behavior (e.g. passive vs. active information seeking) was beyond of scope for this study.

Instead, it was decided to focus on the psychological category in attitudes towards EMS in general, perceptions of EMS characteristics as well as knowledge of other firms' experiences. Information source characteristics were categorized as "relational", "semi-relational" and "non-relational". 


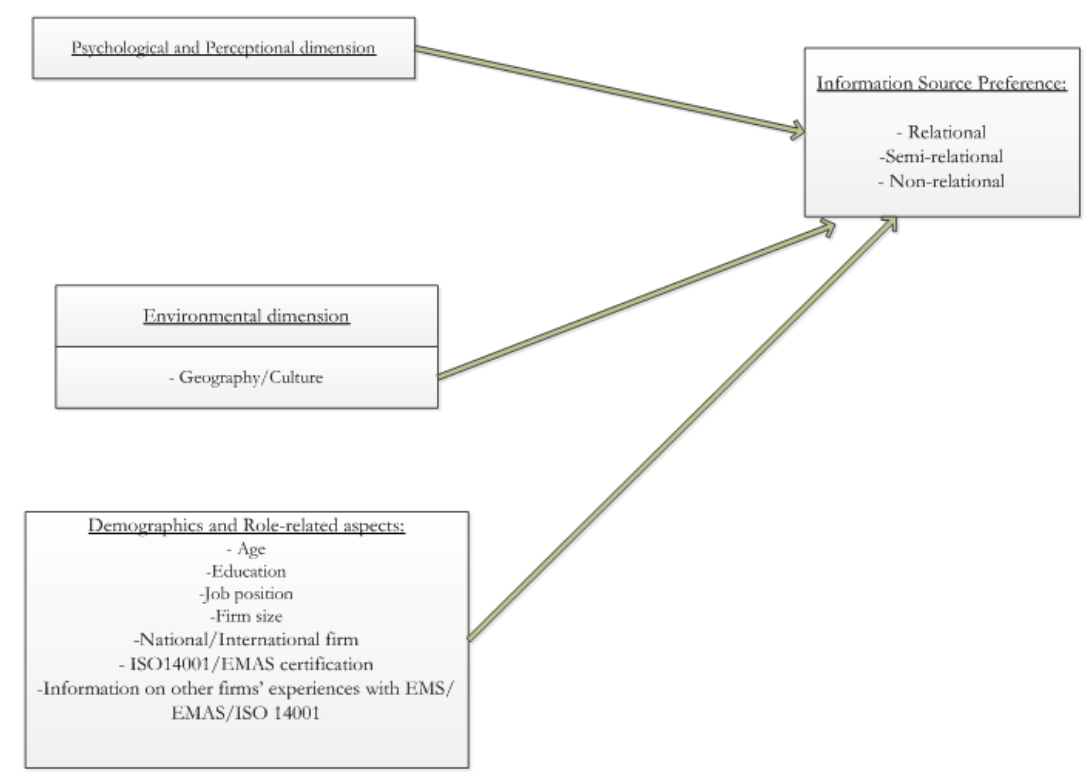

Figure 11.2: Theoretical model of informational sources based on Wilson (1997) and Rulke et al. (2000)

While information sources defined by scholars in this field (e.g. Rulke et al., 2000) include "relational" and "non-relational" sources, this study also integrates the category of "semi-relational" information sources, which are based less on informal characteristics (e.g. interactions with other managers) but are not quite as formal as seeking information from highly formalized information sources such as communal, state or ministry information material.

Even though semi-relational information sources are not part of the relevant literature (e.g. Rulke et al., 2000) dealing with selection of information sources, this concept was introduced to provide a more nuanced account of employees communication decisions. Semi-relational sources in this context are information sources such as industry associations or environmental consultants that occur in the context of EMS adoption decisions.

To analyze whether information source choice will be similar across EMS certification schemes and countries, the ISO 14001 and the EMAS schemes were selected for analysis in Germany. Since only the ISO 14001 scheme is widespread in the Netherlands, the EMAS scheme was not included in the analysis for this country. 


\subsection{Methodology}

To examine the proposed model and the expectations, a survey methodology approach was adopted. Several categories of variables were included, in line with Wilson's (1997) intervening variables constructs. Wilson's (1997) model included psychological, demographic variables, role-related, environmental variables in addition to source characteristics. The variables and their measurements will be discussed in more detail in the following section.

\section{Variables}

a) Information source characteristics:

- "Relational" information sources (Managers in firms within the own industry sector, managers in firms outside of their firms' industry); and

- "Semi-relational" sources (Industry associations, auditors, environmental consultants); and

- "Non-relational" information sources (Communal, state and federal information offices operated by the Ministry of Economic affairs/Commerce and Ministry of Environmental affairs (in both Germany and the Netherlands).

b) Psychological/perceptional variables:

- Perceived importance of Environmental Management System adoption.

- Perceived importance of Environmental Management System certification.

- Perceived influence of other firm's practices on EMS adoption.

- Perceived influence of other firm's practices on EMS certification.

- Perception of general importance of EMSs for environmental management

- Perception of EMS certification voluntariness

- Perception of EMS necessity

- Perceived advantages of EMS certification

- Outcome expectations of EMS certification

- Perceived ease and complexity of EMS certification

- Perceived ability to explain EMS certification

c) Demographic variables (firm size, sector, education level of respondent, professional experience and organization type (i.e. national or international firm), ISO14001/EMAS certification, Information on other firms' experiences with EMS certification).

d) Environmental variables (Geography/Culture)

As the role-related or interpersonal variable category overlaps with both the informationsource characteristic and the psychological dimension in this study, the choice was made to forego this category for the purpose of this research. For instance, perception of EMS 
certification complexity may be role-related but also relate to psychological and perceptional variables.

Additionally, as the study compared two countries (i.e. the Netherlands and Germany), two separate data sets were used for the analysis and no country dummy was integrated in the analysis.

\section{Questionnaire administration}

The questionnaires were programmed and administered online in the "Limesurvey" software. The invitations to participate in this study were sent by the NEN (in the Netherlands) and by the researchers themselves for Germany. While the different forms of data administration may lead to different response rates, this was the only way to obtain responses in both country contexts due to data collection arrangements made prior to questionnaire development and administration.

As for the study administered by the NEN, 1989 emails were sent out to firms that had contacted the NEN in the past about the potential to become ISO 14001 certified. However, not all firms decided to obtain this certification. Hence, the sample consisted of four types of firms: (1) those that did certify with the ISO 14001 scheme, (2) which chose not to certify (3) currently in the process of certification and (4) which are undecided. After a first email invitation, 104 responses were collected and after a reminder, 69 additional responses were returned; due to administrative procedures at the NEN, the responses could only be sent to the 613 addresses that had opened the email before. After a total of 173 responses, the response rate was $9 \%$. Previous studies conducted by the NEN had yielded a similar response rate (Personal Communication Dick Hortensius, NEN). After excluding respondents that provided incomplete sets of information for key variables, 89 respondents remained in the final Dutch sample.

The same questionnaire was administered in a German language version to firms from a list collected from Chamber of Commerce records. Similar to the Dutch survey, the firms covered all sectors of industry and firms of all sizes. From 769 email invitations sent out, 114 responses were obtained. The overall response rate was $17 \%$, which is consistent with other studies having managers as participants (Baruch, 1999). After excluding respondents that provided incomplete sets of information for key variables, 85 respondents remained in the final German sample. As the sampling method was different for both countries and each of the resulting convenience samples suffered from different biases, the decision was taken to analyze the two data sets separately.

An overview of respondent characteristics retained for subsequent statistical analysis, please refer to Appendix C. 


\subsection{Data}

\section{Descriptive Statistics}

\section{The Netherlands: Respondent characteristics}

The following summary of survey participant characteristics refer to all Dutch respondents to the survey, i.e.173 observations.An overview of respondent characteristics (i.e. 89 observations) retained for subsequent statistical analysis, please refer to Appendix C.

In the Netherlands, the respondents were mainly environmental (55 respondents) and quality managers (92 respondents) with additionally thirteen (13) heads of department and thirteen (13) CEOs. The remaining respondents belonged to several other professional groups.Only 6 respondents had job tenure below 5 years; 54 respondents had professional experience between 6 and 15 years while 113 respondents had worked in their profession 16 years or more. While 51 respondents had worked with their current employers for 5 years or less, 78 respondents had worked with their current firm between 6 and 20 years with 43 respondents working in the same firm for 20 years or more.

The firm size varied between respondents in SMEs (53), medium-sized (101) and big firms with over 500 employees (15). Most respondents worked in the headquarters of a Dutch company (94 respondents), a branch of an international firm (43 respondents) and the headquarters of an international firm (27). Out of all respondents, 101 firms had an environmental management system installed, with 30 firms not having implemented one. For the firms of which managers reported having implemented en environmental management system only half reported to have an energy management system as well. Overall, a majority of respondents had implemented an environmental management system also certified this one with ISO 14001, while a low number had certified with EMAS (only 2 in the overall sample) and 17 chose not to certify their environmental management system.

As for the environmental management system certification, $51 \%$ of the respondent's firms were ISO 14001 certified while $49 \%$ were not. While $25 \%$ of the firms with an environmental management system reported to have an energy management system as well, this number fell to $3 \%$ for those firms without an environmental management system installed. Of the firms having certified their environmental management system with ISO 14001, only $22 \%$ of firms reported to have an energy management system while $15 \%$ of firms without ISO 14001 certification did report not to have an energy management system.

Surprisingly, none of the respondent's firms (which may be overall more interested in environmental management than the average) certified with either ISO 50001 or EN 16001. While this may be due to the fact that these schemes are relatively new, there seems to be confusion or a lack of knowledge and interest in these issues at the current time. 
While most respondents correctly identified environmental management systems and 97\% of the respondents deemed ISO 14001 to be the more efficient scheme (not surprising given the Dutch government's choice to promote ISO14001 at the time of study and the fact that the address database was provided by NEN used for he survey, owning the ISO standards in the Netherlands), 56\% of the respondents assumed ISO 14001 to be the superior energy management system, even though ISO 14001 is not developed as energy management system. Still, EN 16001 (28\%), EMAS (8\%) and ISO 50001 (8\%) falling far behind in view of the respondents. Interestingly, even for those identifying energy management standards correctly, being the EN 16001 and ISO 50001 systems, EN 16001 and not the ISO 50001 standard were more present in their mind and probably better known. Since ISO 14001 is the more widely known and used standard in the Netherlands, it was assumed that managers would be more aware of a product from the same issuer, i.e. the NEN.

This pattern was reinforced when asked whether ISO 50001 or EN 16001 adoption would be positive for the respondent's firms. In both cases over $70 \%$ of the respondents claimed not to know whether this would be the case. The same response pattern could be found across all other dimensions of Roger's diffusion of innovation concept tested in the survey. Hence, the decision was taken to conduct primary data analysis with ISO 14001 response as the main dependent variable in this analysis due to data quality and relevance.

Barriers to ISO 14001 certification mentioned by respondents included financial restrictions (4\%), time constraints (13\%), organizational constraints (14\%), lack of knowledgeable employees (4\%), and economic uncertainty (3\%). Even though financial restrictions and economic uncertainty have been found in the relevant literature to constitute a barrier, time and organizational constraints were found to be more important in this study. As mentioned above questions related to EMAS, ISO 50001 and EN 16001were either not answered in large enough numbers or answered by choosing the "don't know" category to yield conclusive results

\section{Germany: Respondent characteristics}

The following summary of survey participant characteristics refer to all German respondents to the survey, i.e.114 observations. An overview of respondent characteristics (i.e.85 observations) retained for subsequent statistical analysis, please refer to Appendix C.

In Germany, the respondents were mainly environmental (78) managers with additionally fourteen (14) heads of department and fifteen (15) CEOs. The remaining seven (7) respondents either did not provide additional information or worked in other functions within the firm. Only three (3) respondents had job tenure below 5 years; 35 respondents had professional experience between 6 and 15 years while 76 respondents had worked in their profession 16 years or more. While 10 respondents had worked with their current employers for 5 years or less, 86 respondents had worked with their current firm between 6 and 20 
years with 38 respondents working in the same firm for 20 years or more. The education level was diverse with 26 respondents in apprenticeship professions, six (6) respondents with a Bachelor's degree, 61 respondents with a Master's degree, $16 \mathrm{PhD}$ title holders and 21 respondents with a German Diploma (Diplom). The firm size varied between respondents in SMEs (28), medium-sized (40) and big firms with over 500 employees (46). Most respondents worked in the headquarters of a German company (80) or a branch of a German firm (15). Only four(4) respondents worked at the German headquarters of an international firm while five (5) respondents worked at a German branch of an international firm. Hence, overall the German employer profile was less international than in the Dutch respondent sample.

Out of all respondents, 92 firms had an environmental management system installed, with 1 firm not having implemented one. Only 29 respondents (22\%) reported to have an energy management system while over $60 \%$ did not have one in place at the time of survey completion. However, this question was met with low response rate overall (93 respondents).

Overall, 62 (48\%) respondent firms had implemented an environmental management system certified with ISO 14001, while EMAS was chosen in 86 firms (66.47\%). All of the respondent firms had certified their systems in the response sample with several firms obtaining both ISO 14001 and EMAS certification, a remarkable difference compared to the Dutch sample.

Of the respondent's firms (which may be overall more interested in environmental management than the average) one (1) was certified with ISO 50001 while five firms (5) chose to certify with EN 16001. While this may be due to the fact that these schemes are relatively new, there seems to be confusion or a lack of knowledge and interest in these issues at the current time.

While respondents correctly identified the environmental management systems and $13 \%$ of the respondents deemed ISO 14001 to be the superior scheme while EMAS was deemed superior in 71 respondent firms (55\%). This is a marked difference to the Dutch practices. EMAS was also seen as the superior energy management scheme (25\%) compared with ISO 14001 (5\%). Interestingly, ISO 50001 and EN 16001 were considered among German respondents as far beyond ISO 1001 with 17\% (ISO 50001) and 15\% (EN 16001) respectively.

\subsection{Analysis}

For the purpose of understanding how factors influence decision-makers in firms to choose their information sources, we adopted a multivariate probabilistic regression using simulated maximum likelihood approach. This technique was deemed the most efficient method since the outcome variable is based on a multiple choice question with several answers 
possible for each respondent. Hence, the analysis needed to take account of the fact that some decision-makers may choose one information source category only (e.g. relational) while others used all three information source options. This type of response variables with correlated binary data is common in cases of multivariate measurement as in the case in this study. A central issue in cases with multiple answers per participants is regression model formulation (Chib and Greenberg, 1998). As there are three information choice categories that the respondents were able to select (i.e. relational, semi-relational and non-relational), a multi-nominal probabilistic regression was considered in the first instance. However, as respondents were able to select several categories, the assumptions of the multi-nominal probabilistic regression were not fulfilled, as evidence suggests that decision-makers may select more than one information source for a decision process.

The second alternative considered was conducting three separate probabilistic regressions with each of the information choices as a dependent variable. However, this solution was also rejected as conducting several separate probabilistic regressions assumes that the error terms are independent. As the three outcome dimensions were regrouped from nine answer options in one survey question, the assumption of independence was not fulfilled. The likelihood that a firm decision-maker only consults one information source can also be considered low. Hence, a model integrating the three equations deemed suitable for this analysis was deemed to be the multivariate probabilistic regression using simulated likelihood was considered to be the most efficient approach (Cappelari and Jenkins, 2003). As the calculation requirements for trivariate probit models go beyond the computations used in univariate and bivariate probit models, the methods resorted to such as the NewtonRaphson method provide inefficient approximations (Hajivassiliou and Ruud 1994).

Simulation-based methods have been found to provide better solutions (Stern, 1997) for maximum likelihood estimations. The Geweke- Hajivassiliou- Keane (GHK) smooth recursive conditioning simulator is the usual choice for the evaluation of multivariate normal distribution functions (Boorsch-Supan et al., 1992, Borsch-Supan and Hajivassiliou, 1993, Keane, 1994 and Hajivassiliou and Ruud (1994)).

Using this simulation method, multivariate normal distribution functions can be easily analyzed as the product of sequentially conditioned univariate normal distribution functions. In the present trivariate case, eight joint probabilities correspond to the eight possible combinations of each of the three binary outcome dimensions.

The advantages of using the GHK simulator for multivariate probit models are that the simulated probabilities are unbiased and are unbounded within the $(0,1)$ interval.

The simulated maximum likelihood (SML) simulation bias is reduced to negligible levels when the number of draws is raised and the ratio of the number of draws to the square root of the sample size is sufficiently large (Hajivassiliou and Ruud 1994). As a general rule, the more draws there are, the more accurate the results can be considered to be. However, it has 


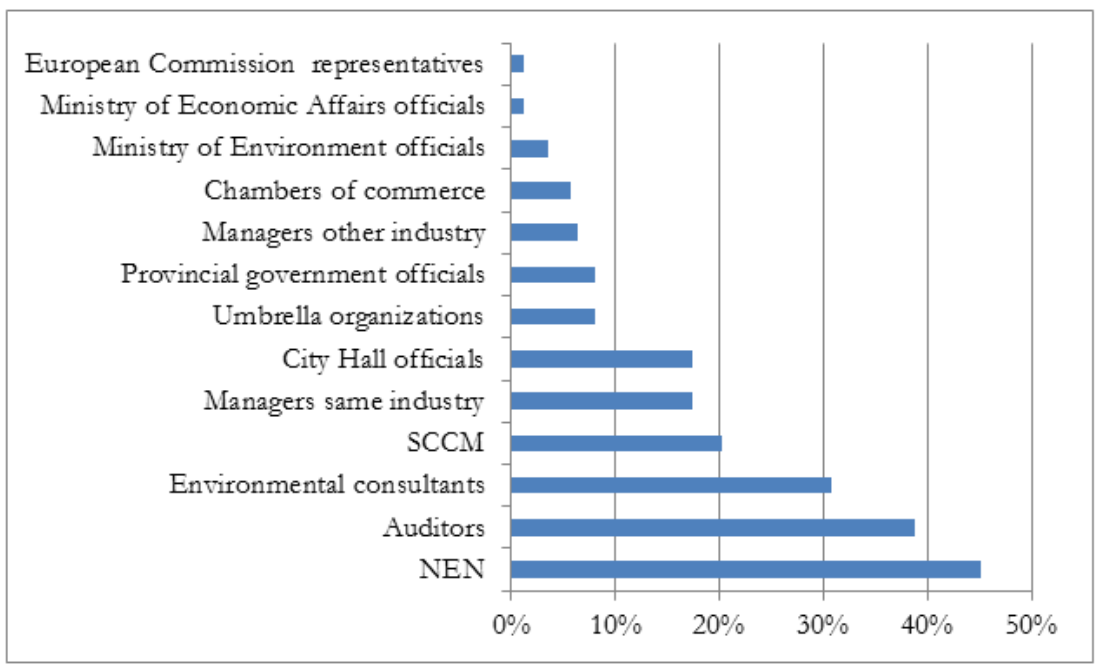

Figure 11.3: Information source selection Netherlands by information source sub-groups (Source: Author's data)

been stated that a relatively small number of draws can be consistent as well and generate smooth likelihoods (Cappellari and Jenkins, 2003).

The results of the analysis are discussed in the following sections. Three models were estimated, one for information choice within the ISO 14001 scheme in the Netherlands and two for Germany (ISO 14001 and EMAS).

\section{The Netherlands}

\section{Information source selection}

As Figure 11.3 shows, the most frequent information sources were the NEN (45\%), Auditors (38\%) and environmental consultants (30\%). The Chamber of Commerce (5\%) and company information services $(8 \%)$ were less used among the "semi-formal" information sources.

From the "informal" information sources such as representatives of local and national governments, local (17\%) and provincial (8\%) officials were mainly consulted. On the national level, ministry officials were consulted with on a much smaller scale: Ministry of Economic Affairs officials (1\%) and representatives of the Ministry of Environment 


\begin{tabular}{|l|l|l|}
\hline Non-relational & Semi-relational & Relational \\
\hline City officials & Auditors & Same sector managers \\
\hline Provincial/State officials & Chambers of Commerce & \multirow{2}{*}{ Other sector managers } \\
\cline { 1 - 2 } European Commission & $\begin{array}{l}\text { Environmental } \\
\text { consultants }\end{array}$ & \\
\cline { 1 - 2 } $\begin{array}{l}\text { Ministry for Economic } \\
\text { Affairs }\end{array}$ & $\begin{array}{l}\text { Industry umbrella } \\
\text { organizations }\end{array}$ & \\
\cline { 1 - 1 } $\begin{array}{l}\text { Ministry for } \\
\text { Environmental Affairs }\end{array}$ & & \\
\hline
\end{tabular}

Figure 11.4: Information sources assigned to relational categories

(3\%) were less in demand for advice on environmental management systems choice and implementation issues. Not much better fared the European Commission with only $1 \%$ of survey respondents having consulted with representatives on environmental management issues. As the Netherlands are however strongly dominated by the ISO14001 management certification scheme and not the European Commission developed EMAS, this result was expected.

In order to analyze the data further, three main categories were formed based on the response choices presented above. The three resulting information source categories were used for the subsequent multivariate probit regressions. Table 11.4 presents those three categories, namely relational, semi-relational and non-relational information sources.

\section{Multivariate probabilistic regression results}

As indicated in the previous section, respondents were able to choose more than one outcomes variable. Hence, several responses across several categories of information sources were permitted. Even though this creates usually higher demands on data analysis, it was seen as likely that people can and will choose several information sources in their selection process. Therefore, the analysis will detail the factors that may contribute to choosing an information source without suggesting that there is only one unique respondent profile that is more likely to choose EMS implementation or ISO 14001 certification.

Interestingly, the model specifications show that in the Netherlands, choosing relational, semi-relational or non-relational relationships are separate decision procedures. The likelihood ratio tests suggest that there is no significant correlation on the error terms among the three equations.The data collected in the Netherlands included in the statistical analysis are based only on observations with full responses $(n=79)$ for the variables of interest.Statistically significant results at the $5 \%$ confidence level are indicated by one asterisk and results at the $10 \%$ confidence level are marked with two asteriks in Table 11.1 


\begin{tabular}{|c|c|c|c|c|c|c|}
\hline & \multicolumn{2}{|c|}{ Relational } & \multicolumn{2}{|c|}{ Semi-relational } & \multicolumn{2}{|c|}{ Non-Relational } \\
\hline & Coef. & $\mathrm{P}>|\mathrm{z}|$ & Coef. & $\mathrm{P}>|\mathrm{z}|$ & Coef. & $\mathrm{P}>|\mathrm{z}|$ \\
\hline Job position & -0.25 & 0.75 & -1.11 & 0.24 & $-2.50^{*}$ & 0.01 \\
\hline Firm size & -0.14 & 0.76 & 0.74 & 0.28 & 0.70 & 0.15 \\
\hline Professional experience( in years) & -1.34 & 0.13 & 0.82 & 0.55 & -0.92 & 0.20 \\
\hline Education level & -0.12 & 0.85 & 0.15 & 0.87 & 0.00 & 0.99 \\
\hline Age & $-1.74^{*}$ & 0.02 & $-1.52^{*}$ & 0.03 & $-1.45^{*}$ & 0.05 \\
\hline Sector (Manufacturing/Services) & 0.20 & 0.69 & -0.28 & 0.66 & -0.50 & 0.37 \\
\hline National/ International firm & $0.99^{*}$ & 0.05 & 0.46 & 0.50 & -0.10 & 0.82 \\
\hline ISO certification & $-1.67^{*}$ & 0.01 & -1.85 & 0.15 & $-1.01^{* *}$ & 0.06 \\
\hline Importance of EMS adoption & -0.44 & 0.34 & 0.08 & 0.87 & $-0.83^{* *}$ & 0.10 \\
\hline Importance of EMS certification & -0.72 & 0.16 & 0.23 & 0.70 & $1.33^{* *}$ & 0.01 \\
\hline $\begin{array}{l}\text { Influence of other firm practices for } \\
\text { EMS* adoption }\end{array}$ & 0.54 & 0.13 & 0.51 & 0.17 & -0.31 & 0.26 \\
\hline $\begin{array}{l}\text { Influence of other firm practices for } \\
\text { EMS* certification }\end{array}$ & $-0.48^{*}$ & 0.05 & 0.01 & 0.95 & 0.17 & 0.40 \\
\hline $\begin{array}{l}\text { ISO14001 importance for } \\
\text { environmental management }\end{array}$ & -0.13 & 0.66 & 0.14 & 0.72 & -0.24 & 0.44 \\
\hline $\begin{array}{l}\text { Voluntariness of ISO14001 } \\
\text { certification }\end{array}$ & $-0.43^{* *}$ & 0.06 & $-0.57^{* *}$ & 0.08 & 0.06 & 0.72 \\
\hline Necessity of ISO14001 certification & 0.09 & 0.70 & 0.08 & 0.80 & $-0.43^{*}$ & 0.04 \\
\hline Advantages of ISO14001certification & 0.62 & 0.11 & 0.57 & 0.12 & $0.65^{* *}$ & 0.08 \\
\hline $\begin{array}{l}\text { Outcome expectations of ISO } 14001 \\
\text { certification }\end{array}$ & 0.33 & 0.47 & -0.59 & 0.32 & 0.18 & 0.70 \\
\hline Ease of ISO14001 certification & -0.11 & 0.62 & 0.21 & 0.45 & 0.25 & 0.22 \\
\hline ISO14001 certification justification & -0.14 & 0.65 & 0.35 & 0.46 & 0.06 & 0.86 \\
\hline $\begin{array}{l}\text { Information on other firm experiences } \\
\text { with ISO14001 certification }\end{array}$ & 0.84 & 0.14 & -0.05 & 0.94 & $0.99^{* *}$ & 0.09 \\
\hline Constant & 2.49 & 0.33 & 0.15 & 0.96 & -4.58 & 0.08 \\
\hline rho21 & 0.46 & 0.38 & & & & \\
\hline rho31 & -0.18 & 0.30 & & & & \\
\hline rho32 & 0.45 & 0.61 & & & & \\
\hline $\begin{array}{l}\text { Likelihood ratio test of rho } 21=\text { rho31 } \\
{ }^{*}=\mathrm{p}<0.05 ;{ }^{* *}=\mathrm{p}<0.1 \\
{ }^{\wedge} \mathrm{EMS}=\text { Environmental Management } \mathrm{S}\end{array}$ & $=$ rho32 & $=0: \mathrm{ch}$ & $(3)=3$. & 8 Prol & $>\operatorname{chi} 2=$ & 0.28 \\
\hline
\end{tabular}

Table 11.1: Multivariate probabilistic regression Netherlands (ISO14001) 


\section{Relational information sources}

In the Netherlands, the likelihood to choose relational information sources with regards to EMS systems decreased with respondent age and if a firm had already opted for ISO 14001 certification. Respondents working within Dutch firms (as opposed to being employed in international firms within the Netherlands) were also less likely to choose relational information sources.

While older age may be linked to higher organizational positions and an insistence on more formalized work processes, respondents in Dutch firms could have a more general knowledge about EMS implementation and certification processes and therefore need to rely less on relational and informal information sources.

There are two potential explanations for the fact that respondents in Dutch (national) firms are less likely to resort to relational, less formalized information sources: On the one hand, as Dutch firms overall may have a better understanding of the Dutch regulatory and business environment, they may not rely on other firms' experiences and informal conversations as much as international firms. On the other hand, it could also be the case that the stage in which a firm is with regards to the EMS adoption and ISO 14001 certification process also plays a significant role in this matter. As the results show, once a firm is ISO 14001 certified, the need for relational information decreases.

As for the psychological variables, perceiving influence of other firms' practices to be unimportant for EMS certification and considering EMS certification to be compulsory decreased the chance of consulting with relational information sources. These findings are in line with expectations, i.e., if other firms are not seen as valuable information sources, managers or other personnel from other firms is unlikely to be consulted. Similarly, if EMS certification is seen as compulsory, relational sources may be considered to be too vague to provide accurate information on certification issues and are less likely to be consulted with.

\section{Semi-relational information sources}

The probability of choosing semi-relational information sources for information provision, such as environmental consultants or NEN staff decreased with age of the respondents. Just as it is the case with relational information sources, if ISO14001 certification was considered to be mandatory, the likelihood of respondents toconsult with semi-relational information sources decreased. These results were surprising given the fact that semi-relational sources overall proved to be the most popular at all stages of the EMS certification process. One explanation is that since the respondents' firms frequently had EMS certification in place, semi-relational sources were less important at that stage. 


\section{Non-Relational Information Sources}

When selecting non-relational information sources, CEOs were more likely to deal with governmental institutions at all levels than environmental managers. Similarly to relational and semi-relational information sources, the propensity to consult with non-relational information sources decreased with age. If firms had ISO 14001 certification in place, non-relational information sources were less likely to be sought. This result seems to suggest that overall information needs for firms decrease once the firm is ISO 14001 certified. Interestingly, this result may point to firms spending less information effort on the maintenance of EMS certification.

If EMS adoption and certification were considered to be not important for the firm, nonrelational information sources were less likely to be consulted for adoption processes than certification processes, suggesting that certification itself to require different kinds of informational input than adoption.

The likelihood of consulting with non-relational information sources, e.g. governmental organizations, increased for those respondents who did not have information on other firms' experiences. This result seems rather intuitive as respondents may resort to more "official" information channels if they are not interested in or unable to find relational information sources.

As for the perceptional variables in the analysis, respondents who disagreed that the advantages of ISO 14001 certifications outweigh the disadvantages were more likely to consult with non-relational information while those who considered ISO 14001 certification not to be necessary for their firm, were less likely to rely on them for certification information. This result may be the consequence of decision-makers when in doubt about the utility and the value of an investment turning more frequently to "official" information sources.

\section{Germany}

\section{Information source selection}

As for "semi-formal" information sources, environmental consultants were one of the most contacted information providers (22\%) but less popular than in the Netherlands (30\%). In Germany, company and industry umbrella organizations were substantially more popular as information sources $(25 \%)$ than in the Netherlands. This result is likely related to the stronger influence of these types of organizations in Germany. In a similar vein, representatives from chambers of commerce were substantially more popular in Germany as information sources (31\%) than in the Netherlands (5\%) (See Figure 11.5).

As for the "informal" information sources, managers in firms within the same industry were hence also more popular as an environmental management system information source 


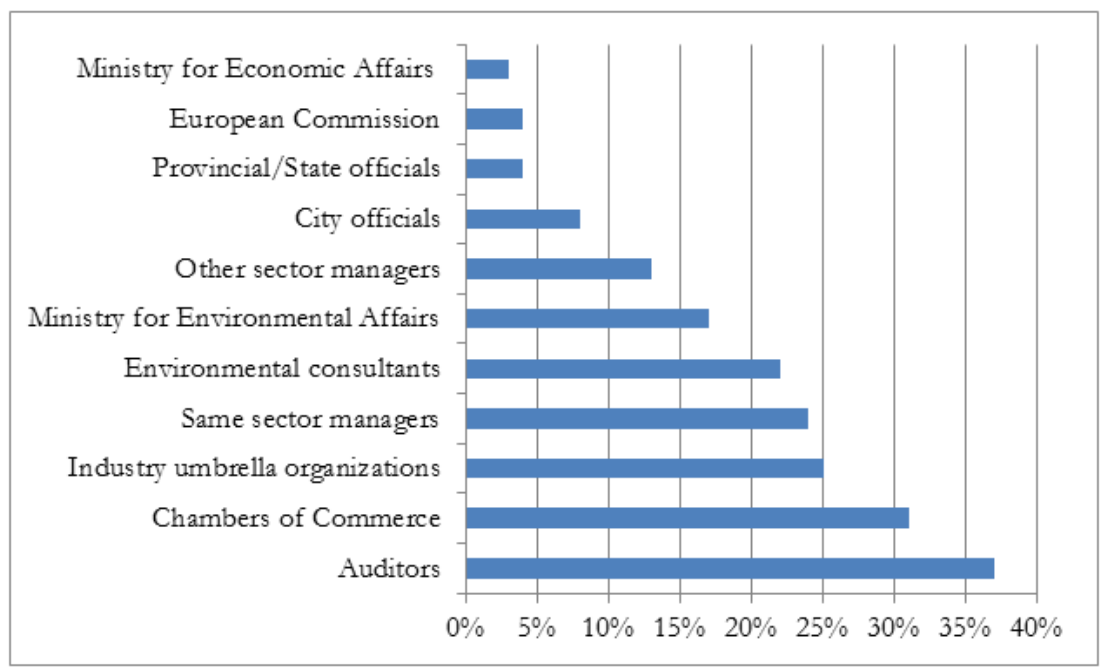

Figure 11.5: Information source selection Germany by information source sub-groups (Source: Author's data)

(24\%) than managers in firms in other industries (13\%). Just as in the Netherlands, auditors were contacted by $38 \%$ of the firms.

For the "formal" information providers and contact with representatives from authorities along the national governance hierarchy, representatives of communes $(8 \%)$ and provinces (4\%) were substantially less contacted than in the Netherlands. Representatives from the Federal Ministries were more frequently consulted with than their Dutch counterparts. However, while the difference between the two countries was relatively slim with regards to the Ministry for Economic Affairs (3\%), the German Ministry for Environmental Affairs was one of the most frequently consulted information sources (17\%).

As the Netherlands has a more "flat" hierarchical structure than Germany when it comes to governance arrangements, these results cannot be seen as entirely surprising. More surprising, however, is the fact that the German respondents were not substantially more likely (3\%) than their Dutch counterparts (1\%) to contact the European Commission for information on environmental management systems. This result is certainly unexpected as the European Union - commissioned EMAS scheme has been successful in Germany. Since German firms, however, are extensively involved in trade, and firms tend to become increasingly certified with both schemes, the decreasing importance of the European Commission in this respect may be related to this result. 


\begin{tabular}{|c|c|c|}
\hline Non-relational & Semi-relational & Relational \\
\hline City officials & Auditors & $\begin{array}{l}\text { Same sector } \\
\text { managers }\end{array}$ \\
\hline Provincial/State officials & Chambers of Commerce & \multirow{4}{*}{$\begin{array}{l}\text { Other sector } \\
\text { managers }\end{array}$} \\
\hline European Commission & Environmental consultants & \\
\hline $\begin{array}{l}\text { Ministry for Economic } \\
\text { Affairs }\end{array}$ & \multirow[t]{2}{*}{$\begin{array}{l}\text { Industry umbrella } \\
\text { organizations }\end{array}$} & \\
\hline $\begin{array}{l}\text { Ministry for Environmental } \\
\text { Affairs }\end{array}$ & & \\
\hline
\end{tabular}

Figure 11.6: Information sources assigned to relational categories (Source: Author's data)

\section{Multivariate Probabilistic Regression results}

As German firms have the choice to certify their EMS systems not only with the ISO 14001 but also have to option to certify with the EMAS scheme, multivariate probit regressions were conducted for both schemes.Statistically significant results at the $5 \%$ confidence level are indicated by one asterisk, at the $10 \%$ with a double asterisk in Table 11.2 The data collected in Gemany included in the statistical analysis for both ISO14001 and EMAS are based only on observations with full responses $(n=84)$ for the variables of interest.

\section{ISO 14001}

\section{Relational Information Sources}

For the ISO 14001 scheme in Germany, the importance of EMS certification was the only significant factor for choosing relational information sources. Managers who deemed EMS certification to be of less importance, interestingly, were more likely to choose to resort to relational sources than those who considered EMS certification to be important.

This result seems to suggest that for ISO 14001 adoption in Germany, decision-makers consult with less "official" information sourced if a decision process is deemed to be of less importance.

\section{Semi-Relational Information Sources}

Respondents in German firms with a higher education level were more likely to consult with semi-relational information sources than those with lower education levels. This may be due to the fact that the semi-relational information sources included environmental consultants and auditors, i.e. the more technical information sources for which more knowledge may be needed to consult with. Additionally, respondents in service sector firms were more 


\begin{tabular}{|c|c|c|c|c|c|c|}
\hline \multirow[t]{2}{*}{ Information Source } & \multicolumn{2}{|c|}{ Relational } & \multicolumn{2}{|c|}{ Semi-relational } & \multicolumn{2}{|c|}{ Non-Relational } \\
\hline & Coef. & $\mathrm{P}>|\mathrm{z}|$ & Coef. & $\mathrm{P}>|\mathrm{z}|$ & Coef. & $\mathrm{P}>|\mathrm{z}|$ \\
\hline Firm size & -0.53 & 0.27 & -0.31 & 0.51 & 0.11 & 0.82 \\
\hline Work experience & -0.40 & 0.48 & -0.45 & 0.36 & 0.05 & 0.91 \\
\hline Firm tenure & -0.35 & 0.47 & 0.22 & 0.65 & 0.09 & 0.82 \\
\hline Education level & 0.03 & 0.93 & $0.89^{*}$ & 0.02 & 0.24 & 0.65 \\
\hline Age group & 0.18 & 0.72 & -0.39 & 0.44 & 0.29 & 0.55 \\
\hline Firm sector & 0.23 & 0.64 & $0.95^{*}$ & 0.02 & 0.52 & 0.25 \\
\hline International firm & -0.32 & 0.63 & -0.43 & 0.57 & 0.89 & 0.14 \\
\hline Job position CEO & 0.95 & 0.17 & 3.54 & 0.98 & 0.58 & 0.40 \\
\hline ISO14001 certification & -0.47 & 0.56 & 0.20 & 0.76 & 0.25 & 0.70 \\
\hline Importance of EMS^^ adoption & -0.38 & 0.39 & 0.01 & 0.97 & 0.25 & 0.62 \\
\hline Importance of $\mathrm{EMS}^{\wedge}$ certification & $0.71^{*}$ & 0.03 & -0.02 & 0.95 & 0.12 & 0.71 \\
\hline $\begin{array}{l}\text { Influence of other firm practices for } \\
\text { EMS adoption }\end{array}$ & -0.01 & 0.22 & -0.01 & 0.43 & -0.17 & 0.26 \\
\hline $\begin{array}{l}\text { Influence of other firm practices for } \\
\text { EMS certification }\end{array}$ & 0.00 & 0.58 & 0.01 & 0.38 & $0.02^{*}$ & 0.05 \\
\hline $\begin{array}{l}\text { ISO14001 importance for } \\
\text { environmental management }\end{array}$ & -0.01 & 0.60 & 0.00 & 0.76 & 0.01 & 0.33 \\
\hline $\begin{array}{l}\text { Voluntariness of } \\
\text { ISO14001certification }\end{array}$ & 0.00 & 0.61 & 0.00 & 0.67 & 0.00 & 0.51 \\
\hline Necessity of ISO14001 certification & -0.02 & 0.24 & -0.02 & 0.25 & -0.02 & 0.19 \\
\hline Advantages of ISO14001 certification & 0.00 & 0.79 & 0.00 & 0.98 & -0.01 & 0.35 \\
\hline $\begin{array}{l}\text { Outcome expectations of } \\
\text { ISO14001 certification }\end{array}$ & -0.07 & 0.82 & 0.00 & 0.99 & 0.08 & 0.79 \\
\hline Ease of ISO14001 certification & -0.02 & 0.44 & 0.00 & 0.38 & -0.01 & 0.67 \\
\hline ISO14001 certification justification & 0.02 & 0.23 & -0.01 & 0.35 & 0.02 & 0.28 \\
\hline $\begin{array}{l}\text { Information on other firm experiences } \\
\text { with ISO } 14001 \text { certification }\end{array}$ & -0.17 & 0.72 & 0.24 & 0.64 & -0.20 & 0.62 \\
\hline Constant & -0.86 & 0.68 & -0.80 & 0.72 & -2.90 & 0.20 \\
\hline rho21 & 0.84 & 0.11 & & & & \\
\hline rho31 & 0.90 & 0.15 & & & & \\
\hline rho32 & 0.87 & 0.14 & & & & \\
\hline $\begin{array}{l}\text { Likelihood ratio test of rho } 21=\text { rho31 } \\
{ }^{*}=\mathrm{p}<0.05 ;^{* *}=\mathrm{p}<0.1^{\wedge} \text { Environmen }\end{array}$ & $\begin{array}{l}=\text { rho32 } \\
\text { al Man }\end{array}$ & $\begin{array}{l}=0: \mathrm{ch} \\
\text { gemen }\end{array}$ & $\begin{array}{l}2(3)= \\
\text { System }\end{array}$ & 42.34 Pro & $b>$ chi 2 & $=0.00$ \\
\hline
\end{tabular}


likely to choose semi-relational information sources than their colleagues in manufacturing firms. These results may suggest that service firms' decision-makers rely more on semirelational information than manufacturing firms as service industries are generally less heavily regulated in terms of environmental management procedures. Hence, decisionmakers in service firms may have overall less knowledge of environmental management systems implementation and certification procedures requiring more technical advice by environmental consultants or auditors.

\section{Non-Relational Information Sources}

Respondents who considered other firms practices non-influential for their firms' EMS certification process were more likely to choose non-relational information sources, i.e. governmental agencies to obtain information on EMS implementation and certification. This result seems intuitive: If respondents did not believe to be able to draw conclusions from other firms' experiences, they opted to resort to "official" and "authoritative" sources of information.

\section{EMAS}

To compare the ISO 14001 certification scheme with the EMAS certification process in Germany, the same multivariate probabilistic regression analysis was conducted.

\section{Relational Information Sources}

As can be seen in Table 11.3, only the age variable was significant for relational information source selection. Interestingly, the likelihood to choose relational information sources increased with age. This result was neither in line with the Dutch ISO 14001 adoption and certification process which observed the opposite trend nor with the German ISO 14001 decision processes in which age was not found to be a significant factor.

\section{Semi-Relational Information Sources}

As with German ISO 14001 information source selection, higher education level increased the likelihood to choose semi-relational information sources, potentially due to higher technical expertise needed to consult with these sources.

Respondents who deemed EMS certification to be less important for their firm and perceived EMS certification to be a difficult process were less likely to contact semi-relational information sources. While a lower likelihood to consult with environmental consultants or auditors could be perceived to be intuitive for firms that do not place much importance on EMS adoption or certification, a lower likelihood to consult with these sources seems 


\begin{tabular}{|c|c|c|c|c|c|c|}
\hline \multirow[t]{2}{*}{ Information Source } & \multicolumn{2}{|c|}{ Relational } & \multicolumn{2}{|c|}{ Semi-relational } & \multicolumn{2}{|c|}{ Non-Relational } \\
\hline & Coef. & $\mathrm{P}>|\mathrm{z}|$ & Coef. & $\mathrm{P}>|\mathrm{z}|$ & Coef. & $\mathrm{P}>|\mathrm{z}|$ \\
\hline Job position & 0.94 & 0.24 & 5.14 & 0.97 & 0.46 & 0.64 \\
\hline Firm size & -0.45 & 0.31 & -0.65 & 0.21 & -0.92 & 0.11 \\
\hline Work experience & -0.35 & 0.51 & -1.00 & 0.15 & -0.31 & 0.61 \\
\hline Work tenure & -0.14 & 0.75 & 0.49 & 0.32 & 0.48 & 0.32 \\
\hline Education level & -0.17 & 0.65 & $2.59^{*}$ & 0.00 & -0.31 & 0.56 \\
\hline Age & $0.89^{* *}$ & 0.08 & 1.1 & 0.13 & $1.43^{*}$ & 0.03 \\
\hline Firm sector & -0.46 & 0.21 & 0.79 & 0.11 & -0.10 & 0.81 \\
\hline National/ International firm & -0.29 & 0.55 & -0.87 & 0.4 & 0.85 & 0.23 \\
\hline EMAS certification & -0.98 & 0.40 & -4.72 & 0.98 & $-2.60^{* *}$ & 0.07 \\
\hline Importance of EMS ^ adoption & -0.21 & 0.58 & -0.12 & 0.80 & -0.06 & 0.90 \\
\hline Importance of EMS $\wedge$ certification & 0.49 & 0.13 & $-0.99^{*}$ & 0.05 & 0.01 & 0.96 \\
\hline $\begin{array}{l}\text { Influence of other firm practices for } \\
\text { EMS* adoption }\end{array}$ & 0.00 & 0.49 & -0.01 & 0.35 & $-0.30^{* *}$ & 0.06 \\
\hline $\begin{array}{l}\text { Influence of other firm practices for } \\
\text { EMS * certification }\end{array}$ & 0.00 & 0.59 & 0.00 & 0.56 & $0.02^{*}$ & 0.01 \\
\hline $\begin{array}{l}\text { EMAS importance for } \\
\text { environmental management }\end{array}$ & 0.23 & 0.31 & $0.68^{*}$ & 0.01 & 0.66 & 0.10 \\
\hline $\begin{array}{l}\text { Voluntariness of EMAS } \\
\text { certification }\end{array}$ & -0.22 & 0.28 & -0.23 & 0.41 & -0.27 & 0.29 \\
\hline Necessity of EMAS certification & 0.07 & 0.50 & -0.07 & 0.63 & -0.13 & 0.39 \\
\hline Advantages of EMAS certification & 0.02 & 0.92 & $0.7^{* *}$ & 0.07 & -0.39 & 0.30 \\
\hline $\begin{array}{l}\text { Outcome expectations of EMAS } \\
\text { certification }\end{array}$ & 0.03 & 0.91 & -0.38 & 0.39 & $0.97^{* *}$ & 0.09 \\
\hline Ease of EMAS certification & -0.03 & 0.59 & $-0.51^{*}$ & 0.01 & $-0.64^{*}$ & 0.00 \\
\hline EMAS certification justification & -0.11 & 0.74 & -0.33 & 0.45 & 0.28 & 0.60 \\
\hline $\begin{array}{l}\text { Information on other firm } \\
\text { experiences with EMAS } \\
\text { certification }\end{array}$ & -0.29 & 0.55 & -0.50 & 0.32 & -0.53 & 0.43 \\
\hline Constant & 0.18 & 0.93 & 1.00 & 0.96 & -0.66 & 0.82 \\
\hline rho21 & 0.88 & 0.12 & & & & \\
\hline rho32 & 0.71 & 0.13 & & & & \\
\hline rho31 & 0.67 & 0.11 & & & & \\
\hline $\begin{array}{l}\text { Likelihood ratio test of rho } 21=\text { rho } \\
*^{*}=0.05 ;{ }^{* *}=p<0.1^{\wedge} \mathrm{EMS}=\mathrm{En}\end{array}$ & $\begin{array}{l}31=\text { rho } \\
\text { ironmer }\end{array}$ & $\begin{array}{l}32=0: \\
\text { tal Mar }\end{array}$ & $\begin{array}{l}\text { hi } 2(3)= \\
\text { agement }\end{array}$ & $\begin{array}{l}=27.48 \mathrm{P} \\
\text { System }\end{array}$ & rob $>$ chi & $=0.00$ \\
\hline
\end{tabular}

Table 11.3: Multivariate probabilistic regression Germany (EMAS) 
counter-intuitive for those respondents who believe EMS adoption or certification to be a difficult process. As semi-relational information sources include consultants or auditors, it may seem that these information sources overall would be best to alleviate concerns about difficult EMS certification processes.

In addition, respondents considering EMS certification to be not so important for environmental management and those considering EMS certification having no clear advantages were more likely to contact semi-relational information sources (e.g. environmental consultants and auditors) than respondents holding the opposing view points. Again, these results seem rather counter-intuitive as one may think that those respondents considering EMS adoption and certification to be important and advantageous would be inclined to consult with more technically-oriented or formal information sources.

However, the results also seem to also suggest that decision-makers may refer to consultants, auditors and other professional groups in this category even if they are not convinced about EMAS' utility. Hence, EMAS may be considered to be less of a choice but an overall requirement, even if not in a legal sense.

\section{Non-Relational Information Sources}

As with relational information sources, the likelihood to contact non-relational information sources increased with age. Respondents in firms without EMAS certification were less likely to contact non-relational information sources on relevant issues. This result seems to suggest that non-relational information sources in this specific context were a less likely information point for firms without certification. However, the result does not conclusively determine whether a decision-maker will contact a non-relational information source in an EMS adoption rather than an implementation process.

Respondents who considered other firms' EMS certification or adoption practices were of no consequence to their own EMS system adoption processes were more likely to contact non-relational (i.e. formal) information sources. If respondents believed that EMAS certification would not be overall positive for their firm, the likelihood to contact non-relational information sources was higher, while there was a lower likeihood for respondents who though that EMAS certification overall was relatively straightforward and easy process.

This result indicates that governmental authorities may be consulted to be informed about the exact conditions of the EMAS certification process and in cases of unclarity in terms of certification use and problems. This approach may serve the purpose to legitimise a firms' adoption and certification approach by using more "authoritative" information sources, especially for a program that initially was government-backed, such as EMAS in Germany. 


\subsection{Discussion}

This study set out to determine the information source choices made by decision-makers in German and Dutch firms with regards to Environmental Management System (EMS) adoption and certification. In this study the ISO 14001 and the EMAS scheme were the main focus. The data analysis has shown that very different factors contribute to whether decision-makers resort to relational, semi-relational or non-relational information sources in their ISO 14001 or EMAS decision-making process.

Table 11.4. summarizes the factors having contributed to choosing the respective information sources:

Three main findings emerged from this study:

First, the findings suggest that EMS adoption and certification is not the standardized process it is sometimes thought to be. The results of this study indicate that information source selection does vary significantly across countries (i.e. ISO 14001 in Germany and the Netherlands) but also within a country (ISO 14001 vs. EMAS certification in Germany).

Furthermore, the multivariate probabilistic regression analysis revealed that the decision options and process itself is quite different in Germany and the Netherlands: The choice of information sources (relational, semi-relational and non-relational) seems to be independent, i.e. choosing one information source does not depend on the other options available. In this respect, selecting non-relational information sources in the Netherlands would not depend on whether alternative information sources were at hand.

This, however, does not mean that a decision-maker only selected one information source over the others. As the data allowed for selecting multiple information sources, the analysis merely suggests that having chosen one, two or three information sources in this case did not depend on the overall number of information sources available.

In Germany, however, the analysis suggests that all three types of information sources are linked, i.e. if a decision-maker chooses to consult with specific information sources, these sources cannot be considered to be entirely independent. Hence, communicating with a non-relational information source would depend on what other types of information sources are available.

Second, returning to our model, based on Wilsons' (1997) information behavior model confirm that psychological, demographic, environmental and role-related variables can influence the selection of specific sources (i.e. relational, semi-relational and non-relational). So-called "intervening" variables need to be paid further attention to in order to understand the reasons for adoption from a more refined perspective. While in the literature "intervening" variables have been characterized as "barriers" to information-seeking behavior, 


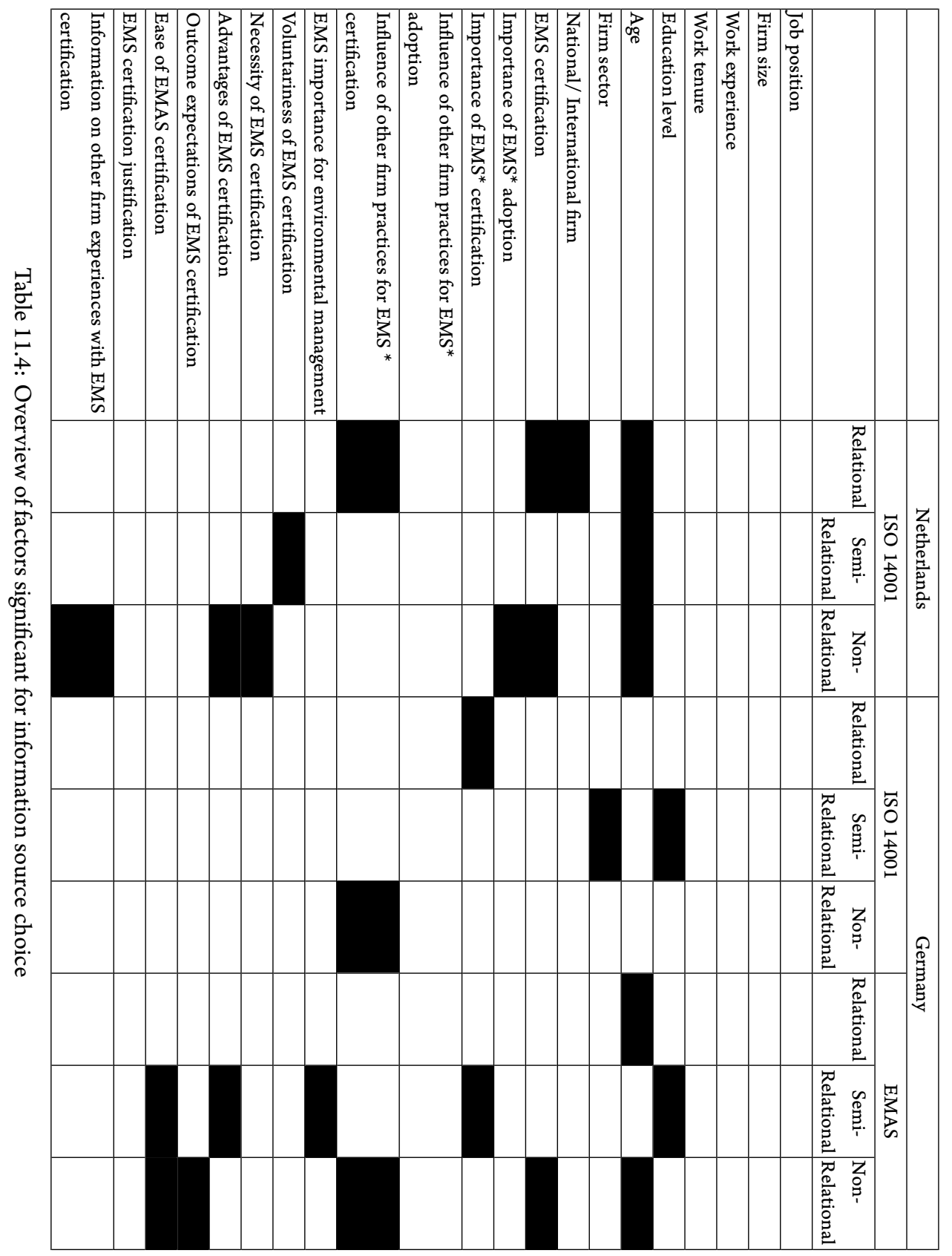


the present research suggests that these variables interact with each other and can influence information source characteristics. Beyond accessibility, credibility and channel of transmission, (Wilson, 1997) this study focused on a different dimension deemed to be another import characteristic of information sources: relational characteristics (Zimmer et al., 2007).

Despite the results being difficult to compare, as two countries and three schemes are compared, overall perceptional variables, i.e. the psychological dimension, explained information source choice better than merely demographic variables. However, the different variables were not found to be consistent across countries and certification schemes and therefore are found to be influenced majorly by situational circumstances.

Third, the results show that beyond "relational" and "non-relational" information sources, there is a place for a third category, "semi-relational" information sources. The problem of defining these categories in multidimensional and complex decision scenarios will have to be further investigated in the future. Certainly there are other limitations to and shortfalls of this study that will be discussed in the following section.

\subsection{Limitations}

The present chapter faces two sets of limitations of which one is theory-related and the other one is data-driven.

While the present chapter is based on the vast literature on information-seeking and mainly on Wilson's (1997) General Model of Information Behavior, only a small fraction of this model was included in this chapter. Including more in-depth analysis such as passive or active information-seeking strategies or elements from Stress/Coping Theory, Risk/Reward Theory or Social Learning Theory as specified by Wilson (1997) would have meant that a questionnaire too extensive.

Issues that were not addressed in the study includes differentiation between internal and external information sources (relational, semi-relational and non-relational). Due to time and resource constraints, information channels were also excluded from the scope of this study. Furthermore, the research project did not investigate attributes of information sources such as perceived source quality, reliability or effectiveness in obtaining the required information for project success. It would be interesting to assess these aspects in future studies.

As for limitations related to data collection procedures, the differences in respondent profiles between Germany and the Netherlands are quite large and therefore are likely to have influenced the results to some extent. First, the data collection process was skewed in favor of respondents interested in the ISO 14001 and EMAS schemes. The procedures of data 
administration conducted in cooperation with an external organization additionally put pressures on the statistical validity of the results obtained. As usual, self-reports in data collection are usually considered to be less reliable in various ways. However, the data did not seem to reflect a desirability bias in responses since many respondents admitted to lack of knowledge or to uncertainty about environmental and energy management system certification benefits.

A certain issue in this aspect is the time dimension. Since the data is cross-sectional, no changes in perceptions over time could be analyzed. Additionally, the respondents were not in all cases participating in the environmental and energy management decisions that led to adoption of ISO 14001 or EMAS. Since most respondents, however, $82 \%$ of the respondents had a professional experience of eleven years or more and $50 \%$ of the respondents have worked more than eleven years with their current employer. Hence, it seems reasonable to assume that they will have faced the decision regarding environmental and energy management system certification in some related capacity.

\subsection{Conclusion}

The results of this investigation show that EMS certification and adoption is far from being a standardized procedure, particularly when it comes to the information sources selected for decision-making processes.

Previous studies (e.g. Rulke et al., 2000) have reported that information sources can determine the success and failure of projects. For this very reason, information behavior and environmental scanning by managers and executives has long been a major research focus in organizational studies. The relevance of information source selection is clearly supported by the current findings.

As differences in information source selection can be found in a relatively confined thematic area, i.e. EMS adoption and certification in the Netherlands and Germany. The factors contributing to information source selection varied markedly in this study. The study suggests that information source selection and their contribution to EMS certification and subsequent project success need to be better understood beyond what is currently known.

This research has raised many questions in need of further investigation. Further investigation in this field with regards to the reason for and the effect of the variation in information source selection on EMS adoption and certification process would help to better understand the overall effect of EMS on environmental protection.

The results obtained from this study are limited due to the small sample sizes and the use of a cross-sectional design, longitudinal studies could better evaluate the information source selection at each stage of the decision process and determine their contributions to EMS adoption and certification effectiveness. 
The findings have a number of important implications for future practice and decisionmakers in firms but also for the way relational, non-relational and semi-relational information sources deliver their advice. As information sources have a prominent role to play and are a crucial factor in project success, it would be time for organizations issuing EMSs and similar systems to include information choice and use in their consideration when developing new certification schemes. 


\section{References}

Afifi, W. A., \& Weiner, J. L. (2004). Toward a theory of motivated information management. Communication Theory, 14(2), 167-190.

Aguilar, F. J. (1967). Scanning the business environment. Macmillan New York.

Allen, T. J. (1984). Managing the flow of technology: Technology transfer and the dissemination of technological information within the red organization. The MIT Press.

Auster, E., \& Choo, C. W. (1993). Environmental scanning by ceos in two canadian industries. JASIS, 44(4), 194-203.

Auster, E., \& Choo, C. W. (1994). How senior managers acquire and use information in environmental scanning. Information Processing \& Management, 30(5), 607-618.

Baruch, Y. (1999). Response rate in academic studies-a comparative analysis. Human relations, 52(4), 421-438.

Berger, C. R., \& Calabrese, R. J. (1975). Some explorations in initial interaction and beyond: Toward a developmental theory of interpersonal communication. Human communication research, 1(2), 99-112.

Bock, G.-W., Kankanhalli, A., \& Sharma, S. (2006). Are norms enough? the role of collaborative norms in promoting organizational knowledge seeking. European Journal of Information Systems, 15(4), 357-367.

Bock, G.-W., Zmud, R. W., Kim, Y.-G., \& Lee, J.-N. (2005). Behavioral intention formation in knowledge sharing: Examining the roles of extrinsic motivators, socialpsychological forces, and organizational climate. MIS quarterly, 87-111.

Borsch-Supan, A., Hajivassiliou, V., \& Kotlikoff, L. J. (1992). Health, children, and elderly living arrangements: a multiperiod-multinomial probit model with unobserved heterogeneity and autocorrelated errors. In Topics in the economics of aging (pp. 79-108). University of Chicago Press.

Börsch-Supan, A., \& Hajivassiliou, V. A. (1993). Smooth unbiased multivariate probability simulators for maximum likelihood estimation of limited dependent variable models. Journal of econometrics, 58(3), 347-368.

Boyd, B. K., \& Fulk, J. (1996). Executive scanning and perceived uncertainty: a multidimensional model. Journal of Management, 22(1), 1-21.

Bunn, M. D., \& Clopton, S. W. (1993). Patterns of information source use across industrial purchase situations*. Decision Sciences, 24(2), 457-478.

Cappellari, L., \& Jenkins, S. P. (2003). Multivariate probit regression using simulated maximum likelihood. The Stata Journal, 3(3), 278-294.

Choo, C. W. (1993). Environmental scanning: acquisition and use of information by managers. In In me williams (ed.), annual review of information science and technology (vol. 28.

Choo, C. W. (1995). Perception and use of information sources by chief executives in environmental scanning. Library \& Information Science Research, 16(1), 23-40. 
Colbert, A. E., Rynes, S. L., \& Brown, K. G. (2005). Who believes us? understanding managers' agreement with human resource research findings. The Journal of Applied Behavioral Science, 41(3), 304-325.

Correia, Z., \& Wilson, T. (2001). Factors influencing environmental scanning in the organizational context. Information research, 7(1), 7-1.

Courtright, C. (2007). Context in information behavior research. Annual review of information science and technology, 41(1), 273-306.

Cross, R., Rice, R. E., \& Parker, A. (2001). Information seeking in social context: Structural influences and receipt of information benefits. Systems, Man, and Cybernetics, Part C: Applications and Reviews, IEEE Transactions on, 31(4), 438-448.

Culnan, M. J. (1983). Environmental scanning: The effects of task complexity and source accessibility on information gathering behavior*. Decision Sciences, 14(2), 194-206.

Daft, R. L., \& Lengel, R. H. (1986). Organizational information requirements, media richness and structural design. Management science, 32(5), 554-571.

Daft, R. L., Lengel, R. H., \& Trevino, L. K. (1987). Message equivocality, media selection, and manager performance: Implications for information systems. MIS quarterly, 11(3), 355-366.

Daft, R. L., \& Macintosh, N. B. (1981). A tentative exploration into the amount and equivocality of information processing in organizational work units. Administrative Science Quarterly, 26(2), 207-224.

Daft, R. L., \& Weick, K. E. (1984). Toward a model of organizations as interpretation systems. Academy of management review, 9(2), 284-295.

Dervin, B., Jacobson, T. L., \& Nilan, M. S. (1982). Measuring aspects of information seeking: a test of a quantitative/qualitative methodology.

Desouza, K. C., Awazu, Y., \& Wan, Y. (2006). Factors governing the consumption of explicit knowledge. Journal of the American society for information science and technology, 57(1), 36-43.

Ebrahimi, B. P. (2000). Perceived strategic uncertainty and environmental scanning behavior of hong kong chinese executives. Journal of Business Research, 49(1), 67-77.

Elenkov, D. (1997). Strategic uncertainty and environmental scanning: the case for institutional influences on scanning behavior. Strategic Management Journal, 18(4), 287-302.

Fahey, L., \& King, W. R. (1977). Environmental scanning for corporate planning. Business Horizons, 20(4), 61-71.

Feick, L. F., \& Price, L. L. (1987). The market maven: A diffuser of marketplace information. The Journal of Marketing, 51, 83-97.

Ford, N. (2004). Modeling cognitive processes in information seeking: From popper to pask. Journal of the American Society for Information Science and Technology, 55(9), 769-782. 
Fulk, J. (1993). Social construction of communication technology. Academy of management journal, 36(5), 921-950.

Garg, V. K., Walters, B. A., \& Priem, R. L. (2003). Chief executive scanning emphases, environmental dynamism, and manufacturing firm performance. Strategic Management Journal, 24(8), 725-744.

Gershoff, A. D., Broniarczyk, S. M., \& West, P. M. (2001). Recommendation or evaluation? task sensitivity in information source selection. Journal of Consumer Research, 28(3), 418-438.

Gray, P. H., \& Durcikova, A. (2006). The role of knowledge repositories in technical support environments: Speed versus learning in user performance. Journal of Management Information Systems, 22(3), 159-190.

Gudykunst, W. (1995). Intercultural communication theory. In R. L. Wiseman (Ed.), (chap. Anxiety/uncertainty management (AUM) theory: Current status.). Thousand Oaks.

Hajivassiliou, V. A., \& Ruud, P. A. (1993). In handbook of econometrics. In R. Engle \& D. McFadden (Eds.), (p. 2383-2441). Amsterdam.

Hambrick, D. C. (1981). Specialization of environmental scanning activities among upper level executives. Journal of management studies, 18(3), 299-320.

Hambrick, D. C. (1982). Environmental scanning and organizational strategy. Strategic Management Journal, 3(2), 159-174.

He, W., \& Wei, K.-K. (2009). What drives continued knowledge sharing? an investigation of knowledge-contribution and-seeking beliefs. Decision Support Systems, 46(4), 826-838.

Hertzum, M., Andersen, H. H., Andersen, V., \& Hansen, C. B. (2002). Trust in information sources: seeking information from people, documents, and virtual agents. Interacting with Computers, 14(5), 575-599.

Hertzum, M., \& Pejtersen, A. M. (2000). The information-seeking practices of engineers: searching for documents as well as for people. Information Processing \& Management, 36(5), 761-778.

Huber, G. (1982). Organizational information systems: Determinants of their performance and behavior. Management Science, 28(2), 138-155.

Jennings, D. F., \& Lumpkin, J. R. (1992). Insights between environmental scanning activities and porter's generic strategies: An empirical analysis. Journal of management, 18(4), 791-803.

Kahneman, D. (2003). Maps of bounded rationality: Psychology for behavioral economics. American economic review, 93(5), 1449-1475.

Keane, M. P. (1994). A computationally practical simulation estimator for panel data. Econometrica: Journal of the Econometric Society, 62, 95-116.

Keegan, W.J. (1974). Multinational scanning: a study of the information sources utilized by headquarters executives in multinational companies. Administrative Science Quarterly, 
$19,411-421$.

Kefalas, A., \& Schoderbek, P. P. (1973). Scanning the business environment: some empirical results. Decision Sciences, 4(1), 63-74.

Lester, R., \& Waters, J. (1989). Environmental scanning and business strategy. British Library Research and Development Department.

Levitt, B., \& March, J. G. (1988). Organizational learning. Annual review of sociology, 14(1), 319-338.

May, R. C., Stewart, W. H., \& Sweo, R. (2000). Environmental scanning behavior in a transitional economy: evidence from russia. Academy of Management Journal, 43(3), 403-427.

Mintzberg, H. (1973). Nature of managerial work. Harper \& Row.

Pettigrew, K. E., Fidel, R., \& Bruce, H. (2001). Conceptual frameworks in information behavior. Annual review of information science and technology (ARIST), 35, 43-78.

Pinelli, T. E. (1991). The information-seeking habits and practices of engineers. Science \& Technology Libraries, 11(3), 5-25.

Reingen, P. H., \& Kernan, J. B. (1986). Analysis of referral networks in marketing: Methods and illustration. Journal of Marketing Research, 23, 370-378.

Rulke, D. L., Zaheer, S., \& Anderson, M. H. (2000). Sources of managers' knowledge of organizational capabilities. Organizational Behavior and Human Decision Processes, 82(1), 134-149.

Simon, H. A. (1991). Bounded rationality and organizational learning. Organization science, 2(1), 125-134.

Smeltzer, L. R., Fann, G. L., \& Nikolaisen, V. N. (1988). Environmental scanning practices in small business. Journal of Small Business Management, 26(3), 55-62.

Stern, S. (1997). Simulation-based estimation. Journal of economic Literature, 35(4), 2006-2039.

Thomas, J. B., Clark, S. M., \& Gioia, D. A. (1993). Strategic sensemaking and organizational performance: Linkages among scanning, interpretation, action, and outcomes. Academy of management Journal, 36(2), 239-270.

Thomas, P. S. (1980). Environmental scanning - the state of the art. Long Range Planning, 13(1), 20-28.

Vancouver, J. B., \& Morrison, E. W. (1995). Feedback inquiry: The effect of source attributes and individual differences. Organizational Behavior and Human Decision Processes, 62(3), 276-285.

Verplanken, B., Hazenberg, P. T., \& Palenewen, G. R. (1992). Need for cognition and external information search effort. Journal of Research in Personality, 26(2), 128-136.

Weick, K. E., \& Kiesler, C. A. (1979). The social psychology of organizing (Vol. 2). Random House New York.

Wilson, T. D. (1997). Information behaviour: an interdisciplinary perspective. Information processing \& management, 33(4), 551-572. 
Wilson, T. D. (1999). Models in information behaviour research. Journal of documentation, 55(3), 249-270.

Wilson, T. D. (2000). Human information behavior. Informing science, 3(2), 49-56.

$\mathrm{Xu}$, Y. C., Tan, B. C., \& Yang, L. (2006). Who will you ask? an empirical study of interpersonal task information seeking. Journal of the American Society for Information Science and Technology, 57(12), 1666-1677.

Yasai-Ardekani, M., \& Nystrom, P. C. (1996). Designs for environmental scanning systems: tests of a contingency theory. Management Science, 42(2), 187-204.

Yitzhaki, M., \& Hammershlag, G. (2004). Accessibility and use of information sources among computer scientists and software engineers in israel: Academy versus industry. Journal of the American society for information science and technology, 55(9), 832-842. 


\section{снитеге 12}

\section{Discussion and Conclusion}

"Don't adventures ever have an end? I suppose not. Someone else always has to carry on the story" (J.R.R Tolkien, Lord of the Rings)

\subsection{Summary of Findings and Main Contributions}

$\mathrm{T}$ his discussion chapter summarizes this research project in three main sections. The first section will review the results obtained from the previous chapters. The second section will deliberate on the potential for improving professional practices in the private sector while the third section will discuss how results derived from this research may be applied to in policy-making and improving decisions for environmental sustainability.

The previous chapters applied a number of frameworks from social psychology, innovation studies, management science, governance and communication studies to analyze the determinants of VEP uptake in the United States, the United Kingdom, Canada, the Netherlands and Germany. Several frameworks were adapted to professional behavior in firms, mainly of schemes such as the LEED, BREEAM and Green Globes schemes in the construction industry in the UK, US and Canada as well as cross-industry analysis of ISO 14001 and EMAS standards in Germany and the Netherlands.

The focus of this series of research studies centers around belief formation, attitudes, norms, perceived behavioral control, social identity, social interdependence, self-determination, innovation beliefs and information source choice. The research studies included in this doctoral dissertation investigated these variables in the context of environmental sustainability. 


\section{Selection of Framework and Qualitative Elicitation Study (Chapter 1 +2)}

Chapter 2 reviewed social cognition models that useful for explaining Voluntary Environmental Program (VEP) program uptake and implementation. This chapter presented several theoretical approaches for VEP analysis. The frameworks were applied in the research studies presented in subsequent chapters.

Chapter 3 adapted the Reasoned Action Approach (RAA) (Fishbein and Ajzen, 2010) to understand beliefs underlying LEED adoption practices. The elicitation study looked behavioral, normative or control beliefs of engineers and architects that might influence their decision to work with the LEED scheme and obtain LEED accreditation. The results revealed that the uptake of the LEED scheme is related to beliefs with regards to the importance of government support, the role of client demands, individual attitudes, group efforts, perceived barriers to work on a LEED project, educational aspects of the LEED scheme, communication aspects as well as the position of LEED in the overall green building governance structure. By examining the underlying beliefs of building professionals, a first step was made to better understand the reasons for professionals to engage in a Voluntary Environmental Program (VEP) such as LEED.

\section{Reasoned Action Approach (RAA): Building Professionals and Real Estate Developers (Chapter 4+5)}

Chapter 4 suggested that to understand building professionals' adoption of LEED and Green Globe in the United States and Canada, the Reasoned Action Approach (RAA) (Fishbein and Ajzen, 2010) can be a useful instrument to analyze the underlying determinants influencing and the intention to adopt and actual scheme uptake. In the first instance the RAA model was applied to Green Globes and LEED uptake with intention as the dependent variable in each case. As a second step, actual behavior for the LEED scheme was included in the analysis.

For behavioral intentions as the dependent variable, all of the three predictor variables were found to influence intention for LEED scheme uptake, with subjective norms the most dominant construct with attitudes and perception of control being less influential. Green Globes adoption, on the other hand, was predicted by attitudes, perceived behavioral control and past behavior. Adding actual behavior for the LEED scheme followed the predictions of the RAA model: attitudes, subjective norms and perceived behavioral control influence intentions and intentions in turn predict actual behavior. Hence, an intention-behavior gap was not observed in this study for LEED adoption.

In Chapter 5, real estate developers and investors' perspective in the United States on a green building VEP, LEED, was the main focus of analysis. As subjective norms and Perceived Behavioral Control (PBC) were found to be strong predictors for one the LEED scheme in 
previous chapters, investors' perspective on these schemes was considered of importance. The results demonstrate that real estate developers consider LEED to be an important marketing tool; the environmental aspect was deemed to be important but less of concern. Interestingly not all investors thought rating schemes to be entirely voluntary. This result could indicate that perceived pressure from either government or shareholders influence the practices of some real estate development and investment firms. As in previous chapters, intention to include the Green Globes scheme was influenced by attitudes while LEED was mainly predicted by norms. In both cases, perceived behavioral control was not found to be statistically significant for real estate developers and investors' intention to include voluntary environmental building assessment programs.

\section{Social Interdependence and Social Identity Theories: VEPs and Cooperation (Chapters 6+7)}

In Chapter 3's elicitation study, a lack of cooperation was found to be a major impediment to innovation and the development of sustainable professional practices. Hence, Chapters 6 and 7 focus on cooperation issues and green building practices.

First, Chapter 6 investigates determinants of perceived inter-firm cooperation in the building and construction sector based on Social Interdependence Theory (Deutsch, 1949; Johnson and Johnson, 1989). In the fragmented building and construction industry cooperation between firms is crucial and inter-organizational cooperation was determined to be the main focus of this chapter. Data collected in the United States, the United Kingdom and Canada suggests that of inter-professional, intra-professional and intra-firm cooperation contribute to explaining inter-firm cooperation to various degrees. Past experience with environmental assessment schemes was not found to be significantly correlated with inter-firm cooperation. Results indicated that the proliferation of these schemes, at least at the present stage, has not significantly contributed to lasting change in the building and construction sector. Potential pathways for improving inter-firm cooperation may lie in fostering several forms of cooperation, as the data suggests.

Staying with cooperation in the building and construction industry, Chapter 7 explores the contribution of Social Identity Theory (SIT) (Tajfel and Turner, 1979; Tajfel, 1981) to working on a green building VEP. Analyzing the adoption of the Green Globes and LEED schemes in the United States and Canada, this chapter incorporates SIT concepts into the Reasoned Action Approach (RAA) (Fishbein and Ajzen, 2010) model to analyze VEP uptake. Group norms, inter-group perceptions and group identity were integrated in the regression analysis for both schemes. Organizational inter group perceptions were found to be significant in influencing the adoption intention with regards to the Green Globes scheme. The Social Identity Approach (SIA) constructs, however, were not found to be statistically significant for LEED scheme. Reasoned Action Approach (RAA) constructs 
emerged as significant predictors of intentions for working on LEED and Green Globes projects. While PBC mattered for LEED adoption but not Green Globes, the strongest predictor in both cases was subjective norms. This result was different to previous chapters, specifically with regards to the Green Globes scheme as previous chapters indicated that attitudes are most indicative of Green Globes adoption intentions.

\section{Self-Determination Theory: VEPs and Motivation (Chapter 8)}

While the two previous chapters focused on cooperation, Chapter 8 highlighted the importance of determining motivational factors underlying individual professional accreditation associated with voluntary building rating schemes. This study was based on SelfDetermination Theory (SDT) (Deci and Ryan, 1985) to determine intrinsic and extrinsic motivations.

The main focus in this chapter is on the LEED Accredited Professional (LEED AP) scheme in the United States and Canada. Professional accreditation (or certification programs, as these schemes are sometimes called) associated with VEPs may improve sustainability in the building and construction industry in addition to training participants for the rating scheme itself. In this study, survey data collected from respondents in the US and Canada was analyzed. Respondents likely to become LEED AP certified were mainly driven by intrinsic motivation and integrated regulation. While exploring the potential for studies targeting at promoting LEED AP certification for building professionals, the chapter raised two important issues. First, the LEED AP scheme may not neither improve sustainability in the building profession nor improve the overall uptake of the LEED assessment program. Second, promoting third party professional accreditation schemes may not be the right target for fostering environmental sustainability and creating more sustainable environments.

\section{Advocacy Coalition Framework (ACF) and Elaboration Likelihood Model (ELM): Integrating VEPs in Public Procurement policies (Chapter 9)}

The last chapter to deal with voluntary rating and assessment schemes in the building and construction industry is theoretical in scope. Despite the claim that VEPs in design and construction may be subject to "green-washing" by building professionals, some principles of these schemes could be potentially useful beyond their application within the building sector. As public procurement processes were found to transform the market significantly and act as a guide for private sector actors, integrating elements from VEPs in procurement principles could be a potential strategy to integrate sustainability principles in a more structured way. However, as in most cases, powerful individuals and groups need to be convinced that this integration could be a worthwhile endeavor. By applying the Advocacy 
Coalition Framework (ACF) (Sabatier and Jenkins-Smith, 1988) and the Elaboration Likelihood Model (ELM) (Petty and Cacioppo, 1986), the chapter illustrates how these theoretical approaches could be used to achieve this goal.

\section{Innovation Acceptance and Information Source Choice theories: ISO 14001 integration (Chapter 10+11)}

Moving from the building and construction industry in the United States, Canada and the United Kingdom to the private sector in continental Europe (Germany and the Netherlands), the main focus of Chapters 10 and 11 is on the adoption of the ISO 14001 scheme. Both chapters are based on a data set collected within the context of this dissertation project in both countries among managers in firms.

An application of the Diffusion of Innovation Model (Rogers, 1995) was applied to understand ISO 14001 and EMAS adoption in Chapter 10. While the factors influencing ISO 14001 certification in differ between the two countries examined, the overall adoption patterns are similar. Respondents in both countries assessed ISO 14001 certification quite critically in terms of perception of ISO 14001 and EMAS adoption complexity, triability, relative advantage, visibility and compatibility. However, it also emerges from the data that even those who responded negatively were still likely to work in firms with ISO 14001 certification. Hence, ISO 14001 seems to have become a de-facto reality for most firms, irrespective of whether they have been certified yet or not. While new schemes such as Energy Management Systems adoption and certification have become the new frontier for firms, it seems that Environmental Management Systems adoption and certification has become fully established. However, the critical tones of many respondents towards the complexity or compatibility of the ISO 14001 scheme in both countries also means that additional Management Systems certifications, e.g. Energy Management schemes, need to be carefully designed to prevent opposition to environmental and energy management issues in firms.

Determining information source choice in Germany and the Netherlands with regards to ISO 14001 adoption, Chapter 11 is based in the General Model of Information Choice proposed by Wilson (1997). The results of this investigation show that EMS certification and adoption is far from being a standardized procedure, particularly when it comes to selecting the information sources used for decision-making processes. Differences in information source selection can be found in a relatively confined thematic area, i.e. EMS adoption and certification in the Netherlands and Germany. The factors contributing to information source selection varied markedly in this study. The study suggests that information source selection and their contribution to EMS certification and subsequent project success need to be better understood beyond what is currently known. 


\section{General Comments}

Results from Chapters 2-11 taken together suggest that social and psychological variables can offer valuable contributions to explain variance in adoption behavior and all of the frameworks contribute to better understand the adoption of environmental professional behaviors. However, the results demonstrate that engaging in environmentally relevant behaviors is highly contextual. Professional behavior changes can be difficult as individuals are reluctant to question previously learned practices and they rely on cooperation from other building professionals. As a consequence, the thesis demonstrates that despite some common behavior patterns VEP adoption processes, these schemes' implementation is rarely straight forward and does not follow a standard formula .With the results obtained, the next section elaborates the potential for improving private sector professional's practices to become more environmentally sustainable.

\subsection{Improving Environmental Compliance}

As this dissertation deals with professional behavior as a function of individual commitment with regards to environmental sustainability, comments on compliance, conformity are warranted.

Voluntary Environmental Programs (VEPs) are due to their "voluntary" nature not enforceable by authorities, unless these programs have been enshrined in legal frameworks and policies. In previous chapter (e.g Chapters 8 and 9), the question was raised whether professional "compliance" with VEPs is desirable, even if the schemes may not be well designed.

Changing of professional practices (i.e. a large-scale pattern of behavior) is very difficult. The results in this dissertation taken together have demonstrated that professionals' behavior is determined by mechanisms of social influence. Hence, the results can be useful for devising strategies for influencing professional's behavior.

Two concepts in the social influence literature, compliance and conformity have been commonly investigated in this respect (e.g. Cialdini and Goldstein, 2004). In their review of the social influence literature, compliance and conformity are determined by three main goals: accuracy, affiliation and positive self-perception. In their view, compliance is the response to a request while conformity refers to change in behavior to be in line with others' responses (Cialdini and Goldstein, 2004). For conformity behaviors, information under uncertainty (Castelli et al., 2001), perceived consensus research (e.g. Moscovici, 1980; Mackie, 1987) and attitude modification were found to be significant in addition to behavioral mimicry, and majority influence (as described by social identity and selfcategorization research). 
Well-known techniques that can be used to induce compliance and/or conformity, depending on the circumstances with regards to affect, resistance, pro-social requests and positive self-concept are:

- Affect: The Affect Infusion model (Forgas, 1995) and the "That's-not-all technique" (TNA)(Burger, 1986). The TNA influences individuals by presenting a request followed directly by reducing the costs or increasing the benefits of compliance. The initial request hence serves as a reference point against which the second offer is benchmarked.

- Resistance: Disrupt-then-reframe techniques (DTR) (Davis and Knowles, 1999, Knowles and Linn, 2003). The DTR technique can be utilized when resistance to a persuasion attempt is interrupted by a disruptive element and then reframed.

- Pro-social requests: Door-in-the-face technique (DITF)(Cialdini et al., 1975). The DITF is based on a first, likely to be rejected request, followed by a second, actually desired request. This could be based on guilt, reciprocity or dialogue involvement.

- Positive self-concept: Foot-in-the door technique (FITD) (Freedman and Fraser, 1966). The FITD starts with a small request that can be completed easily and then followed up by a larger request.

Most of these techniques could be applied to changing professional behavior, even though the exact mechanisms of these change techniques are subject to much debate (Cialdini and Goldstein, 2004). Given that transforming the private sector for sustainability is a pressing issue, the question is who would take on the task to apply large scale behavior change programs, even if there was a will to design and implement them.

Besides the social influence literature, other behavior change models have been covered in Chapter 2 of this dissertation in relation to the adoption of Voluntary Environmental Programs (VEPs). Some of these theories can be applied to improve environmental compliance and pro-environmental behavior. Behavior-oriented theories covered in this dissertation include Reasoned Action Approach (RAA) (Aijzen and Fishbein, 2010), Elaboration Likelihood Model (Petty and Cacioppo, 1986). An overview adopted from Bartholomew et al. (2011) is presented below:

- Individual

- Learning Theories (e.g. Robbins et al., 2001)

- Theories of information processing (e.g. Mayer, 1989)

- Health Belief Model (e.g. Abraham and Sheeran, 2005)

- Protection Motivation Theory and Extended Parallel Process Model (e.g. Norman et.al, 2005; Ruiter and Kok, 2010)

- Theories of Reasoned Action and Planned Behavior (e.g Fishbein and Ajzen, 1985)

- Goal-Setting Theory (e.g. Latham and Locke, 2007) 
- Theories of goal directed behavior (e.g. Gollwitzer, 1999)

- Theories of automatic behavior (e.g. Chartrand and Bargh, 1999)

- Transtheoretical model of behavior change (e.g. Prochaska et al., 2008)

- Precaution Adoption Process Model and risk communication (e.g. Weinstein, 1988)

- Attribution Theory and Relapse Prevention (Weiner, 1986)

- Communication - Persuasion Matrix (e.g. McGuire, 1985)

- Elaboration Likelihood Model (e.g. Petty and Cacioppo, 1986)

- Theories of Self-Regulation (e.g. Baumeister and Vohs, 2004)

- Interpersonal

- Social Cognitive Theory (Bandura, 1986)

- Theories of Stigma and Discrimination (e.g. Dijker and Koomen, 2003)

- Diffusion of Innovations Theory (e.g. Rogers, 2003)

- Multilevel

- Systems Theory (e.g. Naaldenberg et al., 2009)

- Theories of power (e.g. Turner, 2005)

- Empowerment theories (e.g. Minkler et al, 2008)

- Interpersonal environment

- Social networks and social support theories (e.g. Heaney and Israel, 2008)

- Organization

- Stages of Organizational change and Diffusion of Innovations (Boonstra, 2004)

- Stakeholder Theory (e.g. Brown et al., 2003)

- Community

- Coalition Theory (e.g. Feigehry and Rogers, 1990)

- Social Capital Theory (e.g. Portes, 1998)

- Social Norms Theory (e.g. Smelser, 1998)

- Conscientization (e.g. Freire, 1973)

- Community Organization Theory (e.g. Rothman, 2004)

- Society and government

- Agenda Building Theory (e.g. Cobb and Elder, 19823)

- Multiple Streams Theory (e.g. Kingdon, 2003)

- Advocacy Coalitions Framework (e.g. Sabatier et al., 1988)

These theories offer valuable insight in methods and techniques that can be used for improving environmental compliance include:

- Classical and Operant Conditioning (Learning theories) refers to stimulus presentation that can be rewarding (positive reinforcement) and punishment (negative reinforcement);

- Use of imagery and cues (Theories of Information processing such as the Mental Model Theory (Mayer, 1989)); 
- Fear arousal and message framing (Protection Motivation Theory and Extended Parallel processing );

- Changing intentions and shifting perceived norms (Reasoned Action Approach (Fishbein and Ajzen, 2010);

- Risk communication and awareness raising (Precaution-Adoption Process Model (PAPM), Holgrave et al, 1995);

- Attribution Training and Relapse Prevention (Attribution theory (Kok et al, 1992)).

\subsection{Knowledge on Pro-environmental Behavior and Environmental Policy Implications}

The above mentioned results make a more general discussion of the contribution of social sciences, and more particular, psychology, for public policy indispensable. VEPs can be useful instruments but cannot replace more enforceable regulations. Best industry practices take time to develop and these programs may not be the best way to create better awareness for sustainability or a quick-fix option.

The debate on the contributions of behavioral knowledge to policy making has a longstanding tradition. Sechrest and Bootzin (1996) suggest that psychological knowledge can be valuable for public policy design and implementation as it can provide information that is not accessible though common sense alone. Despite their being overall in favor of including psychological knowledge in public policy, they also present potential issues with doing so.

First, a large proportion of studies are conducted with students as the main participant group. General issues with generalizability, however, can limit the validity of such results (Sechrest and Bootzin, 1996). As college students are usually experienced enough in neither fragmented building industry nor have practical experience with Voluntary Environmental Programs (VEPs), this thesis project has for all studies conducted recruited private sector respondents as participants.

This distinction of different participant group reflects on an additional issue, the universality of cognitive processes. Research suggests that attitudes towards any given topic are likely to be very diverse and cover a large spectrum; these can be rather temporary and highly contextual. However, evidence has emerged that some mental processes can be regarded as more universal in character. Sechrest and Bootzin (1996) illustrate this point with a research study conducted by McGuire (1994) and propose that communication from a perceived high profile information sources has a greater effect on individuals than those who are considered to have lower prestige.

As choices made by researchers influence the representation of theoretical knowledge and empirical evidence, direct generalization needs to be considered carefully (Sechrest and 
Bootzin, 1996). It has been suggested that the "over-advocacy trap" (Campbell, 1969) can be very tempting to researchers. In that case, policy effectiveness may be overstated due to a lack of research validation (Darley, 2002; Ceci and Bjork, 2000). Twiford (1986) notes that policy recommendations given should not be based on a weak evidence and validated separately in many research studies.

McKnight et al. (2005) have a more positive assessment of the impact of social science knowledge on public policy decisions. Using Birkland's (2001) definition, they consider policies to be made in the public's name by governmental agencies that are interpreted and acted upon by public and private actors. From their point of view, psychological research can benefit public policy by creating knowledge about large-scale (i.e. societal) behavior change needed to tackle social issues such as environmental degradation.

\subsection{Limitations and Lessons learned}

Inevitably, the conclusions presented in this dissertation are limited by theoretical and empirical constraints.

The main limitations of this dissertation are related to data collection and measurement issues. First, in all countries where the surveys were administered, the United States, Canada, the United Kingdom, Netherlands and Germany, the response rates were not as high as anticipated. Even though private sector professionals are notoriously difficult to convince to participate in research studies, the result was disappointing to some extent. For future reference, other engagement strategies beyond participation in a voucher raffle could yield improved results. Furthermore, as participation was voluntary and not all professionals in the relevant countries could be contacted due practical, time and cost constraints, in all chapters a judgment sample formed the basis of the data analyses.

Second, self-report data is well-known for problems due to biases such as the social desirability bias or unreliable data entry processes. The lack of control and the distance of respondents increase scope for error and unreliable data. As some of the theoretical approaches can be usually tested in controlled experiments, conducting experiments could have reduced the risk for biases. However, as indicated, private sector professionals can hardly be convinced to participate in a self-report study and getting senior management in a testing lab would very unlikely due to time constraints and willingness.

Third, all the studies presented in this dissertation employed cross-sectional research designs and data. Hence, determinants of past behavior and temporal stability of determinants of current behavior could not be measured.

Fourth, the actual constraints to behavior enactment were not always identifiable. While actual constraints to behavior were included by analyzing clients of building professionals, the actual influence of private sector professionals could not be accurately assessed. 
Fifth, due to data constraints and relatively small sample sizes, the complexity of data analysis processes was limited.

Finally, most of the environmental programs discussed in this dissertation are not mutually exclusive, i.e. respondents usually do not have to opt for one program only but may chose to engage with several programs at the same time. The effects of multiple certification was not factored in in these studies due to limitations in respodent samples required for more complex calculations.The focus in the dissertation chapters was mainly on identifying factors that contribute to the adoption of Voluntary Environmental Programs(VEPs) such as attitudes, norms or group affiliation. Hence, the decision was taken to allow for respondents to be included in two samples for the purpose of analysis and it was out of scope for this work to analyse different respondent types (i.e.to distinguish categories of individuals that engage in either one, two or none VEPs).

Further limitations with regards to each topic were discussed in the relevant chapters.

\subsection{Further Research}

Further research that could contribute to the understanding of private sector professionals with regards to environmental sustainability is needed. This research would ideally address the limitations discussed in the previous section. First, experimental longitudinal studies are needed to trace the determinants of behavior over time in a more controlled setting. However, given the difficulties addressed in the limitations sections, this scenario is quite unlikely given the desired sample characteristics. Additionally, VEP adoption is a highly contextual issue. As a consequence, it would be quite difficult to recreate these settings in a laboratory and experimental context.

Since the results of VEP adoption have been out of scope for this dissertation project, further investigations of how respondents consider the consequences for their firm and society as a whole should be determined thoroughly. In order to determine whether some VEPs should be further promoted, post-adoption beliefs and attitudes need to be distinguished more carefully from pre-adoption cognition.

As discussed in the limitations section, shifting the focus of program adoption to distinguishing categories of individuals that engage in either one, two or none VEPs will also yield additional valuable insight in future research studies. 


\section{References}

Abraham, C., \& 2005, S. P. (2005). Predicting health behavior: Research and practice with social cognition models. In M. . P. Norman (Ed.), (chap. The Health Belief Model.). Open University Press. (editor:In M.Conner \& P. Norman (Eds)

Bandura, A. (1986). Social foundations of thought and action. Englewood Cliffs, NJ Prentice Hall.

Birkland, T. A. (2005). An introduction to the policy process: Theories, concepts, and models of public policy making. Gremese Editore.

Boonstra, J. (2008). Dynamics of organizational change and learning. John Wiley \& Sons.

Brown, L. D., Bammer, G., Batliwala, S., \& Kunreuther, F. (2003). Framing practice-research engagement for democratizing knowledge. Action Research, 1(1), 81-102.

Burger, J. M. (1986). Increasing compliance by improving the deal: The that's-not-all technique. Journal of Personality and Social Psychology, 51(2), 277.

Campbell, D. T. (1969). Reforms as experiments. American psychologist, 24(4), 409-429.

Castelli, L., Vanzetto, K., Sherman, S. J., \& Arcuri, L. (2001). The explicit and implicit perception of in-group members who use stereotypes: Blatant rejection but subtle conformity. Journal of Experimental Social Psychology, 37(5), 419-426.

Ceci, S. J., \& Bjork, R. A. (2000). Psychological science in the public interest: The case for juried analyses. Psychological science, 11(3), 177-178.

Chartrand, T.L., \& Bargh, J. A. (1999). The chameleon effect: The perception-behavior link and social interaction. Journal of personality and social psychology, 76(6), 893-910.

Cialdini, R. B., \& Goldstein, N. J. (2004). Social influence: Compliance and conformity. Annu. Rev. Psychol., 55, 591-621.

Cialdini, R. B., Vincent, J. E., Lewis, S. K., Catalan, J., Wheeler, D., \& Darby, B. L. (1975). Reciprocal concessions procedure for inducing compliance: The door-in-the-face technique. Journal of personality and Social Psychology, 31(2), 206-215.

Cobb, R. W., \& Elder, C. D. (1972). Participation in american politics: The dynamics of agenda-building. Allyn and Bacon Boston.

Darley, J. (2002). Gaining traction for psychology in the public arena. APS Observer, 15.

Davis, B. P., \& Knowles, E. S. (1999). A disrupt-then-reframe technique of social influence. Journal of Personality and Social Psychology, 76(2), 192-199.

Deci, E. L., \& Ryan, R. M. (1985). Intrinsic motivation and self-determination in human behavior, 1985. Plenum, New York.

Deci, E. L., \& Ryan, R. M. (2000). The" what" and" why" of goal pursuits: Human needs and the self-determination of behavior. Psychological inquiry, 11(4), 227-268.

Dijker, A. J., \& Koomen, W. (2003). Extending weiner's attribution-emotion model of stigmatization of ill persons. Basic and Applied Social Psychology, 25(1), 51-68.

Feighery, E., \& Rogers, T. (1995). Building and maintaining effective coalitions. Health Promotion Resource Center. 
Fishbein, M., \& Ajzen, I. (2010). Predicting and changing behavior: The reasoned action approach. Taylor \& Francis.

Forgas, J. P. (1995). Mood and judgment: the affect infusion model (aim). Psychological bulletin, 117(1), 39-66.

Freedman, J. L., \& Fraser, S. C. (1966). Compliance without pressure: the foot-in-the-door technique. Journal of personality and social psychology, 4(2), 195-202.

Freire, P. (1973). Education for critical consciousness (Vol. 1). Continuum.

Gollwitzer, P. M. (1999). Implementation intentions: strong effects of simple plans. American Psychologist, 54(7), 493-503.

Heaney, C. A., \& Israel, B. A. (2002). Health behavior and health education: Theory, research and practice. In . K. V. K. Glanz B.K. Rimer (Ed.), (Vol. 3, pp. 185-209). Jossey-Bass San Francisco.

Holtgrave, D. R., Tinsley, B. J., \& Kay, L. S. (1995). Designing health messages: Approaches from communication theory and public health practice. In E. M. . R. Parrott (Ed.), (chap. Encouraging risk reduction: A decision-making approach to message design.). Sage Publications, Inc.

Johnson, D. W., \& Johnson, R. T. (1989). Cooperation and competition: Theory and research. Interaction Book Company.

Kingdon, J. W., \& Thurber, J. A. (1984). Agendas, alternatives, and public policies (Vol. 45). Little, Brown Boston.

Knowles, E. S., \& Linn, J. A. (2004). Approach-avoidance model of persuasion: Alpha and omega strategies for change. Resistance and Persuasion, 117-148.

Kok, G., Den Boer, D., De Vries, H., Gerards, F., Hospers, H., \& Mudde, A. (1992). Selfefficacy: Thought control of action. In R. Schwarzer (Ed.), (chap. Self-efficacy and attribution theory in health education). Washington, DC.: Hemisphere.

Latham, G. P., \& Locke, E. A. (2007). New developments in and directions for goal-setting research. European Psychologist, 12(4), 290-300.

Mackie, D. M. (1987). Systematic and nonsystematic processing of majority and minority persuasive communications. Journal of Personality and Social Psychology, 53(1), 41-52.

Mayer, R. E. (1989). Models for understanding. Review of educational research, 59(1), 43-64.

McGuire, W. J. (1969). The handbook of social psychology: Vol.2. In G. L. . E. Aronson (Ed.), (Vol. 3, pp. 136-314). Reading, Massachusetts.

McGuire, W. J. (1994). Using mass media communication to enhance public health. In Effective dissemination of clinical health information. conference report. rockville, $m d$ : Agency for health care policy and research.

McKnight, K. M., Sechrest, L., \& McKnight, P. E. (2005). Psychology, psychologists, and public policy. Annu. Rev. Clin. Psychol., 1, 557-576. 
Minkler, M., \& Wallerstein, N. (2010). Community-based participatory research for health: From process to outcomes. John Wiley \& Sons.

Moscovici, S. (1980). Toward a theory of conversion behavior. Advances in experimental social psychology, 13, 209-239.

Naaldenberg, J., Vaandrager, L., Koelen, M., Wagemakers, A.-M., Saan, H., \& de Hoog, K. (2009). Elaborating on systems thinking in health promotion practice. Global Health Promotion, 16(1), 39-47.

Petty, R. E., \& Cacioppo, J. T. (1986). The elaboration likelihood model of persuasion. Springer.

Portes, A. (2000). Social capital: Its origins and applications in modern sociology. LESSER, Eric L. Knowledge and Social Capital. Boston: Butterworth-Heinemann, 24, 43-67.

Prochaska, J. O., Redding, C. A., \& E, E. K. (2008). Health behavior and health education: Theory, research and practice. In . K. K. Glanz B.K. Rimer (Ed.), (chap. The Transtheoretical Model and stages of change). Jossey-Bass. (editor:In K. Glanz, B.K. Rimer, \& K.Viswanath. (Eds), Health Behavior and health education: Theory, research and practice. San Francisco: Jossey-Bass)

Rogers, E. M. (2003). Diffusion of innovations. Simon and Schuster.

Rothman, J. (2004). Strategies of community organization: A book of readings. In F. Cox, J. Ehrlich, J. Rothman, \& J. Tropman (Eds.), (chap. Three models of community organization practice, their mixing and phasing.). F.E. Peacock. (editor:In F.M. cox, J.L. Ehrlich, J. Rothman, \&J.E. Tropman (Eds)

Ryan, R. M. (1995). Psychological needs and the facilitation of integrative processes. Journal of personality, 63(3), 397-427.

Sabatier, P. A., \& Jenkins-Smith, H. (1988). An advocacy coalition framework of policy change and the role of policy-oriented learning therein. Policy sciences, 21(2-3), 129-168.

Schwartz, B. (1989). Psychology of learning and behavior. WW Norton \& Co.

Sechrest, L. B., \& Bootzin, R. R. (1996). Psychology and inferences about public policy. Psychology, Public Policy, and Law, 2(2), 377-392.

Smelser, N. J. (1988). Social structure. Sage Publications, Inc.

Tajfel, H. (1981). Intergroup behavior. In Intergroup behavior (pp. 144 -167 (p. 144-167). Blackwell. (editor:In J. C. Turner \& H. Giles (Eds)

Tajfel, H., \& Turner, J. C. (1979). The social psychology of intergroup relations. In W. Austin \& S. Worchel (Eds.), (Vol. 33, chap. An integrative theory of intergroup conflict). Brooks/Cole.

Turner, J. C. (2005). Explaining the nature of power: a three-process theory. European Journal of Social Psychology, 35(1), 1-22.

Twiford, J. R. (1986). Joint custody: A blind leap of faith? Behavioral Sciences \& the Law, $4(2), 157-168$. 
Vohs, K. D., \& Baumeister, R. F. (2011). Handbook of self-regulation: Research, theory, and applications. Guilford Press.

Weiner, B. (1986). An attribution theory of motivation and emotion. Springer.

Weinstein, N. D. (1988). The precaution adoption process. Health psychology, 7(4), 355-386.

Wilson, T. D. (1997). Information behaviour: an interdisciplinary perspective. Information processing \& management, 33(4), 551-572. 



\section{Summary}

Environmental degradation, climate change and management of scarce natural resources are among the most pressing social issues humanity faces today and will face for generations to come. Climate change and environmental damage cannot be seen and treated as separate problems to be solved after other social issues higher on the political agenda have been solved. Due to the enormity of the environmental problems and the almost inevitable challenges that our and future generations will have to deal with, denial of climate change or general apathy is a common consequence. Similar to other areas in which people feel overwhelmed by an enormous task, procrastination and avoidance mechanisms are activated to defer actions and postpone important lifestyle and resource usage decisions. These characteristics are not solely confined to private and household behaviors but also apply to individuals in workplace and professional environments.

While policy-makers have the power to influence the way societies deal with the impeding environmental and climate change issues, laws and regulations are often either not feasible or desirable given the considerable efforts involved and limited enforcement capabilities. Hence, Voluntary Environmental Programs (VEPs) have gained considerable popularity in policy-makers' toolboxes. At first sight, the advantages of these programs are clear: Organizations and individuals engage in environmentally desirable behaviors not because they have to but because they see value in engaging in pro-environmental behaviors.

Sustainable business strategies have been hailed as an important part of the puzzle and individuals in households have simultaneously become a target for government policies to entice them to become more environmentally responsible and save natural resources.

Studies as to what factors contribute to make them more likely to save water, energy and to favor environmentally friendly modes of transport are rife. Economic, sociological, psychological, anthropological factors influencing environmental decisions by individuals and groups have become a matter of interest for policy makers and governments. Particularly Voluntary Environmental Programs (VEPs) as a means of cost-effective environmental governance and regulation has become a major focus of policy and regulatory interest. 
Research in cognition in organizations needs to receive more attention to better understand importance of individual differences to determine organizations' reaction to environmentally friendly solutions. Further development of green technologies and associated reduced costs, however, may not be sufficient to make environmentally friendly solutions in the private sector more popular. Identifying social and psychological factors on the individual, organizational and institutional level is needed to influence social structures by providing rewards and incentives (monetary and non-monetary).

To understand the determinants for voluntary environmental behavior and the effectiveness of VEPs is an intriguing topic. However, the decision processes of policy-makers themselves, business leaders and professionals in their work roles have not been studied extensively. The present dissertation aims to shed a light on environmental decision-making processes in the construction industry in the United Kingdom, the United States and Canada as well as service and manufacturing companies in the Netherlands and Germany. The main focus of these studies is to investigate the actions of business professionals to adopt voluntary environmental programs. The studies presented in this dissertation are based on various theoretical approaches ranging from social psychological models to information science, diffusion of innovation as well as governance and management literature.

A large number of studies have identified factors that influence individuals' propensity for pro-environmental behavior. This dissertation studied the adoption of voluntary environmental programs (VEPs) in five different countries on two continents: Canada and the United States (North America) and Germany, the Netherlands and the United Kingdom (Europe).The research project analyzes socio-psychological determinants of intention and behavior with regards to VEP uptake in several industries with a special focus on the building and construction industry. The data used in this dissertation were self-collected data from interviews and surveys in all five countries.

The factors studied include attitudes, norms, perceived behavioral control, social identity, intrinsic and extrinsic motivations within the contexts of professional decisions and cooperation behavior. This dissertation's main objective is to determine factors that drive voluntary and environmentally sustainable professional practices in the private sector. As voluntary professional behavior is extremely diverse, this thesis investigates "voluntarism" in the form of Voluntary Environmental Programs (VEPs).Several studies were conducted to explain professionals' environmentally relevant behavior within a professional decision-making context.

Results demonstrate that social and psychological variables can offer valuable contributions to explain variance in adoption behavior and all of the frameworks contribute to better understand the adoption of environmental professional behaviors. However, the results demonstrate that engaging in environmentally relevant behaviors is highly contextual. Professional behavior changes can be difficult as individuals are reluctant to question previously 
learned practices and they rely on cooperation from other building professionals. As a consequence, this dissertation demonstrates that despite some common behavior patterns VEP adoption processes, the reasons for adoption among private sector professionals are complex, both from a contextual and psychological point of view. The results confirm, however, that policies and programs cannot be designed and implemented successfully without understanding workers' professional needs and social-psychological determinants that drive program uptake. 



\section{Valorisation Addendum}

\section{Introduction}

The valorisation addendum to the present research project will explore the added value and relevance of the studies included in this project for additional research as well as use by building and construction practitioners, policy-makers and the general public. While potential application of knowledge generated in this research has been referenced within the thesis chapters, further aspects of research valorization have been identified in this addendum. The importance of this research is discussed with a specific focus on (1) relevance, (2) target groups, (3) activities and/or products, (4) innovation and (5) implementation.

\section{Relevance}

Aside from the scientific relevance which has been extensively discussed in the dissertation chapters, the results derived from the research activities are highly relevant to the wider understanding of environmental sustainability as a function of human behavior in the workplace. While intentions, behaviors and their antecedents have been studied in household contexts, professional behaviors have been less subject to scrutiny. As everyone knows, people quite frequently behave differently in their workplace than at home due to increased pressures to perform, to fit in with the crowd and/or retain their jobs. This list includes just a few reasons why workplace behavior may deviate from leisure time behaviors and intentions. While the differences in private and professional attitudes and behaviors may seem to be less problematic in the realm of exercise or food behavior (for instance, an individual may not be a keen runner on their own time but join their colleagues' lunchtime jog to be part of the in-crowd), in the field of environmental sustainability, seemingly privately held attitudes may translate in behaviors that will have an immense impact on society, especially in the context of urban development, planning and construction. To facilitate change for sustainable development at the source, i.e. in the minds of industry professionals, the present research sheds light on commonly held beliefs with regards to designing and constructing sustainable buildings as well as implementing environmental management 
systems in other organizations contributing to economic activity. Using the examples of green building certification in the United States, Canada and the United Kingdom as well as Environmental Management Systems (EMS) in Germany and the Netherlands, behavioral factors are investigated that can be used for the design of behavior change programs and communication strategies to improve environmental sustainability in business decisions.

\section{Target Groups}

The studies included in this research are targeted at a wide range of audiences, including (1) academics studying pro-environmental behavior, (2) educators in higher and vocational education institutions training professionals to include environmental criteria in their decision-making processes, (3) organizational decision-makers to understand and recognize environmental barriers and drivers in their own work context, (4) policy-makers that aim to develop programs and policies to improve professional decision capacity for environmental sustainability, (5) environmental standards issuing organizations and (6) the wider public interested in understanding drivers and barriers for environmentally relevant initiatives in private and public sector organizations. While all of the above mentioned professional groups stand to benefit from the knowledge generated in this research, organizational and policy-decision makers will be most likely to utilize the results.

\section{Activities and Products}

While the results are unlikely to be translated directly into products, they could be integrated by behavior change consultancies and other firms in commercially available tools for organizational change management. Behavioral factors identified in the research projects can be operationalized by the target groups (1)-(5) and translated in communication, education, intervention and behavior change programs to encourage and facilitate the voluntary uptake of environmentally relevant programs and policies. For example, a local policy-maker may be interested in encouraging the building and construction sector in their city to be more proactive with regards to the development of sustainable office buildings and to include building certification schemes in their projects. As normative influences have been found to play a major role in this regard, effective communication of policy-makers' real expectations could lead to change in the environmental building practices within that local city context. In a similar fashion, organizations that have developed standards for environmental sustainability in the private and public sector may better understand the success or failure of their standards as well as advantages and disadvantages of their programs in the eyes of their intended target audiences. 


\section{Innovation}

The results generated in this research can be considered innovative as theoretical and methodological aspects from a wide range of disciplines including economics, management, social psychology, sociology and communication studies were combined to bring an interdisciplinary focus on the issue of environmental decision-making in organizational contexts. As a consequence, the results are relevant for a wide range of target audiences, as listed above. While there has been some research with an interdisciplinary focus, the comparative nature of this research with five countries being studied extensively has yielded knowledge that can be applied in a range of regional contexts. In this sense, the behavioral factors identified can be included in behavior change programs, interventions and policy development in multi-country initiatives.

\section{Implementation and Schedule}

While the results derived from the research studies presented in this thesis can and should be used by target audiences on their own time and adapted to their own purposes, the author has also plans for further studies and the development of an evidence-based behavior change and communication toolkit aimed at professional decision-makers. This toolkit will include strategies that will target mainly construction and building industry professionals (in the wider sense) to promote environmentally sustainable professional practices. These activities are to be carried out in the course of the next year and trialed in a medium-size city context. Several urban communities have been identified and contact with relevant local decisionmakers as well as construction and building professionals has been established. While the study context in the dissertation was the European and North American context, this trial initiative is likely to be focused on the Asia-Pacific regional area to (1) validate the results and (2) include other geographic dimensions to the toolkit. 



\section{Appendix A : Methodological considerations}

\section{Self-reported online survey data: limitations and opportunities}

Conducting self-reported online survey data can present several challenges. For many researchers, surveys are a less attractive option than other research methods. Van Selm and Jankowski (2006) have listed a number of issues that have been raised in social science research over the last decades. In the next paragraph, these issues commonly voiced will be addressed in the context of this dissertation project.

First, surveys are often said to produce less reliable data than experimental studies due to a number of biases, including self-selection and response biases (Arnold and Feldman, 1981). However, surveys have also been found to be an economically efficient data collection method for populations with particular characteristics. Experimental field or laboratory studies can be difficult to organize, specifically when the population includes mid to senior level professional in public and private organizations. Additionally, this dissertation project has focused on collecting comparative data from several countries, including the United States, Canada, the United Kingdom, the Netherlands and Germany. To have organized experimental studies in all of these countries would have turned out to be prohibitively expensive and time-consuming.

When considering the format of surveys, the decision has to be made between interview surveys, mail surveys and online surveys (Van Selm and Jankowski, 2006). While email access has been invoked as a limitation to online surveys in the early 2000s, internet access can also be considered an argument in favor of online surveys. For studies conducted as in this dissertation project, online and email surveys can provide easy and cost effective access to professionals. The advantages include the opportunity for respondents to fill-in the questionnaire in their own time and their own pace. In addition, phone calls to conduct an interview survey could deter individuals from participating due to schedule conflicts or company policies (Van Selm and Jankowski, 2006).

Furthermore, online surveys can prove to be very useful for certain respondent populations or behaviors that may require more anonymity. With regards to social or environmental 
attitudes and behaviors that this dissertation project investigates, online surveys can offer a non-confrontational way to voice controversial opinions but may have the disadvantage of losing sight of who is responding (Mann and Stewart, 2000), invasion of privacy, limitations to internet access in the workplace.

Two further advantages of online surveys include the absence of interviewer biases and subsequent need for data entry and data entry errors (e.g. Sills and Song, 2002).

\section{Sampling}

Online surveys have been found to be appropriate in studies including non-probability samples (Van Selm and Jankowski, 2006). Achieving random sampling of internet users is considered to be problematic as "the internet poses a unique set of problems in guaranteeing a random sample of respondents" (Kaye and Johnson, 1999). However, while online surveys based on non-probability samples may not be representative of the whole population of internet users, they can be representative of a sub-group of the total population (Van Selm and Jankowski, 2006). Acceptable representativeness and randomness levels can be achieved by means of user lists for which email addresses are known and randomly selecting respondents from these lists (Kaye and Johnson, 1999).

This approach has been adopted in this dissertation project in all survey selection processes, resulting in recruited samples (Medlin et al., 1999) obtained from an existing sample frame (e.g. professional accreditation lists). The only survey in which another approach was followed is the Dutch survey, in which the sample frame consisted of a subset of the overall population due to cooperation with another organization owning the contact database. Coverage errors and sampling errors in online surveys cannot be completely eliminated (Dillman et al., 1998).

\section{Questionnaire Design and Data collection}

A further issue that needs to be addressed in online surveys deals with the overall questionnaire design as the questionnaire should be in line with the target population's style (Sheehan and McMillan, 1999). Generally, the longer the survey, the less likely potential respondents will participate (Van Salm and Jankowski, 2006). Advantages of online and web-based surveys include point-and-click options, structured responses provision, electronic data collation, and visual representation for review, flexible time constraints for respondents and the use of adaptive questions dependent on previous answers (Pitkow and Recker, 2005). While online questionnaires can be sent in an email or web-based, a two-step procedure was adopted in this dissertation project: First, personalized emails were sent to potential respondents in which a link to the survey website was embedded. The link 
included token to ensure that only selected respondents are able to fill in the questionnaire once. In line with recommendations by Heerwegh and Loosveldt (2003), a semiautomatic login procedure was employed as it does not reduce response rates while increasing data quality overall.

The questionnaire development followed best practices such as:

- Ensure survey readability (e.g. Dillman and Bowker, 2001; Dillman et al., 1998)

- Access restriction (e.g. Crawford et al., 2001; Heerwegh and Losveldt, 2003)

- Use of a conventional questionnaire format (e.g. Dillman and Bowker, 2001)

- Use of a motivational welcome screen (e.g. Dillman and Bowker, 2001; Couper, 2000)

- Limit line length to avoid misunderstandings (e.g. Couper, 2000)

- Provision of clear and specific instructions with regards to navigation and response formats (e.g. Dillman, 2000; Dillman et al., 1998).

- Testing survey on different computers (e.g. Couper, 2000; Crawford et al., 2001)

- Inclusion of a progress status (e.g. Couper, 2000 )

- Division of survey into sections (e.g. Couper, 2000).

\section{Response rates}

A major issue for all types of surveys is obtaining a sufficient number of responses. With regards to online surveys, there is some criticism that it is difficult to determine "how many people have seen the survey or its links but declined to participate" (Kaye and Johnson, 1999).

Crawford et al. (2001) suggest in a review that online surveys may have lower response rates in general than traditional mail surveys. While this concern has been reiterated in following studies (e.g. Schaefer and Dillman, 1998), techniques for improving response rates have been proposed subsequently. Successively contacting potential respondents and sending reminders can improve response rate increase as well as personalized emails (Schaefer and Dillman, 1998) and appropriate subject lines in email participation invitations (Sheehan and McMillan, 1999).

These recommendations were followed in the context of this dissertation project. For all surveys (except for the Dutch data set in which the reminders were sent by the administering organization), a personalized email was sent to potential respondents including a description of the project, project aims and approximate time needed for completion. All of the surveys were designed to take approximately 10-15 minutes for completion. Two subsequent reminders were sent to potential respondents, unless these provided feedback that they did not wish to receive further notification. 
Despite these reminders, the overall response rate remained relatively low in percentage terms (10-20\%) which is lower than most of the studies reviewed.

\section{Supportive Technology and Data processing}

The use and analysis of data is one of the major advantages of online survey administration (Van Selm and Jankowski, 2006). Despite the raw data still being subject to coding and cleaning, overall costs and time has been found to be significantly reduced.

In this dissertation project, the open source Limesurvey software was embedded in a purpose-built website to which prospective respondents were re-directed after clicking a link in the invitation email. 


\section{Appendix B : Data collection instruments}

\section{Interview guidelines}

For the qualitative part of this dissertation on which Chapter 3 is based and results of which feature in Chapters 5 to 8, a semi-structured approach was followed. While the sampling and response rates are detailed in Chapter 3, the questions asked during the 60 minute interviews can be found below:

1. What are your experiences with the LEED and/or Green Globes program?

2. If you have worked on a LEED and/or Green Globes project before, what are your experiences with regards to working on one of the projects?

3. What are the factors that determine the decision to include a program such as LEED and/or Green Globes in a building project?

4. Which persons or organizational entities usually give the impulse to include LEED and/or Green Globes in a project? What are the procedures?

5. How do your personal approach and your organization's approach with regards to environmental assessment schemes differ?

6. Could you explain the advantages and disadvantages of environmental rating schemes in general? What about the LEED and Green Globes specifically?

7. Besides the points just mentioned, please list other factors that compel your organization and you to work on projects that include the LEED and/or Green Globes scheme?

Questionnaire: Reasoned Action Approach (RAA) (Chapters 4, 5, 7, 8)

Past behavior ([B1] $)$ and Intentions $([\mathrm{B3}+\mathrm{B5}])$

[B1a] Have you worked on a LEED project?

[B1b] Have you worked on a Green Globes project?

Answer Format: Yes/No 
[B3a] I expect that my next commercial building project will include the LEED certification scheme.

[B3b] I expect that my next commercial building project will include the Green Globes certification scheme.

Answer Format: Strongly Agree - Strongly Disagree (7-Point Likert Scale)

[B5a] I intend to include the LEED certification scheme in my next commercial building project.

[B5b] I intend to include the Green Globes certification scheme in my next commercial building project.

Answer Format: Strongly Agree - Strongly Disagree (7-Point Likert Scale)

Attitudes ([B6] - [B9])

[B6a] Working with the LEED scheme is/would be:

[B6b] Working with the Green Globes scheme is/would be:

Answer Format: Strongly Agree - Strongly Disagree (7-Point Likert Scale)

[B7a]The LEED certification scheme has established clear guidelines for sustainability practices in the building industry.

[B7b] The Green Globes certification scheme has established clear guidelines for sustainability practices in the building industry.

Answer Format: Strongly Agree - Strongly Disagree (7-Point Likert Scale)

[B8a] I think that the LEED scheme has educated me about sustainable building practices.

[B8b] I think that the Green Globes scheme has educated me about sustainable building practices.

Answer Format: Strongly Agree - Strongly Disagree (7-Point Likert Scale) 
[B9a] I think that the LEED scheme has provided building professionals with a common language when it comes to sustainable construction.

[B9b] I think that the Green Globes scheme has provided building professionals with a common language when it comes to sustainable construction.

Answer Format: Strongly Agree - Strongly Disagree (7-Point Likert Scale)

\section{Norms $([$ B10]- $[$ B15 $])$}

[B10a] Most important people in my profession think that I should work on a LEED project.

[B10b] Most important people in my profession think that I should work on a Green Globes project.

Answer Format: Strongly Agree - Strongly Disagree (7-Point Likert Scale)

[B11a] Most important people in my profession work with the LEED scheme [B11b] Most important people in my profession work with the Green Globes scheme

Answer Format: Strongly Agree - Strongly Disagree (7-Point Likert Scale)

[B12a] Government/City/State officials expect me to work with the LEED scheme.

[B12b] Government/City/State officials expect me to work with the Green Globes scheme.

Answer Format: Strongly Agree - Strongly Disagree (7-Point Likert Scale)

[B13a] Clients expect me to work with the LEED scheme.

[B13b] Clients expect me to work with the Green Globes scheme.

Answer Format: Strongly Agree - Strongly Disagree (7-Point Likert Scale)

[B14a] Co-workers expect me to work with the LEED scheme.

[B14b] Co-workers expect me to work with the Green Globes scheme.

Answer Format: Strongly Agree - Strongly Disagree (7-Point Likert Scale) 
[B15a] Other building professionals expect me to work with the LEED scheme. [B15b] Other building professionals expect me to work with the Green Globes scheme.

Answer Format: Strongly Agree - Strongly Disagree (7-Point Likert Scale)

\section{Perceived Behavioral Control ([B16]- $[$ B20] $)$}

[B16a]The decision to work on a LEED scheme is entirely up to me [B16b]The decision to work on a Green Globes scheme is entirely up to me

Answer Format: Strongly Agree - Strongly Disagree (7-Point Likert Scale)

[B17a] It would be easy for me to work with the LEED scheme if I wanted to.

$[\mathrm{B} 17 \mathrm{~b}]$ It would be easy for me to work with the Green Globes scheme if I wanted to.

Answer Format: Strongly Agree - Strongly Disagree (7-Point Likert Scale)

[B18a] Organizational practices prevent me from working on a LEED project. $[\mathrm{B} 18 \mathrm{~b}]$ Organizational practices prevent me from working on a Green Globes project.

Answer Format: Strongly Agree - Strongly Disagree (7-Point Likert Scale)

[B19a] Financial constraints prevent me/ my organization from working with the LEED scheme.

[B19b] Financial constraints prevent me/ my organization from working with the Green Globes scheme.

Answer Format: Strongly Agree - Strongly Disagree (7-Point Likert Scale)

[B20a] Other building professionals' decisions prevent me from working with the LEED scheme.

[B20b] Other building professionals' decisions prevent me from working with the Green Globes scheme.

Answer Format: Strongly Agree - Strongly Disagree (7-Point Likert Scale) 


\section{Questionnaire: Social Identity Theory (Chapter 6)}

[D1a] How many people in your organization engage in green building practices?

[D1b]How many people in your professional group engage in green building practices?

Answer Format: All - None (7-Point Likert Scale)

[D2a] How likely are people in your organization to engage in environmental sustainable practices?

[D2b] How likely are people in your professional group to engage in environmental sustainable practices?

Answer Format: Very likely - Very Unlikely (7-Point Likert Scale)

[D3a] How much agreement is there in your organization to engage in environmental sustainable practices

[D3b] How much agreement is there in your professional group to engage in environmental sustainable practices

Answer Format: Full Agreement - No Agreement (7-Point Likert Scale)

[D4a] How much do you identify with your organization in terms of environmental sustainability?

[D4b] How much do you identify with your professional group in terms of environmental sustainability?

Answer Format: Not at all - Completely (7-Point Likert Scale)

[D5a] How similar do you feel you are to you organization overall in terms of beliefs?

[D5b] How similar do you feel you are to you professional group overall in terms of beliefs?

Answer Format: Very similar - Not at all similar (7-Point Likert Scale)

[D6a] How much do you like your organization as a whole?

[D6b] How much do you like your professional group as a whole?

Answer Format: Completely - Not at all (7-Point Likert Scale) 
[D7a] How well do you feel you fit into your organization?

[D7b] How well do you feel you fit into your professional group?

Answer Format: Completely - Not at all (7-Point Likert Scale)

[D8a]How strong are your ties with your organization?

[D8b] How strong are your ties with your professional group?

Answer Format: Very strong - Not strong at all (7-Point Likert Scale)

[D9a] Although there are different organizations in the building industry, it feels like we are all on the same page when it comes to environmental sustainability. [D9b] Although there are different professional groups in the building industry, it feels like we are all on the same page when it comes to environmental sustainability.

Answer Format: Strongly Agree - Strongly Disagree (7-Point Likert Scale)

[D10a] There is a sense that organizations in the building industry are split in many different camps with regards to environmental sustainability.

[D10b] There is a sense that professional groups in the building industry are split in many different camps with regards to environmental sustainability.

Answer Format: Strongly Agree - Strongly Disagree (7-Point Likert Scale)

[D11a] Environmental sustainability practices are mainly determined by organizations.

[D11b] Environmental sustainability practices are mainly determined by professional groups.

Answer Format: Strongly Agree - Strongly Disagree (7-Point Likert Scale)

[D14a] The organizations that strongly influence environmental sustainability practices in the building industry have little understanding of the difficulties to implement these practices.

[D14b] The professional groups that strongly influence environmental sustainability practices in the building industry have little understanding of the difficulties to implement these practices.

Answer Format: Strongly Agree - Strongly Disagree (7-Point Likert Scale) 
[D15a] The organizations that strongly influence environmental sustainability practices in the building industry have the enough expertise and knowledge in this matter.

[D15b] The professional groups that strongly influence environmental sustainability practices in the building industry have the enough expertise and knowledge in this matter.

Answer Format: Strongly Agree - Strongly Disagree (7-Point Likert Scale)

[D19] Engaging in sustainable building practices is an important part of who I am. Answer Format: Strongly Agree - Strongly Disagree (7-Point Likert Scale)

\section{Questionnaire: Social Interdependence Theory (Chapter 7)}

[D12a] You are keen to help colleagues from your own firm achieve project goals. [D12b] You are keen to help colleagues from other project firms achieve project goals.

[D12c] You are keen to help members of your own professional group achieve project goals.

[D12d] You are keen to help members of other professional groups achieve project goals.

Answer Format: Strongly Agree - Strongly Disagree (7-Point Likert Scale)

[D13a] You wilfully contribute useful ideas and opinions to colleagues from your own firm.

[D13b] You wilfully contribute useful ideas and opinions to colleagues from other project firms.

[D13c] You wilfully contribute useful ideas and opinions to members of your own professional group.

[D13d] You wilfully contribute useful ideas and opinions to members of other professional groups.

Answer Format: Strongly Agree - Strongly Disagree (7-Point Likert Scale) 
[D14a] You actively assist colleagues from your own firm in solving difficult problems.

[D14b] You actively assist colleagues from other project firms in solving difficult problems.

[D14c] You actively assist members of your own professional group in solving difficult problems.

[D14d] You actively assist members of other professional groups in solving difficult problems.

Answer Format: Strongly Agree - Strongly Disagree (7-Point Likert Scale)

[D15a] You volunteer personal resources like time and effort to colleagues from your own firm.

[D15b] You volunteer personal resources like time and effort to colleagues from other project firms.

[D15c] You volunteer personal resources like time and effort to members of your own professional group.

[D15d] You volunteer personal resources like time and effort to members of other professional group.

Answer Format: Strongly Agree - Strongly Disagree (7-Point Likert Scale)

\section{Questionnaire Self-Determination Theory (Chapter 8)}

[C1] I find it difficult to assess which voluntary AP schemes are really necessary Answer Format: Strongly Agree - Strongly Disagree (7-Point Likert Scale)

[C2] Which voluntary AP scheme for sustainable construction have you passed?

LEED AP

Other

[C3] The AP scheme (s) were chosen for me by my organization

Answer Format: Strongly Agree - Strongly Disagree (7-Point Likert Scale) 
[C5] Voluntary AP schemes can:

promote professionalism

enhance the prestige of my profession

distinguish professionals from peers and colleagues

stabilize job security

protect clients from incompetent practitioners

help to qualify for bids and tenders

help to avoid external government regulation

improve income

[C6] Achieving LEED AP accreditation was boring.

Answer Format: Strongly Agree - Strongly Disagree (7-Point Likert Scale)

[C7] I think I did pretty well on the LEED AP exam.

Answer Format: Strongly Agree - Strongly Disagree (7-Point Likert Scale)

[C8] I did not put much energy into taking the LEED AP exam

Answer Format: Strongly Agree - Strongly Disagree (7-Point Likert Scale)

[C9] It was important to me to do well at the LEED AP exam.

Answer Format: Strongly Agree - Strongly Disagree (7-Point Likert Scale)

[C10] I felt pressured to take the LEED AP exam.

Answer Format: Strongly Agree - Strongly Disagree (7-Point Likert Scale)

[C11] I did take the LEED AP exam because I wanted to.

Answer Format: Strongly Agree - Strongly Disagree (7-Point Likert Scale)

[C12] I think that taking the LEED AP exam is an important activity.

Answer Format: Strongly Agree - Strongly Disagree (7-Point Likert Scale) 
[C13] Taking the LEED AP exam is a waste of time.

Answer Format: Strongly Agree - Strongly Disagree (7-Point Likert Scale)

[C14] I can't see what I am getting out of taking the LEED AP exam

Answer Format: Strongly Agree - Strongly Disagree (7-Point Likert Scale)

[C15] Taking the LEED AP exam means to avoid being criticized.

Answer Format: Strongly Agree - Strongly Disagree (7-Point Likert Scale)

[C16] Taking the LEED AP exam means getting recognition from others.

Answer Format: Strongly Agree - Strongly Disagree (7-Point Likert Scale)

[C17] Taking the LEED AP exam is a sensible thing to do.

Answer Format: Strongly Agree - Strongly Disagree (7-Point Likert Scale)

[C18] It is a good idea to take the LEED AP exam

Answer Format: Strongly Agree - Strongly Disagree (7-Point Likert Scale)

[C19] Taking the LEED AP exam is a natural thing to do.

Answer Format: Strongly Agree - Strongly Disagree (7-Point Likert Scale)

[C20] Taking the LEED AP exam is/ would be a sign of my professional attitude towards sustainable construction practices

Answer Format: Strongly Agree - Strongly Disagree (7-Point Likert Scale) 


\section{Questionnaire Diffusion of Innovation (Chapter 10) and Information Behavior (Chapter 11)- The Netherlands}

\begin{tabular}{l} 
[A1] Wat is uw huidige functie? \\
CEO/Directeur \\
Afdelingshoofd \\
Milieu Manager \\
\hline
\end{tabular}

[A2] Hoeveel werknemers zijn er momenteel werkzaam in uw organisatie? (Voltijds and deeltijds)
$0-50$
$51-100$
$101-500$
$>500$

[A12]In welke stad is uw bedrijf gevestigd?

Open ended format

\begin{tabular}{l}
\hline [A4]Hoeveel jaar professionele werkervaring heeft $u$ ? \\
\hline $0-5$ \\
$6-10$ \\
$11-15$ \\
$>15$ \\
\hline
\end{tabular}

[A5] Hoeveel jaar werkt $\mathrm{u}$ in uw huidige bedrijf?

$0-5$

6-10

$11-15$

$>15$ 
[A6]Binnen uw huidige bedrijf, hoeveel jaar werkt $\mathrm{u}$ in uw huidige functie?

$0-5$

6-10

$11-15$

$>15$

[A7]Wat is uw hoogst afgeronde opleiding

Basis School

Lager beroepsonderwijs (VMBO)

Voortgezet onderwijs (HAVO-MAVO-VWO)

HBO-Bachelor

HBO-Master

Universiteit-Bachelor

Universiteit-Master

Anders

[A9]Binnen welke sector opereert uw bedrijf?

Services

Manufactuur

[A10] In welk jaar is uw bedrijf opgestart?

Open ended

[A11]In welk deel van de organisatie bent u werkzaam?

Hoofdkantoor van een internationaal bedrijf

Hoofdkantoor van een Nederlands bedrijf

Filiaal/ nevenlocatie van een internationaal bedrijf

Filiaal/ nevenlocatie van een Nederlands bedriijf

[B1a] Heeft uw bedrijf een Milieumanagementsysteem?

[B1a] Heeft uw bedrijf een Energiemanagementsysteem?

$\mathrm{Ja}$

Nee

Weet Niet 
[B2] Is uw bedrijf gecertificeerd op basis van...

ISO 14001

EMAS

ISO 50001

EN 16001

Niet gecertificeerd

Anders

[B3]Zo ja, in welk jaar?

ISO 14001 :

EMAS :

ISO 50001:

Weet niet

[B4a]Is uw bedrijf gewisseld of van plan te wisselen van certificering van ISO 14001 naar EMAS

[B4b]Is uw bedrijf gewisseld of van plan te wisselen van certificering van EMAS naar ISO 14001

[B4c] Is uw bedrijf gewisseld of van plan te wisselen van certificering van ISO 50001 naar EN 16001

[B4d] ]Is uw bedrijf gewisseld of van plan te wisselen van certificering van EN 16001 naar ISO 50001

$\mathrm{Ja}$

Nee

Niet van toepassing

[B5] Hoe innovatief denkt $u$ dat uw bedrijf is in milieu aangelegenheden, in vergelijking tot andere bedrijven in uw sector?

Heel innovatief

Boven gemiddeld innovatief

Gemiddeld innovatief

Onder gemiddeld innovatief

Niet innovatief 
[B6a]Hoe belangrijk is het voor uw bedrijf om een Milieumanagementsysteem te hebben?

[B6b]Hoe belangrijk is het voor uw bedrijf om een Energiemanagementsysteem te hebben?

Heel belangriijk

Belangrijk

Neutraal

Niet belangrijk

Weet niet

[B8a] Hoe invloedrijk zijn of waren de gewoonten van andere bedrijven bij uw keuze voor certificering van een Milieumanagementsysteem?

[B8b]Hoe invloedrijk zijn of waren de gewoonten van andere bedrijven bij uw keuze voor certificering van een Milieumanagementsysteem?

Heel belangriijk

Belangrijk

Neutraal

Niet belangrijk

Weet niet

[B10a]Hoe invloedrijk zijn of waren de gewoonten van anderen bedrijven bij uw keuze te certificeren op basis van ISO14001?

[B10b]Hoe invloedrijk zijn of waren de gewoonten van anderen bedrijven bij uw keuze te certificeren op basis van EMAS?

$[\mathrm{B} 10 \mathrm{c}]$ Hoe invloedrijk zijn of waren de gewoonten van anderen bedrijven bij uw keuze te certificeren op basis van ISO50001?

[B10d]Hoe invloedrijk zijn of waren de gewoonten van anderen bedrijven bij uw keuze te certificeren op basis van EN16001?

Heel belangriijk

Belangrijk

Neutraal

Niet belangrijk

Weet niet 
[B11a] ISO 14001 is een belangrijk instrument om bedrijven milieu en energie bewust te laten opereren.

[B11b] EMAS is een belangrijk instrument om bedrijven milieu en energie bewust te laten opereren.

[B11c] ISO50001 is een belangrijk instrument om bedrijven milieu en energie bewust te laten opereren.

[B11d] EN16001 is een belangrijk instrument om bedrijven milieu en energie bewust te laten opereren.

Volledig mee eens

Mee eens

Neutraal

Mee oneens

Weet niet

[B12a]Certificering op basis van ISO14001 is vrijwillig

[B12b]Certificering op basis van EMAS is vrijwillig

[B12c]Certificering op basis van ISO50001 is vrijwillig

[B12d]Certificering op basis van EN16001 is vrijwillig

Volledig mee eens

Mee eens

Neutraal

Mee oneens

Weet niet

[B13a] ISO 14001 is niet verplicht in mijn industrie.

[B13b] EMAS is niet verplicht in mijn industrie.

[B13c] ISO50001 is niet verplicht in mijn industrie.

[B13d] EN16001 is niet verplicht in mijn industrie.

Volledig mee eens

Mee eens

Neutraal

Mee oneens

Weet niet 
[B14]Wat houdt $\mathrm{u}$ of hield $\mathrm{u}$ tegen om met Energiemanagementsystee, ISO14001/EMAS/ISO50001/EN16001 te certificeren? (Kies een antwoord)

Financiële Beperkingen

Tijdsbeperkingen

Organisatorische redenen

Gebreek an kennis bij het anweezige personeel

Onzekerheid (economisch)

Niet van toepassing

[B15a] Welke vaardigheden zijn nodig om te certificeren op basis van ISO 14001 [B15b] Welke vaardigheden zijn nodig om te certificeren op basis van EMAS

[B15c] Welke vaardigheden zijn nodig om te certificeren op basis van ISO50001

[B15d] Welke vaardigheden zijn nodig om te certificeren op basis van EN16001

Open ended

[B16a]Welke certificering is volgens u superieur voor milieu management systemen?

[B16b]Welke certificering is volgens u superieur voor energie management systemen?

ISO 14001

EMAS

ISO 50001

EN 16001 
[B18a]De voordelen van certificering op basis van ISO14001 zijn groter dan de nadelen.

[B18b]De voordelen van certificering op basis van EMAS zijn groter dan de nadelen.

[B18c]De voordelen van certificering op basis van ISO 50001 zijn groter dan de nadelen.

[B18d]De voordelen van certificering op basis van EN16001 zijn groter dan de nadelen.

Volledig mee eens

Mee eens

Neutraal

Mee oneens

Weet niet

[B19a]Ik denk dat het certificeren op basis van ISO 14001 positief is/zou zijn voor mijn bedrijf.

[B19b]Ik denk dat het certificeren op basis van EMAS positief is/zou zijn voor mijn bedrijf.

[B19c]Ik denk dat het certificeren op basis van ISO 50001 positief is/zou zijn voor mijn bedrijf.

[B19d]Ik denk dat het certificeren op basis van EN16001 positief is/zou zijn voor mijn bedrijf.

Volledig mee eens

Mee eens

Neutraal

Mee oneens

Weet niet

[B20a]Ik denk dat ISO 14001 integreerbaar is of zou zijn voor mijn bedrijf.

[B20b]Ik denk dat EMAS integreerbaar is of zou zijn voor mijn bedrijf.

[B20c]Ik denk dat ISO 50001 integreerbaar is of zou zijn voor mijn bedrijf.

[B20d]Ik denk dat EN16001 integreerbaar is of zou zijn voor mijn bedrijf.

Volledig mee eens

Mee eens

Neutraal

Mee oneens

Weet niet 
[B21a]Ik denk dat certificering op basis van ISO14001 een makkelijk proces is/zou zijn.

[B21b]Ik denk dat certificering op basis van EMAS een makkelijk proces is/zou zijn.

[B21c]Ik denk dat certificering op basis van ISO50001 een makkelijk proces is/zou zijn.

[B21d]Ik denk dat certificering op basis van EN16001 een makkelijk proces is/zou zijn.

Volledig mee eens

Mee eens

Neutraal

Mee oneens

Weet niet

[B22a]Ik denk dat ik andere mensen kan uitleggen wat de resultaten van certificering op basis van ISO 14001 zijn.

[B22b]Ik denk dat ik andere mensen kan uitleggen wat de resultaten van certificering op basis van EMAS zijn.

[B22c]Ik denk dat ik andere mensen kan uitleggen wat de resultaten van certificering op basis van ISO 50001 zijn.

[B22d]Ik denk dat ik andere mensen kan uitleggen wat de resultaten van certificering op basis van EN16001 zijn.

Volledig mee eens

Mee eens

Neutraal

Mee oneens

Volledig mee oneens

Weet niet

[B23a]Weet $\mathrm{u}$ wat de ervaringen van andere bedrijven met ISO14001 zijn?

[B23b]Weet $\mathrm{u}$ wat de ervaringen van andere bedrijven met EMAS zijn?

[B23c]Weet $u$ wat de ervaringen van andere bedrijven met ISO50001 zijn?

[B23d]Weet $u$ wat de ervaringen van andere bedrijven met EN16001 zijn?

ja

nee 
[B24a]Heeft de ervaring van andere bedrijven een rol gespeeld bij de tijdskeuze van certificering op basis van ISO14001?

[B24a]Heeft de ervaring van andere bedrijven een rol gespeeld bij de tijdskeuze van certificering op basis van EMAS?

[B24a]Heeft de ervaring van andere bedrijven een rol gespeeld bij de tijdskeuze van certificering op basis van ISO 50001?

[B24a]Heeft de ervaring van andere bedrijven een rol gespeeld bij de tijdskeuze van certificering op basis van EN16001?

$\mathrm{Ja}$

Nee

Weet niet

Niet van toepassing

[B25a]Het implementeren van een milieu management systeem is een testfase voor certificeren op basis van ISO14001.

[B25b] Het implementeren van een milieu management systeem is een testfase voor certificeren op basis van EMAS.

[B25c]Het implementeren van een milieu management systeem is een testfase voor certificeren op basis van ISO50001.

[B25d]Het implementeren van een milieu management systeem is een testfase voor certificeren op basis van EN16001.

Volledig mee eens

Mee eens

Neutraal

Mee oneens

Weet niet

[B26a]In mijn organisatie is ISO 14001 erg zichtbaar.

[B26b]In mijn organisatie is EMAS erg zichtbaar.

[B26c]In mijn organisatie is ISO 50001 erg zichtbaar.

[B26d]In mijn organisatie is EN16001 erg zichtbaar.

Volledig mee eens

Mee eens

Neutraal

Mee oneens

Weet niet 
[C23a] Geeft $\mathrm{u}$ aub vijf organisaties aan die $\mathrm{u}$ heeft geraadpleegd (of die voor $\mathrm{u}$ van belang zijn/waren) tijdens de beslissing om ISO 14001 certificering aan te vragen. Als $u$ geen organisatie heeft geraadpleegd, hoeft $u$ niet te antwoorden [C23b] Geeft $\mathrm{u}$ aub vijf organisaties aan die $\mathrm{u}$ heeft geraadpleegd (of die voor $\mathrm{u}$ van belang zijn/waren) tijdens de beslissing om EMAS certificering aan te vragen. Als u geen organisatie heeft geraadpleegd, hoeft $\mathrm{u}$ niet te antwoorden [C23c] Geeft $\mathrm{u}$ aub vijf organisaties aan die $\mathrm{u}$ heeft geraadpleegd (of die voor $\mathrm{u}$ van belang zijn/waren) tijdens de beslissing om ISO50001 certificering aan te vragen. Als u geen organisatie heeft geraadpleegd, hoeft $u$ niet te antwoorden [C23d] Geeft $u$ aub vijf organisaties aan die $u$ heeft geraadpleegd (of die voor $u$ van belang zijn/waren) tijdens de beslissing om EN16001 certificering aan te vragen. Als u geen organisatie heeft geraadpleegd, hoeft $u$ niet te antwoorden

Open ended

[C27a]Geeft $\mathrm{u}$ aub voor elk van de 5 bovengenoemde relaties aan welke samenwerkingsvorm uw voorkeur heeft betreffende informatie uitwisseling over ISO 14001 ?

[C27b]Geeft $\mathrm{u}$ aub voor elk van de 5 bovengenoemde relaties aan welke samenwerkingsvorm uw voorkeur heeft betreffende informatie uitwisseling over EMAS?

[C27c] Geeft $\mathrm{u}$ aub voor elk van de 5 bovengenoemde relaties aan welke samenwerkingsvorm uw voorkeur heeft betreffende informatie uitwisseling over ISO 50001?

[C27d] Geeft $\mathrm{u}$ aub voor elk van de 5 bovengenoemde relaties aan welke samenwerkingsvorm uw voorkeur heeft betreffende informatie uitwisseling over EN16001?

Email

Personlijke Contacten

Telefoon

Bedrijfsbijenkomsten

Niet van toepassing 
[C2a]Heeft u contact gehad met een of meerdere van de volgende organisaties? (ISO14001)

[C2b]Heeft $\mathrm{u}$ contact gehad met een of meerdere van de volgende organisaties? (EMAS)

[C2c]Heeft $\mathrm{u}$ contact gehad met een of meerdere van de volgende organisaties? (ISO50001)

[C2d]Heeft $\mathrm{u}$ contact gehad met een of meerdere van de volgende organisaties? (EN16001)

\section{NEN}

Bedrijven belangengroepen

Managers in bedrijven in een andere sector/industrie

Managers in andere bedrijven in uw sector/industrie

Auditoren

SCCM

Kamer van Koophandel

Ambtenaren en consultants van gemeenten

Ambtenaren van provincies

Ambtenaren van het ministerie van economische zaken, landbouw en innovatie Ambtenaren van het ministerie van infrastructuur en milieu

Europese Commissie

Milieu consultants 
[C3] Hoe vaak heeft $\mathrm{u}$ contact gehad met deze bronnen betreffende milieu en energie gerelateerde zaken?

Niet van toepassing/elke paar maanden/Een of tweemaal in de laatste twee maanden/Eens per week of eens per twee weken/Meerdere malen per week

\section{NEN}

Bedrijven belangengroepen

Managers in bedrijven in een andere sector/industrie

Managers in andere bedrijven in uw sector/industrie

Auditoren

SCCM

Kamer van Koophandel

Ambtenaren en consultants van gemeenten

Ambtenaren van provincies

Ambtenaren van het ministerie van economische zaken, landbouw en innovatie Ambtenaren van het ministerie van infrastructuur en milieu

Europese Commissie

Milieu consultants 
[C4a]Hoe belangrijk zijn of waren deze bronnen voor uw beslissing ISO 14001 certificering aan te vragen?

[C4b]Hoe belangrijk zijn of waren deze bronnen voor uw beslissing ISO 14001 certificering aan te vragen?

[C4c]Hoe belangrijk zijn of waren deze bronnen voor uw beslissing ISO 14001 certificering aan te vragen?

[C4d]Hoe belangrijk zijn of waren deze bronnen voor uw beslissing ISO 14001 certificering aan te vragen?

Heel belangrijk/Belangrijk/Neutral/ Niet belangrijk/Geheel niet belangrijk

\section{NEN}

Bedrijven belangengroepen

Managers in bedrijven in een andere sector/industrie

Managers in andere bedrijven in uw sector/industrie

Auditoren

SCCM

Kamer van Koophandel

Ambtenaren en consultants van gemeenten

Ambtenaren van provincies

Ambtenaren van het ministerie van economische zaken, landbouw en innovatie Ambtenaren van het ministerie van infrastructuur en milieu

Europese Commissie

Milieu consultants 
[C10a $]$ Hoe goed is elk van de onderstaande organisaties in staat $u$ te informeren over ISO 14001?

$[\mathrm{C} 10 \mathrm{~b}]$ Hoe goed is elk van de onderstaande organisaties in staat $\mathrm{u}$ te informeren over EMAS?

[C10b]Hoe goed is elk van de onderstaande organisaties in staat $u$ te informeren over ISO50001?

[C10b]Hoe goed is elk van de onderstaande organisaties in staat $u$ te informeren over EN16001?

Heel effectief/Effectief/ Neutral/ Niet effectief/ Geheel niet effectief

\section{NEN}

Bedrijven belangengroepen

Managers in bedrijven in een andere sector/industrie

Managers in andere bedrijven in uw sector/industrie

Auditoren

SCCM

Kamer van Koophandel

Ambtenaren en consultants van gemeenten

Ambtenaren van provincies

Ambtenaren van het ministerie van economische zaken, landbouw en innovatie Ambtenaren van het ministerie van infrastructuur en milieu

Europese Commissie

Milieu consultants

[C12]Wie geeft u normaliter informatie over milieu en energie management?

Managers van bedrijven in uw sector/industrie

Managers van bedrijven buiten uw sector/industrie

Consultants

Ambtenaren van gemeenten

Ambtenaren van provincies

Andere betrokkenen

Niemand

Anders: 
[C13] Heeft $\mathrm{u}$ een training gevolgd of materialen opgevraagd voor implementatie van ISO14001/16001/EMAS/EN16001?

Training gevolgd bij NEN

Training gevolgd bij een andere organisatie

Materialen betreffende ISO 14004 (algemene richtlijnen voor de principes, systemen en ondersteunende technieken)

Materialen betreffende ISO 19011 (richtlijnen voor het uitvoeren van kwaliteits en/of milieu management systeem audits)

NEN praktijkgids "Werken met ISO 14001"

Anders:

Niemand

Anders:

[C14] Welke publicaties van NEN heeft u gebruikt bij de implementatie en certificering van ISO14001/16001/EMAS/EN16001?

ISO 14004 norm (Algemene richtlijnen voor de principes, systemen en ondersteunende technieken)

SCCM informatie bladen

ISO 19011 norm (Richtlijnen voor het uitvoeren van kwaliteits- en/of milieu management systeem audits)

ISO 14050 norm (verklarende woordenlijst milieumanagement)

Andere:

Andere betrokkenen

Niemand

Anders:

[C15] Welk deel van de voorbereiding van certificering was het moeilijkste voor uw bedrijf?

Milieu aspecten analyse

De identificatie van wettelijke verplichtingen

Interne milieu audits

Opzetten van documentatiesysteem 
Questionnaire Diffusion of Innovation (Chapter 10) and Information Behavior (Chapter 11)- Germany

\begin{tabular}{l}
\hline A1] Ihre Funktion im Unternehmen ist... \\
\hline Unternehmensleiter/Geschaeftsfuehrer \\
Abteilungsleiter \\
Umweltmanager/Umweltbeauftragter \\
Andere Funktion:
\end{tabular}

\begin{tabular}{l}
\hline A2] Anzahl der Beschaeftigten \\
\hline $0-50$ \\
$51-100$ \\
$101-500$ \\
$>500$ \\
\hline
\end{tabular}

[A4] Berufserfahrung (in Jahren):

0-5

6-10

11-15

$>15$

[A5] Seit wievielen Jahren arbeiten Sie schon in diesem Unternehmen?

0-5

6-10

11-15

$>15$

[A6] Seit wievielen Jahren arbeiten Sie in der aktuellen Position in diesem Unternehmen?

$0-5$

6-10

11-15

$>15$ 
[A7] Welche Ausbildung haben Sie abgeschlossen?

Ausbildung

Bachelor (FH)

Bachelor (Uni)

Master (FH)

Master (Uni)

Diplom (FH)

Doktortitel

[A8]Welcher Altersgruppe gehoeren Sie an?

20-30

$31-40$

$41-50$

$>50$

[A9] In welcher Branche ist Ihr Unternehmen taetig?

Dienstleistungen

Produktionsorientiert

[A10] In welchem Jahr wurde dieses Unternehmen gegruendet? ${ }^{*}$

Open ended

[A11] In welchem Teil des Unternehmes arbeiten Sie?

Stammsitz eines auslaendischen Unternehmens

Stammsitz eines deutschen Unternehmens

Filiale eines auslaendischen Unternehmens

Filiale eines deutschen Unternehmens

[B1]Ist in diesem Unternehmen ein Umweltmanagementsystem installiert?

[B1]Ist in diesem Unternehmen ein Energiemanagementsystem installiert?

Ja

Nein

Weiss nicht 
[B2] Ist ihr Unternehmen zertifiziert auf Basis von....

ISO 14001

EMAS

ISO 50001

EN 16001

[B3] Falls ihr Unternehmen ein Umwelt oder Energiemanagementsystem zertifiziert hat, in welchem Jahr wurde die Zertifizierung ausgestellt?

Open ended

[B4] Hat ihr Unternehmen je ein Managementsystem gewechselt oder plant zu wechseln?

$\mathrm{Ja} /$ Nein/Weiss nicht

von ISO $14001 \mathrm{zu}$ EMAS

von EMAS zu ISO 14001

von ISO $50001 \mathrm{zu}$ EN 16001

von EN $16001 \mathrm{zu}$ ISO 50001

[B5]Nach ihrer Einschaetzung, wie innovativ ist Ihr Unternehmen im Bereich Umweltschutz im Vergleich mit anderen Unternehmen der Branche?

Sehr innovativ

Innovativ

Weder noch

Nicht innovativ

Ueberhaupt nicht innovativ

Answer Format: Strongly Agree - Strongly Disagree (7-Point Likert Scale) 
[B6a] Wie wichtig ist fuer ihr Unternehmen die Installation eines

Umweltmanagementsystems?

[B6b] Wie wichtig ist fuer ihr Unternehmen die Installation eines

Energiemanagementsystems?

Sehr wichtig

Wichtig

Weder noch

Unwichtig

Ueberhapt nicht wichtig

[B7a] Wie wichtig ist es fuer ihr Unternehmen mit einem

Umweltmanagementystem zertifiziert zu sein?

[B7b] Wie wichtig ist es fuer ihr Unternehmen mit einem

Energiemanagementystem zertifiziert zu sein?

Sehr wichtig

Wichtig

Weder noch

Unwichtig

Ueberhapt nicht wichtig

Weiss nicht

[B8a] Wie einflussreich sind oder waren die Praktiken anderer Unternehmen bei der Auswahl des Umweltmanagementsystems?

[B8b] Wie einflussreich sind oder waren die Praktiken anderer Unternehmen bei der Auswahl des Energiemanagementsystems?

Sehr einflussreich

Einflussreich

Weder noch

Nicht einflussreich

Ueberhaupt nicht einflussreich

Weiss nicht 
[B10a]Wie einflussreich sind oder waren die Praktiken anderer Unternehmen bei der Wahl ISO 14001 Zertifizierung zu erlangen?

[B10b]Wie einflussreich sind oder waren die Praktiken anderer Unternehmen bei der Wahl EMAS Zertifizierung zu erlangen?

[B10c]Wie einflussreich sind oder waren die Praktiken anderer Unternehmen bei der Wahl ISO 50001 Zertifizierung zu erlangen?

[B10d]Wie einflussreich sind oder waren die Praktiken anderer Unternehmen bei der Wahl EN16001 Zertifizierung zu erlangen?

Sehr einflussreich

Einflussreich

Weder noch

Nicht einflussreich

Ueberhaupt nicht einflussreich

Weiss nicht

[B11a] ISO 14001 ist ein wichtiges Instrument um Unternehmen Umwelt-und Energiemanagement bewusst zu machen

[B11b] EMAS ist ein wichtiges Instrument um Unternehmen Umwelt-und

Energiemanagement bewusst zu machen

[B11c] ISO 50001 ist ein wichtiges Instrument um Unternehmen Umwelt-und Energiemanagement bewusst zu machen

[B11d] EN 16001 ist ein wichtiges Instrument um Unternehmen Umwelt-und Energiemanagement bewusst zu machen

Stimme voll zu

Stimme zu

Weder noch

Stimme nicht zu

Stimme ueberhaupt nicht zu

Weiss nicht 
[B12a] Zertifizierung mit ISO 14001 geschieht auf freiwilliger Basis

[B12b] Zertifizierung mit EMAS geschieht auf freiwilliger Basis

[B12c] Zertifizierung mit ISO 50001 geschieht auf freiwilliger Basis

[B12d] Zertifizierung mit EN16001 geschieht auf freiwilliger Basis

Stimme voll zu

Stimme zu

Weder noch

Stimme nicht zu

Stimme ueberhaupt nicht zu

Weiss nicht

[B13a] ISO 14001 Zertifizierung ist in diesem Sektor nicht unbedingt notwendig. [B13b] EMAS Zertifizierung ist in diesem Sektor nicht unbedingt notwendig.

[B13c] ISO 50001 Zertifizierung ist in diesem Sektor nicht unbedingt notwendig. [B13d] EN 16001 Zertifizierung ist in diesem Sektor nicht unbedingt notwendig.

Stimme voll zu

Stimme zu

Weder noch

Stimme nicht zu

Stimme ueberhaupt nicht zu

Weiss nicht

[B14a]Aus welchem Grund ist ihr Unternehmen nicht mit ISO 14001 zertifiziert? [B14b]Aus welchem Grund ist ihr Unternehmen nicht mit EMAS zertifiziert?

[B14c]Aus welchem Grund ist ihr Unternehmen nicht mit ISO 50001 zertifiziert?

[B14d]Aus welchem Grund ist ihr Unternehmen nicht mit EN 16001 zertifiziert?

Finanzielle Aspekte

Zeitmangel

Organisatorische Probleme

Mangel an fachkundigem Personal

Wirtschaftliche Unsicherheit

Probleme sich fuer ein System zu entscheiden

Sonstiges 
[B15a] Welche spezifischen Qualifikationen oder Faehigkeiten sind notwendig um ISO 14001 Zertifizierung zu erlangen?

[B15b] Welche spezifischen Qualifikationen oder Faehigkeiten sind notwendig um EMAS Zertifizierung zu erlangen?

[B15c] Welche spezifischen Qualifikationen oder Faehigkeiten sind notwendig um ISO 50001 Zertifizierung zu erlangen?

[B15d] Welche spezifischen Qualifikationen oder Faehigkeiten sind notwendig um EN16001 Zertifizierung zu erlangen?

Open ended

[B16a] Welches Umweltmanagementzertifizierungssystem ist Ihrer Meinung nach das Bessere?

[B16b] Welches Energiemanagementzertifizierungssystem ist Ihrer Meinung nach das Bessere?

ISO 14001

EMAS

ISO 50001

EN 16001

[B17a] Aus welchem Grund sind Sie der Ansicht dass ISO 14001 das beste

Zertifizierungssystem darstellt?

[B17b] Aus welchem Grund sind Sie der Ansicht dass EMAS das beste

Zertifizierungssystem darstellt?

[B17c] Aus welchem Grund sind Sie der Ansicht dass ISO 50001 das beste

Zertifizierungssystem darstellt?

[B17d] Aus welchem Grund sind Sie der Ansicht dass ISO EN 16001 das beste Zertifizierungssystem darstellt?

Open ended 
[B18a]Die Vorteile der ISO 14001 Managementsystemzertifizierung sind groesser als die Nachteile.

[B18b]Die Vorteile der EMAS Managementsystemzertifizierung sind groesser als die Nachteile.

[B18c]Die Vorteile der ISO 50001 Managementsystemzertifizierung sind groesser als die Nachteile.

[B18d]Die Vorteile der EN 16001 Managementsystemzertifizierung sind groesser als die Nachteile.

Stimme voll zu

Stimme zu

Weder noch

Stimme nicht zu

Stimme ueberhaupt nicht zu

Weiss nicht

[B19a] Ich bin der Ansicht dass ISO 14001 Zertifizierung fuer mein Unternehmen positiv ist/sein wird.

[B19b] Ich bin der Ansicht dass EMAS Zertifizierung fuer mein Unternehmen positiv ist/sein wird.

[B19c] Ich bin der Ansicht dass ISO 50001 Zertifizierung fuer mein Unternehmen positiv ist/sein wird.

[B19d] Ich bin der Ansicht dass ISO 16001 Zertifizierung fuer mein Unternehmen positiv ist/sein wird.

Stimme voll zu

Stimme zu

Weder noch

Stimme nicht $\mathrm{zu}$

Stimme ueberhaupt nicht zu

Weiss nicht 
[B21a] Ich bin der Ansicht, dass der ISO 14001 Zertifizierungsprozess einfach ist/sein wird.

[B21b] Ich bin der Ansicht, dass der EMAS Zertifizierungsprozess einfach ist/sein wird.

[B21c] Ich bin der Ansicht, dass der ISO 50001 Zertifizierungsprozess einfach ist/sein wird.

[B21d] Ich bin der Ansicht, dass der EN 16001 Zertifizierungsprozess einfach ist/sein wird.

Stimme voll zu

Stimme zu

Weder noch

Stimme nicht zu

Stimme ueberhaupt nicht zu

Weiss nicht

[B22a]Ich denke dass ich anderen Mitarbeitern die Resultate einer ISO 14001

Zertifizierung erklaeren kann.

[B22b]Ich denke dass ich anderen Mitarbeitern die Resultate einer EMAS

Zertifizierung erklaeren kann.

[B22c]Ich denke dass ich anderen Mitarbeitern die Resultate einer ISO 50001

Zertifizierung erklaeren kann.

[B22d]Ich denke dass ich anderen Mitarbeitern die Resultate einer EN 16001

Zertifizierung erklaeren kann.

Stimme voll zu

Stimme zu

Weder noch

Stimme nicht zu

Stimme ueberhaupt nicht zu

Weiss nicht 
[B23a]Haben Sie Informationen betreffend der Erfahrungen anderer Unternehmen mit ISO 14001?

[B23b] Haben Sie Informationen betreffend der Erfahrungen anderer Unternehmen mit EMAS?

[B23c] Haben Sie Informationen betreffend der Erfahrungen anderer Unternehmen mit ISO 50001?

[B23d] Haben Sie Informationen betreffend der Erfahrungen anderer Unternehmen mit EN16001?

Ja

Nein

Weiss nicht

[B24a] Hat/ Hatte die Erfahrung anderer Betriebe Einfluss auf die Zeitpunktwahl der ISO 14001 Zertifizierung?

[B24b] Hat/ Hatte die Erfahrung anderer Betriebe Einfluss auf die Zeitpunktwahl der EMAS Zertifizierung?

[B24c] Hat/ Hatte die Erfahrung anderer Betriebe Einfluss auf die Zeitpunktwahl der ISO 50001 Zertifizierung?

[B24d] Hat/ Hatte die Erfahrung anderer Betriebe Einfluss auf die

Zeitpunktwahl der EN 16001 Zertifizierung?

Ja

Nein

Weiss nicht

Trifft nicht zu, da keine Zertifizierung

[B25a] Die Implementierung eines ISO 14001 basierten Managementsystemes kann als Testphase vor dem Zertifizierungsprozess angesehen werden.

[B25b] Die Implementierung eines EMAS basierten Managementsystemes kann als Testphase vor dem Zertifizierungsprozess angesehen werden.

[B25c] Die Implementierung eines ISO 50001 basierten Managementsystemes kann als Testphase vor dem Zertifizierungsprozess angesehen werden.

[B25d] Die Implementierung eines EN 16001 basierten Managementsystemes kann als Testphase vor dem Zertifizierungsprozess angesehen werden.

Ja

Nein

Weiss nicht

Trifft nicht zu, da keine Zertifizierung 
[B26a] In diesem Unternehmen ist ISO $14001 \mathrm{im}$ Unternehmensablauf sichtbar. [B26b] In diesem Unternehmen ist EMAS im Unternehmensablauf sichtbar.

[B26c] In diesem Unternehmen ist ISO 50001 im Unternehmensablauf sichtbar. [B26d] In diesem Unternehmen ist EN $16001 \mathrm{im}$ Unternehmensablauf sichtbar.

Stimme voll zu

Stimme zu

Weder noch

Stimme nicht zu

Stimme ueberhaupt nicht zu

Weiss nicht

[C23a] Geben Sie bitte 5 Organisationen an, welche waehrend des ISO 14001

Zertifizierungsprozesses belangreich sind/waren.

[C23b] Geben Sie bitte 5 Organisationen an, welche waehrend des EMAS

Zertifizierungsprozesses belangreich sind/waren.

[C23c] Geben Sie bitte 5 Organisationen an, welche waehrend des ISO 50001

Zertifizierungsprozesses belangreich sind/waren.

[C23d] Geben Sie bitte 5 Organisationen an, welche waehrend des EN 16001

Zertifizierungsprozesses belangreich sind/waren.

List 5 Organisations 
[C27a] Geben Sie bitte fuer jede der obengenannten Organisationen an, welche Methoden des Informationsaustauschs bezueglich ISO 14001 belangreich sind/waren?

[C27b] Geben Sie bitte fuer jede der obengenannten Organisationen an, welche Methoden des Informationsaustauschs bezueglich EMAS belangreich sind/waren?

[C27c] Geben Sie bitte fuer jede der obengenannten Organisationen an, welche Methoden des Informationsaustauschs bezueglich ISO 50001 belangreich sind/waren?

[C27d] Geben Sie bitte fuer jede der obengenannten Organisationen an, welche Methoden des Informationsaustauschs bezueglich EN 16001 belangreich sind/waren?

Email

Persoenliche meetings

Telefonische Kontakte

Unternehmensmeetings

Sonstige

Trifft nicht zu

[C2] Waren oder sind Sie bezueglich Umwelt-und Energiethemen in Kontakt mit einer oder mehreren der folgenden Organisationen?

Unternehmensverbaende

Manager in Unternehmen der selben Branche wie ihr Unternehmen

Manager in Unternehmen anderer Branchen

Auditoren

Handelskammervertretern

Gemeindevertretern

Beauftragte der Laender

Beauftragte des Wirtschaftsministerium

Beauftragte des Umweltministeriums

Beauftragte der Europaeischen Kommission

Sonstiges: 
[C3] Wie oft waren oder sind Sie in Kontakt mit diesen Organsationen Umwelt-und Energiethemen betreffend?

Alle paar Monate/Ein-oder zweimal im Monat/ Alle vierzehn Tage/Mehrmals pro Woche/ Nicht zutreffend

Unternehmensverbaende

Manager in Unternehmen der selben Branche wie ihr Unternehmen

Manager in Unternehmen anderer Branchen

Auditoren

Handelskammervertretern

Gemeindevertretern

Beauftragte der Laender

Beauftragte des Wirtschaftsministerium

Beauftragte des Umweltministeriums

Beauftragte der Europaeischen Kommission

Sonstiges:

[C4a]Wie wichtig waren/sind diese Kontakte fuer die Entscheidung ISO 14001

Zertifizierung einzuleiten

[C4b]Wie wichtig waren/sind diese Kontakte fuer die Entscheidung EMAS

Zertifizierung einzuleiten

[C4c]Wie wichtig waren/sind diese Kontakte fuer die Entscheidung ISO 50001

Zertifizierung einzuleiten

[C4d]Wie wichtig waren/sind diese Kontakte fuer die Entscheidung EN 16001

Zertifizierung einzuleiten

Sehr wichtig/Wichtig/Weder noch/Unwichtig/Ueberhaupt nicht wichtig/ Nicht zutreffend

Unternehmensverbaende

Manager in Unternehmen der selben Branche wie ihr Unternehmen

Manager in Unternehmen anderer Branchen

Auditoren

Handelskammervertretern

Gemeindevertretern

Beauftragte der Laender

Beauftragte des Wirtschaftsministerium

Beauftragte des Umweltministeriums

Beauftragte der Europaeischen Kommission

Sonstiges: 
[C10] Wie effektiv ist/war jede der aufgelisteten Organisationen im Bereich des Informationsaustausches?

Sehr effektiv/Effektiv/Weder noch/Ineffektiv/Sehr ineffektiv/Nicht zutreffend

Unternehmensverbaende

Manager in Unternehmen der selben Branche wie ihr Unternehmen

Manager in Unternehmen anderer Branchen

Auditoren

Handelskammervertretern

Gemeindevertretern

Beauftragte der Laender

Beauftragte des Wirtschaftsministerium

Beauftragte des Umweltministeriums

Beauftragte der Europaeischen Kommission

Umweltconsultants

Sonstiges:

[C12] Mit welchen Personen tauschen Sie sich normalerweise betreffend

Umwelt-und Energiethemen aus?

Manager in Unternehmen der selben Branche wie ihr Unternehmen

Manager in Unternehmen anderer Branchen

Consultants

Gemeindevertretern

Beauftragte der Laender

Niemand

Sonstige: 
[C13a]Haben Sie einen Trainingskursus absolviert oder andere Materialien angefordert betreffend einer ISO 14001 Implementierung und/oder

Zertifizierung?

[C13b] Haben Sie einen Trainingskursus absolviert oder andere Materialien angefordert betreffend einer EMAS Implementierung und/oder Zertifizierung? [C13c] Haben sie einen Trainingskursus absolviert oder andere Materialien angefordert betreffend einer ISO 50001 Implementierung und/oder Zertifizierung?

[C13d]Haben Sie einen Trainingskursus absolviert oder andere Materialien angefordert betreffend einer EN 16001 Implementierung und/oder Zertifizierung?

Trainingsprogramm

Broschueren

Sonstiges:

[C16a] Welche Aspekte des ISO 14001 Zertifizierungsprozesses halten/hielten ihr Unternehmen von der Zertifizierung ab?

[C16b] Welche Aspekte des ISO 14001 Zertifizierungsprozesses halten/hielten ihr Unternehmen von der Zertifizierung ab?

[C16c] Welche Aspekte des ISO 14001 Zertifizierungsprozesses halten/hielten ihr Unternehmen von der Zertifizierung ab?

[C16d] Welche Aspekte des ISO 14001 Zertifizierungsprozesses halten/hielten ihr Unternehmen von der Zertifizierung ab?

Umweltaspektenanalyse

Identifizierung der genauen gesetzlichen Verpflichtungen

Interne Umweltaudits

Das Einrichten eines Dokumentationssystems

Sonstiges: 
[C15a] Welche Aspekte des ISO 14001 Zertifizierungsprozesses waren/sind fuer Ihr Unternehmen am schwierigsten umzusetzen?

[C15b] Welche Aspekte des EMAS Zertifizierungsprozesses waren/sind fuer Ihr Unternehmen am schwierigsten umzusetzen?

[C15c] Welche Aspekte des ISO 50001 Zertifizierungsprozesses waren/sind fuer Ihr Unternehmen am schwierigsten umzusetzen?

[C15d] Welche Aspekte des EN 16001 Zertifizierungsprozesses waren/sind fuer Ihr Unternehmen am schwierigsten umzusetzen?

Umweltaspektenanalyse

Identifizierung der genauen gesetzlichen Verpflichtungen

Interne Umweltaudits

Das Einrichten eines Dokumentationssystems

Sonstiges: 


\section{Questionnaire use per chapter, theoretical framework and country}

\begin{tabular}{|c|c|c|c|}
\hline Chapters & Theories & Survey name & Country \\
\hline 4 & $\begin{array}{l}\text { Reasoned Action } \\
\text { Approach }\end{array}$ & Green Building Practices & Canada \\
\hline 4 & $\begin{array}{l}\text { Reasoned Action } \\
\text { Approach }\end{array}$ & $\begin{array}{l}\text { Sustainable Building and } \\
\text { Construction }\end{array}$ & Canada \\
\hline 4 & $\begin{array}{l}\text { Reasoned Action } \\
\text { Approach }\end{array}$ & $\begin{array}{l}\text { Green Construction } \\
\text { Practices }\end{array}$ & United States \\
\hline 4 & $\begin{array}{l}\text { Reasoned Action } \\
\text { Approach }\end{array}$ & $\begin{array}{l}\text { Sustainable Construction } \\
\text { Practices }\end{array}$ & United States \\
\hline 4 & $\begin{array}{l}\text { Reasoned Action } \\
\text { Approach }\end{array}$ & $\begin{array}{l}\text { Follow-up LEED intention } \\
\text { and behavior }\end{array}$ & $\begin{array}{l}\text { United States and } \\
\text { Canada }\end{array}$ \\
\hline 5 & $\begin{array}{l}\text { Reasoned Action } \\
\text { Approach }\end{array}$ & $\begin{array}{l}\text { Real Estate Investment and } \\
\text { Sustainable Construction } \\
\text { Practices }\end{array}$ & United States \\
\hline 6 & $\begin{array}{l}\text { Social Interdependence } \\
\text { Theory }\end{array}$ & $\begin{array}{l}\text { Sustainable Building and } \\
\text { Construction }\end{array}$ & Canada \\
\hline 6 & $\begin{array}{l}\text { Social Interdependence } \\
\text { Theory }\end{array}$ & $\begin{array}{l}\text { Sustainable Construction } \\
\text { Practices }\end{array}$ & United States \\
\hline 6 & $\begin{array}{l}\text { Social Interdependence } \\
\text { Theory }\end{array}$ & $\begin{array}{l}\text { Sustainable Building } \\
\text { Design and Construction }\end{array}$ & United Kingdom \\
\hline 7 & $\begin{array}{l}\text { Reasoned Action } \\
\text { Approach }\end{array}$ & Green Building Practices & Canada \\
\hline 7 & Social Identity Theory & Green Building Practices & Canada \\
\hline 7 & Social Identity Theory & $\begin{array}{l}\text { Green Construction } \\
\text { Practices }\end{array}$ & United States \\
\hline 7 & $\begin{array}{l}\text { Reasoned Action } \\
\text { Approach }\end{array}$ & $\begin{array}{l}\text { Green Construction } \\
\text { Practices }\end{array}$ & United States \\
\hline 8 & Self-Determination Theory & $\begin{array}{l}\text { Sustainable Building and } \\
\text { Construction }\end{array}$ & Canada \\
\hline 8 & Self-Determination Theory & $\begin{array}{l}\text { Sustainable Construction } \\
\text { Practices }\end{array}$ & United States \\
\hline 10 & $\begin{array}{l}\text { Model of Information } \\
\text { Behavior }\end{array}$ & $\begin{array}{l}\text { Environmental } \\
\text { Management Systems NL }\end{array}$ & Netherlands \\
\hline 10 & $\begin{array}{l}\text { Model of Information } \\
\text { Behavior }\end{array}$ & $\begin{array}{l}\text { Environmental } \\
\text { Management Systems } \\
\text { GER }\end{array}$ & Germany \\
\hline
\end{tabular}




\begin{tabular}{llll}
\hline Chapters & Theories & Survey name & Country \\
\hline 11 & Diffusion of Innovation & Environmental & Netherlands \\
& Theory & Management Systems NL & \\
11 & Diffusion of Innovation & Environmental & Germany \\
& Theory & Management Systems & \\
& & GER & \\
\hline
\end{tabular}





\section{Appendix C : Study respondent characteristics overview}

\section{Overview}

The following tables provide an overview of the respondent characteristics in each of the dissertation chapters. Unless indicated otherwise, the tables should be read as follows:

1. Not included: These observations were elicited and count towards the response rate but were not included in statistical analyses due to several potential reasons (e.g. not relevant to the country analyzed, not relevant to the environmental program analyzed or missing observations).

2. Included in the study: These observations are part of the overall response to the survey and were included in subsequent statistical analyses due to being relevant to the study object. These observations are usually listed as the " $n$ " sample in each of the regression tables. It must be noted that in cases of several environmental programs analyzed, as in Chapter 4, the overall number of included observations for both environmental programs (i.e. 650 for LEED and 636 for Green Globes) may go beyond the overall number of responses, as these programs are not mutually exclusive. Remaining with the Chapter 4 example, the overall number of responses is $n=914$, and all certification instances $n=1286$ (650 LEED and 636 Green Globes) which leads to $n=372$ respondents with experiences in both. This result is not an error but a methodological choice, as not respondent profiles but factors determining adoption and uptake is the main interest of this dissertation project.

3. Total (All respondents): The overall number of respondents elicited for each chapter, including relevant and non-relevant observations. 
Chapter 3: Environmental Assessment Methodologies for Commercial Buildings: A study of building professionals' beliefs and the adoption of the LEED scheme in the United States.

As Chapter 3 relates mainly to interview data, no further socio-economic data beyond descriptions in the chapter text were recorded.

\begin{tabular}{lc}
\hline Administration countries & United States \\
Sample size & 34 \\
Number of respondents & 14 \\
Number of respondents used in analysis & 14 \\
Profession & 10 architects and 4 engineers \\
Gender & 12 male and 2 female \\
\hline
\end{tabular}

Chapter 4: Adoption of Voluntary Environmental Building Rating Schemes: a Reasoned Action Approach (RAA) perspective on building professionals' LEED and Green Globes adoption in the US and Canada

Total respondent characteristics LEED (Study 1)

\begin{tabular}{lccc}
\hline Professional groups & \multicolumn{3}{c}{ LEED analysis } \\
\cline { 2 - 4 } & Not included & $\begin{array}{c}\text { Included in } \\
\text { study }\end{array}$ & $\begin{array}{c}\text { Total (ALL } \\
\text { respondents) }\end{array}$ \\
\cline { 2 - 4 } Architect & 119 & 334 & 453 \\
Commissioning & 2 & 2 & 4 \\
professional & & & \\
Construction professional & 39 & 75 & 114 \\
Engineer & 62 & 167 & 229 \\
Interior designer & 9 & 22 & 31 \\
Landscape architect & 2 & 11 & 13 \\
Other & 26 & 32 & 58 \\
Real Estate Developer & 1 & 1 & 2 \\
Urban planning/Other & 5 & 6 & 11 \\
planning professional & & & 915 \\
\hline Total & 265 & 650 & \\
\hline
\end{tabular}




\begin{tabular}{|c|c|c|c|}
\hline \multirow{2}{*}{ Country } & \multicolumn{3}{|c|}{ LEED analysis } \\
\hline & Not included & $\begin{array}{l}\text { Included in } \\
\text { study }\end{array}$ & $\begin{array}{c}\text { Total (ALL } \\
\text { respondents) }\end{array}$ \\
\hline Canada & 148 & 324 & 472 \\
\hline United States & 116 & 326 & 442 \\
\hline Total & 264 & 650 & 914 \\
\hline \multirow{2}{*}{ Gender } & \multicolumn{3}{|c|}{ LEED analysis } \\
\hline & Not included & $\begin{array}{l}\text { Included in } \\
\text { study }\end{array}$ & $\begin{array}{c}\text { Total (ALL } \\
\text { respondents) }\end{array}$ \\
\hline Female & 72 & 187 & 259 \\
\hline Male & 192 & 463 & 655 \\
\hline Total & 264 & 650 & 914 \\
\hline \multirow{2}{*}{ Professional level } & \multicolumn{3}{|c|}{ LEED analysis } \\
\hline & Not included & $\begin{array}{l}\text { Included in } \\
\text { study }\end{array}$ & $\begin{array}{c}\text { Total (ALL } \\
\text { respondents) }\end{array}$ \\
\hline Executive/Partner/CEO & 114 & 270 & 384 \\
\hline Junior Level & 25 & 76 & 101 \\
\hline Mid-Career & 59 & 139 & 198 \\
\hline Senior level & 66 & 165 & 231 \\
\hline Total & 264 & 650 & 914 \\
\hline \multirow{2}{*}{ Job tenure } & \multicolumn{3}{|c|}{ LEED analysis } \\
\hline & Not included & $\begin{array}{l}\text { Included in } \\
\text { study }\end{array}$ & $\begin{array}{c}\text { Total (ALL } \\
\text { respondents) }\end{array}$ \\
\hline $0-5$ years & 34 & 79 & 113 \\
\hline $6-10$ years & 45 & 113 & 158 \\
\hline $11-15$ years & 48 & 107 & 155 \\
\hline$>15$ years & 137 & 351 & 488 \\
\hline Total & 264 & 650 & 914 \\
\hline
\end{tabular}




\begin{tabular}{lccc}
\hline Education level & \multicolumn{3}{c}{ LEED analysis } \\
\cline { 2 - 4 } & Not included & $\begin{array}{c}\text { Included in } \\
\text { study }\end{array}$ & $\begin{array}{c}\text { Total (ALL } \\
\text { respondents) }\end{array}$ \\
\hline Bachelor & 123 & 327 & 450 \\
Master & 110 & 264 & 374 \\
Other & 25 & 51 & 76 \\
PhD & 5 & 8 & 13 \\
\hline Total & 263 & 650 & 913 \\
\hline
\end{tabular}

Total respondent characteristics Green Globes (Study 1)

\begin{tabular}{|c|c|c|c|}
\hline \multirow{2}{*}{ Country } & \multicolumn{3}{|c|}{ GG analysis } \\
\hline & Not included & $\begin{array}{l}\text { Included in } \\
\text { study }\end{array}$ & $\begin{array}{c}\text { Total (ALL } \\
\text { respondents) }\end{array}$ \\
\hline Canada & 156 & 316 & 472 \\
\hline United States & 124 & 318 & 442 \\
\hline Total & 278 & 636 & 914 \\
\hline \multirow{2}{*}{ Gender } & \multicolumn{3}{|c|}{ GG analysis } \\
\hline & Not included & $\begin{array}{l}\text { Included in } \\
\text { study }\end{array}$ & $\begin{array}{c}\text { Total (ALL } \\
\text { respondents) }\end{array}$ \\
\hline Female & 85 & 174 & 259 \\
\hline Male & 193 & 462 & 655 \\
\hline Total & 278 & 636 & 914 \\
\hline \multirow{2}{*}{ Professional level } & \multicolumn{3}{|c|}{ GG analysis } \\
\hline & Not included & $\begin{array}{l}\text { Included in } \\
\text { study }\end{array}$ & $\begin{array}{c}\text { Total (ALL } \\
\text { respondents) }\end{array}$ \\
\hline Executive/Partner/CEO & 113 & 271 & 384 \\
\hline Junior Level & 41 & 60 & 101 \\
\hline Mid-Career & 67 & 131 & 198 \\
\hline Senior level & 57 & 174 & 231 \\
\hline Total & 278 & 636 & 914 \\
\hline
\end{tabular}




\begin{tabular}{lccc}
\hline Job tenure & \multicolumn{3}{c}{ GG analysis } \\
\cline { 2 - 4 } & Not included & $\begin{array}{c}\text { Included in } \\
\text { study }\end{array}$ & $\begin{array}{c}\text { Total (ALL } \\
\text { respondents) }\end{array}$ \\
\hline 0-5 years & 48 & 65 & 113 \\
6-10 years & 59 & 99 & 158 \\
11-15 years & 43 & 112 & 155 \\
$>15$ years & 128 & 360 & 488 \\
\hline Total & 264 & 650 & 914 \\
\hline
\end{tabular}

\begin{tabular}{lccc}
\hline Education level & \multicolumn{3}{c}{ GG analysis } \\
\cline { 2 - 4 } & Not included & $\begin{array}{c}\text { Included in } \\
\text { study }\end{array}$ & $\begin{array}{c}\text { Total (ALL } \\
\text { respondents) }\end{array}$ \\
\hline Bachelor & 140 & 310 & 450 \\
Master & 112 & 262 & 374 \\
Other & 22 & 54 & 76 \\
PhD & 3 & 10 & 13 \\
\hline Total & 277 & 636 & 913 \\
\hline
\end{tabular}


Follow-up study LEED (Study 2)

\begin{tabular}{lccc}
\hline \multirow{2}{*}{ Professional groups } & \multicolumn{3}{c}{ LEED Follow up Study (Study 2) } \\
\cline { 2 - 4 } & Not included & $\begin{array}{c}\text { Included in } \\
\text { study }\end{array}$ & $\begin{array}{c}\text { Total (ALL } \\
\text { respondents) }\end{array}$ \\
\hline Architect & 362 & 91 & 453 \\
Commissioning & 4 & 0 & 4 \\
professionals & 104 & 10 & 114 \\
Construction professionals & 188 & 41 & 229 \\
Engineer & 24 & 7 & 31 \\
Interior designer & 12 & 1 & 13 \\
Landscape architect & 48 & 10 & 58 \\
Other & 1 & 0 & 1 \\
Real Estate Developer & 9 & 2 & 11 \\
Urban planning/Planning & & & 914 \\
firms & 752 & 162 & \\
\hline Total & & & \\
\hline
\end{tabular}

\begin{tabular}{lccc}
\hline \multirow{2}{*}{ Firm type } & \multicolumn{3}{c}{ LEED Follow up Study (Study 2) } \\
\cline { 2 - 4 } & Not included & $\begin{array}{c}\text { Included in } \\
\text { study }\end{array}$ & $\begin{array}{c}\text { Total (ALL } \\
\text { respondents) }\end{array}$ \\
\hline Architecture firm & 324 & 79 & 403 \\
Architecture/Engineer & 84 & 21 & 105 \\
Commissioning firm & 11 & 0 & 11 \\
Construction firm & 136 & 21 & 157 \\
Engineering firm & 142 & 28 & 170 \\
Interior design firm & 20 & 4 & 24 \\
Landscape architecture & 9 & 2 & 10 \\
Planning firm & 23 & 7 & 30 \\
\hline Total & 749 & 162 & 910 \\
\hline
\end{tabular}




\begin{tabular}{|c|c|c|c|}
\hline \multirow{2}{*}{ Country } & \multicolumn{3}{|c|}{ LEED Follow up Study (Study 2) } \\
\hline & Not included & $\begin{array}{l}\text { Included in } \\
\text { study }\end{array}$ & $\begin{array}{c}\text { Total (ALL } \\
\text { respondents) }\end{array}$ \\
\hline Canada & 412 & 62 & 471 \\
\hline United States & 340 & 100 & 440 \\
\hline Total & 752 & 162 & 914 \\
\hline \multirow{2}{*}{ Gender } & \multicolumn{3}{|c|}{ LEED Follow up Study (Study 2) } \\
\hline & Not included & $\begin{array}{l}\text { Included in } \\
\text { study }\end{array}$ & $\begin{array}{c}\text { Total (ALL } \\
\text { respondents) }\end{array}$ \\
\hline Female & 216 & 43 & 259 \\
\hline Male & 536 & 119 & 655 \\
\hline Total & 752 & 162 & 914 \\
\hline \multirow{2}{*}{ Job position } & \multicolumn{3}{|c|}{ LEED Follow up Study (Study 2) } \\
\hline & Not included & $\begin{array}{l}\text { Included in } \\
\text { study }\end{array}$ & $\begin{array}{c}\text { Total (ALL } \\
\text { respondents) }\end{array}$ \\
\hline Executive/Partner/CEO & 316 & 68 & 384 \\
\hline Junior Level & 85 & 16 & 101 \\
\hline Mid-Career & 163 & 35 & 198 \\
\hline Senior level & 188 & 43 & 231 \\
\hline Total & 752 & 162 & 914 \\
\hline \multirow{2}{*}{ Job tenure } & \multicolumn{3}{|c|}{ LEED Follow up Study (Study 2) } \\
\hline & Not included & $\begin{array}{l}\text { Included in } \\
\text { study }\end{array}$ & $\begin{array}{c}\text { Total (ALL } \\
\text { respondents) }\end{array}$ \\
\hline $0-5$ years & 92 & 21 & 113 \\
\hline $6-10$ years & 133 & 25 & 158 \\
\hline $11-15$ years & 134 & 21 & 155 \\
\hline$>15$ years & 393 & 95 & 488 \\
\hline Total & 752 & 162 & 914 \\
\hline
\end{tabular}




\begin{tabular}{lccc}
\hline Education level & \multicolumn{3}{c}{ LEED Follow up Study (Study 2) } \\
\cline { 2 - 4 } & Not included & $\begin{array}{c}\text { Included in } \\
\text { study }\end{array}$ & $\begin{array}{c}\text { Total (ALL } \\
\text { respondents) }\end{array}$ \\
\hline Bachelor & 377 & 73 & 450 \\
Master & 295 & 79 & 374 \\
Other & 69 & 7 & 76 \\
PhD & 10 & 3 & 13 \\
\hline Total & 752 & 162 & 914 \\
\hline
\end{tabular}

Chapter 5: What do clients want? Commercial Real Estate Developers' views on the LEED and Green Globes certification schemes in the United States

\begin{tabular}{lc}
\hline Profession & Number of respondents \\
\hline Architect & 7 \\
Construction professional (general) & 2 \\
Engineer & 2 \\
Other & 16 \\
Urban planning/planning professional & 2 \\
\hline Total & 29 \\
\hline
\end{tabular}

\begin{tabular}{lc}
\hline Firm type & Number of respondents \\
\hline Architecture firm & 1 \\
Planning firm & 1 \\
Real Estate Agent & 2 \\
Real Estate Developer & 21 \\
Real Estate Investment & 4 \\
\hline Total & 29 \\
\hline
\end{tabular}

\begin{tabular}{lc}
\hline Gender & Number of respondents \\
\hline Female & 7 \\
Male & 22 \\
\hline Total & 29 \\
\hline
\end{tabular}


Job position

Number of respondents

Executive/Partner/CEO

11

Mid-career professional

7

Senior level professional

11

Total

29

\begin{tabular}{lc}
\hline Job tenure & Number of respondents \\
\hline $5-10$ years & 5 \\
$11-15$ years & 4 \\
$>15$ years & 20 \\
\hline Total & 29 \\
\hline
\end{tabular}

\begin{tabular}{lc}
\hline Education level & Number of respondents \\
\hline Bachelor & 14 \\
Master & 14 \\
Other & 1 \\
\hline Total & 29 \\
\hline
\end{tabular}


Chapter 6: Environmental Building Rating and Assessment schemes and inter-firm cooperation: an application of Social Interdependence Theory in the US, the UK and Canada

United States respondent characteristics

\begin{tabular}{lccc}
\hline Professional groups & Not included & $\begin{array}{c}\text { Included in } \\
\text { study }\end{array}$ & $\begin{array}{c}\text { Total (ALL } \\
\text { respondents) }\end{array}$ \\
\hline Architect & 327 & 80 & 407 \\
Commissioning & 61 & 77 & 138 \\
professional (general) & 4 & 0 & 4 \\
Construction professional & & & \\
(general) & 62 & 19 & 81 \\
Engineer & 10 & 0 & 10 \\
Interior designer & 15 & 12 & 27 \\
Landscape architect & 10 & 3 & 13 \\
Other & 16 & 21 & 37 \\
Real Estate Developer & 505 & 212 & 717 \\
\hline Total & &
\end{tabular}

\begin{tabular}{lccc}
\hline Gender & $\begin{array}{c}\text { Not included } \\
\text { in study }\end{array}$ & $\begin{array}{c}\text { Included in } \\
\text { study }\end{array}$ & $\begin{array}{c}\text { Total (ALL } \\
\text { respondents) }\end{array}$ \\
\hline Female & 110 & 64 & 174 \\
Male & 395 & 148 & 543 \\
\hline Total & 505 & 212 & 717 \\
\hline
\end{tabular}

\begin{tabular}{lccc}
\hline Professional level & $\begin{array}{c}\text { Not included } \\
\text { in study }\end{array}$ & $\begin{array}{c}\text { Included in } \\
\text { study }\end{array}$ & $\begin{array}{c}\text { Total (ALL } \\
\text { respondents) }\end{array}$ \\
\hline Executive/Partner/CEO & 19 & 38 & 57 \\
Junior Level & 67 & 72 & 139 \\
Mid-Career & 115 & 62 & 177 \\
Senior level & 304 & 40 & 344 \\
\hline Total & 505 & 212 & 717 \\
\hline
\end{tabular}




\begin{tabular}{lccc}
\hline Job tenure & $\begin{array}{c}\text { Not included } \\
\text { in study }\end{array}$ & $\begin{array}{c}\text { Included in } \\
\text { study }\end{array}$ & $\begin{array}{c}\text { Total (ALL } \\
\text { respondents) }\end{array}$ \\
\hline 0-5 years & 25 & 46 & 71 \\
6-10 years & 61 & 59 & 120 \\
11-15 years & 79 & 32 & 111 \\
$>15$ years & 340 & 75 & 415 \\
\hline Total & 505 & 212 & 717 \\
\hline
\end{tabular}

\begin{tabular}{lccc}
\hline Education level & $\begin{array}{c}\text { Not included } \\
\text { in study }\end{array}$ & $\begin{array}{c}\text { Included in } \\
\text { study }\end{array}$ & $\begin{array}{c}\text { Total (ALL } \\
\text { respondents) }\end{array}$ \\
\hline Bachelor & 210 & 132 & 342 \\
Master & 240 & 76 & 316 \\
Other & 12 & 4 & 16 \\
$\mathrm{PhD}$ & 43 & 0 & 43 \\
\hline Total & 505 & 212 & 717 \\
\hline
\end{tabular}

\section{Canadian respondent characteristics}

\begin{tabular}{lccc}
\hline Professional group & $\begin{array}{c}\text { Not included } \\
\text { in study }\end{array}$ & $\begin{array}{c}\text { Included in } \\
\text { study }\end{array}$ & $\begin{array}{c}\text { Total (ALL } \\
\text { respondents) }\end{array}$ \\
\hline Architect & 269 & 138 & 407 \\
Commissioning & 95 & 43 & 138 \\
professional (general) & 1 & 3 & 4 \\
Construction professional & & & \\
(general) & 43 & 38 & 81 \\
Engineer & 2 & 8 & 10 \\
Interior designer & 16 & 11 & 27 \\
Landscape architect & 7 & 6 & 13 \\
Other & 26 & 11 & 37 \\
Real Estate Developer & 459 & 258 & 717 \\
\hline Total & &
\end{tabular}




\begin{tabular}{lccc}
\hline Gender & $\begin{array}{c}\text { Not included } \\
\text { in study }\end{array}$ & $\begin{array}{c}\text { Included in } \\
\text { study }\end{array}$ & $\begin{array}{c}\text { Total (ALL } \\
\text { respondents) }\end{array}$ \\
\hline Female & 111 & 63 & 174 \\
Male & 348 & 195 & 543 \\
\hline Total & 459 & 258 & 717 \\
\hline
\end{tabular}

\begin{tabular}{lccc}
\hline Professional level & $\begin{array}{c}\text { Not included } \\
\text { in study }\end{array}$ & $\begin{array}{c}\text { Included in } \\
\text { study }\end{array}$ & $\begin{array}{c}\text { Total (ALL } \\
\text { respondents) }\end{array}$ \\
\hline Executive/Partner/CEO & 48 & 9 & 57 \\
Junior Level & 108 & 31 & 139 \\
Mid-Career & 127 & 50 & 177 \\
Senior level & 176 & 168 & 344 \\
\hline Total & 459 & 258 & 717 \\
\hline
\end{tabular}

\begin{tabular}{lccc}
\hline Job tenure & $\begin{array}{c}\text { Not included } \\
\text { in study }\end{array}$ & $\begin{array}{c}\text { Included in } \\
\text { study }\end{array}$ & $\begin{array}{c}\text { Total (ALL } \\
\text { respondents) }\end{array}$ \\
\hline 0-5 years & 60 & 11 & 71 \\
6-10 years & 98 & 22 & 120 \\
11-15 years & 73 & 38 & 111 \\
$>15$ years & 228 & 187 & 415 \\
\hline Total & 459 & 258 & 717 \\
\hline
\end{tabular}

\begin{tabular}{lccc}
\hline Education level & $\begin{array}{c}\text { Not included } \\
\text { in study }\end{array}$ & $\begin{array}{c}\text { Included in } \\
\text { study }\end{array}$ & $\begin{array}{c}\text { Total (ALL } \\
\text { respondents) }\end{array}$ \\
\hline Bachelor & 216 & 126 & 342 \\
Master & 196 & 120 & 316 \\
Other & 11 & 5 & 16 \\
PhD & 36 & 7 & 43 \\
\hline Total & 459 & 258 & 717 \\
\hline
\end{tabular}


United Kingdom respondent characteristics

\begin{tabular}{lccc}
\hline Professional group & $\begin{array}{c}\text { Not included } \\
\text { in study }\end{array}$ & $\begin{array}{c}\text { Included in } \\
\text { study }\end{array}$ & $\begin{array}{c}\text { Total (ALL } \\
\text { respondents) }\end{array}$ \\
\hline Architect & 266 & 141 & 407 \\
Commissioning & 138 & 0 & 138 \\
professional (general) & 4 & 0 & 4 \\
Construction professional & & & \\
(general) & 80 & 1 & 81 \\
Engineer & 10 & 0 & 10 \\
Interior designer & 27 & 0 & 27 \\
Landscape architect & 12 & 1 & 13 \\
Other & 37 & 0 & 37 \\
Real Estate Developer & 574 & 143 & 717 \\
\hline Total & &
\end{tabular}

\begin{tabular}{lccc}
\hline Gender & $\begin{array}{c}\text { Not included } \\
\text { in study }\end{array}$ & $\begin{array}{c}\text { Included in } \\
\text { study }\end{array}$ & $\begin{array}{c}\text { Total (ALL } \\
\text { respondents) }\end{array}$ \\
\hline Female & 149 & 25 & 174 \\
Male & 425 & 118 & 543 \\
\hline Total & 574 & 143 & 717 \\
\hline
\end{tabular}

\begin{tabular}{lccc}
\hline Professional level & $\begin{array}{c}\text { Not included } \\
\text { in study }\end{array}$ & $\begin{array}{c}\text { Included in } \\
\text { study }\end{array}$ & $\begin{array}{c}\text { Total (ALL } \\
\text { respondents) }\end{array}$ \\
\hline Executive/Partner/CEO & 56 & 1 & 57 \\
Junior Level & 120 & 19 & 139 \\
Mid-Career & 129 & 48 & 177 \\
Senior level & 269 & 75 & 344 \\
\hline Total & 574 & 143 & 717 \\
\hline
\end{tabular}




\begin{tabular}{lccc}
\hline Job tenure & $\begin{array}{c}\text { Not included } \\
\text { in study }\end{array}$ & $\begin{array}{c}\text { Included in } \\
\text { study }\end{array}$ & $\begin{array}{c}\text { Total (ALL } \\
\text { respondents) }\end{array}$ \\
\hline 0-5 years & 67 & 4 & 71 \\
6-10 years & 99 & 21 & 120 \\
11-15 years & 83 & 28 & 111 \\
$>15$ years & 325 & 90 & 415 \\
\hline Total & 574 & 143 & 717 \\
\hline
\end{tabular}

\begin{tabular}{lccc}
\hline Education level & $\begin{array}{c}\text { Not included } \\
\text { in study }\end{array}$ & $\begin{array}{c}\text { Included in } \\
\text { study }\end{array}$ & $\begin{array}{c}\text { Total (All } \\
\text { respondents) }\end{array}$ \\
\hline Bachelor & 311 & 31 & 342 \\
Master & 241 & 75 & 316 \\
Other & 10 & 6 & 16 \\
PhD & 12 & 31 & 43 \\
\hline Total & 574 & 143 & 717 \\
\hline
\end{tabular}

Chapter 7: Constructing Green: Social Identity, Professional and Organizational Group Affiliation in the US and Canadian Building and Construction Industry

\section{LEED}

\begin{tabular}{lccc}
\hline Professional group & $\begin{array}{c}\text { Not included } \\
\text { in study }\end{array}$ & $\begin{array}{c}\text { Included in } \\
\text { study }\end{array}$ & $\begin{array}{c}\text { Total (ALL } \\
\text { respondents) }\end{array}$ \\
\hline Architect & 72 & 124 & 196 \\
Construction professional & 12 & 21 & 33 \\
Engineer & 28 & 55 & 83 \\
Interior designer & 2 & 1 & 3 \\
Landscape architect & 0 & 3 & 3 \\
Other & 12 & 10 & 22 \\
Real Estate Developer & 1 & 1 & 2 \\
\hline Total & 127 & 215 & 342 \\
\hline
\end{tabular}




\begin{tabular}{lccc}
\hline Gender & $\begin{array}{c}\text { Not included } \\
\text { in study }\end{array}$ & $\begin{array}{c}\text { Included in } \\
\text { study }\end{array}$ & $\begin{array}{c}\text { Total (All } \\
\text { respondents) }\end{array}$ \\
\hline Female & 43 & 63 & 106 \\
Male & 83 & 152 & 235 \\
\hline Total & 126 & 215 & 341 \\
\hline
\end{tabular}

\begin{tabular}{lccc}
\hline Professional level & $\begin{array}{c}\text { Not included } \\
\text { in study }\end{array}$ & $\begin{array}{c}\text { Included in } \\
\text { study }\end{array}$ & $\begin{array}{c}\text { Total (ALL } \\
\text { respondents) }\end{array}$ \\
\hline Executive/Partner/CEO & 43 & 71 & 114 \\
Junior Level & 12 & 27 & 39 \\
Mid-Career & 35 & 46 & 81 \\
Senior level & 36 & 71 & 107 \\
\hline Total & 126 & 215 & 341 \\
\hline
\end{tabular}

\begin{tabular}{lccc}
\hline Job tenure & $\begin{array}{c}\text { Not included } \\
\text { in study }\end{array}$ & $\begin{array}{c}\text { Included in } \\
\text { study }\end{array}$ & $\begin{array}{c}\text { Total (ALL } \\
\text { respondents) }\end{array}$ \\
\hline 0-5 years & 16 & 28 & 44 \\
6-10 years & 26 & 35 & 61 \\
11-15 years & 31 & 37 & 68 \\
$>15$ years & 53 & 115 & 168 \\
\hline Total & 126 & 215 & 341 \\
\hline
\end{tabular}

\begin{tabular}{lccc}
\hline Education level & $\begin{array}{c}\text { Not included } \\
\text { in study }\end{array}$ & $\begin{array}{c}\text { Included in } \\
\text { study }\end{array}$ & $\begin{array}{c}\text { Total (All } \\
\text { respondents) }\end{array}$ \\
\hline Bachelor & 57 & 114 & 171 \\
Master & 54 & 79 & 133 \\
Other & 12 & 21 & 33 \\
PhD & 3 & 1 & 4 \\
\hline Total & 126 & 215 & 341 \\
\hline
\end{tabular}




\begin{tabular}{lccc}
\hline Country & $\begin{array}{c}\text { Not included } \\
\text { in study }\end{array}$ & $\begin{array}{c}\text { Included in } \\
\text { study }\end{array}$ & $\begin{array}{c}\text { Total (All } \\
\text { respondents) }\end{array}$ \\
\hline Canada & 90 & 142 & 232 \\
United States & 36 & 73 & 109 \\
\hline Total & 126 & 215 & 341 \\
\hline
\end{tabular}

\section{Green Globes}

\begin{tabular}{lccc}
\hline Professional group & $\begin{array}{c}\text { Not included } \\
\text { in study }\end{array}$ & $\begin{array}{c}\text { Included in } \\
\text { study }\end{array}$ & $\begin{array}{c}\text { Total (ALL } \\
\text { respondents) }\end{array}$ \\
\hline Architect & 157 & 39 & 196 \\
Construction professional & 26 & 7 & 33 \\
Engineer & 63 & 20 & 83 \\
Interior designer & 3 & 0 & 3 \\
Landscape architect & 1 & 2 & 3 \\
Other & 20 & 2 & 22 \\
Real Estate Developer & 1 & 1 & 2 \\
\hline Total & 271 & 71 & 341 \\
\hline
\end{tabular}

\begin{tabular}{lccc}
\hline Gender & $\begin{array}{c}\text { Not included } \\
\text { in study }\end{array}$ & $\begin{array}{c}\text { Included in } \\
\text { study }\end{array}$ & $\begin{array}{c}\text { Total (All } \\
\text { respondents) }\end{array}$ \\
\hline Female & 93 & 13 & 106 \\
Male & 177 & 58 & 235 \\
\hline Total & 270 & 71 & 341 \\
\hline
\end{tabular}

\begin{tabular}{lccc}
\hline Professional level & $\begin{array}{c}\text { Not included } \\
\text { in study }\end{array}$ & $\begin{array}{c}\text { Included in } \\
\text { study }\end{array}$ & $\begin{array}{c}\text { Total (ALL } \\
\text { respondents) }\end{array}$ \\
\hline Executive/Partner/CEO & 87 & 27 & 114 \\
Junior Level & 31 & 8 & 39 \\
Mid-Career & 70 & 11 & 81 \\
Senior level & 82 & 25 & 107 \\
\hline Total & 270 & 71 & 341 \\
\hline
\end{tabular}




\begin{tabular}{lccc}
\hline Job tenure & $\begin{array}{c}\text { Not included } \\
\text { in study }\end{array}$ & $\begin{array}{c}\text { Included in } \\
\text { study }\end{array}$ & $\begin{array}{c}\text { Total (ALL } \\
\text { respondents) }\end{array}$ \\
\hline 0-5 years & 36 & 8 & 44 \\
6-10 years & 50 & 11 & 61 \\
11-15 years & 57 & 11 & 68 \\
$>15$ years & 127 & 41 & 168 \\
\hline Total & 270 & 71 & 341 \\
\hline
\end{tabular}

\begin{tabular}{lccc}
\hline Education level & $\begin{array}{c}\text { Not included } \\
\text { in study }\end{array}$ & $\begin{array}{c}\text { Included in } \\
\text { study }\end{array}$ & $\begin{array}{c}\text { Total (All } \\
\text { respondents) }\end{array}$ \\
\hline Bachelor & 131 & 40 & 171 \\
Master & 108 & 25 & 133 \\
Other & 27 & 6 & 33 \\
PhD & 4 & 0 & 4 \\
\hline Total & 270 & 71 & 341 \\
\hline
\end{tabular}

\begin{tabular}{lccc}
\hline Country & $\begin{array}{c}\text { Not included } \\
\text { in study }\end{array}$ & $\begin{array}{c}\text { Included in } \\
\text { study }\end{array}$ & $\begin{array}{c}\text { Total (All } \\
\text { respondents) }\end{array}$ \\
\hline Canada & 187 & 45 & 232 \\
United States & 83 & 26 & 109 \\
\hline Total & 270 & 71 & 341 \\
\hline
\end{tabular}


Chapter 8: Voluntary Professional Accreditation for Sustainability: an application of Self-Determination Theory to LEED AP professional accreditation in the United States and Canada

\begin{tabular}{lccc}
\hline Professional group & $\begin{array}{c}\text { Not included } \\
\text { in study }\end{array}$ & $\begin{array}{c}\text { Included in } \\
\text { study }\end{array}$ & $\begin{array}{c}\text { Total (ALL } \\
\text { respondents) }\end{array}$ \\
\hline Architect & 70 & 202 & 272 \\
Commissioning & 2 & 2 & 4 \\
professional & 32 & 52 & 84 \\
Construction professional & 32 & 120 & 152 \\
Engineer & 7 & 21 & 28 \\
Interior designer & 3 & 7 & 10 \\
Landscape architect & 10 & 31 & 41 \\
Other & 0 & 1 & 1 \\
Real Estate Developer & 7 & 4 & 11 \\
Urban planning/Planning & 163 & 440 & 603 \\
\hline Total & & &
\end{tabular}

\begin{tabular}{lccc}
\hline Country & $\begin{array}{c}\text { Not included } \\
\text { in study }\end{array}$ & $\begin{array}{c}\text { Included in } \\
\text { study }\end{array}$ & $\begin{array}{c}\text { Total (All } \\
\text { respondents) }\end{array}$ \\
\hline Canada & 46 & 224 & 268 \\
United States & 117 & 216 & 333 \\
\hline Total & 163 & 440 & 603 \\
\hline
\end{tabular}

\begin{tabular}{lccc}
\hline Gender & $\begin{array}{c}\text { Not included } \\
\text { in study }\end{array}$ & $\begin{array}{c}\text { Included in } \\
\text { study }\end{array}$ & $\begin{array}{c}\text { Total (All } \\
\text { respondents) }\end{array}$ \\
\hline Female & 39 & 125 & 164 \\
Male & 124 & 315 & 439 \\
\hline Total & 163 & 440 & 603 \\
\hline
\end{tabular}




\begin{tabular}{lccc}
\hline Professional level & $\begin{array}{c}\text { Not included } \\
\text { in study }\end{array}$ & $\begin{array}{c}\text { Included in } \\
\text { study }\end{array}$ & $\begin{array}{c}\text { Total (All } \\
\text { respondents) }\end{array}$ \\
\hline Executive/Partner/CEO & 99 & 174 & 273 \\
Junior Level & 16 & 47 & 63 \\
Mid-Career & 25 & 104 & 129 \\
Senior level & 23 & 115 & 138 \\
\hline Total & 163 & 440 & 603 \\
\hline
\end{tabular}

\begin{tabular}{lccc}
\hline Job tenure & $\begin{array}{c}\text { Not included } \\
\text { in study }\end{array}$ & $\begin{array}{c}\text { Included in } \\
\text { study }\end{array}$ & $\begin{array}{c}\text { Total (All } \\
\text { respondents) }\end{array}$ \\
\hline 0-5 years & 19 & 56 & 75 \\
6-10 years & 16 & 74 & 90 \\
11-15 years & 22 & 83 & 105 \\
$>15$ years & 106 & 227 & 333 \\
\hline Total & 163 & 440 & 603 \\
\hline
\end{tabular}

\begin{tabular}{lccc}
\hline Education level & $\begin{array}{c}\text { Not included } \\
\text { in study }\end{array}$ & $\begin{array}{c}\text { Included in } \\
\text { study }\end{array}$ & $\begin{array}{c}\text { Total (All } \\
\text { respondents) }\end{array}$ \\
\hline Bachelor & 84 & 215 & 299 \\
Master & 68 & 178 & 246 \\
Other & 8 & 39 & 47 \\
PhD & 2 & 8 & 10 \\
\hline Total & 162 & 440 & 602 \\
\hline
\end{tabular}


Chapter 10: ISO 14001 certification of Environmental Management Standards: Comparing the Netherlands and Germany

\section{The Netherlands}

\begin{tabular}{lccc}
\hline Job position & $\begin{array}{c}\text { Not included } \\
\text { in study }\end{array}$ & $\begin{array}{c}\text { Included in } \\
\text { study }\end{array}$ & $\begin{array}{c}\text { Total (All } \\
\text { respondents) }\end{array}$ \\
\hline CEO/Director & 4 & 9 & 13 \\
Head of Department & 8 & 5 & 13 \\
Envionmental Manager & 27 & 28 & 55 \\
Other & 45 & 47 & 92 \\
\hline Total & 84 & 89 & 173 \\
\hline
\end{tabular}

\begin{tabular}{lccc}
\hline Firm size & Not in study & $\begin{array}{c}\text { Included in } \\
\text { study }\end{array}$ & $\begin{array}{c}\text { Total (All } \\
\text { respondents) }\end{array}$ \\
\hline 0-50 employees & 32 & 21 & 53 \\
51-100 employees & 18 & 15 & 33 \\
101-500 employees & 29 & 42 & 71 \\
$>500$ employees & 5 & 11 & 16 \\
\hline Total & 84 & 89 & 173 \\
\hline
\end{tabular}

\begin{tabular}{lccc}
\hline Job tenure & Not in study & $\begin{array}{c}\text { Included in } \\
\text { study }\end{array}$ & $\begin{array}{c}\text { Total (All } \\
\text { respondents) }\end{array}$ \\
\hline 0-5 years & 4 & 2 & 6 \\
6-10 years & 10 & 10 & 20 \\
11-15 years & 19 & 15 & 34 \\
16-20 years & 14 & 16 & 30 \\
$>20$ years & 37 & 46 & 83 \\
\hline Total & 84 & 89 & 173 \\
\hline
\end{tabular}




\begin{tabular}{lccc}
\hline Part of firm & Not in study & $\begin{array}{c}\text { Included in } \\
\text { study }\end{array}$ & $\begin{array}{c}\text { Total (All } \\
\text { respondents) }\end{array}$ \\
\hline HQ foreign firm & 10 & 17 & 27 \\
HQDutch firm & 49 & 45 & 94 \\
Branch foreign firm & 20 & 23 & 43 \\
Branch Dutch firm & 5 & 4 & 9 \\
\hline Total & 84 & 89 & 173 \\
\hline
\end{tabular}

\begin{tabular}{lccc}
\hline Education level & Not in study & $\begin{array}{c}\text { Included in } \\
\text { study }\end{array}$ & $\begin{array}{c}\text { Total (All } \\
\text { respondents) }\end{array}$ \\
\hline Secondary School & 1 & 1 & 2 \\
Technical School & 10 & 16 & 26 \\
Apprenticeship & 29 & 31 & 60 \\
Applied Bachelor & 17 & 17 & 34 \\
Applied Master & 2 & 2 & 4 \\
University Bachelor & 14 & 11 & 25 \\
University Master & 2 & 0 & 2 \\
PhD & 9 & 11 & 20 \\
\hline Total & 84 & 89 & 173 \\
\hline
\end{tabular}

\section{Germany}

\begin{tabular}{lccc}
\hline Job position & $\begin{array}{c}\text { Not included } \\
\text { in study }\end{array}$ & $\begin{array}{c}\text { Included in } \\
\text { study }\end{array}$ & $\begin{array}{c}\text { Total (All } \\
\text { respondents) }\end{array}$ \\
\hline CEO/Director & 18 & 60 & 78 \\
Head of Department & 2 & 12 & 14 \\
Envionmental Manager & 7 & 8 & 15 \\
Other & 2 & 5 & 7 \\
\hline Total & 29 & 85 & 114 \\
\hline
\end{tabular}




\begin{tabular}{lccc}
\hline Firm size & Not in study & $\begin{array}{c}\text { Included in } \\
\text { study }\end{array}$ & $\begin{array}{c}\text { Total (All } \\
\text { respondents) }\end{array}$ \\
\hline 0-50 employees & 8 & 20 & 28 \\
51-100 employees & 3 & 7 & 10 \\
101-500 employees & 9 & 21 & 30 \\
$>500$ employees & 9 & 37 & 46 \\
\hline Total & 29 & 85 & 114 \\
\hline
\end{tabular}

\begin{tabular}{lccc}
\hline Job tenure & Not in study & $\begin{array}{c}\text { Included in } \\
\text { study }\end{array}$ & $\begin{array}{c}\text { Total (All } \\
\text { respondents) }\end{array}$ \\
\hline 0-5 years & 2 & 12 & 14 \\
6-10 years & 5 & 16 & 21 \\
11-15 years & 7 & 14 & 21 \\
16-20 years & 13 & 42 & 55 \\
$>20$ years & 2 & 1 & 3 \\
\hline Total & 29 & 85 & 114 \\
\hline
\end{tabular}

\begin{tabular}{lccc}
\hline Part of firm & Not in study & $\begin{array}{c}\text { Included in } \\
\text { study }\end{array}$ & $\begin{array}{c}\text { Total (All } \\
\text { respondents) }\end{array}$ \\
\hline HQ foreign firm & 1 & 3 & 4 \\
HQ German firm & 23 & 57 & 80 \\
Branch foreign firm & 1 & 4 & 5 \\
Branch German firm & 4 & 11 & 15 \\
Other & 0 & 10 & 10 \\
\hline Total & 29 & 85 & 114 \\
\hline
\end{tabular}




\begin{tabular}{lccc}
\hline Education level & Not in study & $\begin{array}{c}\text { Included in } \\
\text { study }\end{array}$ & $\begin{array}{c}\text { Total (All } \\
\text { respondents) }\end{array}$ \\
\hline Apprenticeship & 6 & 20 & 26 \\
Applied Bachelor & 1 & 1 & 2 \\
Applied Master & 1 & 3 & 4 \\
University Bachelor & 2 & 2 & 4 \\
University Master & 9 & 32 & 41 \\
Diploma & 6 & 15 & 21 \\
PhD & 4 & 12 & 16 \\
\hline Total & 29 & 85 & 114 \\
\hline
\end{tabular}

\begin{tabular}{lccc}
\hline Age group & Not in study & $\begin{array}{c}\text { Included in } \\
\text { study }\end{array}$ & $\begin{array}{c}\text { Total (All } \\
\text { respondents) }\end{array}$ \\
\hline $20-30$ & 2 & 2 & 4 \\
$31-40$ & 5 & 16 & 21 \\
$41-50$ & 13 & 17 & 30 \\
$>50$ & 9 & 50 & 59 \\
\hline Total & 29 & 85 & 114 \\
\hline
\end{tabular}

\section{Chapter 11: Information source choice and Environmental Management Systems (EMSs) certification in the Netherlands and Germany}

\section{The Netherlands}

\begin{tabular}{lccc}
\hline Job position & Not in study & $\begin{array}{c}\text { Included in } \\
\text { study }\end{array}$ & $\begin{array}{c}\text { Total (All } \\
\text { respondents) }\end{array}$ \\
\hline CEO/Director & 6 & 7 & 13 \\
Head of Department & 8 & 5 & 13 \\
Envionmental Manager & 28 & 27 & 55 \\
Other & 52 & 40 & 92 \\
\hline Total & 94 & 79 & 173 \\
\hline
\end{tabular}




\begin{tabular}{lccc}
\hline Firm size & Not in study & $\begin{array}{c}\text { Included in } \\
\text { study }\end{array}$ & $\begin{array}{c}\text { Total (All } \\
\text { respondents) }\end{array}$ \\
\hline 0-50 employees & 33 & 20 & 53 \\
51-100 employees & 20 & 13 & 33 \\
101-500 employees & 35 & 36 & 71 \\
$>500$ employees & 6 & 10 & 16 \\
\hline Total & 94 & 79 & 173 \\
\hline
\end{tabular}

\begin{tabular}{lccc}
\hline Job tenure & Not in study & $\begin{array}{c}\text { Included in } \\
\text { study }\end{array}$ & $\begin{array}{c}\text { Total (All } \\
\text { respondents) }\end{array}$ \\
\hline $0-5$ years & 4 & 2 & 6 \\
6-10 years & 12 & 8 & 20 \\
11-15 years & 20 & 14 & 34 \\
16-20 years & 14 & 16 & 30 \\
$>20$ years & 44 & 39 & 83 \\
\hline Total & 94 & 79 & 173 \\
\hline
\end{tabular}

\begin{tabular}{lccc}
\hline Part of firm & Not in study & $\begin{array}{c}\text { Included in } \\
\text { study }\end{array}$ & $\begin{array}{c}\text { Total (All } \\
\text { respondents) }\end{array}$ \\
\hline HQ foreign firm & 11 & 16 & 27 \\
HQDutch firm & 55 & 39 & 94 \\
Branch foreign firm & 23 & 20 & 43 \\
Branch Dutch firm & 5 & 4 & 9 \\
\hline Total & 94 & 79 & 173 \\
\hline
\end{tabular}




\begin{tabular}{lccc}
\hline Education level & Not in study & $\begin{array}{c}\text { Included in } \\
\text { study }\end{array}$ & $\begin{array}{c}\text { Total (All } \\
\text { respondents) }\end{array}$ \\
\hline Secondary School & 13 & 13 & 26 \\
Technical School & 33 & 27 & 60 \\
Apprenticeship & 17 & 17 & 34 \\
Applied Bachelor & 3 & 1 & 4 \\
Applied Master & 14 & 11 & 25 \\
University Bachelor & 1 & 1 & 2 \\
University Master & 11 & 9 & 20 \\
PhD & 2 & 0 & 2 \\
\hline Total & 94 & 79 & 173 \\
\hline
\end{tabular}

\section{Germany}

\begin{tabular}{lccc}
\hline Job position & Not in study & $\begin{array}{c}\text { Included in } \\
\text { study }\end{array}$ & $\begin{array}{c}\text { Total (All } \\
\text { respondents) }\end{array}$ \\
\hline CEO/Director & 18 & 60 & 78 \\
Head of Department & 2 & 12 & 14 \\
Environmental Manager & 7 & 8 & 15 \\
Other & 3 & 4 & 7 \\
\hline Total & 30 & 84 & 114 \\
\hline
\end{tabular}

\begin{tabular}{lccc}
\hline Firm size & Not in study & $\begin{array}{c}\text { Included in } \\
\text { study }\end{array}$ & $\begin{array}{c}\text { Total (All } \\
\text { respondents) }\end{array}$ \\
\hline 0-50 employees & 9 & 19 & 28 \\
51-100 employees & 3 & 7 & 10 \\
101-500 employees & 7 & 23 & 30 \\
$>500$ employees & 11 & 35 & 46 \\
\hline Total & 30 & 84 & 114 \\
\hline
\end{tabular}




\begin{tabular}{lccc}
\hline Job tenure & Not in study & $\begin{array}{c}\text { Included in } \\
\text { study }\end{array}$ & $\begin{array}{c}\text { Total (All } \\
\text { respondents) }\end{array}$ \\
\hline 0-5 years & 2 & 1 & 3 \\
6-10 years & 1 & 13 & 14 \\
11-15 years & 4 & 17 & 21 \\
16-20 years & 6 & 15 & 21 \\
$>20$ years & 17 & 38 & 55 \\
\hline Total & 30 & 84 & 114 \\
\hline
\end{tabular}

\begin{tabular}{lccc}
\hline Part of firm & Not in study & $\begin{array}{c}\text { Included in } \\
\text { study }\end{array}$ & $\begin{array}{c}\text { Total (All } \\
\text { respondents) }\end{array}$ \\
\hline HQforeign firm & 0 & 4 & 4 \\
HQ German firm & 21 & 59 & 80 \\
Branch foreign firm & 2 & 3 & 5 \\
Branch German firm & 5 & 10 & 15 \\
Other & 2 & 8 & 10 \\
\hline Total & 30 & 84 & 114 \\
\hline
\end{tabular}

\begin{tabular}{lccc}
\hline Education level & Not in study & $\begin{array}{c}\text { Included in } \\
\text { study }\end{array}$ & $\begin{array}{c}\text { Total (All } \\
\text { respondents) }\end{array}$ \\
\hline Apprenticeship & 6 & 20 & 26 \\
Applied Bachelor & 1 & 1 & 2 \\
Applied Master & 1 & 3 & 4 \\
University Bachelor & 1 & 3 & 4 \\
University Master & 12 & 29 & 41 \\
Diploma & 5 & 16 & 21 \\
PhD & 4 & 12 & 16 \\
\hline Total & 30 & 84 & 114 \\
\hline
\end{tabular}




\begin{tabular}{lccc}
\hline Age group & Not in study & $\begin{array}{c}\text { Included in } \\
\text { study }\end{array}$ & $\begin{array}{c}\text { Total (All } \\
\text { respondents) }\end{array}$ \\
\hline $20-30$ & 2 & 2 & 4 \\
$31-40$ & 2 & 19 & 21 \\
$41-50$ & 13 & 17 & 30 \\
$>50$ & 13 & 46 & 59 \\
\hline Total & 30 & 84 & 114 \\
\hline
\end{tabular}





\section{MGSoG Dissertation Series}

Mehmet Güney Celbiş

Regional Policies: Convergence, Trade, and the Allocation of Public Capital

MGSoG Dissertation Series, $\mathrm{nr} 61$ (2015)

Florian Henning

Living Up to Standards: Interoperability Governance and Standards Adoption in Government Information Networks

MGSoG Dissertation Series, $\mathrm{nr} 60$ (2015)

Niels P. Groen

The Never-ending Project: Understanding E-Government Project Escalation

MGSoG Dissertation Series, nr 59 (2015)

Derek Copp

Teacher-based Reactivity to Provincial Large-scale Assessment in Canada

MGSoG Dissertation Series, nr 58 (2015)

Michaella Vanore

Family-Member Migration and the Psychosocial Health Outcomes of Children in Moldova and Georgia

MGSoG Dissertation Series, nr 57 (2015)

\section{Sonja Fransen}

The Economic and Social Effects of Remittances and Return Migration in Conflict-Affected Areas: The Case of Burundi

MGSoG Dissertation Series, nr 56 (2015)

Ibrahim Khalil Conteh

The Impact of Floods on Primary School Education in Zambia

MGSoG Dissertation Series, nr 55 (2015) 
Richard Bluhm

Growth Dynamics and Development: Essays in Applied Econometrics and Political Economy

MGSoG Dissertation Series, nr 54 (2015)

Nevena P. Zhelyazkova

Work-Family Reconciliation and Use of Parental Leave in Luxembourg: Empirical Analysis of Administrative Records

MGSoG Dissertation Series, nr 53 (2015)

Sachin Kumar Badkas

Metachoice and Metadata: Innovating with Environmental Policy Analysis in Europe

MGSoG Dissertation Series, nr 52 (2014)

Irina S. Burlacu

An Evaluation of Tax-Benefit Systems Impact on the Welfare of Frontier Workers: The Case of Luxembourg and Belgium

MGSoG Dissertation Series, nr 51 (2014)

Özge Bilgili

Simultaneity in Transnational Migration Research: Links Between Migrants' Host and Home Country Orientation

MGSoG Dissertation Series, nr 50 (2014)

Yulia Privalova Krieger

Reshaping the Big Agenda: Transnational Politics and Domestic Resistance - Financial crisis and social protection reform in Bosnia and Herzegovina

MGSoG Dissertation Series, nr 49 (2014)

Marieke van Houte

Moving Back or Moving Forward? Return migration after conflict

MGSoG Dissertation Series, nr 48 (2014)

Oxana Slobozhan

Global Governance in the Management of Natural Resources: The Case of the Extractive Industries Transparency Initiative (EITI)

MGSoG Dissertation Series, nr 47 (2014)

Luis Bernardo Mejia Guinand

The Changing Role of the Central Planning Offices in Latin America: A Comparative 
Historical Analysis Perspective (1950-2013)

MGSoG Dissertation Series, nr 46 (2014)

\section{Cheng Boon Ong}

Ethnic Segregation in Housing, Schools and Neighbourhoods in the Netherlands

MGSoG Dissertation Series, nr 45 (2014)

Luciana V. Cingolani

Bureaucracies for Development: Oxymoron or Reality? Studies on State Capacity in Challenging Governance Contexts

MGSoG Dissertation Series, nr 44 (2014)

Carlos Cadena Gaitán

Green Politics in Latin American Cities - Sustainable Transport Agendas

MGSoG Dissertation Series, nr 43 (2014)

Katie Kuschminder

Female Return Migration and Reintegration Strategies in Ethiopia

MGSoG Dissertation Series, nr 42 (2014)

Metka Hercog

Highly-Skilled Migration and New Destination Countries

MGSoG Dissertation Series, nr 41 (2014)

Margaret Agaba Rugadya

Can Remittances Influence the Tenure and Quality of Housing in Uganda?

MGSoG Dissertation Series, nr 40 (2014)

Ilire Agimi

New Governance Under Limited Statehood: The Case of Local Government Reform in Kosovo

MGSoG Dissertation Series, nr 39 (2014)

Kristine Farla

Empirical Studies on Institutions, Policies and Economic Development

MGSoG Dissertation Series, nr 38 (2013)

Marina Petrovic

Social Assistance and Activation in the Pursuit of Happiness: Shedding New Light on Old Policy Solutions to Social Exclusion

MGSoG Dissertation Series, nr 37 (2013) 
Laura Torvinen

Assessing Governance Assessments: The Case of Mozambique Governance Assessments in the Context of Aid Effectiveness Discourse

MGSoG Dissertation Series, nr 36 (2013)

Biniam Egu Bedasso

Institutional Change in the Long Shadow of Elites: Essays on Institutions, Human Capital and Ethnicity in Developing Countries

MGSoG Dissertation Series, nr 35 (2013)

Sepideh Yousefzadeh Faal Deghati

Childhoods Embargoed: Constructing and Reconstructing Multidimensional Child Poverty in Iran 1984-2009

MGSoG Dissertation Series, nr 34 (2013)

Robert Bauchmüller

Investing in Early Childhood Care and Education: The Impact of Quality on Inequality

MGSoG Dissertation Series, nr 33 (2013)

Martin Rehm

Unified Yet Separated: Empirical Study on the Impact of Hierarchical Positions within Communities of Learning

MGSoG Dissertation Series, nr 32 (2013)

Dorcas Mbuvi

Utility Reforms and Performance of the Urban Water Sector in Africa

MGSoG Dissertation Series, nr 31 (2012)

Lina Salanauskaite

Distributional Impacts of Public Policies: Essays in Ex-Ante and Ex-Post

Evaluation

MGSoG Dissertation Series, nr 30 (2012)

Esther Schüring

To Condition or not - is that the Question? An Analysis of the Effectiveness of Ex-Ante and Ex-Post Conditionality in Social Cash Transfer Programs

MGSoG Dissertation Series, nr 29 (2012)

Joe Abah

Strong Organisations in Weak States: Atypical Public Sector Performance in Dysfunctional 
Environments

MGSoG Dissertation Series, nr 28 (2012)

Zina Samih Nimeh

Social Citizenship Rights: Inequality and Exclusion

MGSoG Dissertation Series, nr 27 (2012)

Lenka Eisenhamerová

Legitimacy of 'Humanitarian Military Intervention'

MGSoG Dissertation Series, nr 26 (2011)

Sonila Tomini

Informal Payments for Health Care Services in Albania

MGSoG Dissertation Series, nr 25 (2011)

Jinjing Li

Dynamic Microsimulation for Public Policy Evaluation

MGSoG Dissertation Series, nr 24 (2011)

Aziz Atamanov

Rural Nonfarm Employment and International Migration as Alternatives to Agricultural Employment: The Case of Kyrgyzstan

MGSoG Dissertation Series, nr 23 (2011)

Frieda Vandeninden

Poverty Alleviation: Aid and Social Pensions

MGSoG Dissertation Series, nr 22 (2011)

Juliana Nyasha Tirivayi

The Welfare Effects of Integrating AIDS Treatment with Food Transfers: Evidence from

Zambia

MGSoG Dissertation Series, nr 21 (2011)

Agnieska Ewa Sowa

Who's Left Behind? Social Dimensions of Health Transition and Utilization of Medical

Care in Poland

MGSoG Dissertation Series, nr 20 (2011)

Emmanaouil Sfakianakis

The Role of Private Actors in the Provision of Public Goods with Applications to Infrastructure and Financial Stability

MGSoG Dissertation Series, nr 19 (2011) 
Siu Hing Lo

White Collars Green Sleeves: An Interonganizational Comparison of Determinants of Energy-Related Behaviors among Office Workers

MGSoG Dissertation Series, nr 18 (2011)

Treena $\mathrm{Wu}$

Constraints to Human Capital Investment in Developing Countries: Using the Asian Financial Crisis in Indonesia as a Natural Experiment

MGSoG Dissertation Series, nr 17 (2011)

Henry Espinoza Peña

Impact Evaluation of a Job-Training Programme for Disadvantaged Youths: The Case of Projoven

MGSoG Dissertation Series, nr 16 (2011)

Florian Tomini

Between Family and Friends: Understanding the Interdependency of Private Transfers

MGSoG Dissertation Series, nr 15 (2010)

Michał Polalowski

The Institutional Transformation of Social Policy in East Central Europe: Poland and Hungary in comparative and historical perspective

MGSoG Dissertation Series, nr 14 (2010)

Maha Ahmed

Defining, Measuring and Addressing Vulnerability: The Case of Post Conflict Environments MGSoG Dissertation Series, nr 13 (2010)

Pascal Beckers

Local Space and Economic Success: The role of spatial segregation of migrants in the Netherlands

MGSoG Dissertation Series, nr 12 (2010)

Victor Cebotari

Conplicting Demands in Ethnically Diverse Societies: Ethnopolitical Contention and Identity Values in Europe

MGSoG Dissertation Series, nr 11 (2010)

Dennis Gyllensporre

Competing and Complementary Perspectives on the EU as a Crisis Management Actor: An 
Examination of the Common Security and Defence Policy through the Lenses of Idealism and Realism

MGSoG Dissertation Series, $\mathrm{nr} 10$ (2010)

Judit Vall Castello

Business Cycle and Policy Effects on Labour Market Transitions of Older and Disabled Workers in Spain

MGSoG Dissertation Series, nr. 9 (2010)

Keetie Roelen

False Positives or Hidden Dimensions: the definition and measurement of child poverty MGSoG Dissertation Series, nr. 8 (2010)

Denisa Maria Sologon

Earning Dynamics in Europe

MGSoG Dissertation Series, nr. 7 (2010)

Melissa Siegel

Money and Mobility: Migration and Remittances

MGSoG Dissertation Series, nr. 6 (2010)

Jessica S. Hagen-Zanker

Modest Expectations: Causes and effects of migration on migrant households in source countries

MGSoG Dissertation Series, nr. 5 (2010)

Mirtha R. Muniz Castillo

Human Development and Autonomy in Project Aid: Experiences from four bilateral projects in Nicaragua and El Salvador

MGSoG Dissertation Series, nr. 4 (2009)

Christiane Arndt

Governance Indicators

MGSoG Dissertation Series, nr. 3 (2009)

Britta Augsburg

Microfinance - Greater Good or Lesser Evil?

MGSoG Dissertation Series, nr. 2 (2009)

Geranda Notten

Measuring and Managing Poverty Risks

MGSoG Dissertation Series, nr. 1 (2008) 